ESCOLA POLITÉCNICA DA UNIVERSIDADE DE SÃO PAULO

WILINGTHON GUERRA ZVIETCOVICH

ESTIMADOR DE VARIAÇÕES DE TENSÃO DE CURTA DURAÇÃO EM SISTEMAS ELÉTRICOS DE POTÊNCIA UTILIZANDO ESTRATÉGIAS EVOLUTIVAS

São Paulo 


\title{
ESTIMADOR DE VARIAÇÕES DE TENSÃO DE CURTA DURAÇÃO EM SISTEMAS ELÉTRICOS DE POTÊNCIA UTILIZANDO ESTRATÉGIAS EVOLUTIVAS
}

\author{
Tese apresentada à Escola Politécnica da \\ Universidade de São Paulo para obtenção de \\ título de Doutor em Ciências \\ Área de concentração: \\ Sistemas de Potência
}

Orientador: Prof. Doutor Nelson Kagan

São Paulo 
Este exemplar foi revisado e alterado em relação à versão original, sob responsabilidade única do autor e com a anuência de seu orientador.

São Paulo, de novembro de 2011.

Assinatura do autor

Assinatura do orientador

FICHA CATALOGRÁFICA

Zvietcovich, Wilingthon Guerra

Estimador de variações de tensão de curta duração em sis temas elétricos de potência utilizando estratégias evolutivas / W.G. Zvietovich. -- ed.rev. -- São Paulo, 2011. $156 \mathrm{p}$.

Tese (Doutorado) - Escola Politécnica da Universidade de São Paulo. Departamento de Engenharia de Energia e Automação Elétricas.

1. Engenharia elétrica 2. Sistemas elétricos de potência 3. Energia (Qualidade) I. Universidade de São Paulo. Escola Politécnica. Departamento de Engenharia de Energia e Automação Elétricas II. t. 
Dedicado este trabalho à minha família, por todo apoio, compreensão, amor e carinho que sempre me concederam. 


\section{Agradecimentos}

Dedico meus sinceros agradecimentos:

Á Deus, por conceder-me saúde e inteligência;

Ao meu orientador, professor Nelson Kagan, por me dar a oportunidade de alcançar um dos meus logros profissionais, ajudando-me a fortalecer meu interesse pela vida acadêmica, também pela orientação, apoio e amizade;

Aos professores Marcos Gouvêa, Hernán Prieto e Carlos Márcio Tahan, pelas sugestões e atenções que me deram;

A Sinapsis Inovação em Energia, por me permitir utilizar a plataforma computacional Sinap t\&d para o desenvolvimento deste trabalho; também ao João Guaraldo pela atenção.

À Escola Politécnica da Universidade de São Paulo e aos funcionários desta casa de ensino, pelo bom atendimento;

A Enerq e aos meus colegas deste grupo de pesquisa, por auxiliar-me quando precisei, e também pela amizade.

À Erica, pelo carinho, apoio e compreensão no desenvolvimento da pesquisa;

À Sra. Ana Maria da biblioteca de Eng. Elétrica pelo auxílio e atenção;

A UFOP por me dar as facilidades quando precisei, e a meus colegas, por sempre estarem dispostos para me auxiliar.

A CAPES, pelo apoio financeiro. 


\section{RESUMO}

Neste trabalho, é proposta uma metodologia para estimar o estado de um sistema elétrico de potência (SEPs) durante variações de tensão de curta duração (VTCDs) causadas por faltas elétricas nas linhas que compõem a rede elétrica avaliada. Para cumprir esta meta, são utilizados os valores registrados nos equipamentos de medição instalados nas redes elétricas. $\mathrm{Na}$ realidade, existem poucos equipamentos nas redes elétricas devido aos custos elevados dos medidores de qualidade de energia elétrica (QEE). Embora estes custos tenham diminuído nos últimos anos, ainda é inviável a utilização de um número suficiente de medidores para garantir a monitoração de toda a rede, por tornar-se muito oneroso. Esta realidade constitui um desafio para se desenvolver técnicas que permitam, a partir de um pequeno número de pontos de monitoração, determinar os locais de faltas e estimar os valores das VTCDs em todas as barras que compõem um sistema elétrico.

Como contribuição à solução destes problemas, esta tese propõe a utilização do algoritmo denominado "Estratégias Evolutivas” (EEs), que integra a família dos Algoritmos Evolutivos. Tal algoritmo mostrou ser viável por sua facilidade de implementação e rapidez de resposta na busca de uma solução dentro de um vasto espaço de soluções.

As EEs, nesta tese, são utilizadas para se determinar: o local de falta, tipo de falta e impedância de falta, que caracterizam um indivíduo, de forma que as tensões resultantes nas barras monitoradas sejam as mais próximas possíveis das medições realizadas. Para alcançar esse objetivo, inicialmente se constrói uma população inicial de indivíduos que representam alternativas de solução do problema. Em seguida, uma parte destes indivíduos será submetida a mutação e recombinação para então serem selecionados os indivíduos que sobreviverão na geração futura. Este processo iterativo é realizado até que se encontre uma solução o mais próximo da procurada.

Cada indivíduo é avaliado através de função objetivo, que representa o erro quadrático entre os valores medidos e os valores calculados. Para este cálculo, é necessário simular um curto-circuito com as características do indivíduo avaliado com base em informações da rede bem como dos valores das tensões provenientes dos medidores. 
A partir da determinação das características da falta, é feita a estimação dos valores das tensões em toda a rede levando à avaliação das VTCDs. Uma vez atingido este objetivo, é possível, por exemplo, determinar indicadores de qualidade associados às VTCDs, como o SARFI (System Average RMS Frequency Index), determinar as áreas mais propensas a causar as VTCDs e elaborar planos de manutenção preventiva.

Foram implementados dois algoritmos que calculam o número mínimo de medidores e os locais onde estes devem ser instalados. O primeiro algoritmo tem a finalidade de garantir o monitoramento de toda a rede em relação às VTCDs enquanto o segundo garante o menor erro de estimação de VTCDs nas barras onde não se têm medidores instalados.

A referida metodologia pode ser aplicada em redes radiais ou em malha, sendo inicialmente aplicada em sistemas de pequeno porte (redes de 14 e 30 barras do IEEE) com intuito de verificar a capacidade do algoritmo. Foram então simuladas redes de maior complexidade, por meio de testes em redes de 57 barras e 118 barras do IEEE. Para avaliar a eficiência da metodologia desenvolvida foi feita uma comparação com outra metodologia de otimização baseada em Algoritmos Genéticos (AGs).

Palavras chaves: Faltas elétricas, Estimador de variações de tensão de curta duração, Alocação ótima de medidores, Estratégias evolutivas, Busca em vizinhança variável. 


\section{ABSTRACT}

A methodology is herein proposed to estimate Short Duration Voltage Variation (SDVV) in electric power systems, caused by electrical faults. To attain this target, values recorded by measurement equipment in specific sites are used. In fact, there are few power quality meters installed in power networks, due to the high cost of such meters. Although these costs have decreased in recent years, the installation of a sufficient number of meters to ensure monitoring the entire network is still unfeasible. This reality poses a challenge to developing techniques that, with a small number of monitoring points, allow the determination of fault locations and estimation of SDVV values in specified buses.

As contribution this thesis proposes an algorithm called "Evolutionary Strategies" (ESE), which integrates the group of evolutionary algorithms. This algorithm can be easily implemented and finds a solution within a wide solution space.

The ESE determines the fault location, fault type and fault impedance, that characterize an individual, so that the resulting voltages on monitored buses are as close as possible to the measured ones. An initial population is generated as alternative solutions to the problem. Some of the individuals in the population will be submitted to mutation and recombination operators. Individuals are then selected to the future generation. An iterative process is carried out to determine a solution as close as possible to the desired one.

Each individual is evaluated by the objective function, which represents the quadratic error between the measured and calculated values. This calculation is based on short circuit calculation related to the evaluated individual and from information of voltage values gathered from power quality meters. Voltage values in specific network buses can then be determined to monitor their corresponding SDVV values. This allows, for example, determining quality indicators associated to the SDVV, such as the System Average RMS Frequency Index (SARFI), to evaluate sensitive areas, i.e. which are prone to cause SDVVs and to develop plans for preventive maintenance.

Two algorithms that calculate the minimum number of meters and their locations have been implemented. The first algorithm aims to ensure monitoring the entire network regarding 
SDVVs, while the second algorithm ensures the smallest error of SDVV estimation in buses where no meters are installed.

This methodology can be applied to meshed or radial networks. It was initially implemented in small networks (IEEE 14 and 30 buses) with the purpose of verifying the ability of algorithm. In sequence the methodology was applied to more complex networks (IEEE 57 and 118 buses). To assess the efficiency of the methodology a comparison with other optimization methodology based on Genetic Algorithms (GA) was carried out.

Keyword: Electrical faults, State estimate short duration voltage variation, Fault location, Evolutionary strategies, Variable neighborhood algorithm. 


\section{LISTA DE FIGURAS}

Figura 3.1 - Seqüência de Evolução (a) EEs (b) AGs........................................................ 19

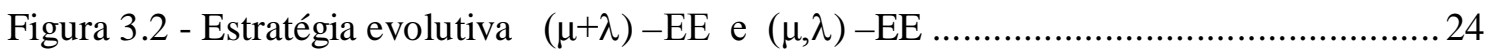

Figura 3.3 - Operador Recombinação .................................................................. 25

Figura 3.4 - Trajetória percorrido em Zig-zag .......................................................... 27

Figura 3.5 - (a) Mutação com $l \sigma=1 \quad$ (b) $l \sigma=2 \quad$ (c) $l \sigma=2$ e $l \theta=1$ (assumindo

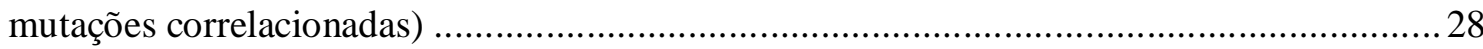

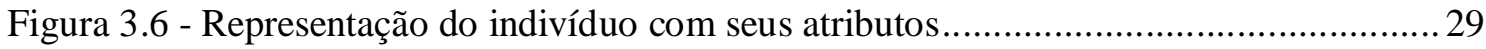

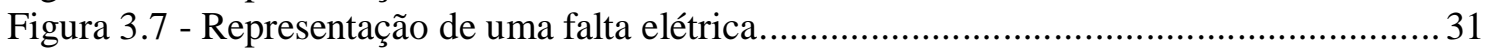

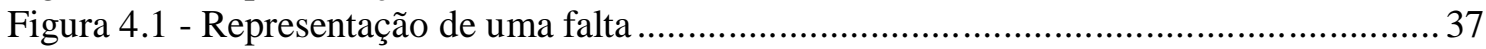

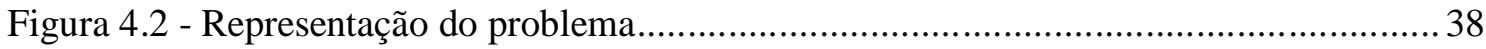

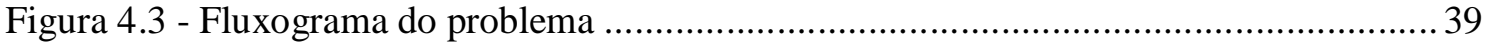

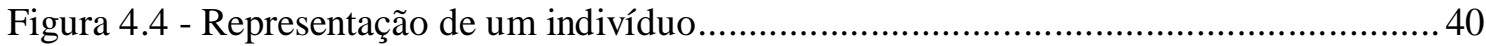

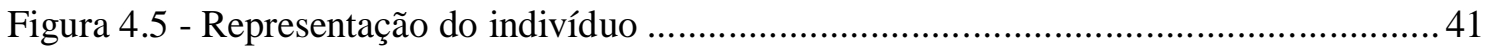

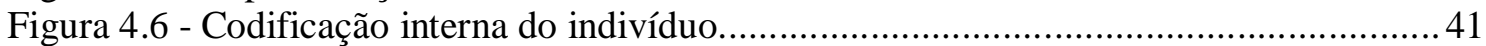

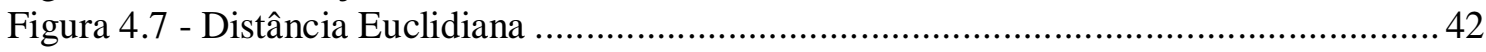

Figura 4.8 - Convergência do algoritmo ............................................................... 43

Figura 4.9 - Aplicação do operador Recombinação ..................................................... 49

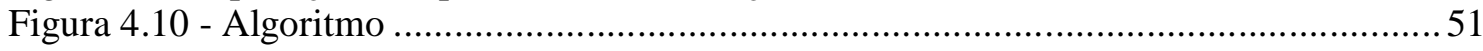

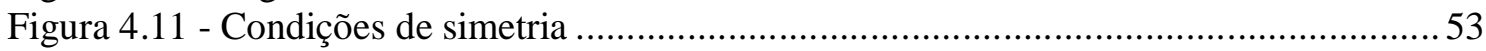

Figura 5.1 - Codificação de uma solução (Alocação-Barra) ...............................................56

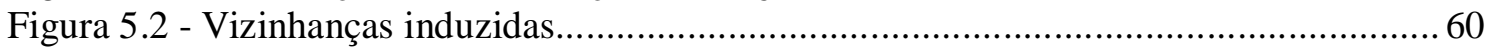

Figura 5.3 - Geração de estruturas de vizinhança através de k-mudança ............................. 62

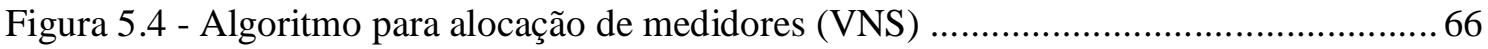

Figura 5.5 - Operador Recombinação - Alocação ótima de medidores............................... 71

Figura 5.5 - Algoritmo para alocação de medidores (EEs) ............................................... 75

Figura 6.1 - Configuração ótima de medidores (6 medidores) -30 barras .........................77

Figura 6.2 - Configuração ótima de medidores visando Faltas monofásicas

(impedância de falta nula) - 30 barras ........................................................................ 78

Figura 6.3 - Configuração ótima de medidores visando VTCDs ( faltas monofásicas e

impedância de defeito nula) - 30 barras........................................................................... 80

Figura 6.4 - Alocação ótima de medidores (Faltas monofásicas) visando VTCDs - 57 barras

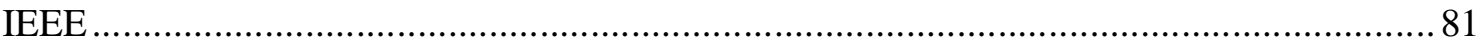

Figura 6.5 - Alocação ótima de medidores (Faltas monofásicas) visando VTCDs -118

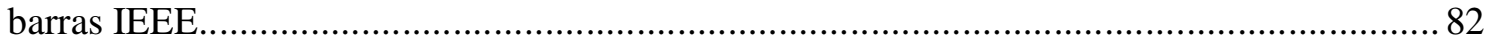

Figura 6.6 - Sistema de 14 barras do IEEE................................................................... 84

Figura 6.7 - Evolução variação do Tamanho da População e do número de Mutações por

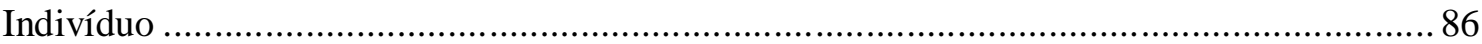

Figura 6.8 - Evolução do algoritmo frente aos valores iniciais de $\sigma$ (local de falta e

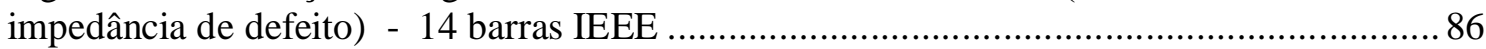

Figura 6.9 - Perfil de tensões nas barras afetadas por VTCDs (14 barras IEEE) .................. 88

Figura 6.10 - Sistema de 30 barras do IEEE......................................................... 88 
Figura 6.11 - Evolução do algoritmo frente aos valores iniciais de $\sigma$ (local de falta e

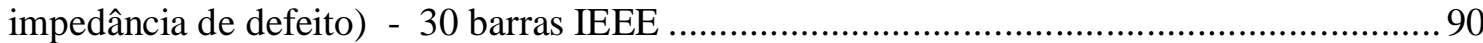

Figura 6.12 - Perfil de tensões nas barras (30 barras IEEE) ............................................. 91

Figura 6.13 - Comparação do comportamento de convergência entre EEs e AGs (30 barras IEEE).....

Figura 6.14 - Sistema de 57 barras do IEEE............................................................ 93

Figura 6.15 - Evolução do algoritmo frente à variação dos parâmetros (57 barras IEEE)...... 95

Figura 6.16 - Casos de simetria (57 barras IEEE) ........................................................... 97

Figura 6.17 - Evolução do algoritmo considerando penalização da função objetivo depois da

$100^{\circ}$ geração (57 barras IEEE) - medidores instalados aleatoriamente ................................98

Figura 6.18 - Comparação do comportamento de convergência entre EEs e AGs (57 barras

IEEE).

Figura 6.19 - Perfil de erros na estimação de VTCDs (57 barras IEEE) - medidores

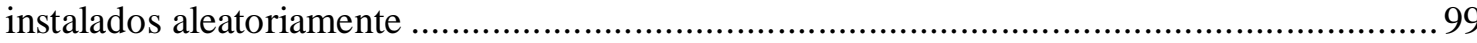

Figura 6.20 - Perfil de erros médios na estimação de VTCDs - Simetria (57 barras IEEE) -

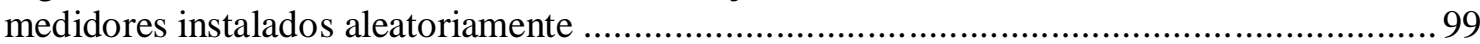

Figura 6.21 - Perfil dos valores médios das tensões nas barras (57 barras IEEE) - medidores

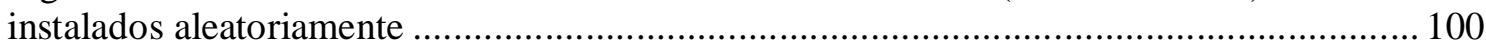

Figura 6.22 - Perfil dos valores das tensões nas barras monitoradas (57 barras IEEE)

utilizando módulo de alocação ótima de medidores ........................................................... 101

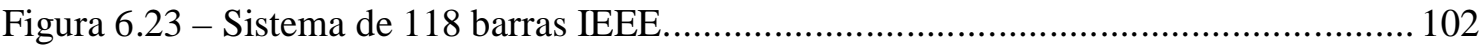

Figura 6.25 - Evolução do processo de evolução frente aos parâmetros próprios (118 barras

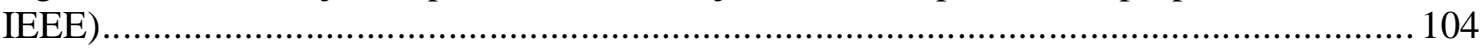

Figura 6.26 - Casos de simetria (118 barras do IEEE) ............................................. 105

Figura 6.27 - Comparação do comportamento de convergência entre EEs e AGs (118 barras

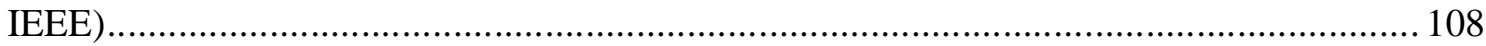

Figura 6.28 - Perfil de erros médios na estimação de VTCDs (118 barras IEEE)................ 108

Figura 6.29 - Perfil de erros médios na estimação de VTCDs - com Simetria (118 barras

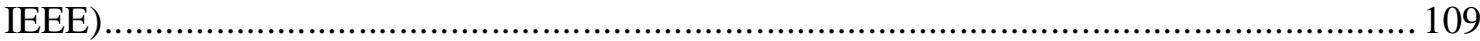

Figura 6.30 - Perfil dos valores médios das tensões nas barras (118 barras IEEE) ............. 109

Figura 6.31 - Perfil dos valores médios das tensões nas barras -Simetria (118 barras IEEE)

Figura 6.31 - Perfil dos valores das tensões nas barras monitoradas (118 barras IEEE) ... 111

Figura A.1 - Codificação de indivíduo (AGs) ...................................................... 121

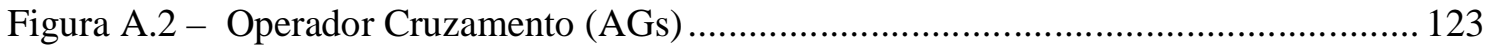

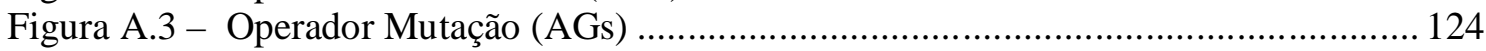

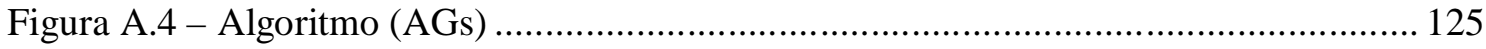

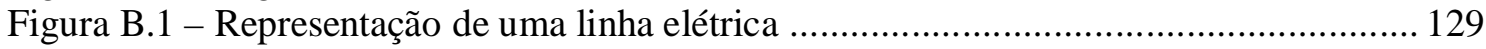

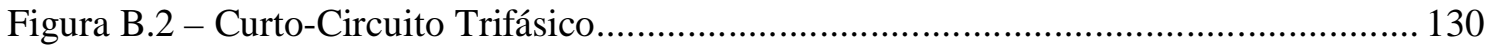

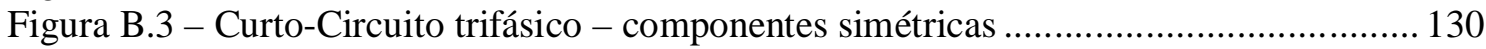

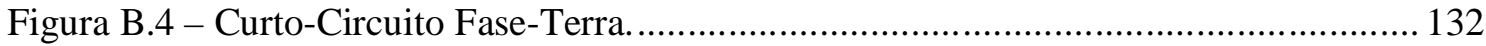

Figura 11-4 - Curto-Circuito fase-terra - componentes simétricas................................... 133

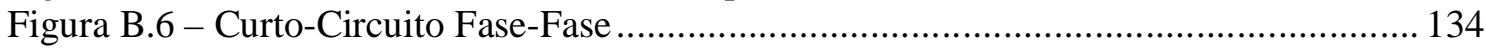

Figura B.7 - Curto-Circuito fase- fase - componentes simétricas ................................. 135

Figura B.7 - Curto-Circuito Fase-Fase-Terra - componentes simétricas ........................... 136

Figura B.7 - Curto-Circuito Fase-Fase-Terra ............................................................... 137 


\section{LISTA DE TABELAS}

Tabela 3.1 - Características ( Algoritmos Genéticos - Estratégias Evolutivas) .................... 18

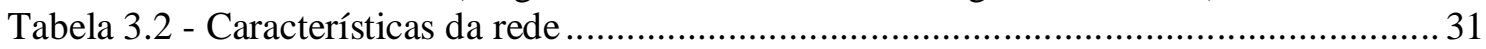

Tabela 3.3 - (a) População (b) Indivíduos gerados ......................................................... 32

Tabela 4.1 - Lista de trechos para uma falta trifásica ................................................... 45

Tabela 4.2 - Listas armazenadas para os curtos-circuitos considerados ............................. 46

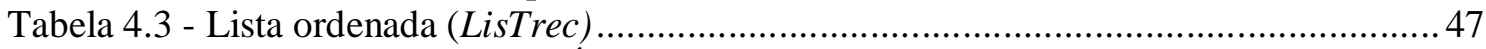

Tabela 6.1 - Resultados Alocação Ótima de Medidores utilizando VNS - 30 barras IEEE... 78

Tabela 6.2 - Resultados - Alocação Ótima de Medidores utilizando EEs - 30 barras IEEE .. 79

Tabela 6.3 - Resultados - Alocação Ótima de Medidores utilizando EEs (Faltas monofásicas)

Tabela 6.4 - Características - 14 barras IEEE ............................................................. 85

Tabela 6.5 - Parâmetros iniciais para a rede de 14 barras IEEE ........................................ 85

Tabela 6.6 - Resultados da avaliação 14 barras IEEE (utilizando Alocação Ótima de

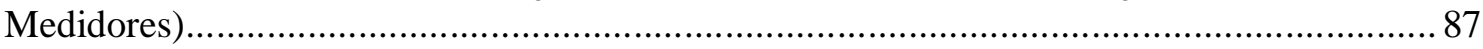

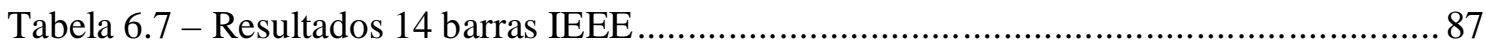

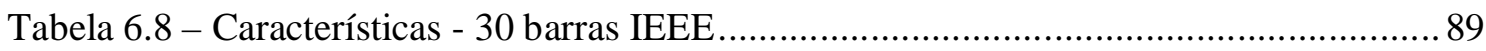

Tabela 6.9 - Parâmetros iniciais 30 barras IEEE .......................................................... 89

Tabela 6.10 - Resultados da avaliação 30 barras IEEE (utilizando alocação ótima de

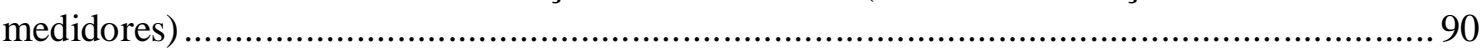

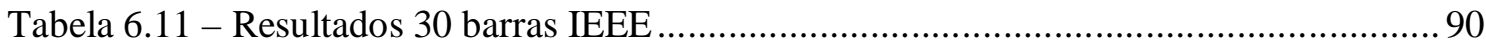

Tabela 6.12 - Comparação dos resultados entre EEs e AGs (30 barras IEEE)..................... 92

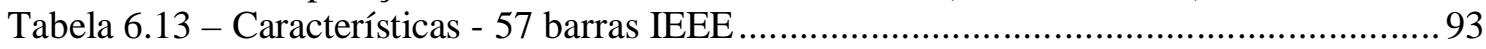

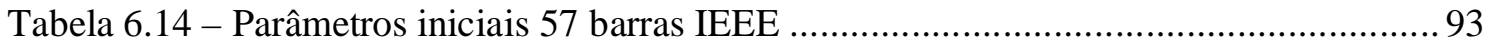

Tabela 6.15 - Resultados da avaliação 57 barras IEEE....................................................96

Tabela 6.16 - Condições de curto-circuito com simetria (57 barras IEEE ) - medidores

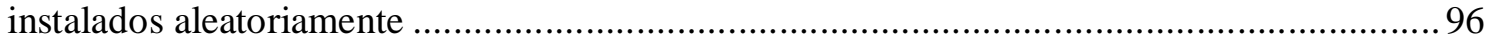

Tabela 6.17 - Resultados 57 barras IEEE - medidores instalados aleatoriamente ................97 Tabela 6.18 - Comparação dos resultados entre EEs e AGs (57 barras IEEE) - medidores

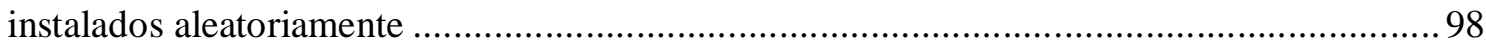

Tabela 6.19 - Resultados 57 barras IEEE utilizando módulo de alocação ótima de medidores

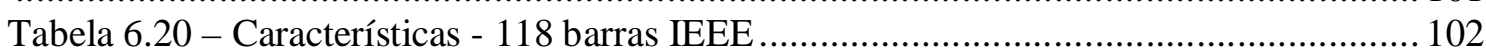

Tabela 6.21 - Parâmetros iniciais 118 barras IEEE..................................................... 103

Tabela 6.22 - Condições de curto-circuito com simetria (118 barras IEEE)...................... 105

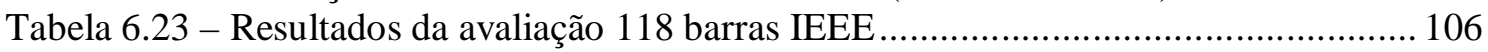

Tabela 6.24 - Resultados 118 barras IEEE - medidores instalados aleatoriamente .............. 106

Tabela 6.25 - Resultados 118 barras IEEE (considerando valores fasoriais registrados pelos

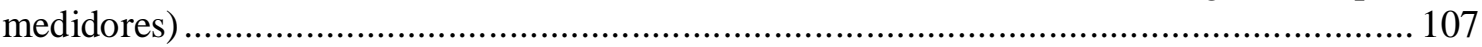

Tabela 6.26 - Comparação dos resultados entre EEs e AGs (118 barras IEEE)................... 107 Tabela 6.27 - Resultados 118 barras IEEE utilizando módulo de alocação ótima de medidores 


\section{LISTA DE ABREVIATURAS E SIGLAS}

$\begin{array}{ll}\text { ANEEL } & \text { Agência Nacional de Energia Elétrica } \\ \text { AG } & \text { Algoritmo Genético } \\ \text { DEC } & \text { Duração equivalente de interrupção por consumidor } \\ \text { DIC } & \text { Duração de interrupção individual por unidade consumidora } \\ \text { DMIC } & \text { Duração máxima de interrupção por unidade consumidora } \\ \text { DFR } & \text { Registrador de falta digital } \\ \text { EE } & \text { Estratégia Evolutiva } \\ \text { END } & \text { Energia não distribuída } \\ \text { FEC } & \text { Frequiência equivalente de interrupção por consumidor } \\ \text { FIC } & \text { Frequiência de interrupção individual por unidade consumidora } \\ \text { IEEE } & \text { Institute of Electrical and Electronic Engineers } \\ \text { ONS } & \text { Operador Nacional do Sistema } \\ \text { PE } & \text { Programação Evolutiva } \\ \text { QEE } & \text { Qualidade de Energia Elétrica } \\ \text { SEP } & \text { Sistema Elétricos de Potência } \\ \text { SVM } & \text { Máquina de suporte vetorial } \\ \text { SARFI } & \text { System Average RMS Frequency Index } \\ \text { VTCD } & \text { Variação de tensão de curta duração } \\ \text { VTLD } & \text { Variação de tensão de longa duração } \\ \text { TA } & \text { Tempo de atendimento }\end{array}$




\section{LISTA DE SÍMBOLOS}

$\begin{array}{ll}\mathrm{v} & \text { População } \\ \mathrm{x} & \text { Parâmetros que representam um indivíduo } \\ \sigma & \text { Vetor de desvios padrões (passos) } \\ \theta & \text { Direção preferencial de movimento } \\ N(0, \sigma) & \text { Função gaussiana de média zero e desvio padrão } \sigma \\ \Phi & \text { Variação do desvio (regra do sucesso) } \\ \mu & \text { Grupo de pais } \\ \lambda & \text { Grupo de filhos }\end{array}$




\section{SUMÁRIO}

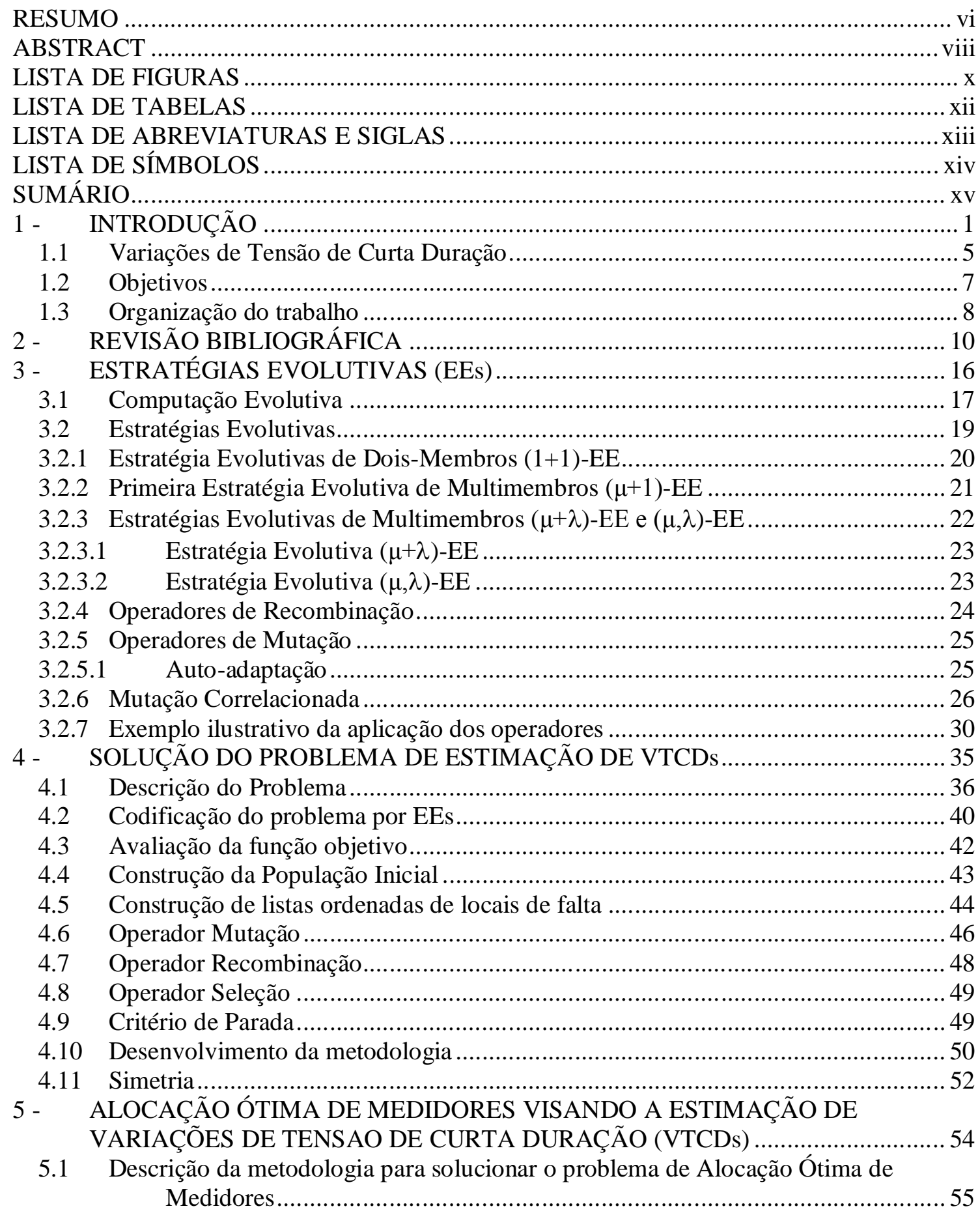




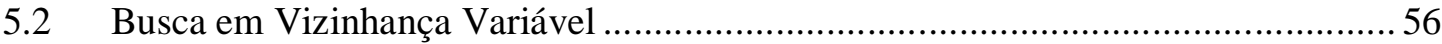

5.2.1 Metodologia para solucionar o problema de Alocação Ótima de medidores

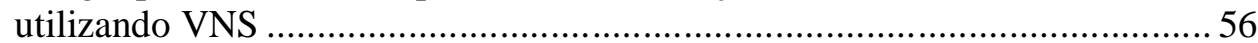

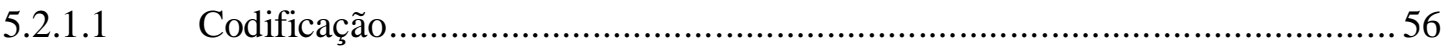

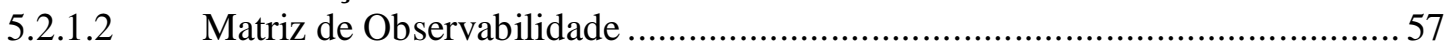

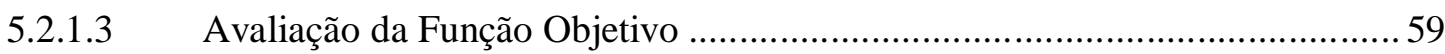

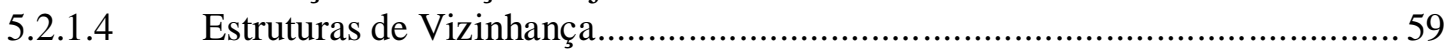

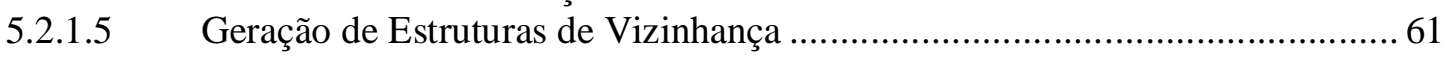

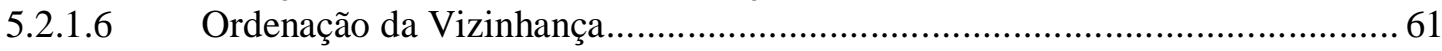

5.2.1.7 Estratégias de Busca e Mudança da Vizinhança ...........................................63

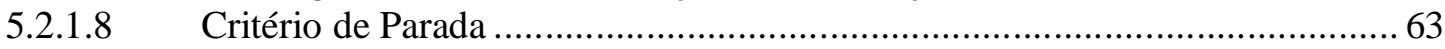

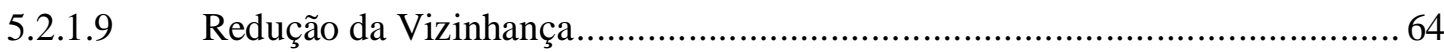

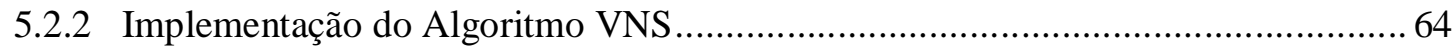

5.3 Descrição da metodologia para resolver o problema de Alocação Ótima de Medidores considerando Simetria ..............................................................6 67

5.3.1 Metodologia para solucionar o problema de Alocação Ótima de medidores visando

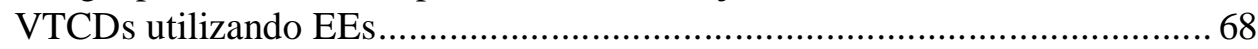

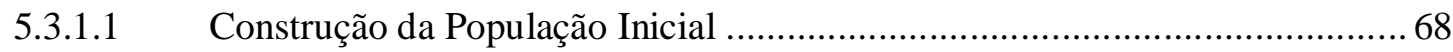

5.3.1.2 Matriz de Observabilidade e Matriz de Simetria..........................................6 68

5.3.1.3 Avaliação da Função Objetivo ............................................................... 70

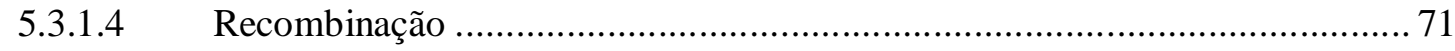

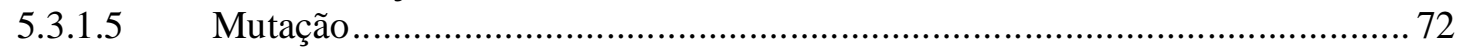

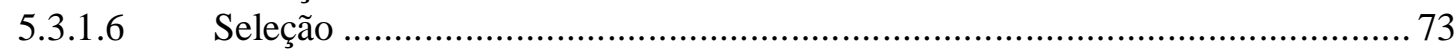

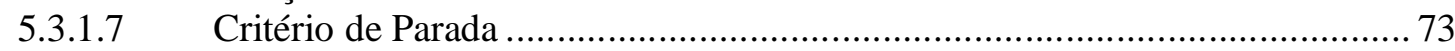

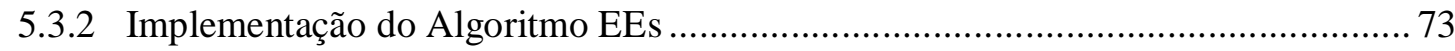

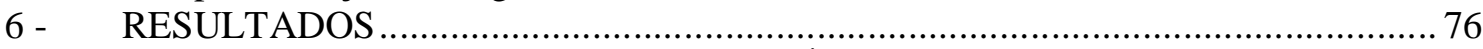

6.1 Resultados da Metodologia de Alocação Ótima de Medidores ............................. 76

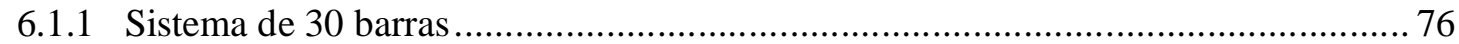

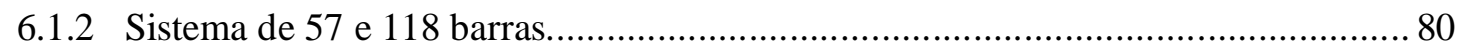

6.2 Resultados da Metodologia de Estimação de VTCD .............................................. 83

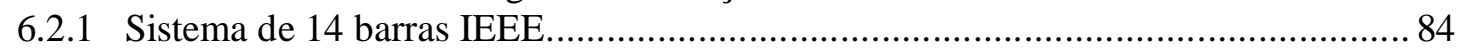

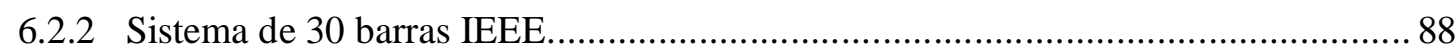

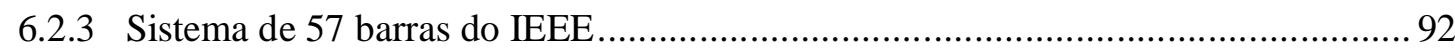

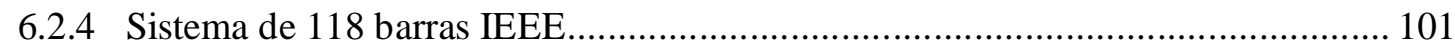

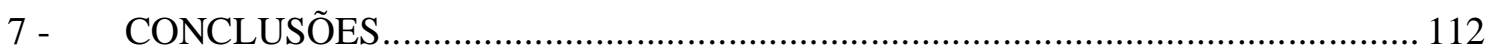

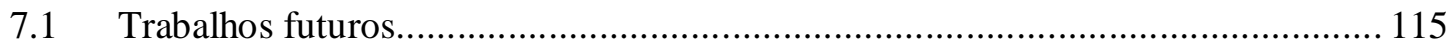

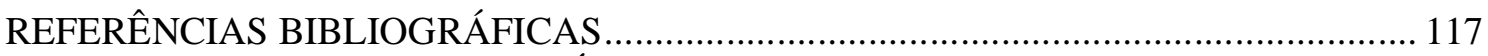

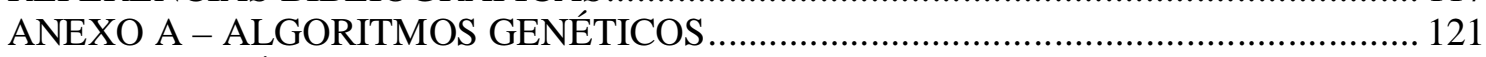

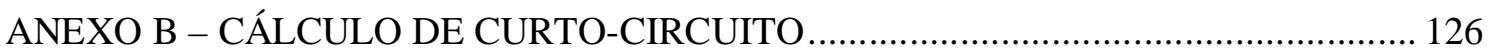

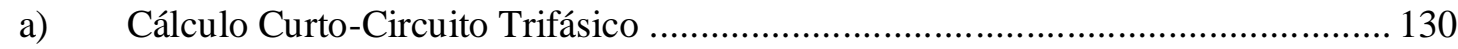

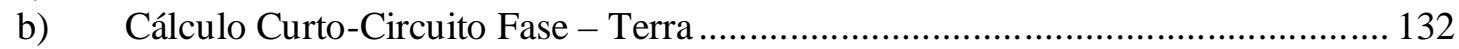

c) Cálculo Curto-Circuito Fase-Fase (Fases B e C) ............................................... 134

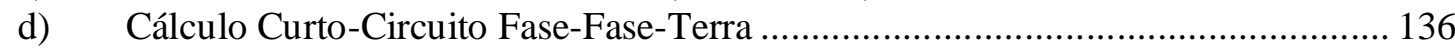

ANEXO C - LISTA DE ARTIGOS PUBLICADOS .................................................... 139 


\section{1 - INTRODUÇÃO}

As mudanças que vêm acontecendo no mercado do setor elétrico nas últimas décadas trazem como consequência a aplicação de um modelo que exige maior competitividade dos operadores que formam este setor. O governo desempenha papéis de fiscalização e regulação através de agências reguladoras como a Agência Nacional de Energia Elétrica - ANEEL. Esta tendência mundial cria nas empresas concessionárias a necessidade de elaborar metas e objetivos a serem alcançados, tomar medidas para o cumprimento destas metas e se adaptar às novas regras do mercado. Este processo gera um desafio constante, para se obter a cada dia uma maior eficiência econômica e uma maior Qualidade de Fornecimento de Energia Elétrica. Observa-se que a melhoria na Qualidade de Energia Elétrica tem se tornado uma grande preocupação dos operadores que compõem o mercado elétrico.

Neste cenário, o desenvolvimento de novos métodos para análise, planejamento e operação dos sistemas de energia elétrica torna-se uma grande necessidade que, associada aos custos de investimento, gera desafios maiores. Esses métodos devem, portanto, buscar mecanismos que garantam padrões de qualidade e confiabilidade exigidos pelo mercado consumidor e pelas agências regulatórias. Hoje, um critério adicional a estas medidas é o retorno dos investimentos, já que a energia elétrica deve ser tratada como um produto comercialmente competitivo.

Quando se trata do tema de qualidade de energia elétrica (QEE), os seguintes três aspectos devem ser referenciados, conforme (KAGAN; ROBBA; SCHMIDT, 2009):

- Qualidade do produto: Esta característica refere-se basicamente às formas de onda de tensão e corrente, o que envolve principalmente:

$>$ Variações de freqüência: que são definidas como sendo desvios no valor da freqüência fundamental do sistema elétrico $(50 \mathrm{ou} 60 \mathrm{~Hz})$.

$>$ Variações de tensão de longa duração (VTLDs): que podem ser interrupções, sobtensões ou sobretensões sustentadas.

$>$ Variações de tensão de curta duração (VTCDs): que podem ser instantâneas, momentâneas, ou temporárias. 
Distorções harmônicas de tensão e corrente: que podem ser classificadas em cinco tipos: nível CC, harmônicos, interharmônicos, "notching", e ruídos.

> Desequilíbrio de tensão e corrente: causados principalmente por má distribuição de cargas monofásicas, e que fazem surgir no circuito tensões de seqüência negativa.

$>$ Flutuações de tensão: que são variações sistemáticas dos valores eficazes da tensão de suprimento (dentro da faixa compreendida entre 0,95 e 1,05 pu), e que podem ser aleatórias, repetitivas ou esporádicas.

- Qualidade do serviço: Esta característica refere-se basicamente à continuidade de fornecimento, ou seja, às interrupções no sistema elétrico provocadas por falhas no sistema (manutenção corretiva) e por atividades de manutenção programada (manutenção preventiva). É definida através de índices operativos avaliados em um determinado período, seja para um grupo de consumidores ou, seja por unidade consumidora. Seus principais indicadores são:

$>$ Duração equivalente de interrupção por consumidor (DEC);

> Freqüência equivalente de interrupção por consumidor (FEC);

$>$ Energia não distribuída (END);

$>$ Duração de interrupção individual por unidade consumidora (DIC);

$>$ Freqüência de interrupção individual por unidade consumidora (FIC);

> Duração máxima de interrupção por unidade consumidora (DMIC).

- Qualidade do Atendimento Comercial: Esta característica refere-se ao relacionamento comercial entre empresa e cliente. Alguns tópicos afins com a qualidade de atendimento podem ser citados, como os procedimentos para ligação nova de consumidor, para religamento de consumidor, para elaboração de estudos e orçamentos de serviços na rede de distribuição, dentre outros. Uma forma de mensurar estes atributos é através do tempo para realização de cada uma destas atividades comerciais.

Nos últimos anos, as pesquisas técnicas e a tecnologia de equipamentos de controle e medição trouxeram novos desafios para melhorar o monitoramento de todos estes índices de qualidade. Através de um adequado monitoramento é possível tomar as medidas necessárias para melhorar os índices mencionados, como por exemplo: 
- Diminuir o tempo de restabelecimento de energia elétrica ante uma falta elétrica;

- Estabelecer áreas de risco ante VTCDs causadas por faltas, o que leva a tomar ações de manutenção preventiva e corretiva;

- Instalar chaves de interconexão para reduzir o número de consumidores afetados por uma falta elétrica;

- Instalar equipamentos para diminuir as correntes harmônicas circulantes na rede elétrica;

- Balancear as fases de conexão das cargas;

- Introduzir medidas de automação utilizando o conceito de rede inteligente (Smart Grid);

- Adequar as normas a um contexto real.

Dos índices mencionados, as VTCDs se constituem em um aspecto muito importante referente à qualidade de energia elétrica, e que está demandando grande esforço por parte dos pesquisadores pelo fato de provocar sérios prejuízos para os consumidores, como falhas e operações indevidas de equipamentos elétricos. Os principais problemas relacionados a este fenômeno ocorrem devido às ocorrências de faltas e às manobras de grandes cargas na rede. Um exemplo típico desta última causa é a partida de grandes motores, o que provoca altas correntes, entre 6 a 10 vezes a corrente nominal, tornando maior o problema quando o método de partida desses motores não for adequado.

Como já mencionado, outro fenômeno desencadeador das VTCDs são as faltas elétricas, que consistem no foco principal deste trabalho de doutorado. Os curtos-circuitos que acontecem nas linhas elétricas de uma rede elétrica geram correntes de curto-circuito através das impedâncias do sistema causando quedas (afundamentos) de tensão ao longo da rede.

Por outro lado, as VTCDs são caracterizadas por dois parâmetros, quais sejam a magnitude e duração. Este último parâmetro está diretamente relacionado com dois tipos de tempos: i) O Tempo de atuação do relé mais o tempo de abertura do disjuntor, neste caso a atuação dos dispositivos de proteção provocariam interrupções de curta ou de longa duração, e ii) Tempo da extinção natural da falta, este tempo se refere a efeito de faltas de curtíssima duração nos quais os dispositivos de proteção não são sensibilizados. Dentre todas as causas de curto-circuito, as maiores responsáveis são as descargas atmosféricas, tendo estas um caráter aleatório.

Através de uma eficiente localização de faltas é possível determinar os parâmetros que caracterizam uma condição de curto-circuito. Assim, com a informação obtida, os valores das 
tensões são estimados naquelas barras onde não se têm medidores instalados, sendo este o principal objetivo deste trabalho conforme acima destacado.

Ressalta-se que uma interrupção de longa duração pode se tornar permanente. Por exemplo, quando há uma descarga atmosférica, onde o religamento automático é realizado com sucesso; no entanto, durante esta falta, pode haver avaria no isolador diante das altas temperaturas do arco elétrico, tornando-se a falta permanente.

Neste tipo de eventos a localização constitui uma ferramenta poderosa para diminuir o tempo de restabelecimento, que pode ser elevado, principalmente se a região de ocorrência da falta permanente for de difícil acesso, como florestas e regiões montanhosas, o que não é um fato comum, estando normalmente o trajeto das linhas próximo às vias de acesso fácil, como estradas.

Dentre as maiores dificuldades encontradas para se resolver o problema de estimação das VTCDs, destacam-se: as características próprias da rede, ou seja, tipo de condutores, configuração, impedância do sistema que se encontra atrás da subestação e impedância de falta. Acrescenta-se ainda que o número insuficiente de medidores instalados nas redes elétricas para registrar todas as VTCDs ante uma falta elétrica é um fato usual. Uma outra questão importante a se mencionar é que nem sempre as empresas concessionárias mantêm seu banco de dados atualizado, o que influenciará nos resultados.

$\mathrm{Na}$ literatura, trata-se pouco sobre a estimação de estado da rede elétrica durante VTCDs (LEDESMA, 2004). Vários trabalhos relacionados com a localização de faltas foram pesquisados (JOHNS; JAMALI, 1990a; JOHNS; JAMALI, 1990b; HONG; COLWELL, 1997; SOUSA et al., 2001; ZIJAD; ALI, 2002; KEZUNOVIC; LUO; SEVCIK, 2002; YUAN, 2007; 0 PEREIRA et al., 2009). A maioria das técnicas difere basicamente na metodologia e nas informações que utilizam para seu desenvolvimento. Esta última característica está condicionada muitas vezes com a disponibilidade de equipamentos de medição e controle existentes na rede e com o planejamento da empresa de investir na aquisição de novos equipamentos (hardware) e software necessários. Na tomada de decisão, deve-se buscar uma relação de custo-benefício adequada, ou seja, otimizar os custos envolvidos na implementação da técnica (hardware e/ou software), custos da instalação de medidores, custos dos reparos na rede, custos na manutenção da qualidade e redução dos tempos de reparo.

Nesta tese é desenvolvida uma ferramenta para localização de faltas em sistemas elétricos, que é utilizada para a estimação de VTCDs. A técnica desenvolvida é de Estratégias Evolutivas (EEs) (RECHENBERG, 1973; BÄCK; HOFFMEISTER; SCHWEFEL, 1991; TETTAMANZI; TOMASSINI, 2001) que integra a família dos Algoritmos Evolutivos 
(SCHWEFEL, 1965; DAVID; FOGEL, 1995; BACK; FOGEL; MICHALEWICZ, 2000), sendo sua filosofia baseada na emulação da evolução de espécies através de três operadores: Mutação, Recombinação e Seleção. Destaca-se que no campo da inteligência artificial esta técnica já demonstrou ser eficiente para resolver problemas complexos de otimização com inúmeras aplicações (SCHWEFEL, 1987; SCHWEFEL; RUDOLPH, 1995; MAGELE, 2001).

As EEs, nesta tese, são utilizadas para se determinar o local de falta, o tipo de falta e a impedância de falta, que caracterizam um indivíduo, de forma que seu efeito sobre as barras monitoradas seja o mais próximo possível das medições realizadas. Para tanto, se constrói uma população inicial de indivíduos que representam soluções alternativas do problema. Em seguida, uma parte dos indivíduos irá se reproduzir e sofrer mutação/recombinação (alterar características do fenótipo), e finalmente selecionar quais os indivíduos que sobreviverão na geração futura, tornando-se um processo iterativo até encontrar uma solução para o problema mais próxima da real.

Para desenvolver esta técnica, são necessários, durante a falta elétrica, os valores das tensões em algumas barras e correntes em alguns trechos da rede registrados pelos medidores instalados. Dependendo das respostas dos equipamentos de medição, essas grandezas serão expressas fasorialmente ou através da sua magnitude. Além desses valores, são utilizados dados operacionais da rede para se calcular o curto-circuito.

Também foram desenvolvidos dois algoritmos que determinam o número mínimo e local de instalação de medidores e onde eles devem ser instalados: o primeiro para garantir o monitoramento de todas VTCDs decorrentes de qualquer condição de curto-circuito; e o segundo algoritmo visa a estimação de VTCDs nas barras onde se deseja monitorar considerando incertezas na estimação dos valores de tensão durante a falta.

Para avaliar a eficiência da metodologia proposta, foram utilizados sistemas elétricos de teste de pequeno e grande porte do IEEE. Também se fez uma comparação com outra técnica de otimização, qual seja os Algoritmos Genéticos $(A G s)$, com intuito de avaliar a eficiência da metodologia desenvolvida neste trabalho.

\subsection{Variações de Tensão de Curta Duração}

Segundo a normalização relativa aos principais fenômenos envolvidos à qualidade de energia (IEEE Std, 1995), define-se a variação de curta duração (VTCDs) como uma 
alteração no valor da tensão eficaz com duração entre 0,5 ciclo (da freqüência fundamental) até 1 minuto, compreendendo afundamentos ou elevações de tensão.

Segundo o IEEE, afundamento de tensão (voltage sag ou voltage dip) corresponde a uma diminuição do valor eficaz da tensão para 0,1 a 0,9 pu. Elevações de tensão (voltage swell) são definidas como aumentos do valor da tensão eficaz para 1,1 a 1,8 pu.

No Brasil, a Resolução n ${ }^{\circ} 24$ de janeiro 2000 e a Resolução n ${ }^{\circ} 505$ de novembro 2001, publicadas pela ANEEL, estabelecem indicadores e metas de qualidade relativas à continuidade e tensão de fornecimento de energia elétrica para agentes distribuidores. Visando oferecer medidas de desempenho da rede básica compatíveis com tais indicadores, as resoluções estabelecem indicadores de continuidade para a fronteira, que deverão ser apurados e divulgados pelo Operador Nacional do Sistema (ONS).

A Resolução 024/2000 apresenta indicadores de duração e frequiência de interrupção referente às barras de conexão da rede básica com os demais agentes. Ao operador nacional do sistema cabe a apuração e divulgação de tais indicadores, bem como a proposição de padrões de desempenho.

Para atender a atribuição recebida do órgão regulador, os procedimentos necessários na rede de distribuição podem ser observados na publicação feita pela ANEEL, em setembro do 2007, consistindo no PRODIST (Procedimentos de Distribuição de Energia Elétrica no Sistema Elétrico Nacional) em seu Item 7 do Módulo 8 (AGENCIA NACIONAL DE ENERGIA ELÉTRICA, 2007), que estabelece padrões de desempenho da rede de distribuição conforme definidos a seguir.

Para as Variações de tensão de curta duração (VTCD), estabelece:

-VMT (variações momentâneas de tensão):

$\begin{array}{lrr}\text { Interrupção } & \mathrm{t} \leq 3 \mathrm{~s} & \mathrm{~V}<0,1 \mathrm{pu} \\ \text { Afundamento } & 1 \text { ciclo } \leq \mathrm{t} \leq 3 \mathrm{~s} & 0,1 \leq \mathrm{V}<0,9 \mathrm{pu} \\ \text { Elevação } & 1 \text { ciclo } \leq \mathrm{t} \leq 3 \mathrm{~s} & \mathrm{~V}>1,1 \mathrm{pu}\end{array}$

- VTT (variação temporária de tensão):

$\begin{array}{llr}\text { Interrupção } & 3 \mathrm{~s}<\mathrm{t} \leq 1 \mathrm{~min} & \mathrm{~V}<0,1 \mathrm{pu} \\ \text { Afundamento } & 3 \mathrm{~s}<\mathrm{t} \leq 1 \mathrm{~min} & 0,1 \leq \mathrm{V}<0,9 \mathrm{pu} \\ \text { Elevação } & 3 \mathrm{~s}<\mathrm{t} \leq 1 \mathrm{~min} & \mathrm{~V}>1,1 \mathrm{pu}\end{array}$


Como já mencionado anteriormente, as perturbações de tensão são descritas normalmente em termos de valor eficaz e duração. A partir de um levantamento de formas de onda de VTCDs (IEEE 1159.2, 1999), observou-se que o valor eficaz não descreve completamente o evento devido à forma de onda, que não é necessariamente senoidal, e aquele parâmetro não permite inferir completamente o fenômeno. Considerando essa característica, se torna necessário definir de forma quantitativa alguns parâmetros que descrevem o fenômeno, sendo os principais os seguintes:

- Valor eficaz;

- Duração;

- Instante ou ângulo de fase inicial;

- Instante ou ângulo de fase final.

Por outro lado, muitos equipamentos industriais estão ligados às três fases da rede elétrica e operam entre fases. A influência de diferenças nas fases pode ser significativa; assim, há que considerar o desequilíbrio de tensão, em geral decorrente de diferença de amplitude entre fases e/ou de diferença de ângulo de fases.

Através de uma ferramenta computacional associada a um monitoramento eficiente pode-se estimar valores de todos os parâmetros mencionados com precisão. Mas, a grande dificuldade, como já mencionado, são os custos ainda elevados dos equipamentos de medição, tornando-se ainda mais elevados quando eles possuem canais de medição para registrar diferentes grandezas.

\subsection{Objetivos}

Este trabalho tem como objetivo principal o desenvolvimento de uma metodologia capaz de estimar o estado da rede elétrica (visando aos valores da magnitude das tensões) com relação às variações de tensão de curta duração (VTCDs) causada por alguma falta elétrica. Para cumprir este objetivo, foi necessário o desenvolvimento de:

- Um algoritmo próprio de localização de faltas utilizando as Estratégias Evolutivas (EEs), que seja capaz de determinar ante uma falta elétrica, as características da condição de curto-circuito, ou seja, local de falta, impedância de defeito e tipo de falta.

- Um algoritmo que calcula o número mínimo de medidores e determina onde estes devem ser instalados para monitorar a rede toda, visando a estimação das 
VTCDs decorrentes de faltas elétricas. A técnica implementada foi a de Busca em Vizinhança Variável (VNS).

- Um algoritmo que calcula o número mínimo de medidores e determina onde estes devem ser instalados para monitorar as VTCDs naquelas barras onde não se têm instalados medidores, considerando incertezas na estimação. A técnica implementada foi de EEs.

Foi necessário implementar os dois últimos algoritmos, tendo em vista que os medidores instalados nas redes elétricas não visam necessariamente à estimação de VTCDs.

Para avaliar a potencialidade da metodologia apresentada, realizou-se uma comparação dos resultados com outra técnica de otimização, qual seja de Algoritmos Genéticos (AGs).

\subsection{Organização do trabalho}

O presente documento de Tese foi organizado da seguinte forma:

O Capítulo 1 apresenta uma introdução dos conceitos relacionados à qualidade de energia elétrica com destaque para as VTCDs, sua definição e seus efeitos nos diferentes consumidores.

O Capítulo 2 apresenta uma revisão bibliográfica que abrange um panorama de diferentes estudos realizados no Brasil e no mundo sobre temas referentes à estimação de VTCDs e localização de faltas elétricas nas redes elétricas. Também são analisados trabalhos que aplicam a técnica de otimização desenvolvida nesta tese (EEs) para outros problemas de Engenharia Elétrica.

O Capítulo 3 apresenta aspectos teóricos e conceituais sobre "Estratégias evolutivas", para posteriormente aplicar e resolver o problema de localização de faltas elétricas. São analisados de forma detalhada os operadores próprios da metodologia: Mutação, Recombinação e Seleção, bem como as estratégias particulares que utilizam estes operadores.

O Capítulo 4 apresenta a aplicação da metodologia ao problema de "Localização de Faltas Elétricas". De forma detalhada é descrita cada etapa do processo de otimização, começando pela codificação do indivíduo, passando pela construção da população inicial, avaliação da função objetivo, e aplicação dos operadores de evolução (mutação, recombinação e seleção). Neste Capítulo se desenvolvem as estratégias próprias dos operadores, a auto-adaptação e mutação correlacionada. Finalmente, faz-se uma análise do 
conceito de simetria, apresentando algumas estratégias para minimizar os erros grosseiros apresentados em tais casos.

O Capítulo 5 apresenta de forma detalhada o desenvolvimento de dois algoritmos. O primeiro intitulado “Alocação Ótima de Medidores de Qualidade de Energia utilizando Busca em Vizinhança Variável" (GUERRA; KAGAN, 2010a) e o segundo "Alocação Ótima de Medidores de Qualidade de Energia visando monitoramento de VTCDs utilizando Estratégias Evolutivas" (GUERRA; KAGAN, 2010b), que determina o número mínimo de medidores, bem como os pontos onde os mesmos devem ser instalados, para garantir o monitoramento de VTCDs decorrente de qualquer condição de curto-circuito.

O Capítulo 6 apresenta os resultados obtidos. Uma primeira rede de 14 barras do IEEE é utilizada para avaliar a viabilidade de aplicação da metodologia. Depois são utilizadas redes de médio porte e finalmente uma rede de 118 barras do IEEE é utilizada para avaliar a eficiência e potencialidade da metodologia. Os resultados são comparados com outra metodologia de otimização, a qual envolve o uso de Algoritmos Genéticos (AGs).

O Capítulo 7 apresenta conclusões finais deste trabalho, assim como as suas principais contribuições. Trabalhos futuros também são comentados e apresentados na parte final deste capítulo.

O ANEXO A apresenta o desenvolvimento dos Algoritmos Genéticos (AGs) para solucionar o problema de estimação de estados de VTCDs, com intuito de comparar os resultados com a metodologia proposta nesta tese. Para isso, são considerados os operadores de evolução próprios dessa metodologia.

O ANEXO B apresenta formulações básicas, utilizadas para o cálculo das correntes e tensões em condições de curto-circuito, considerando os diferentes tipos de curto-circuito. A formulação é feita através do método de Componentes Simétricas para redes trifásicas.

O ANEXO C apresenta trabalhos desenvolvidos e publicados em congressos e conferências nacionais e internacionais, durante o período dos estudos do Doutorado. 


\section{2- REVISÃO BIBLIOGRÁFICA}

A pesquisa bibliográfica mostrou que existem poucos trabalhos sobre a estimação de estado que visam a avaliação da qualidade de energia no sistema elétrico, com particular ênfase quando ocorrem variações de tensão de curta duração (VTCDs).

Os trabalhos publicados em (EPRI, 1998) foram as primeiras publicações específicas, voltadas à área de qualidade de energia, em que foram desenvolvidos algoritmos de estimação de estados para avaliação de níveis de tensão, harmônicas, variações de tensão de curta duração - afundamentos e elevações de tensão e transitórios para aplicação principal em sistemas de distribuição.

O algoritmo de estimação de VTCDs procura reproduzir a falta ocorrida no sistema elétrico e fornece as tensões resultantes do caso que melhor se ajustam às medições, sendo considerados dois cenários: o primeiro, quando dispõe-se apenas de monitoramento na subestação, e o segundo, quando são disponíveis vários medidores no alimentador. Para ambos cenários é aplicada uma variedade de condições de falta em cada barramento da área considerada, com base numa estimativa das fases envolvida. A falta admitida como a ocorrida é aquela que apresenta os resultados de variações de tensão mais próximos dos valores medidos. Assim, as tensões calculadas para essa condição são consideradas as estimadas. $\mathrm{O}$ estimador é tão mais preciso quanto maior é o número de medidores distribuídos no alimentador, sendo possível obter precisões inferiores a 0,01 p.u das tensões lidas.

Outro trabalho de estimação de VTCDs é apresentado em (LEDESMA, 2004) para sistemas de distribuição primária, no qual foi desenvolvido um módulo de localização de faltas. Os dados são obtidos de um banco de ocorrências visando as VTCDs. O algoritmo desenvolvido para a localização se baseia em um modelo de cálculo através de equacionamentos de tensão e correntes em trechos do alimentador em função do tipo de falta e dos parâmetros de linha, partindo dos valores de tensão e corrente medidos no início do alimentador, e considerando também os valores das correntes de carga nos trechos do alimentador. Uma característica dos alimentadores primários de distribuição é que, além de operarem radialmente, eles possuem ramificações. Assim sendo, faltas em diferentes pontos 
da rede podem resultar nos mesmos valores de tensão e de corrente na subestação. Para essas condições o algoritmo determina possíveis pontos de ocorrência de falta.

Wang; Xu; Pan (2005) apresentam um método para estimação de VTCDs, considerando três premissas: aplicação em redes elétricas radiais, que o número de medidores simulados seja limitado a um valor escolhido, e, finalmente, que se utilize o método de mínimos quadrados para avaliar os valores de tensão ao longo das linhas. O método se baseia em determinar um perfil dos valores das tensões (nas barras) ao longo do caminho da falta e que estejam mais próximas ao perfil de valores de tensões nos medidores instalados no mesmo caminho. É aplicado em um sistema de 123 barras do IEEE, com a obtenção de resultados aceitáveis para o cálculo de índices de qualidade como o SARFI (System Average RMS Frequency Index), ou índice médio da freqüência de valores eficazes do sistema. A limitação do método consiste na necessidade de se contar com mais de um medidor em cada alimentador da rede radial.

Por outro lado, vários métodos de localização de faltas têm sido desenvolvidos e aperfeiçoados de forma a aumentar a precisão na determinação do local de falta, visto que os sistemas elétricos de potência vêm aumentando sua complexidade.

Kawdy; Stenzel (2002) dividem os métodos de localização de faltas em dois grandes grupos:

- Métodos que têm por base a técnica de ondas trafegantes;

- Métodos que têm por base a técnica de medição dos fasores das tensões e das correntes em regime permanente.

Os métodos que têm por base a medição dos fasores em regime permanente, o qual é utilizado neste trabalho, são em maior número se comparados aos métodos que têm por base a técnica de ondas trafegantes utilizando as formas de onda das tensões e correntes. Isso se deve ao fato dos métodos baseados nos fasores em regime permanente utilizarem os dados registrados dos sinais de tensão e corrente, enquanto os métodos baseados em ondas trafegantes precisam da instalação de equipamentos específicos para que o método possa ser utilizado, tornando a aplicação do referido método mais cara e, às vezes, inviável.

Os métodos de localização de faltas que têm por base a medição dos fasores em regime permanente são divididos em dois grupos:

- Métodos que utilizam dados dos medidores instalados apenas nos extremos do local de falta;

- Métodos que utilizam dados de vários medidores dispersos na rede elétrica. 
$\mathrm{Na}$ literatura, encontra-se uma variedade de trabalhos relacionados com o tema. Nesta revisão serão apresentados aqueles publicados a partir de 1990.

O método de Johns; Jamali (1990a) apresenta modelagem simples de uma linha de transmissão para resolver o problema de localização de faltas, sendo utilizados os valores de pré-falta e pós-falta das tensões e correntes nos extremos da linha onde aconteceu a falta. A rede é modelada através de um circuito simples e outro duplo. Considera-se a transposição das configurações das linhas, com a finalidade de melhorar a precisão dos resultados. Os resultados apresentam uma boa precisão com um erro máximo igual a 1,5\%. O método está limitado à aplicação em uma única linha, seja simples ou dupla. A aplicação é realizada em uma linha de transmissão de $250 \mathrm{~km}$.

Em Johns; Jamali (1990b), os autores aplicaram um método denominado melhoramento híbrido, baseado na teoria da máquina de suporte vetorial SVM, como técnica para localização de faltas. Os autores depreendem da análise que não é confiável utilizar apenas os valores de tensão e corrente de ordem fundamental quando acontece uma falta, já que a variação da frequiência nesse período transitório altera os resultados. Por este motivo os autores propõem a utilização das frequiências altas no momento da falta. Os autores demonstraram que a variação dos valores de tensão nas diferentes freqüências (altas) é influenciada pela distância da falta. Por esses motivos utilizam as seguintes informações:

- A magnitude das harmônicas fundamentais da tensão e corrente em um extremo da linha;

- As características da tensão em freqüências altas, medida no mesmo extremo da linha.

A metodologia consiste em dois passos:

$1^{\circ}$ Passo: a rede neural SVM calcula uma distância aproximada em relação ao local procurado com certo erro, utilizando os dados dos componentes harmônicos das tensões e correntes.

$2^{\circ}$ Passo: correção da estimação da distância mediante o uso da informação contida nas características em altas freqüências. O método é aplicado a uma linha de transmissão de $200 \mathrm{~km}$.

Em Hong, Colwel (1997), a metodologia de localização de falta é realizada através da instalação de relés digitais, sendo propostos diferentes tipos de equipamentos, tais como: relés digitais, instrumentos para provas e gravadores de faltas. É feita uma aplicação em uma rede de $500 \mathrm{kV}$. 
Técnicas de inteligência artificial, como as redes neurais, são propostas em Sousa et al. (2001), empregando-se no treinamento da rede os sinais fornecidos pelos disjuntores, relés diferenciais e de proteção. São considerados três grupos de variáveis:

Grupo 01: Informações sobre o funcionamento de disjuntores, relés diferenciais e relés de proteção de linha, sem indicação de qual zona de proteção (1, 2 ou principal) atuou.

Grupo 02: Informação sobre os dados dos relés (zona de proteção) que atuaram nas linhas de transmissão.

Grupo 03: Informação sobre a operação de proteção de falhas do disjuntor é adicionada ao conjunto de variáveis de entrada do Grupo 02.

Cada grupo é representado por um vetor cujos elementos (variáveis de entrada) são binários, apresentando o valor 1 se o relé correspondente ou disjuntor operou, ou 0 se não operou. O modelo utilizado contempla a introdução de conhecimento qualitativo sobre o problema tratado e pela utilização de lógica fuzzy, que representa estados das configurações de alarmes. A metodologia é aplicada em um sistema composto de transmissão e distribuição.

Em Zijad; Ali, (2002), é utilizado o conceito de vulnerabilidade de contornos. Neste método os valores das VTCDs são conhecidos previamente, através da simulação de curtoscircuitos em toda a rede, formando contornos de locais de falta. A cada contorno é associado um medidor que monitora esse contorno.

O método consiste em dois passos: o primeiro chamado "on line", onde se simula o curto-circuito em todas as barras da rede para diferentes valores de impedância de falta. Estes valores se associam aos medidores instalados (aqueles que observam a falta). $\mathrm{O}$ segundo passo, chamado de "off line", consiste na estimação do local de falta através da comparação dos valores lidos e simulados. Quando da ocorrência de um defeito, o método verifica quais medidores registram as VTCDs e faz a intersecção desses. Finalmente são simulados curtoscircuitos nas barras selecionadas e, através da regra de mínima distância, determina-se a barra onde os valores das tensões estão mais próximos aos valores das tensões dos medidores. Para determinar a impedância de defeito, os autores utilizam a Lógica Fuzzy.

Em Kezunovic; Luo; Sevcik (2002), o problema é resolvido através dos Algoritmos Genéticos $(A G s)$, utilizando os operadores de seleção, cruzamento e mutação. São utilizados os dados registrados pelos medidores (valores fasoriais e formas de onda), de tensão e corrente e os dados obtidos pelas simulações de curto-circuito em toda a rede. A função objetivo é composta pelas distâncias entre os valores de tensão e corrente lidas pelos medidores e simuladas, afetados pelos fatores de erros. Faz-se uma análise do estado da rede em condição pré-falta para sincronizar os medidores e os possíveis erros. 
Além dos dados registrados pelos medidores, são utilizados dados dos disjuntores, com a finalidade de reduzir o espaço de busca. Os autores ilustram três casos para um sistema de 4840 barras, 5895 linhas, 375 geradores, 3788 cargas, 907 transformadores e 30 equipamentos registradores de faltas digitais (DFRs). Nos três casos ilustrados o sistema reduz o espaço de busca (menor número de trechos), já que os dispositivos de proteção isolam só a região onde aconteceu o defeito. Algumas das características analisadas deste método são:

- propor uma função objetiva composta pela soma das distâncias entre os valores de tensão e corrente afetadas por fatores de erros. Os valores destes fatores (de erros) não são detalhados, considerando que estas grandezas são de diferentes tipos.

- ilustrar uma aplicação para um sistema de grande porte, porém nos três casos o tamanho do espaço de busca foi reduzido para poucos trechos. Este fato demonstra que o método é aplicado quando os dispositivos de proteção de uma rede ante um defeito abrem chaves minimizando o espaço de busca, sendo possível quando estes dispositivos possuem essas características.

- o método desenvolvido (AGs) dos operadores foram articulados de forma aleatória. Isso provavelmente faz que o algoritmo não seja eficiente na aplicação em redes de grande porte.

Em Yuan (2007) é apresentada outra técnica para a localização de faltas utilizando medições fasoriais das correntes registradas nos equipamentos de medição em diferentes trechos da rede de forma esparsa. A rede é modelada através de expressões matemáticas para o caso de faltas monofásica-terra e bifásica-terra. Os autores denominam essa técnica de Matriz Impedância $\left(Z_{\text {bus }}\right)$. Das expressões matemáticas os autores depreendem que, utilizando valores de correntes, a técnica encontra resultados com maior precisão.

$\mathrm{Na}$ prática, os medidores de qualidade de energia instalados nas redes elétricas possuem mais canais que registram valores de tensão do que canais que registram valores de correntes. Isso faz com que esta técnica apresente a desvantagem de só ser aplicada quando tiver registros de correntes.

Em Pereira et al. (2009) é tratado o problema de localização de faltas em alimentadores aéreos de distribuição de energia elétrica usando medições esparsas de tensões. O modelo considera redes elétricas com cargas desequilibradas, que podem possuir ramais trifásicos, bifásicos e monofásicos. As equações que compõem esta técnica foram 
desenvolvidas com base nos métodos de fluxo de potência do tipo varredura. No desenvolvimento da mesma, considera-se que haja disponibilidade de medições de tensões no inicio do alimentador e também medições esparsas de tensão em alguns pontos ao longo do alimentador de distribuição. Adicionalmente, a técnica para localização de faltas baseia-se em um modelo matemático de programação binária para alocação otimizada de medidores (de tensões) esparsos ao longo do alimentador, com o propósito de melhorar a precisão. Os autores apresentam resultados e análises das simulações realizadas em um alimentador de distribuição de 13,8 kV contando com 134 barras, pertencente a um sistema real de distribuição de médio porte.

Em Kwang; Lee; Frank (1998) é apresentada uma aplicação de algoritmos evolucionários no problema de planejamento ótimo de potência reativa. Os autores desenvolvem os seguintes três algoritmos: a Programação Evolutiva (PE); Os Algoritmos Genéticos $(A G s)$ e as Estratégias Evolutivas $(E E s)$. Os resultados são ilustrados em uma rede de 30 barras do IEEE. As Estratégias Evolutivas precisam menos gerações para convergir ao ótimo global, mas têm maior probabilidade de convergir para um ótimo local. A Programação Evolutiva precisa maior número de gerações para convergir ao ótimo global, e tem menos probabilidade de cair em ótimos locais. Uma combinação entre as EEs e $P E$, faz com que método seja mais robusto em encontrar o ótimo global.

Em Arruda; Kagan; Ribeiro (2010) é apresentado o algoritmo das EEs para estimar a distorção harmônica em barras do sistema a partir de medições em locais específicos. Os autores utilizam os operadores próprios desta metodologia. O algoritmo começa com a construção de uma população inicial composta por indivíduos, que representam um possível estado harmônico do sistema.

$\mathrm{Na}$ aplicação do operador de mutação foi considerado o conceito de autoadaptabilidade, que ajusta os valores dos passos de mutação em função da evolução da população de soluções de forma que, à medida que a população se aproxima da solução do problema, o passo de mutação diminua. Foram apresentados os resultados das tensões (para cada ordem harmônica) na simulação de 30 casos, mostrando excelentes resultados de estimação. 


\section{3 - ESTRATÉGIAS EVOLUTIVAS (EEs)}

O conceito de Estratégias Evolutivas (EEs) tem sido empregado como parte dos conceitos da Computação Evolutiva (BACK; FOGEL; MICHALEWICZ, 2000).

A família da Computação Evolutiva baseia-se em princípios que governam a evolução da vida, utilizando níveis avançados da evolução, que são determinados pelos conceitos da seleção natural e o processo de sobrevivência, e permitem desenvolver conceitos de adaptabilidade evolutiva, presentes na natureza, desde os vírus até os mamíferos. A seleção natural restringe o desenvolvimento de diferentes organismos a partir de seu comportamento em face de tarefas específicas, e condiciona a possibilidade de que o número de indivíduos de uma espécie desapareça por sua incompetência.

Existem vários tipos de algoritmos na família da Computação Evolutiva. São distinguidos pelo tipo de estruturas que compõem os indivíduos da sua população. Essas características determinam como alguns fatores permitem que um indivíduo possa ser diferente do outro, variando suas características genéticas. Outras diferenças são filosóficas, como o respeito aos operadores usados para criar a descendência de seus pais.

O termo de Computação Evolutiva surgiu de maneira independente e quase simultaneamente em três escolas de pesquisadores, dando lugar aos paradigmas clássicos: os Algoritmos Genéticos, a Programação Evolutiva e as Estratégias Evolutivas, tratados de forma mais abrangente nas referências (SCHWEFEL, 1965; BACK; FOGEL; MICHALEWICZ, 2000), e descritos sucintamente a seguir:

- Algoritmos Genéticos - Introduzidos por Holland em 1975 com o objetivo de formalizar matematicamente e explicar rigorosamente processos de adaptação em sistemas naturais e desenvolver sistemas artificiais (simulados pelo computador) que retenham mecanismos originais encontrados em sistemas naturais.

- Programação Evolutiva - Introduzida por Fogel, foi originalmente proposta como uma técnica para criar inteligência artificial através da evolução de máquinas de estado finito.

- Estratégias Evolutivas - Introduzidas por Rechenberg e Schwefel nos anos 70, foram inicialmente propostas com o objetivo de solucionar problemas de otimização de parâmetros, tanto discretos quanto contínuos. 
Todas estas técnicas compartilham certa similaridade com respeito a sua interpretação, havendo diferenças em suas definições e como interpretar o processo de evolução natural.

O princípio da Computação Evolutiva é a aplicação de conceitos de seleção natural baseados nas características próprias de uma população, simuláveis em computador. Nestes processos, a hereditariedade é a idéia fundamental, porque, usualmente, quando se analisa a relação entre pais e filhos, existem características genéticas relacionadas que são potencialmente diferentes.

A vantagem do uso prático de algoritmos que envolvem a Computação Evolutiva se baseia em poder conceituar a solução do problema com busca abrangente sobre o espaço de possíveis soluções. Esta visão não é característica de outras técnicas exaustivas ou aleatórias de busca. Desta forma, como em outros métodos de modelagem, são encontradas soluções aos problemas, depois de explorar soluções que, de outra maneira, poderiam utilizar tempos de análises proibitivos ou transgressão de restrições que levariam ao descarte de soluções.

O interesse deste trabalho é o desenvolvimento de conceitos da sub-classe Estratégias Evolutivas $(E E s)$, que é a metodologia proposta para solucionar o problema de estimação de VTCDs em sistemas elétricos. Neste capítulo, são apresentadas as particularidades das EEs.

\subsection{Computação Evolutiva}

Como já mencionado anteriormente, os algoritmos da Computação Evolutiva apresentam uma estrutura comum, apesar de que a seqüência da aplicação dos operadores seja diferente. Esta estrutura pode ser dada na seguinte forma:

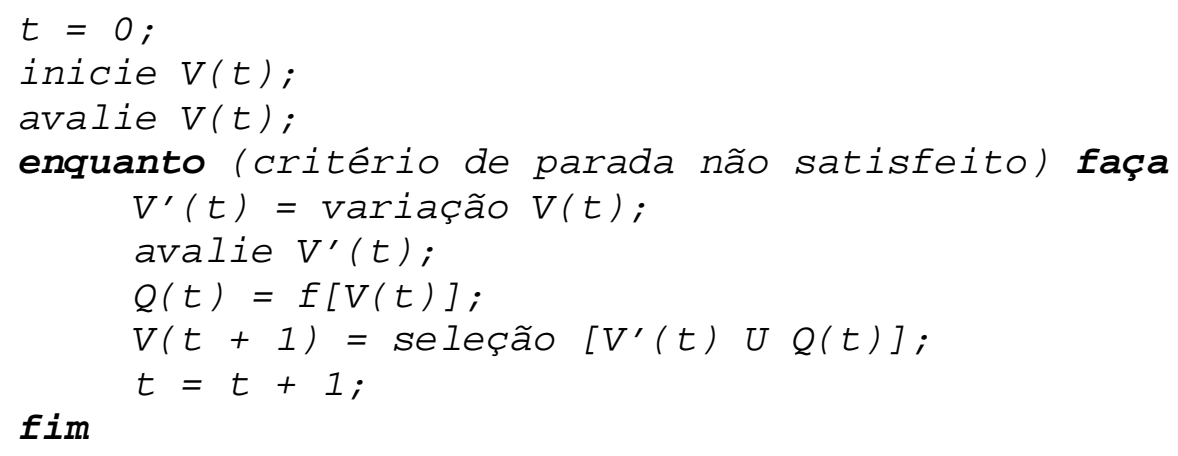

Neste algoritmo, $V(t)$ denota uma população de $\mu$ indivíduos na geração $t$. $Q$ representa um conjunto de indivíduos que podem ser considerados para a seleção. Por exemplo, $Q$ pode ser igual ao conjunto $V(t)$, no entanto $Q$ também pode ser igual ao conjunto nulo. Desta forma, o conjunto $Q$ pode ser escrito como uma função da população 
$V(t)$, ou seja, $Q(t)=f[V(t)]$. Uma nova geração de indivíduos $V^{\prime}(t)$ de tamanho $\lambda$ é gerada pela variação do conjunto $V(t)$ através de operadores tais como recombinação e/ou mutação. Os novos indivíduos $V^{\prime}(t)$ são então avaliados medindo-se a "distância" de cada um destes da solução "ótima" do problema considerado. Como produto da avaliação, a cada indivíduo é atribuída uma nota (medida de adaptação), sendo que as maiores notas são atribuídas aos indivíduos que representam uma solução mais próxima da almejada. Então, uma nova população é formada na iteração $t+1$ pela seleção dos indivíduos mais adaptados.

Após um determinado número de gerações, a condição de parada deve ser atendida, a qual usualmente indica a existência, na população, de um indivíduo que represente uma solução aceitável para o problema, ou quando o número máximo de gerações foi atingido (BACK; SCHWEFEL, 1996).

As abordagens dos algoritmos da Computação Evolutiva apresentadas nesta seção diferem em diversos aspectos, como ilustra a Tabela 3.1 (Algoritmos Genéticos e as Estratégias Evolutivas). A Programação Evolutiva é um caso particular das Estratégias Evolutivas, onde seus operadores utilizados são: mutação, função de ajuste e a seleção, não existindo o cruzamento. Além das características apresentadas na Tabela 3.1, destacam-se também diferenças relacionadas às estruturas de dados utilizadas para codificar um indivíduo, métodos para criar a população inicial, para selecionar indivíduos, para gerar a seguinte população, dentre outras. Entretanto, perdura o princípio comum: Uma população de indivíduos sofre algumas transformações e durante a evolução os indivíduos competem pela sobrevivência.

Tabela 3.1 - Características ( Algoritmos Genéticos - Estratégias Evolutivas)

\begin{tabular}{|c|c|c|}
\cline { 2 - 3 } \multicolumn{1}{c|}{} & Algoritmos Genéticos & Estratégias Evolutivas \\
\hline Representação & Codificada, genótipo & Não codificada, fenótipo \\
\hline Seleção & $\begin{array}{c}\text { Não tem forma canônica, sobrevivem } \\
\text { os mais adaptados }\end{array}$ & $\begin{array}{c}\text { Duas formas canônicas } \\
(\mu, \lambda) \mathrm{e}(\mu+\lambda)\end{array}$ \\
\hline Mutação & Operador Secundário & Operador Principal \\
\hline $\begin{array}{c}\text { Recombinação } \\
\begin{array}{c}\text { Parâmetros de } \\
\text { variação } \\
\text { genética }\end{array}\end{array} \quad$ Operador Principal & Operador Secundário \\
\hline
\end{tabular}


A Figura 3.1 ilustra os algoritmos correspondentes. Como já mencionado, a ordem de aplicação dos operadores é distinta.

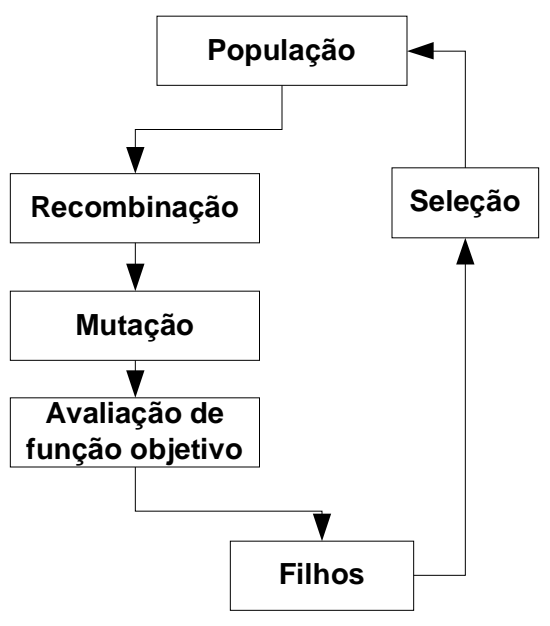

(a)

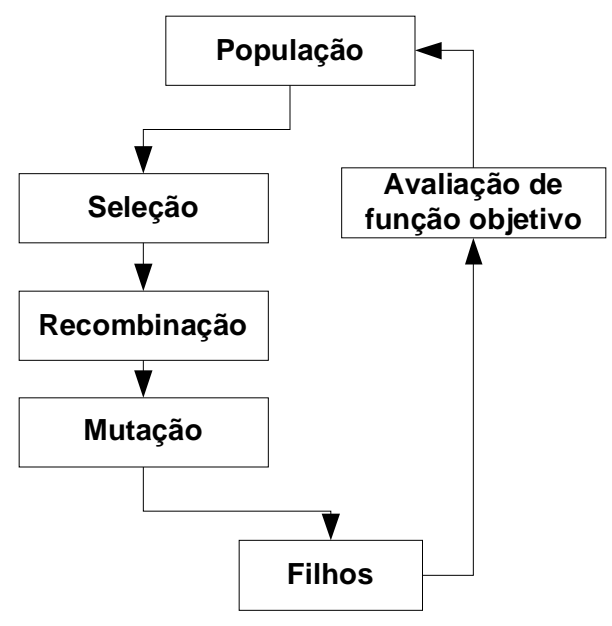

(b)

Figura 3.1 - Seqüência de Evolução (a) EEs (b) AGs

\subsection{Estratégias Evolutivas}

As Estratégias Evolutivas (EEs) (Evolutionary Strategies - ES) foram desenvolvidas por Rechenberg e Schwefel (SCHWEFEL, 1965; RECHENBERG, 1965). Estes iniciaram os primeiros estudos nesta área, nos anos 60 na Technical University of Berlin, Alemanha. A metodologia inicial tratou problemas de otimização em mecânica de fluidos. Em seguida passaram a tratar problemas de funções de forma mais genérica, enfocando o caso de funções gerais (DAVID; FOGEL, 1995). Também utilizavam só um indivíduo na população, sujeito à mutação e seleção. Décadas depois, incorporaram-se os conceitos de auto-adaptação e mutação correlacionada dos parâmetros da estratégia durante o processo evolutivo, sendo parte da representação dos indivíduos. A seguir, são detalhados os diferentes tipos de EEs: 


\subsubsection{Estratégia Evolutivas de Dois-Membros (1+1)-EE}

Como mencionado anteriormente, esta estratégia foi a primeira a ser utilizada. As estruturas de dados são vetores reais e o único operador capaz de inserir variação é a mutação. Ou seja, a população é composta só por um indivíduo, representado como $v=(x, \sigma)$, onde $x$ representa um ponto no espaço de busca, e $\sigma$ é um vetor de desvios padrões (passos) a ser utilizado na atualização de $x$ através do operador mutação, da seguinte forma:

$$
x^{t+1}=x^{t}+N(0, \sigma)
$$

onde $N(0, \sigma)$ é um vetor composto por números gerados independentemente por uma função gaussiana de média zero e desvio padrão $\sigma$. Nos AGs, esta mutação é denominada mutação gaussiana. E o parâmetro té o número da geração.

É necessário mencionar que a escolha da distribuição normal para realizar a mutação sobre o indivíduo da população é arbitrária (TETTAMANZI; TOMASSINI, 2001). Esta mutação está de acordo com a observação biológica de que pequenas variações ocorrem com maior frequiência do que grandes variações, e que os filhos herdam características dos pais, ou seja, são parecidos com eles (BÄCK; HOFFMEISTER; SCHWEFEL, 1991).

Uma das estratégias de seleção é aceitar o filho, só se sua função objetivo (nota) é melhor que a do pai. Apesar da população só dispor de um indivíduo, esta estratégia evolutiva é denominada estratégia de dois membros, pois o filho compete com o pai (ZBIGNIEW, 1996). A característica mais importante na etapa da evolução é que o desvio padrão permanece inalterado durante todo o processo de evolução.

Um termo introduzido no processo de otimização é a taxa de convergência, definida como o quociente entre a distância percorrida até o ótimo e a quantidade de gerações (iterações) necessárias para percorrer esta distância. Em Rechenberg (1973) foi proposta uma regra denominada de "regra de sucesso 1/5", que consiste em avaliar a variação do desvio através da seguinte relação matemática:

$$
\varphi=\frac{\text { NumMutPos }}{\text { NumTotalMut }}
$$


onde NumTotalMut representa o número total de mutações que um determinado indivíduo sofreu e NumMutPos representa o número de mutações em que a função objetivo melhorou. Por conseguinte, NumTotalMut $\geq$ NumMutPos .

Se $\varphi>1 / 5$, aumenta-se a variância de mutação e, caso contrário, se diminui. Esta regra foi baseada em um estudo feito para calcular as taxas de convergência de duas funções modelo: a função corretor e o modelo da esfera (RECHENBERG, 1973). Entretanto, existe uma razão intuitiva da "regra do sucesso 1/5" baseada no aumento da eficiência de busca:

- Se bem sucedida, a busca deve continuar com um passo maior;

- Caso contrário, o passo deve ser menor.

Para encontrar o ajuste dinâmico do passo a cada $k$ iterações (SCHWEFEL, 1981), têm-se a seguinte heurística:

$$
\sigma^{t+1}=\left\{\begin{array}{l}
C_{d} \cdot \sigma^{t} \rightarrow \operatorname{se\varphi }(k)<1 / 5 \\
C_{i} \cdot \sigma^{t} \rightarrow \operatorname{se\varphi }(k)>1 / 5 \\
\sigma^{t} \rightarrow \operatorname{se\varphi } \varphi(k)=1 / 5
\end{array}\right.
$$

Em Schwefel (1981), os valores calculados empiricamente foram $C_{d}=0,82$ e $C_{i}=$ 1,22. Apesar de nem todos os problemas apresentarem características semelhantes ao modelo do corretor e da esfera, a adoção destes valores tem levado a bons resultados.

\subsubsection{Primeira Estratégia Evolutiva de Multimembros $(\mu+1)-E E$}

Esta estratégia pode ser vista como uma espécie de método de gradiente probabilístico, onde a perturbação é Gaussiana e adaptativa (ZBIGNIEW, 1996). O conceito de população foi utilizado pela primeira vez por Rechenberg, que propôs as Estratégias Evolutivas Multimembros, onde $\mu>1$, isto é, vários pais podem participar na geração de um único filho. Esta estratégia foi chamada de $(\mu+1)$-EE. 
Com a introdução de $\mu$ pais, a reprodução sexuada torna-se possível, via um operador de recombinação $r$, que é aplicado aos dois vetores que compõem um indivíduo $v$ da população:

$$
r(v)=v^{\prime}=\left(x^{\prime}, \sigma^{\prime}\right)
$$

Matematicamente, para dois indivíduos escolhidos (aleatoriamente) $v_{1}$ e $v_{2}$ da população, será gerado um terceiro indivíduo $v_{3}$, cujos parâmetros são calculados através de uma possível função $r$ dada pela média aritmética entre dois indivíduos, ou seja:

$$
\begin{array}{cc}
x_{i}^{\prime}\left(v_{3}\right)=\frac{x_{i}\left(v_{1}\right)+x_{i}\left(v_{2}\right)}{2} & \forall \mathrm{l} \in\{1, \ldots, \mathrm{h}) \\
\sigma^{\prime}\left(v_{3}\right)=\frac{\sigma_{i}\left(v_{1}\right)+\sigma_{i}\left(v_{2}\right)}{2} & \forall \mathrm{l} \in\{1, \ldots, \mathrm{h})
\end{array}
$$

onde $i$ é a quantidade de dimensões do vetor $r(v)=(x, \sigma)$. Este operador é denominado de operador de recombinação discreto e é equivalente nos AGs ao cruzamento (crossover) uniforme (BACK; FOGEL; MICHALEWICZ, 2000).

Por outro lado, o operador de mutação aplicado aos vetores $x$ e $\sigma$ é implementado como no caso $(1+1)$-EE. O operador de seleção escolhe o indivíduo mais apto (melhor adaptado) dentre os pais e o filho gerado.

\subsubsection{Estratégias Evolutivas de Multimembros $(\mu+\lambda)$-EE e $(\mu, \lambda)$-EE}

Nas estratégias anteriores, o desvio padrão $\sigma$ presente na equação 3.1 permanece constante por toda a evolução. Desta forma, para um desvio de mutação pequeno a evolução é lenta e, consequentemente, o algoritmo demorará a encontrar a solução para o problema proposto. Por outro lado, a escolha de um desvio maior de mutação proporcionará uma evolução mais rápida; porém, a grande variação dos indivíduos em torno da solução ótima pode direcioná-los para um ótimo local ou apresentar dificuldades na convergência do algoritmo. Para tentar melhorar este inconveniente, como já mencionado no item 3.2.1 é utilizado uma regra heurística através da equação 3.3 , alterando o valor do desvio de mutação 
$\sigma$. O critério utilizado está baseado na aplicação de problemas específicos de otimização, o que não necessariamente levaria aos bons resultados na aplicação de outros problemas.

Com a finalidade de generalizar o inconveniente mencionado no parágrafo anterior e motivado pela utilização de computadores paralelos, Schwefel (1981) introduz novos parâmetros na representação do indivíduo. Tais parâmetros proporcionam a auto-adaptação dos indivíduos. Ou seja, $\sigma$ é parte da informação genética do indivíduo de forma a controlar o passo da mutação. Conseqüentemente $\sigma$ também estaria sujeito tanto à mutação quanto à recombinação. E ao mesmo tempo fornece instruções ao indivíduo de como sofrer a mutação.

Com esta mudança, uma das principais diferenças entre as primeiras estratégias propostas e as últimas, é a forma de atualização do vetor de parâmetros $\sigma$, que não é mais controlado pela "regra do sucesso 1/5", embora $\sigma$ já fazia parte da codificação genética de cada indivíduo da população. Seu valor era atualizado heuristicamente, e não evolutivo como proposto através da auto-adaptação que será detalhado no item 3.2.5.1.

\subsubsection{Estratégia Evolutiva $(\mu+\lambda)-E E$}

A estratégia $(\mu+\lambda)$-EE foi proposta inicialmente, onde $\mu$ pais produzem $\lambda$ filhos e a população $\mu+\lambda$ é posteriormente reduzida pelo operador de seleção para $\mu$ indivíduos, como ilustra a Figura 3.2. Desta forma, a seleção opera no conjunto união de pais e filhos. Assim, os pais sobrevivem até que filhos com funções objetivos superiores a eles sejam produzidos. Uma série de problemas resolvidos com esta estratégia $(\mu+\lambda)$-EE pode ser encontrada em (SCHWEFEL, 1995).

\subsubsection{Estratégia Evolutiva $(\mu, \lambda)-E E$}

Em Schwefel (1995) foram investigadas as propriedades de uma estratégia $(\mu, \lambda)$-EE, onde somente os filhos sofrem seleção, como ilustra a Figura 3.2. Por conseguinte, o período de vida de cada indivíduo está restrito a uma geração. Esta particularidade consiste na diferença com a estratégia $(\mu+\lambda)$-EE. 


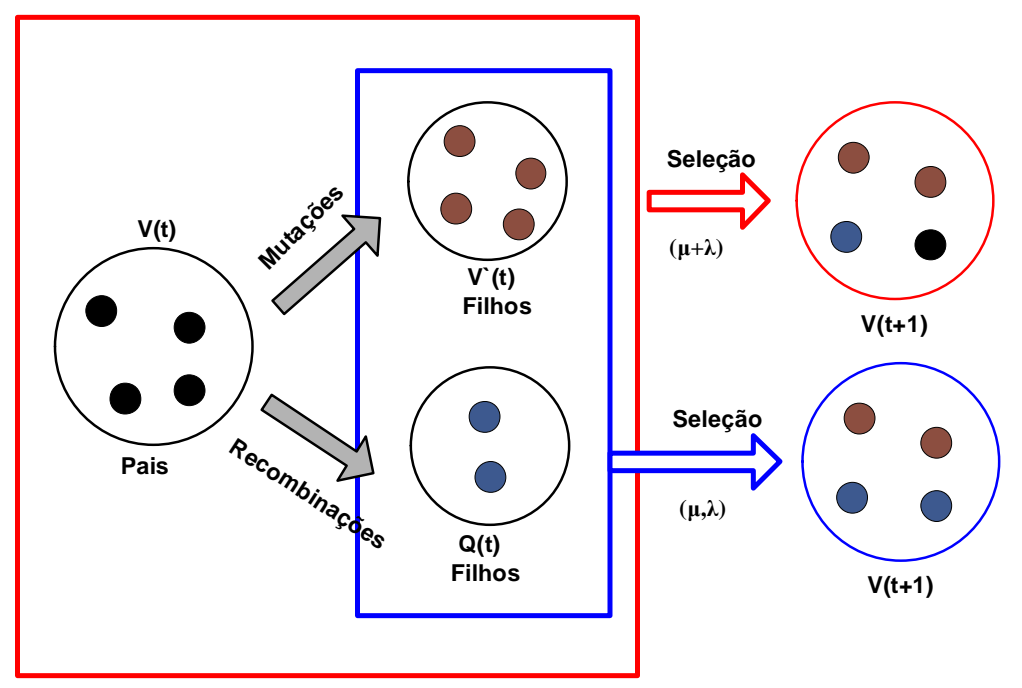

Figura 3.2 - Estratégia evolutiva $(\mu+\lambda)-\mathrm{EE}$ e $(\mu, \lambda)-\mathrm{EE}$

\subsubsection{Operadores de Recombinação}

No item 3.2.2 foi definida a primeira estratégia para aplicar a recombinação, onde os valores dos parâmetros que representam ao novo indivíduo são obtidos através da média aritmética dos parâmetros dos pais. Esta estratégia é definida como uma recombinação intermediária global e expressada através das equações 3.5 e 3.6. Posteriormente foi melhorada esta recombinação através de uma intermediária local, como uma combinação convexa dos vetores correspondentes aos pais $v_{1}\left(x_{i}, \sigma_{i}\right)$ e $v_{2}\left(x_{i}, \sigma_{i}\right)$ (MAGELE, 2001; SCHWEFEL; RUDOLPH, 1995), como mostram as equações 3.7 ou 3.8. A Figura 3.3 ilustra estas duas estratégias de recombinação.

$$
\begin{aligned}
& x_{i}^{\prime}\left(v_{3}\right)=a x_{i}\left(v_{1}\right)+(1-a) x_{i}\left(v_{2}\right) \quad \forall i \in\{1, \ldots, h\} \\
& \text { ou } \\
& x_{i}^{\prime}\left(v_{3}\right)=(1-a) x_{i}\left(v_{1}\right)+a x_{i}\left(v_{2}\right) \quad \forall i \in\{1, \ldots, h\} \\
& \sigma_{i}^{\prime}\left(v_{3}\right)=a \sigma_{i}\left(v_{1}\right)+(1-a) \sigma_{i}\left(v_{2}\right) \quad \forall i \in\{1, \ldots, h\} \\
& \text { ou } \\
& \sigma_{i}^{\prime}\left(v_{3}\right)=(1-a) \sigma_{i}\left(v_{1}\right)+a \sigma_{i}\left(v_{2}\right) \quad \forall i \in\{1, \ldots, h\}
\end{aligned}
$$


onde $a \in[0,1]$ é um valor sorteado com distribuição normal de média zero e desvio padrão 1 e $h$ é o tamanho do vetor de parâmetros que representam o indivíduo.

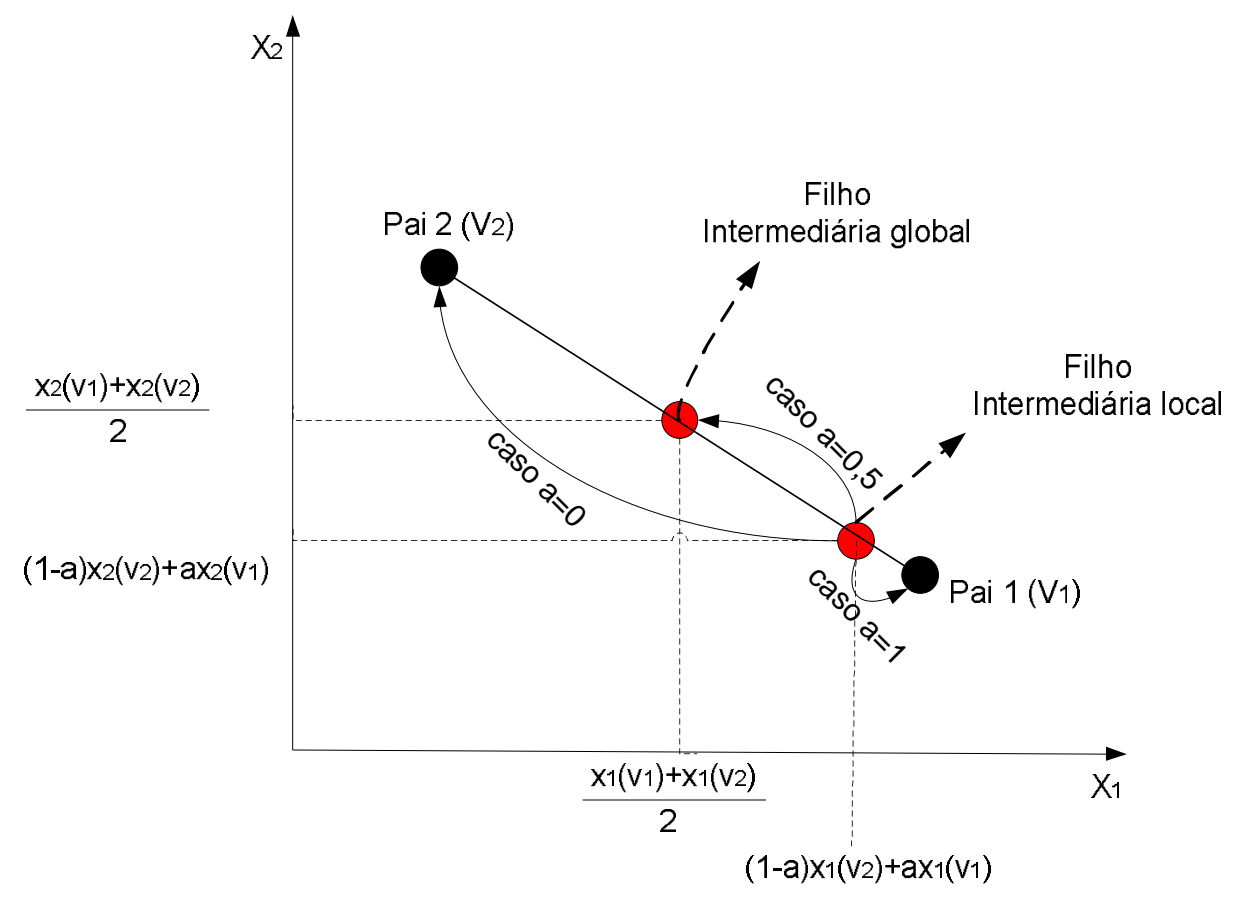

Figura 3.3 - Operador Recombinação

\subsubsection{Operadores de Mutação}

Como já mencionado anteriormente, a mutação é o principal operador de evolução, pois introduz variabilidade aos indivíduos através da mudança da informação do fenótipo contida nos atributos (parâmetros) que representam ao indivíduo. $\mathrm{O}$ operador mutação atua em cada elemento do vetor de atributos de forma independente, adicionando um valor aleatório pertencente a uma distribuição normal com média zero e desvio padrão $\sigma$ modificado através da auto-adaptação detalhada a seguir.

\subsubsection{Auto-adaptação}

Como descrito em Schwefel (1995), foram introduzidos novos parâmetros na representação dos indivíduos de forma a controlar os desvios de mutação ou passo de 
evolução. Tais parâmetros proporcionaram uma auto-adaptação dos indivíduos. Neste procedimento, detalhado na referência Schwefel (1981), o passo de mutação passa a representar uma variável que também sofre mutação e ao mesmo tempo fornece instruções ao indivíduo de como sofrer mutação (DAVID; FOGEL, 1995).

Formalmente um indivíduo $v=(\vec{x}, \vec{\sigma})$ consiste em variáveis $\vec{x} \in \mathfrak{R}^{n}$ e parâmetros estratégicos $\vec{\sigma} \in \mathfrak{R}^{n}$. Desta forma a mutação ocorre como o apresentado na equação a seguir:

$$
\begin{aligned}
& \sigma_{i}^{\prime}=\sigma_{i} \exp \left(\tau^{\prime} \cdot N(0,1)+\tau \cdot N_{i}(0,1)\right) \\
& x_{i}^{\prime}=x_{i}+\sigma_{i}^{\prime} \cdot N_{i}(0,1)
\end{aligned}
$$

\section{Onde,}

$$
\begin{array}{lll}
\sigma_{i}^{\prime} & : & \text { variação do parâmetro } \sigma^{t} \text { de índice } i \\
\sigma_{i}: & \text { passo de mutação } \\
N_{i}(0,1): & \text { valor sorteado com distribuição normal de média } 0 \text { e desvio padrão } \\
& 1 \\
N(0,1): & \text { valor sorteado com distribuição normal de média } 0 \text { e desvio padrão } \\
& 1 \text {, este se mantém constante para cada indivíduo } \\
\tau & : \text { taxa de aprendizado }\left(\propto(\sqrt{2 \beta})^{-1}\right) \\
\tau & : \text { taxa de aprendizado }\left(\propto(\sqrt{2 \sqrt{\beta}})^{-1}\right)
\end{array}
$$

Os termos $\tau^{\prime}$ e $\tau$ são equivalentes ao fator de aprendizagem empregado nas redes neurais. Utiliza-se frequentemente $\beta=2$ como mencionados em ( BACK; SCHWEFEL, 1996). Nesta técnica, a densidade de probabilidade da distribuição normal é formada por hiperesferas em um espaço de n-dimensional.

\subsubsection{Mutação Correlacionada}

No modelo de mutação anterior, cada variável (atributo) tem seu próprio desvio para produzir mutações (alterações não correlacionadas) que produzem deslocamentos perpendiculares aos eixos coordenados dentro do espaço de busca, como ilustra a Figura 3.4, onde o melhor deslocamento seria na direção da solução ótima, sendo pouco provável que se encontre alinhado com os eixos coordenados. Isto significa que a trajetória de busca segue um caminho zig-zag, de certa forma perpendicular ao vetor na direção da solução ótima. 
Com a finalidade de reduzir esta trajetória zig-zag na procura da solução ótima, Schwefel (BÄCK; HOFFMEISTER; SCHWEFEL, 1991) modificou este operador, aplicando mutações correlacionadas, criando uma variável estratégica a mais, o ângulo " $\theta$ ”, que representa a direção preferencial do movimento.

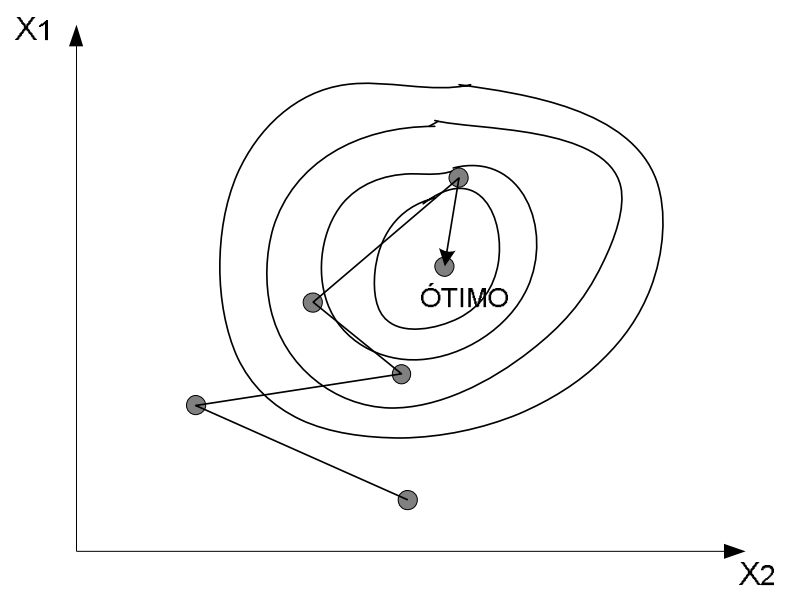

Figura 3.4 - Trajetória percorrido em Zig-zag

Com a utilização de mutações correlacionadas, os movimentos mais favorecidos serão aqueles que seguem a direção daquele vetor que leve à solução procurada. Isso se obtém minimizando o percorrido em zig-zag (quando no espaço de busca as mutações são não correlacionadas).

Uma mutação correlacionada se obtém fazendo girar uma mutação não correlacionada um ângulo $\theta$, que é proporcional à matriz de covariâncias $C_{i j}$ existente entre $\sigma_{i}$ e $\sigma_{j}$ (desvios padrões), de acordo com a seguinte expressão:

$$
\operatorname{Tang}\left(2 \theta_{i j}\right)=\frac{2 C_{i j}}{\left(\sigma_{i}^{2}-\sigma_{j}^{2}\right)}
$$

As combinações de desvios padrão $\sigma_{1}, \sigma_{2} \ldots \sigma_{k}$ produzem uma matriz de covariâncias $C$ com $k^{2}$ elementos. Por exemplo, para dois desvios padrão se tem: 


$$
C=\left|\begin{array}{ll}
\sigma_{1} \sigma_{1} & \sigma_{1} \sigma_{2} \\
\sigma_{2} \sigma_{1} & \sigma_{2} \sigma_{2}
\end{array}\right|
$$

Desta forma a mutação será através da seguinte expressão:

$$
x_{i}^{t+1}=x_{i}^{t}+N\left(0, C\left(\sigma^{t+1}, \theta^{t+1}\right)\right)
$$

onde $C\left(\sigma^{t+1}, \theta^{t+1}\right)$ representa ao vetor de mutações correlacionadas. Esta mutação corresponde a hiper-elipsóides arbitrariamente rotacionáveis e os $\theta_{k}$ caracterizam os ângulos de rotação em relação aos eixos de coordenadas no espaço de busca. A Figura 3.5 ilustra um esboço de linhas de igual densidade de probabilidade para um espaço de dimensão $l=2$ e distribuição normal.

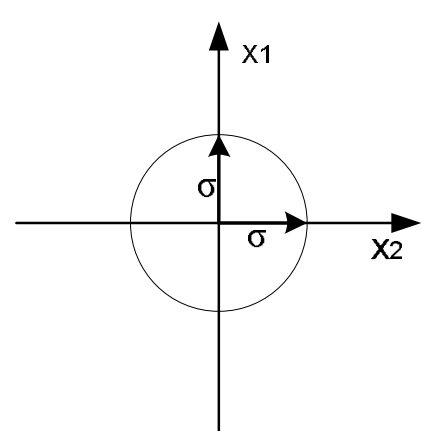

(a)

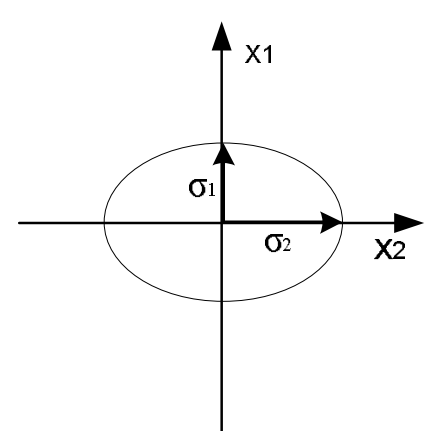

(b)

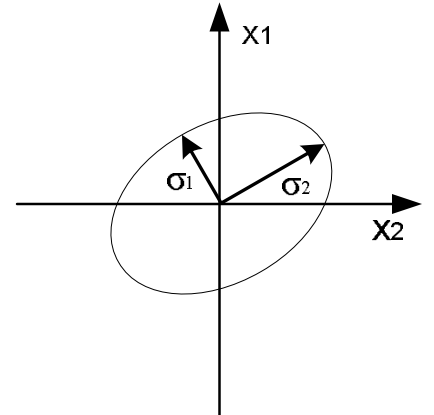

(c)

Figura 3.5 - (a) Mutação com $l \sigma=1 \quad \begin{aligned} & \text { (b) } l \sigma=2 \quad \text { (c) } l \sigma=2 \\ & \text { correlacionadas) }\end{aligned}$

Desta maneira, cada indivíduo está representado por atributos de controle $\vec{X}$ e as variáveis estratégias que constam de duas partes: vetor de desvios padrões $\vec{\sigma}$ e vetor de ângulos de rotação $\vec{\theta}$ formado por $\theta_{i j}$ para cada par $\sigma_{i}$ e $\sigma_{j}$. A Figura 3.6 ilustra a nova representação do indivíduo. 


\begin{tabular}{|c|c|c|}
\hline Atributos & Variáv & eis estratégicas \\
\hline$X_{1}, X_{2}, \ldots X_{n}$ & $\sigma_{1}, \sigma_{2}, \ldots \sigma_{n}$ & $\theta_{12}, \theta_{13}, \ldots \theta_{1 n}, \theta_{23}, \theta_{24} \ldots \theta_{2 n}, \ldots \theta_{n(n-1)}$ \\
\hline
\end{tabular}

Figura 3.6 - Representação do indivíduo com seus atributos

As dimensões dos vetores são:

$x[1: n]=X \quad:$ Tamanho do vetor Atributos

$\sigma[1: n]=\sigma \quad:$ Tamanho do vetor Variáveis-Estratégicas (Desvios padrões)

$m=n(n-1) / 2$

$\theta[1: m]=\theta \quad:$ Tamanho do vetor Variáveis-Estratégicas (Ângulos de rotação)

Sendo assim, a mutação de um indivíduo será feita através da seguinte seqüência de programação (pseudo-código):

\section{Inicio}

1. Para $i=1$ até $n$ fazer

$$
\sigma_{i}^{t+1}=\sigma_{i}^{t} \exp \left(t^{\prime} . N(0,1)+t \cdot N_{i}(0,1)\right)
$$

Fim

2. Para $j=1$ até $m$ fazer

$$
\left.\theta_{j}^{t+1}=\theta_{j}^{t}+\lambda \cdot N_{j}(0,1)\right)
$$

Fim

3. Para $i=1$ até $n$ fazer

$$
\Delta x_{i}^{t+1}=\sigma_{i}^{t+1} \cdot N_{i}(0,1)
$$

Fim

4. Para $k=m$ até 1 fazer

$$
\begin{gathered}
(i, j)=\text { indices }(k) \\
\Delta x_{i}^{t+1}=\Delta x_{i}^{t+1} \cos \left(\theta_{k}\right)-\Delta x_{j}^{t+1} \operatorname{sen}\left(\theta_{k}\right)
\end{gathered}
$$




$$
\Delta x_{j}^{t+1}=\Delta x_{i}^{t+1} \operatorname{sen}\left(\theta_{k}\right)-\Delta x_{j}^{t+1} \cos \left(\theta_{k}\right)
$$

Fim

5. Para $i=1$ até $n$ fazer

$$
x_{i}^{t+1}=x_{i}^{t}+\Delta x_{i}^{t+1}
$$

Fim

\section{Fim}

A estrutura de repetição 1 realiza o cálculo da primeira expressão pertencente à equação 3.13, onde se utiliza o conceito de auto-adaptação, para determinar valores dos desvios padrões.

A estrutura de repetição 2 calcula os novos valores dos ângulos de rotação que serão utilizados para fazer a mutação correlacionada. Para isso, o valor de $\lambda$ é adotado igual a 0,0873 (BACK; SCHWEFEL, 1996).

A estrutura de repetição 3 produz uma mutação não correlacionada, para depois na estrutura de repetição 4, por meio dos ângulos de rotação, seja convertida em correlacionada, observando que a ordem de rotação é iniciada pelo último ângulo. Finalmente, na estrutura de repetição 5, é feita a mutação dos atributos do indivíduo.

\subsubsection{Exemplo ilustrativo da aplicação dos operadores}

No Capítulo 4, descreve-se de forma detalhada a metodologia de localização de faltas. Porém, para um melhor entendimento da aplicação dos operadores de evolução das EEs, aqui é desenvolvido um exemplo aplicando estes operadores para a localização de falta em um sistema elétrico de pequeno porte operando em $69 \mathrm{kV}$, conforme ilustrado na Figura 3.7. Alguns dados necessários são apresentados na Tabela 3.2.

O cenário considerado é quando ocorre uma falta elétrica (curto-circuito) monofásica terra exatamente no ponto central da linha. O medidor de qualidade, instalado na barra bar1 (med1), registra o afundamento de tensão com valores em p.u. dados por $\mathrm{Va}=0,626 ; \mathrm{Vb}=1 \mathrm{e}$ $\mathrm{Vc}=1$. 
O modelo EEs deve determinar o valor das variáveis: posição na linha e valor de impedância de falta, de modo que, os resultados sejam os mais próximos possíveis aos valores das tensões registradas no medidor instalado.

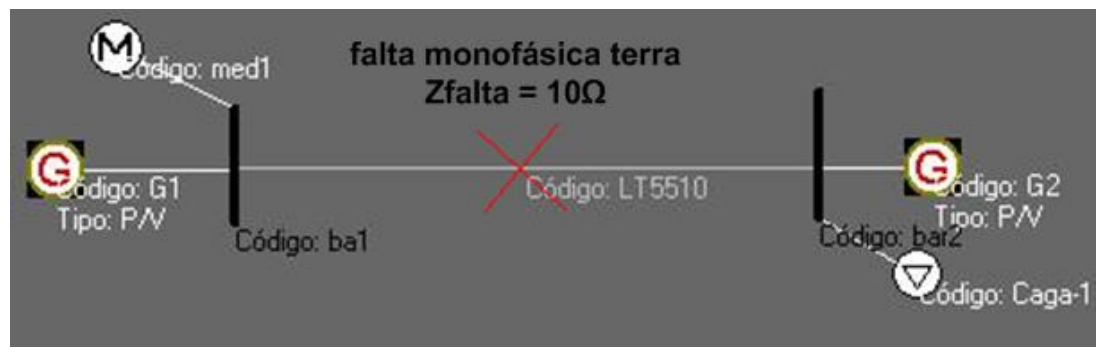

Figura 3.7 - Representação de uma falta elétrica

Tabela 3.2 - Características da rede

\begin{tabular}{|c|c|c|c|c|}
\cline { 2 - 5 } \multicolumn{1}{c|}{} & \multicolumn{2}{c|}{ Impedância } & \multicolumn{2}{c|}{ Potência } \\
\hline Itém & $\mathrm{R}(\mathrm{p} . \mathrm{u})$ & $\mathrm{X}(\mathrm{p} . \mathrm{u})$ & $\mathrm{P}(\mathrm{Mw})$ & $\mathrm{Q}($ Mvar $)$ \\
\hline Geradores & 0,00 & 0,05 & ----- & ----- \\
\hline Linha & 0,00 & 0,05 & ---- & ---- \\
\hline Carga & ----- & ----- & 2,00 & 0,50 \\
\hline $\begin{array}{c}\text { Curto-circuito } \\
\text { simulado }\end{array}$ & \multicolumn{3}{c|}{ no meio da linha $=5 \mathrm{~km}$} \\
\hline
\end{tabular}

Segundo descrito no item 3.1, o algoritmo começa com a construção aleatória da população $V(t)$, formada por indivíduos $\vec{X}=\left(X_{1}, X_{2}\right), \vec{\sigma}=\left(\sigma_{1}, \sigma_{2}\right)$ e $\vec{\theta}=\theta_{12}$, onde $X_{1}$ é a distância do início da linha ao ponto de falta e $X_{2}$ é a impedância (resistência) de falta.

Depois, cada indivíduo da população deve ser avaliado através da Função Objetivo (F.O) utilizando a seguinte expressão:

$$
F . O=\sqrt{\left(V_{a_{m}}-V_{a_{s}}\right)^{2}+\left(V_{b_{m}}-V_{b_{s}}\right)^{2}+\left(V_{c_{m}}-V_{c_{s}}\right)^{2}}
$$

\section{Onde,}

$V_{m}: \quad$ Valor da tensão medida pelo medidor;

$V$ : Valor da tensão simulada pelo curto-circuito;

Neste exemplo, é considerado o tamanho da população igual a 5 indivíduos, conforme ilustrado na Tabela 3.3(a). 
Tabela 3.3 - (a) População (b) Indivíduos gerados

\begin{tabular}{|c|c|c|c|c|c|c|}
\hline \multicolumn{7}{|c|}{ (a) } \\
\hline & \multicolumn{2}{|c|}{ Atributos } & \multicolumn{3}{|c|}{ Variáveis estratégicas } & \multirow{3}{*}{$\begin{array}{l}\text { Valor } \\
\text { F.O. }\end{array}$} \\
\hline & $\begin{array}{l}\text { Local } \\
\text { de falta } \\
(\mathrm{km})\end{array}$ & $\begin{array}{c}\text { Impedância } \\
\text { de defeito } \\
(\Omega)\end{array}$ & \multicolumn{2}{|c|}{ Desvio padrão } & $\begin{array}{c}\text { Ângulo } \\
\text { de } \\
\text { rotação }\end{array}$ & \\
\hline $\begin{array}{l}\mathbf{N}^{\circ} \text { de indivíduo } \\
\text { da população }\end{array}$ & $X_{1}$ & $X_{2}$ & $\sigma_{1}$ & $\sigma_{2}$ & $\theta_{1}$ & \\
\hline 1 & 2,35 & 2,45 & 0,05 & 0,06 & $25,23^{\circ}$ & 0,428 \\
\hline 2 & 7,31 & 13,98 & 0,05 & 0,06 & $74,76^{\circ}$ & 0,122 \\
\hline 3 & 3,89 & 7,23 & 0,05 & 0,06 & $10,43^{\circ}$ & 0,124 \\
\hline 4 & 9,65 & 3,64 & 0,05 & 0,06 & $112,57^{\circ}$ & 0,308 \\
\hline 5 & 6,43 & 17,53 & 0,05 & 0,06 & $60,56^{\circ}$ & 0,189 \\
\hline \multicolumn{7}{|c|}{ (b) } \\
\hline $\begin{array}{l}\text { Ind. Gerado } \\
\text { Recombinação }\end{array}$ & 5,16 & 12,380 & 0,050 & 0,060 & $59,33^{\circ}$ & 0,078 \\
\hline $\begin{array}{l}\text { Ind. Gerado } \\
\text { Mutação }\end{array}$ & 5,068 & 12,44 & 0,1154 & 0,1011 & $59,373^{\circ}$ & 0,079 \\
\hline
\end{tabular}

Uma vez construída a população, são aplicados os operadores próprios das EEs, para o qual é eleito um indivíduo da população aleatoriamente. Os indivíduos a serem submetidos aos operadores de evolução são escolhidos aleatoriamente. Supõe-se que foram sorteados os indivíduos $v_{3}$ e $v_{5}$ pertences às linhas 3 e 5 (cor azul) da Tabela 3.3(a).

Aplicando o operador recombinação na primeira geração (recombinação intermediária local), por meio das equações (3.5) e (3.6) gera-se um novo indivíduo $v_{\text {NOVO }}$, da seguinte forma:

$$
\begin{aligned}
& x_{1}^{1}(\text { novo })=\frac{x_{1}\left(v_{3}\right)+x_{1}\left(v_{5}\right)}{2}=\frac{3,89+6,43}{2}=5,16 \quad \text { (local de falta) } \\
& x_{2}^{1}(\text { novo })=\frac{x_{2}\left(v_{3}\right)+x_{2}\left(v_{5}\right)}{2}=\frac{7,23+17,53}{2}=12,38 \quad \text { (Impedância de falta) } \\
& \sigma_{1}^{1}(\text { novo })=\frac{\sigma_{1}\left(v_{3}\right)+\sigma_{1}\left(v_{5}\right)}{2}=\frac{0,05+0,05}{2}=0,05
\end{aligned}
$$




$$
\begin{aligned}
& \sigma_{2}^{1}(\text { novo })=\frac{\sigma_{2}\left(v_{3}\right)+\sigma_{2}\left(v_{5}\right)}{2}=\frac{0,06+0,06}{2}=0,06 \\
& \theta_{1}^{1}(\text { novo })=\frac{\theta_{1}\left(v_{3}\right)+\theta_{1}\left(v_{5}\right)}{2}=\frac{25,23+60,56}{2}=59,33
\end{aligned}
$$

Aplicando o operador de Mutação ao $v_{\text {NOVO }}$, por meio das equações (3.11) a (3.19) obtêm-se novos valores de variáveis que representam o indivíduo. Este procedimento é detalhado a seguir:

\section{Inicio}

1. Para $i=1$ e 2 fazer

$$
\begin{aligned}
& \sigma_{1}^{2}=\sigma_{1}^{1} \exp \left(t^{\prime} . N(0,1)+t \cdot N_{1}(0,1)\right)=(0,05) * \exp ((0,5) *(0,48)+(0,8409) *(0,71))=0,1154 \\
& \sigma_{2}^{2}=\sigma_{2}^{1} \exp \left(t^{\prime} . N(0,1)+t \cdot N_{2}(0,1)\right)=(0,05) * \exp ((0,5) *(0,35)+(0,8409) *(0,63))=0,1011
\end{aligned}
$$

Fim

2. Paraj=1 fazer

$$
\left.\theta_{1}^{2}=\theta_{1}^{1}+\lambda \cdot N_{1}(0,1)\right)=59,33+(0,0873 * 0,49)=59,373
$$

Fim

3. Para $i=1$ e 2 fazer

$$
\begin{aligned}
& \Delta x_{1}^{2}=\sigma_{1}^{2} \cdot N_{1}(0,1)=0,1154 * 0,72=0,0830 \\
& \Delta x_{2}^{2}=\sigma_{2}^{2} \cdot N_{2}(0,1)=0,1011 * 0,39=0,0394
\end{aligned}
$$

Fim 
4. Para $k=1$ e 2 fazer

$$
\begin{aligned}
& (1,2)=\text { indices }(1) \\
& \Delta x_{1}^{2}=\Delta x_{1}^{2} \cos \left(\theta_{1}\right)-\Delta x_{2}^{2} \operatorname{sen}\left(\theta_{1}\right)=0,0830 * \cos (60,31)-0,0394 * \operatorname{sen}(60,31)=-0,0912 \\
& \Delta x_{2}^{2}=\Delta x_{1}^{2} \operatorname{sen}\left(\theta_{1}\right)-\Delta x_{2}^{2} \cos \left(\theta_{1}\right)=0,0830 * \operatorname{sen}(60,31)-0,0394 * \cos (60,31)=0,0633
\end{aligned}
$$

Fim

5. Para $i=1$ até $n$ fazer

$$
\begin{aligned}
x_{1}^{2}=x_{1}^{1}+\Delta x_{1}^{2}=5,16+(-0,0912)=5,068 \quad \text { (local de falta) } \\
x_{1}^{2}=x_{1}^{1}+\Delta x_{1}^{2}=12,38+(0,0633)=12,44 \quad \text { (Impedância de falta) }
\end{aligned}
$$

Fim

\section{Fim}

Os valores que caracterizam os novos indivíduos gerados pelos operadores são ilustrados na Tabela 3.3(b) (linhas vermelhas).

Este processo é iterativo, de forma a gerar uma quantidade de indivíduos préestabelecida ( $n^{\circ}$ de indivíduos submetidos à mutação), que representam o novo grupo $(\lambda)$.

Para aplicar a seleção, cada indivíduo dos grupos $\mu$ (população atual) e $\lambda$ deverá concorrer no processo de sobrevivência através da seleção $(\mu+\lambda)$-EE. Aqueles melhores adaptados (melhor função aptidão) sobrevirão para a próxima geração. 


\section{4 - SOLUÇÃO DO PROBLEMA DE ESTIMAÇÃO DE VTCDs}

Como mencionado no Capítulo 1, técnicas e metodologias para a estimação de estados de VTCDs (produzidas por faltas elétricas) são importantes, porque auxiliam na monitoração da qualidade de energia elétrica em barras onde não se tem medidores instalados, o que traz redução de custos em instalação de novos equipamentos (medidores), assim como redução nos custos de operação e manutenção da rede elétrica relativos à qualidade da energia elétrica.

Por outro lado, quando uma falta se torna permanente (de longa duração), a localização da falta se torna muito útil para as equipes de manutenção, auxiliando no seu rastreio, de modo a reduzir o tempo de reparo e de restabelecimento da energia.

Neste capítulo é aplicada a metodologia "Estratégias Evolutivas" (EEs), descrita no capítulo anterior para solucionar o problema de estimação de estados de VTCDs, causadas por faltas elétricas na rede elétrica determinando as condições de curto-circuito (local de falta, impedância de falta e tipo de falta) no instante da falta.

Para a implementação da metodologia proposta, é necessário o conhecimento das características físicas das redes para o cálculo de curto-circuito. Em muitos casos, a obtenção destes dados constitui uma dificuldade, já que muitas concessionárias não disponibilizam valores atualizados destas informações, o que influenciará na eficiência da metodologia. Em outras palavras, a precisão dos resultados obtidos para sistemas testados é função da qualidade da base de dados utilizada.

Além dessas informações, são utilizados os valores das magnitudes das tensões e correntes registradas pelos equipamentos de medição instalados em alguns pontos da rede. No caso de contar com medidores que registrem valores fasoriais, estes serão utilizados.

A metodologia é detalhada passo a passo, desde a construção da população inicial até a seleção dos indivíduos que farão parte da nova população. 


\subsection{Descrição do Problema}

Como mencionado no Capítulo 1, são dois os principais fenômenos desencadeadores de VTCDs: ocorrência de faltas e manobras de grandes cargas na rede. Este último é devido principalmente à partida de grandes motores, onde a corrente aumenta entre 6 a 8 vezes sua corrente nominal durante alguns segundos, o que produz uma queda de tensão (afundamento) em algumas barras do sistema elétrico.

Em ambos casos, ou seja, devido à ocorrência de faltas ou às variações de grandes cargas, as VTCDs são caracterizadas por dois parâmetros, quais sejam a "magnitude" e a “duração”. Este último parâmetro está diretamente relacionado com dois tipos de tempos:

a) Tempo de atuação do relé mais o tempo de abertura do disjuntor, e

b) Tempo da extinção natural da falta, que está associado a faltas de curtíssima duração, em que os dispositivos de proteção não são sensibilizados. Dentre todas as causas de curto-circuito, as de maior incidência são as descargas atmosféricas, tendo estas um caráter aleatório.

Por outro lado, quando a interrupção torna-se de longa duração, ou seja, os dispositivos de proteção atuam, desligando parte da rede, a maioria das empresas concessionárias, através da área de operação, envia equipes de manutenção para localizar a falta e proceder ao restabelecimento do serviço elétrico. Muitas vezes os telefonemas provenientes dos consumidores interrompidos facilitam a localização das faltas.

Neste contexto, com o emprego da metodologia descrita nesta tese, pode-se determinar as condições de curto-circuito que provocaram o desligamento de uma parte da carga e, por outro lado, estimar o estado da rede em condição de falta visando as magnitudes das tensões (VTCDs).

Para este estudo, determinar as condições de curto-circuito ou localizar a falta significa basicamente determinar três parâmetros: local de falta, tipo de falta e impedância de defeito. O local de falta é um número real associado a um nome de trecho. Por exemplo, a falta foi a 5,34 km da barra barl3 no trecho LT1320. O tipo de falta pode ser trifásica, monofásica, dupla-fase ou dupla-fase-terra. $\mathrm{O}$ valor da impedância de defeito é um número real, por exemplo, um valor igual a $12,34 \Omega$. 
A Figura 4.1 ilustra uma falta caracterizada por estes três parâmetros que, por sua vez, representam uma solução para o problema de localização de faltas.

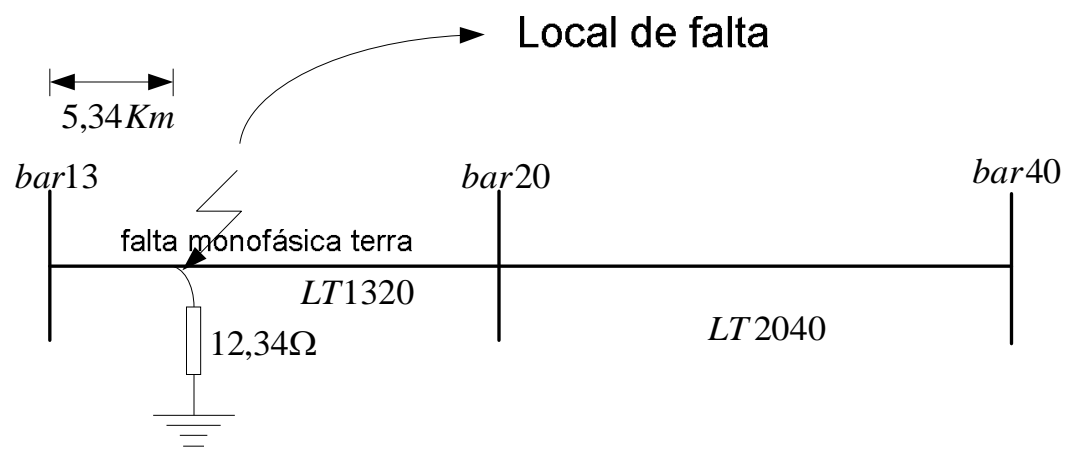

Figura 4.1 - Representação de uma falta

Na prática, o parâmetro de maior interesse é o local de falta. Porém, para este estudo, todos os parâmetros são importantes, porque com os valores obtidos pretende-se estimar o estado da rede em condições de falta, visando valores de tensões.

A Figura 4.2 ilustra uma rede na qual estão instalados três medidores (M1, M2 e M3) que registram, em tempo quase real, valores de tensão. Quando acontece uma falta nesta rede, conforme Figura 4.2, os medidores observam (registram) a variação dos valores das tensões. Caso os equipamentos de proteção atuem e desliguem parte da rede, imediatamente é ativado um alarme (ou através de telefonemas) para a equipe de operação, de modo a tomar medidas necessárias e restabelecer o fornecimento de energia. 


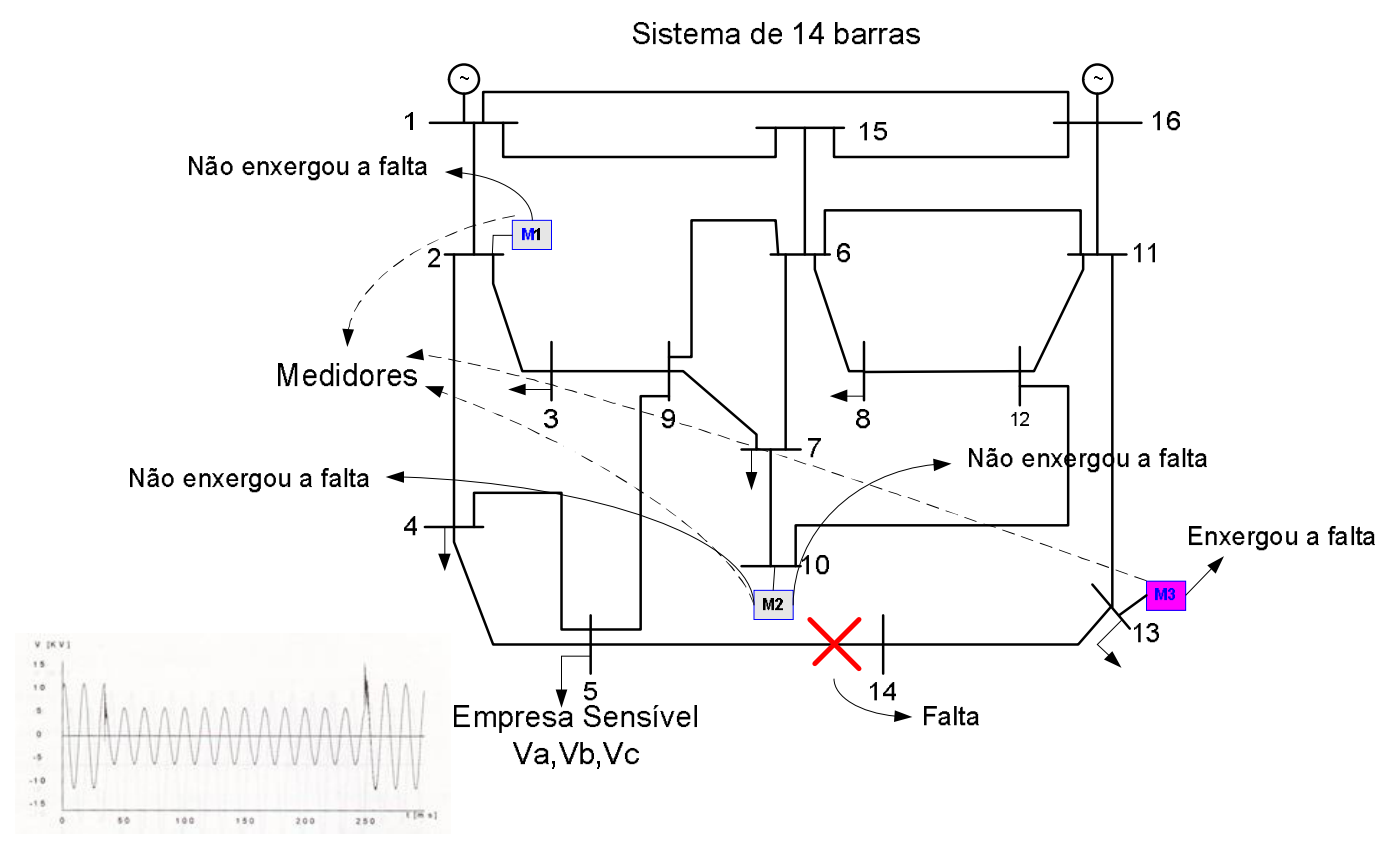

Figura 4.2 - Representação do problema

Neste caso, torna-se desafiador responder à seguinte pergunta: como estas faltas e as correspondentes VTCDs afetam os clientes que possuem equipamentos sensíveis num sistema? Surge então a necessidade de determinar o estado da rede no momento da falta, visando à estimação das VTCDs. Um exemplo disto está na Figura 4.2, onde na barra 5 está conectado um cliente que possui uma carga sensível.

Uma restrição tanto para a localização como para a estimação de VTCDs é que pelo menos um medidor instalado na rede deve registrar as VTCDs. Isso constitui um tema específico para o desenvolvimento da metodologia, a ser tratado no Capítulo 5.

Como conseqüência de uma adequada monitoração seria possível melhorar procedimentos de manutenção preditiva e corretiva visando à qualidade de energia elétrica, como por exemplo, determinar aquelas regiões mais propensas às faltas elétricas. 


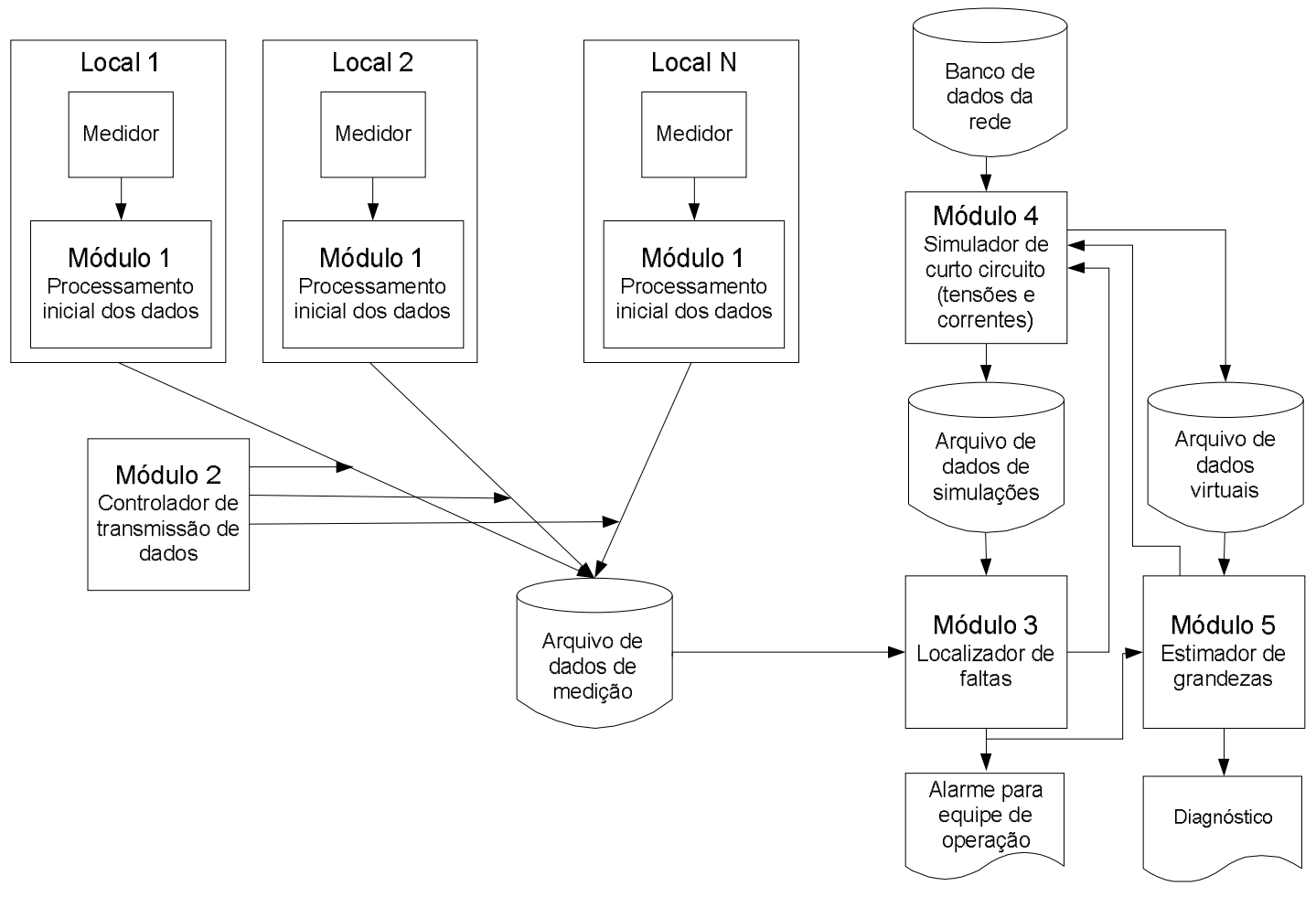

Figura 4.3 - Fluxograma do problema

Para um melhor entendimento da concepção do estimador aplicado numa empresa de energia é ilustrado um fluxograma na Figura 4.3, onde o problema é dividido em cinco módulos, descritos a seguir:

Módulo 1: Está formado por uma central de dados provenientes dos equipamentos de medição utilizando um interface própria de cada medidor. Considerando que cada medidor tem características próprias e diferentes respostas, este módulo padroniza as informações.

Módulo 2: Este módulo faz uma análise das informações salvas no módulo 1. Quando há uma VTCDs, envia a informação dos valores das tensões e correntes nesse instante através de uma interface para um arquivo de dados de medição e ativa o localizador de faltas.

Módulo 3: Uma vez ativado este módulo, que é desenvolvido nesta tese, ele aplica a metodologia proposta neste trabalho para determinar a condição da falta, utilizando um arquivo de dados de simulação de curto-circuito (Módulo 4). Uma vez atingido o objetivo, ativa um alarme (diagnóstico) para a equipe de operação caso a interrupção tenha desligado parte da carga e, em seguida, ativa o Módulo 5 para estimar as VTCDs em barras de interesse.

Módulo 4: É composto por uma ferramenta de cálculo de curto-circuito, que é ativada pelo Módulo 3 ou pelo Módulo 5. A resposta deste módulo é fornecer informação relativa aos valores das tensões nas barras e correntes nos trechos do sistema avaliado no instante de 
curto-circuito. Para esta tese, este módulo é uma ferramenta computacional denominada SINAP t\&d.

Módulo 5: consiste no estimador de VTCDs, sendo desenvolvido neste trabalho. Com os valores obtidos do Módulo 3 (localizador de faltas), estimam-se os valores das tensões nas barras de interesse, para o qual se utiliza um arquivo de dados de simulação de curto-circuito (Módulo 4) e, finalmente, é obtido um diagnóstico da rede.

\subsection{Codificação do problema por EEs}

Os indivíduos representam uma solução viável do problema de localização de faltas. Estão codificados por um vetor composto por atributos (características do fenótipo). Estes atributos podem ser variáveis discretas e contínuas. A Figura 4.4 representa um indivíduo ou uma solução possível do problema:

\begin{tabular}{|c|c|c|c|}
\hline & $\begin{array}{l}\text { Local da falta } \\
\quad(\mathrm{km})\end{array}$ & Tipo da falta & $\begin{array}{c}\text { Impedância de } \\
\text { defeito }(\Omega)\end{array}$ \\
\hline Indivíduo & 325,24 & Monofásica & 17,45 \\
\hline
\end{tabular}

Figura 4.4 - Representação de um indivíduo

\section{Onde,}

Os atributos são detalhados a seguir:

Local da Falta: este parâmetro (variável contínua) representa o ponto exato onde o curto-circuito será simulado. Para isso os trechos da rede são agrupados como uma série no tratamento interno do algoritmo. Este valor está associado a um nome do trecho e uma distância em relação de uma das barras extremas desse trecho, como ilustra a Figura 4.5.

Tipo de falta: este parâmetro (variável discreta) representa o tipo de curto-circuito. Foram considerados quatro tipos de curto-circuito: trifásico, bifásico, fase-terra e dupla fase terra com e sem impedância de defeito.

Impedância de defeito: este parâmetro (variável contínua) representa a impedância de defeito. Esta impedância é considerada numa faixa entre 0 e Zmax. O valor de $Z$ max pode variar dependendo da região onde se deseja implementar o estimador ${ }^{1}$.

\footnotetext{
${ }^{1}$ Considerou-se Zmax igual a $20 \Omega$ para os casos testados porque, na prática, a maioria dos curtos-circuitos que envolvem terra apresenta valores de impedância dentro da faixa considerada (CEBRIAN, A.J.C; 2008)
} 


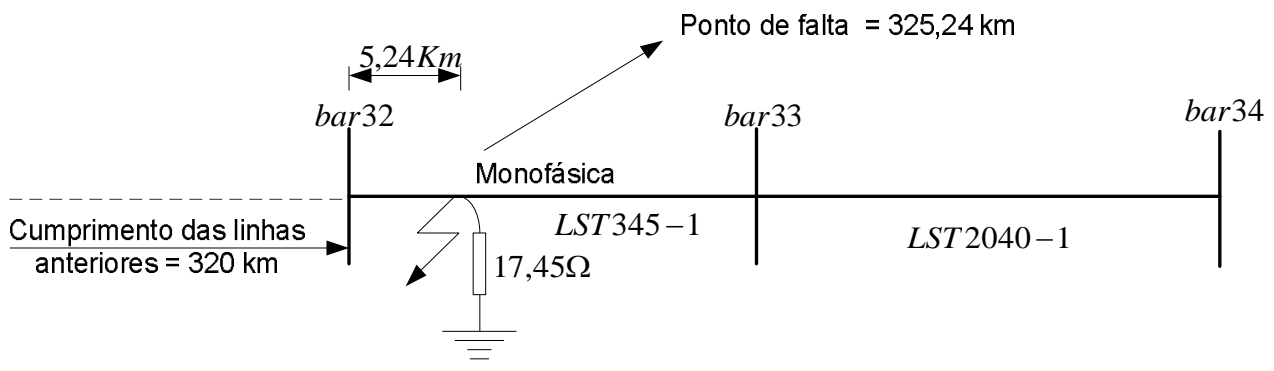

Figura 4.5 - Representação do indivíduo

Numa primeira etapa do desenvolvimento deste trabalho, foram utilizados três atributos para representar uma solução (local de falta, tipo de falta e impedância de defeito). Como conseqüência dos testes e análises, foi reduzido o número de atributos para dois parâmetros: local de falta e impedância de defeito, devido ao incremento mínimo de tempo para calcular todos os tipos de as correntes de curto-circuito e contribuições em tensão nas barras de interesse.

É necessário mencionar que, na codificação interna do algoritmo, o indivíduo, além dos atributos, possui as variáveis estratégicas mencionadas no Capítulo 3. A Figura 4.6 ilustra a codificação de um indivíduo (uma solução para o problema) de acordo com a solução ilustrada na Figura 4.5.

\begin{tabular}{|c|c|c|c|c|}
$\begin{array}{c}\text { Local da } \\
\text { falta } \\
X 1(\mathrm{~km})\end{array}$ & $\begin{array}{c}\text { Impedância } \\
\text { de defeito } \\
X 2(\Omega)\end{array}$ & $\begin{array}{c}\text { Passo do } \\
\text { local de } \\
\text { falta } \\
\left(\sigma_{1}\right)\end{array}$ & $\begin{array}{c}\text { Passo da } \\
\text { Impedância } \\
\text { de defeito } \\
\left(\sigma_{2}\right)\end{array}$ & $\begin{array}{c}\text { Direção } \\
\text { prefencial } \\
\left(\theta_{X_{1}, X_{2}}\right)\end{array}$ \\
\hline 325,24 & 17,45 & 0,05 & 0,02 & $61,75^{\circ}$ \\
\hline
\end{tabular}

Figura 4.6 - Codificação interna do indivíduo 


\subsection{Avaliação da função objetivo}

A função de avaliação deve ser um índice de mérito não negativo. Para o problema de localização será a soma quadrática das diferenças entre os valores das magnitudes de tensão lidos pelos medidores instalados e dos calculados. Isto resulta na aplicação do método de Mínimos Quadrados através da seguinte expressão:

$$
f_{\text {aval }}=\sum_{i=1}^{N m}\left[\left(V_{m_{i} A}-V_{c A}\right)^{2}+\left(V_{m_{i} B}-V_{c B}\right)^{2}+\left(V_{m_{i} C}-V_{c C}\right)^{2}\right]
$$

\section{Onde,}

$V_{m_{i} A}:$ Magnitude da tensão lida pelo medidor $m_{i}$ na fase A;

$V_{c A}$ : Magnitude da tensão calculada na barra do medidor $m_{i}$ na fase A;

Nm: Número de medidores instalados na rede.

Caso os equipamentos de medição possuam respostas de valores fasoriais das tensões, para o cálculo da função de avaliação será aplicado o método da Distância Euclidiana como ilustra a

Figura 4.7.

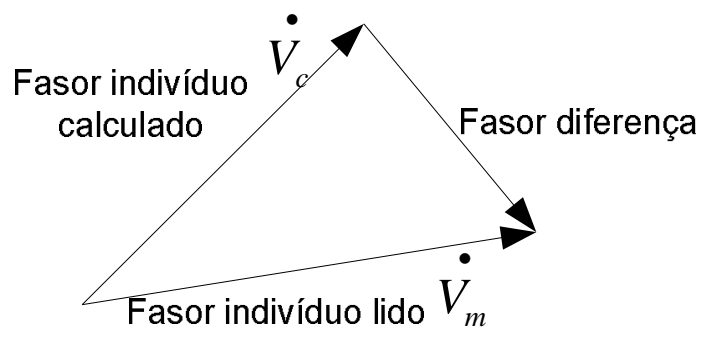

Figura 4.7 - Distância Euclidiana

A maioria dos problemas de otimização apresenta restrições. No problema em questão, serão as restrições próprias do cálculo de curto-circuito. Este cálculo foi feito através de uma ferramenta computacional denominada SINAP $t \& d$ (SINAPSIS INOVAÇÃO EM ENERGIA), cuja modelagem para o cálculo de curto-circuito encontra-se no Anexo B. 


\subsection{Construção da População Inicial}

A população inicial representa um conjunto de possíveis soluções (indivíduos) para resolver o problema de localização de faltas, que são representados por uma codificação descrita no item 4.2. O tamanho dela será determinado considerando alguns critérios como, por exemplo, o tamanho da rede e a velocidade de evolução do algoritmo.

São consideradas duas maneiras para construir a população inicial: de forma aleatória ou através de alguma regra heurística. A vantagem de utilizar a aleatoriedade é de dotar ao algoritmo de diversidade no processo de otimização, ou seja, começar de forma dispersa. Por outro lado, a velocidade de convergência do algoritmo pode ser demorada em redes de grande porte, como ilustra a Figura 4.8 (b), onde as populações são representadas pelos pontos (indivíduos) nas seguintes cores: azul, preto, vermelho, verde e lilás, durante o processo de otimização. O ponto marrom é a solução procurada. É recomendável utilizar o critério de aleatoriedade em redes de pequeno porte, de modo a não direcionar a busca para uma solução ótima local como ilustra a Figura 4.8 (a). Com uma população construída aleatoriamente, o processo de convergência tende a encontrar a solução procurada.

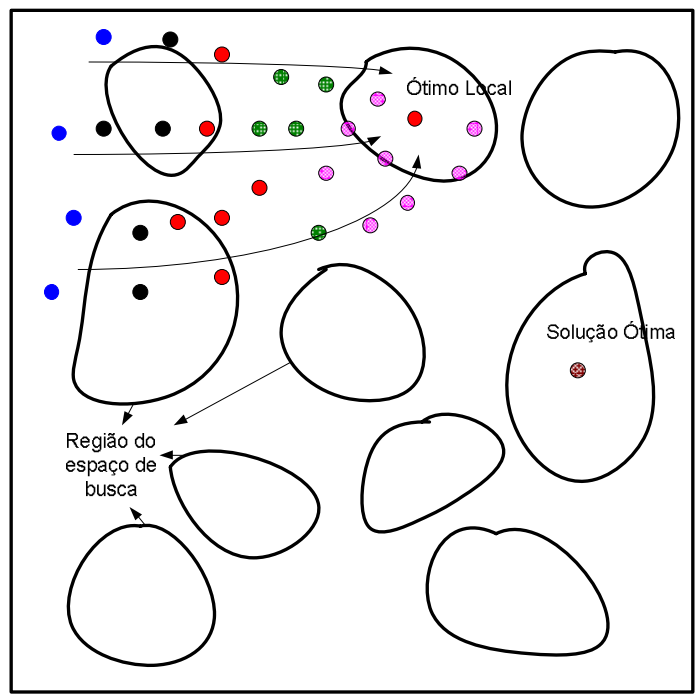

(a) População inicial não dispersa

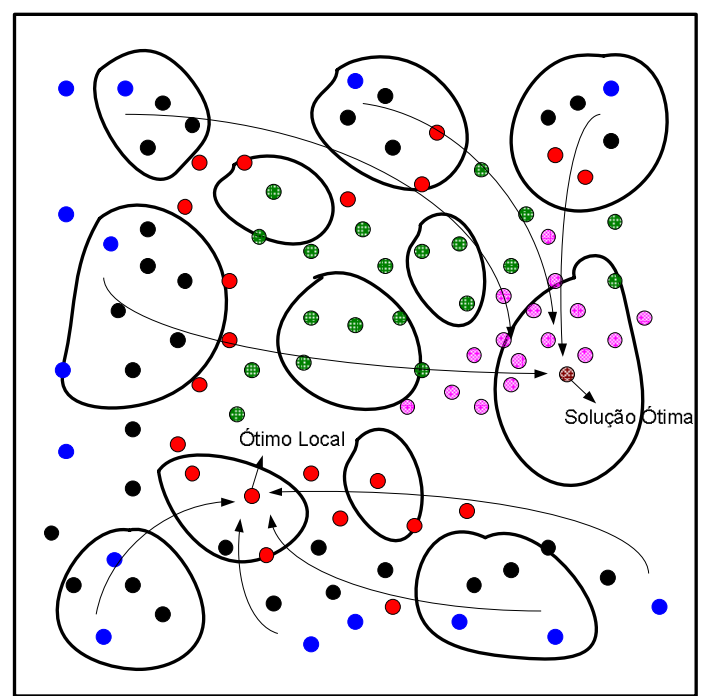

(b) População inicial dispersa

Figura 4.8 - Convergência do algoritmo

Nas redes de grande porte é necessário aplicar algum critério heurístico para definição da população inicial de modo a reduzir o espaço de busca e, evitar que o processo não seja muito demorado. O critério adotado neste trabalho baseia-se na taxa de falha de cada um dos 
trechos que formam o sistema elétrico. Esta taxa de falha informa, de forma quantitativa, num período de tempo considerado, a sensibilidade do trecho em sofrer alguma falha. Esta informação pode ser armazenada e obtida por análises estatísticas. Porém, nem todas as empresas concessionárias mantêm esta informação.

Considerando o exposto nos parágrafos anteriores, os valores dos parâmetros de cada indivíduo são gerados de seguinte forma:

- Local de falta: caso não contar com a informação estatística de taxas de falha, é considerado aleatório. Sorteiam-se trechos e posições nos trechos.

- Impedância de falta: geram-se aleatoriamente valores entre 0 e $20 \Omega$. O valor desta faixa poderá ser influenciado pela região onde se pretenda implementar o localizador.

- Tipo de falta: é utilizada uma regra heurística baseada em probabilidades de ocorrências nos sistemas elétricos, referenciados aos seguintes tipos de falta:

- Falta Trifásica, por exemplo, $5 \%$

- Falta Monofásica, por exemplo, $70 \%$

- Falta Duas-Fases, por exemplo, $10 \%$

- Falta Duas-Fases-Terra, por exemplo, $15 \%$

Segundo esta informação, as faltas monofásicas a terra ocorrem com maior freqüência nos sistemas elétricos. Por outro lado, as que menos ocorrem são as faltas trifásicas. Este critério pode ajudar a direcionar a busca em sistemas de grande porte.

\subsection{Construção de listas ordenadas de locais de falta}

Com a finalidade de guiar a busca e ter uma visão geral das Distâncias Euclidianas entre uma condição de falta (local de falta, impedância de falta e tipo de falta) e outra, foi necessário utilizar um critério determinístico. Através deste critério constrói-se uma lista de trechos (LisTrec) associando um valor calculado a cada um dos trechos para, em seguida, ordenar essa lista com base nesse valor calculado. Este processo consiste em simular, para todos os trechos, três faltas (nos extremos e no meio do trecho), considerando todos os tipos de falta e impedâncias de falta específicas $(0 ; 5 ; 10 ; 15$ e $20 \Omega)$. Calcula-se a função objetivo através da equação 4.1 para cada condição de curto-circuito simulado e, finalmente, calcula-se 
a média aritmética dos valores da função objetivo destes três pontos de falta, atribuindo esse valor calculado ao trecho como ilustra a Tabela 4.1 (a). Terminados todos os cálculos, as listas são ordenadas de forma decrescente de acordo com o valor associado aos trechos como ilustra a Tabela 4.1 (b). Só os nomes dos trechos são guardados em um banco de dados. Este processo é feito antes de executar o algoritmo do estimador de VTCDs.

A Tabela 4.2 ilustra os tipos de curto-circuito e os valores das impedâncias de falta consideradas para construir as listas. Os valores: 1,2,3.., 12 na Tabela 4.2 correspondem aos índices das listas construídas. Por exemplo, a lista 5 armazena resultados de uma falta monofásica para terra com impedância de defeito $10 \Omega$.

Tabela 4.1 - Lista de trechos para uma falta trifásica

(a) Lista não ordenada

\begin{tabular}{|c|l|r|}
\hline $\mathbf{N}^{\circ}$ & \multicolumn{1}{|c|}{$\begin{array}{c}\text { Nome do } \\
\text { trecho }\end{array}$} & $\begin{array}{c}\text { Média da } \\
\text { função objetivo }\end{array}$ \\
\hline 1 & LT68-1 & 0,159959 \\
\hline 2 & LST1819-1 & 0,110998 \\
\hline 3 & LST2627-1 & 0,284830 \\
\hline 4 & LST2530-1 & 0,191779 \\
\hline 5 & LST4156-1 & 0,229150 \\
\hline 6 & LST3132-1 & 0,252217 \\
\hline 7 & LST2728-1 & 0,266057 \\
\hline 8 & LST5253-1 & 0,130375 \\
\hline 9 & LT912-1 & 0,229704 \\
\hline 10 & LST2952-1 & 0,188335 \\
\hline 11 & LST4142-1 & 0,215504 \\
\hline 12 & LST2829-1 & 0,261284 \\
\hline 13 & LST4256-1 & 0,241466 \\
\hline 14 & LST1920-1 & 0,099585 \\
\hline 15 & LT1012-1 & 0,254194 \\
\hline 16 & LST5354-1 & 0,133381 \\
\hline 17 & LT116-1 & 0,259574 \\
\hline 18 & LT67-1 & 0,253360 \\
\hline 19 & LST5657-1 & 0,242076 \\
\hline 20 & LST5051-1 & 0,264507 \\
\hline 21 & LT89-1 & 0,287089 \\
\hline 22 & LST5455-1 & 0,152395 \\
\hline 23 & LT910-1 & 0,266221 \\
\hline 24 & LT56-1 & 0,277665 \\
\hline 25 & LT46-1 & 0,289020 \\
\hline 26 & LT78-1 & 0,252217 \\
\hline 27 & LT89-2 & 0,284830 \\
\hline 28 & LST3031-1 & 0,197376 \\
\hline & & \\
\hline
\end{tabular}

(b) Lista ordenada

\begin{tabular}{|l|r|}
\hline $\begin{array}{c}\text { Nome do trecho } \\
\text { ordenado }\end{array}$ & $\begin{array}{c}\text { Média da } \\
\text { função objetivo }\end{array}$ \\
\hline LT46-1 & 0,289020 \\
\hline LT89-1 & 0,287089 \\
\hline LT89-2 & 0,284830 \\
\hline LST2627-1 & 0,284830 \\
\hline LT56-1 & 0,277665 \\
\hline LT910-1 & 0,266221 \\
\hline LST2728-1 & 0,266057 \\
\hline LST5051-1 & 0,264507 \\
\hline LST2829-1 & 0,261284 \\
\hline LT116-1 & 0,259574 \\
\hline LT1012-1 & 0,254194 \\
\hline LT67-1 & 0,253360 \\
\hline LT78-1 & 0,252217 \\
\hline LST3132-1 & $\mathbf{0 , 2 5 2 2 1 7}$ \\
\hline LST5657-1 & 0,242076 \\
\hline LST4256-1 & 0,241466 \\
\hline LT912-1 & 0,229704 \\
\hline LST4156-1 & 0,229150 \\
\hline LST4142-1 & 0,215504 \\
\hline LST3031-1 & 0,197376 \\
\hline LST2530-1 & 0,191779 \\
\hline LST2952-1 & 0,188335 \\
\hline LT68-1 & 0,159959 \\
\hline LST5455-1 & 0,152395 \\
\hline LST5354-1 & 0,133381 \\
\hline LST5253-1 & 0,130375 \\
\hline LST1819-1 & 0,110998 \\
\hline LST1920-1 & 0,099585 \\
\hline
\end{tabular}


Tabela 4.2 - Listas armazenadas para os curtos-circuitos considerados

\begin{tabular}{|l|c|c|c|c|c|}
\hline \multirow{2}{*}{$\begin{array}{c}\text { Tipos de curto- } \\
\text { circuito }\end{array}$} & \multicolumn{6}{|c|}{ Impedância de defeito $(\boldsymbol{\Omega})$} \\
\cline { 2 - 6 } & $\mathbf{0}$ & $\mathbf{5}$ & $\mathbf{1 0}$ & $\mathbf{1 5}$ & $\mathbf{2 0}$ \\
\hline Trifásica & 1 & --- & --- & --- & --- \\
\hline Duas-Fases & 2 & --- & --- & --- & --- \\
\hline Monofásica & 3 & 4 & 5 & 6 & 7 \\
\hline Duas-Fases-Terra & 8 & 9 & 10 & 11 & 12 \\
\hline
\end{tabular}

\subsection{Operador Mutação}

Como já descrito no Capítulo 3, no desenvolvimento das EEs foram propostas diferentes técnicas para aplicar o operador de mutação, com a finalidade de melhorar o desempenho e eficiência do algoritmo. Por outro lado, sendo a mutação o principal operador da evolução, a sua correta aplicação associada às demais estratégias é imprescindível para o sucesso do algoritmo.

O número de mutações é definido de forma a controlar a evolução em cada geração. Sendo assim, cada indivíduo gera " $m$ ” indivíduos.

As estratégias de auto-adaptação e mutação correlacionadas, descritas no item 3.2.6, são utilizadas, conforme valores dos parâmetros descritos a seguir:

$x[1: 2]=[$ local de falta, Impedância de falta $] \rightarrow$ atributos do indivíduo

$\sigma[1: 2]=[\sigma$ local de falta, $\sigma$ limpedância de falta $] \rightarrow$ parâmetros estratégicos

$m=2(2-1) / 2=1$ (número de parâmetros da direção preferencial do movimento)

$\theta[1: 1]=\left[\theta_{12}\right] \rightarrow$ parâmetro estratégico

Os desvios padrão $\boldsymbol{\sigma}$ serão fixados para cada indivíduo de forma a controlar o desvio (passo) individualmente. Todos os indivíduos da população inicial começam com um passo pré-determinado, por exemplo, $0,01 \mathrm{~km}$, para o local de falta. No processo de evolução os desvios tendem a se adaptar, aumentando ou diminuindo de valor.

Uma vez aplicado o operador mutação aos parâmetros estratégicos através das equações 3.13 e 3.14, procede-se à mutação aplicada aos atributos do indivíduo (local de falta e impedância de falta) utilizando as equações 3.15, 3.16 e 3.17 e a lista de trechos (LisTrec), da seguinte maneira: 
Passo 1: Determinar a lista de trechos (LisTrec) a ser utilizada. A lista é selecionada, dependendo do tipo de falta, conforme a Tabela 4.2. Se o indivíduo possui um valor de impedância de falta não nula, a lista selecionada será aquela onde a diferença entre a impedância das listas $(0 ; 5 ; 10 ; 15$ e $20 \Omega)$ e do indivíduo escolhido seja menor.

Passo 2: Uma vez identificado nesta lista o nome do trecho do indivíduo escolhido, reordena-se a lista, começando pelo trecho (do indivíduo escolhido) para cima e para baixo de forma intercalada. Desta forma, obtém-se uma visão de quais trechos estão mais próximos do trecho avaliado. Como exemplo, é utilizada a Tabela 4.1 (b). Considerando que o trecho avaliado é LST3132-1, a nova lista ordenada fica da seguinte maneira:

Tabela 4.3 - Lista ordenada (LisTrec)

\begin{tabular}{|r|l|r|r|}
\hline $\mathbf{N}^{\circ}$ & Nome do trecho ordenado & $\begin{array}{r}\text { Pto. Inicial } \\
\mathbf{( k m})\end{array}$ & \multicolumn{1}{c|}{$\begin{array}{c}\text { Pto. Final } \\
\mathbf{( k m})\end{array}$} \\
\hline 1 & LST3132-1 & 0,001 & 10,00 \\
\hline 2 & LT78-1 & 10,001 & 20,00 \\
\hline 3 & LST5657-1 & 20,001 & 30,00 \\
\hline 4 & LT67-1 & 30,01 & 40,00 \\
\hline 5 & LST4256-1 & 40,001 & 50,00 \\
\hline 6 & LT1012-1 & 50,001 & 60,00 \\
\hline 7 & LT912-1 & 60,001 & 70,00 \\
\hline 8 & LT116-1 & 70,001 & 80,00 \\
\hline 9 & LST4156-1 & 80,001 & 90,00 \\
\hline 10 & LST2829-1 & 90,001 & 100,00 \\
\hline 11 & LST4142-1 & 100,001 & 110,00 \\
\hline 12 & LST5051-1 & 110,001 & 120,00 \\
\hline 13 & LST3031-1 & 120,001 & 130,00 \\
\hline 14 & LST2728-1 & 130,001 & 140,00 \\
\hline 15 & LST2530-1 & 140,001 & 150,00 \\
\hline 16 & LT910-1 & 150,001 & 160,00 \\
\hline 17 & LST2952-1 & 160,001 & 170,00 \\
\hline 18 & LT56-1 & 170,001 & 180,00 \\
\hline 19 & LT68-1 & 180,001 & 190,00 \\
\hline 20 & LST2627-1 & 190,001 & 200,00 \\
\hline 21 & LST5455-1 & 200,001 & 210,00 \\
\hline 22 & LT89-2 & 210,001 & 220,00 \\
\hline 23 & LST5354-1 & 220,001 & 230,00 \\
\hline 24 & LT89-1 & 230,001 & 240,00 \\
\hline 25 & LST5253-1 & 240,001 & 250,00 \\
\hline 26 & LT46-1 & 250,001 & 260,00 \\
\hline 27 & LST1819-1 & 260,001 & 270,00 \\
\hline 28 & LST1920-1 & 270,001 & 280,00 \\
\hline & & & \\
\hline
\end{tabular}


Passo 3: Utilizando a equação 3.16 são calculados os valores reais de $\Delta x_{i}$. Este valor, para ser utilizado em LisTrec, deverá adaptar-se a um valor real através da seguinte expressão:

$$
\Delta x_{\text {real }}=\Delta x_{i} * \text { Dist }
$$

Onde Dist é a distância entre o ponto de falta do indivíduo escolhido e o ponto de falta do último trecho da lista. Para o exemplo, supõe-se que o ponto de falta esteja a 3,25 km no trecho LST3132-1. Sendo assim, Dist (280,00-3,25) é igual a 276,75 km. Calculado o valor da expressão 4.2, procede-se ao cálculo do valor correspondente ao local de falta (novo indivíduo gerado através da mutação) através da equação 3.17 .

Para aplicar a mutação da impedância de falta, aplica-se o mesmo processo, já ilustrado para local de falta. É construída uma lista de valores entre 0 e Zmax $=20 \Omega$, com variação de 0,1 , ou seja: $[0 ; 0,1 ; 0,2 ; \ldots 1 ; 1,1 ; \ldots 19,8 ; 19,9 ; 20]$.

\subsection{Operador Recombinação}

O operador recombinação, como mencionado no item 3.2.4, é um operador que, aliado ao de mutação, introduz variabilidade ao processo de evolução. Este processo cria um novo indivíduo que contém informação genética resultante da combinação das informações genéticas dos seus pais.

Para a solução do problema desta tese, optou-se por utilizar uma recombinação intermediária global (média aritmética) dos atributos que representam os indivíduos (local de falta, impedância de defeito, passo e direções preferenciais), expressa pelas equações 3.5 e 3.6. Por exemplo, sejam os indivíduos 1 e 2 representados na Figura 4.9, o novo indivíduo gerado a partir da recombinação é o indivíduo 3. 


\begin{tabular}{|c|c|c|c|c|c|}
\hline & $\begin{array}{c}\text { Local da } \\
\text { falta } \\
X 1(\mathrm{~km})\end{array}$ & $\begin{array}{l}\text { Impedância } \\
\text { de defeito } \\
\times 2(\Omega)\end{array}$ & $\begin{array}{l}\text { Passo do } \\
\text { local de falta } \\
\qquad\left(\sigma_{1}\right)\end{array}$ & $\begin{array}{c}\text { Passo da } \\
\text { Impedância de } \\
\text { defeito }\left(\sigma_{2}\right)\end{array}$ & $\begin{array}{c}\text { Direção } \\
\text { preferencial } \\
\left(\theta_{X_{1}, X_{2}}\right)\end{array}$ \\
\hline Indivíduo 1 & 312,34 & 12,34 & 0,05 & 0,043 & $61,75^{\circ}$ \\
\hline Indivíduo 2 & 53,67 & 15,54 & 0,02 & 0,05 & $10,12^{\circ}$ \\
\hline
\end{tabular}

(a) Pais

Indivíduo 3

\begin{tabular}{|l|l|l|l|l|}
\hline 182,84 & 13,94 & 0,035 & 0,046 & $35,93^{\circ}$ \\
\hline
\end{tabular}

(b) Indivíduo gerado

Figura 4.9 - Aplicação do operador Recombinação

\subsection{Operador Seleção}

A seleção de indivíduos é feita deterministicamente, pois se limita a selecionar os melhores indivíduos para a formação de gerações futuras. Depois de aplicar os operadores de mutação e recombinação, o universo da população estará composto por indivíduos pais e filhos.

A regra utilizada para a seleção é denominada $(\mu+\lambda)+E E$, como apresentada no Capítulo 3, onde $\mu$ representa a população (número de pais) que gera $\lambda>\mu$ indivíduos filhos. Então, o conjunto da união de indivíduos pais e indivíduos filhos são utilizados de tal forma que, nas gerações futuras, aqueles indivíduos melhores adaptados (menor função objetivo) sobrevivam, caracterizando o elitismo. A Figura 3.2 ilustra o método de seleção.

\subsection{Critério de Parada}

O critério de parada é aplicado quando se considera o problema resolvido, observando-se alguns indicadores de qualidade, como por exemplo:

1- Valor máximo pré-estabelecido do $n^{\circ}$ de gerações;

2- Número de gerações sem produzir nenhuma melhora da função objetivo;

3- Tempo computacional total. 
Para o problema de localização de faltas e estimação de VTCDs, o indicador empregado foi o número 2 (número de gerações que não produz melhora da função objetivo).

\subsection{Desenvolvimento da metodologia}

Em geral, os medidores são instalados nas redes elétricas não necessariamente visando ao problema de localização de faltas e estimação de VTCDs. Isso significa que muitas condições de curto-circuito podem não ser registradas pelos medidores. Este fato aumenta o grau de dificuldade para solucionar o problema da localização de falta.

Os medidores, em geral, só registram os eventos de VTCDs quando o valor das tensões (valor eficaz) cai abaixo de um valor pré-determinado (afundamento de tensão) ou se eleva acima de um valor pré-determinado (elevação de tensão).

Como consequência deste cenário, no Capítulo 5 foram desenvolvidas metodologias para determinar o mínimo número de medidores e onde eles devem ser instalados com intuito de que os medidores instalados registrem qualquer condição ou a maioria de condições de curto-circuito que possam ocorrer na rede elétrica.

A partir do registro de uma dada falta nos medidores, serão determinadas as características dessa ocorrência (local de falta, impedância de falta e tipo de falta). Em seguida, estima-se o estado da rede durante essa ocorrência visando aos valores de tensão em barras de interesse, aplicando a metodologia desenvolvida neste trabalho.

Para o desenvolvimento, considerou-se a premissa que só é possível estimar as VTCDs quando pelo menos um medidor registra essa ocorrência com leitura da tensão abaixo de 0,90 pu ou acima de 1,10 pu.

Antes de executar o algoritmo é construída a lista de trechos (LisTrec) desenvolvida no item 4.5. Esta lista é construída só uma vez e atualizada somente quando as características físicas da rede mudam.

O algoritmo inicia com a construção da população inicial aplicando o método proposto no item 4.4 e avalia-se a função objetivo de cada indivíduo utilizando a equação 4.1 descrita no item 4.3, para finalmente ordenar a população com base no valor da função objetivo.

Para aplicar o operador de Mutação é definido, a priori, o valor de $N R O_{m u t}$ (número de mutações por indivíduo), e para a recombinação é definido $t_{\text {recom }}$ (taxa de recombinação) com a finalidade de limitar o número de indivíduos que são submetidos a este operador, sendo este valor muito baixo $\approx 0,05$. 
Uma vez gerada uma quantidade de indivíduos através dos processos de mutação e recombinação, o universo de indivíduos estará formado por $\mu$ pais e $\lambda$ filhos. O operador de seleção é aplicado a este novo universo de indivíduos, utilizando os critérios estabelecidos no item 4.8. Na Figura 4.10 ilustra-se o algoritmo de forma resumida. Os detalhes foram desenvolvidos nos respectivos itens.

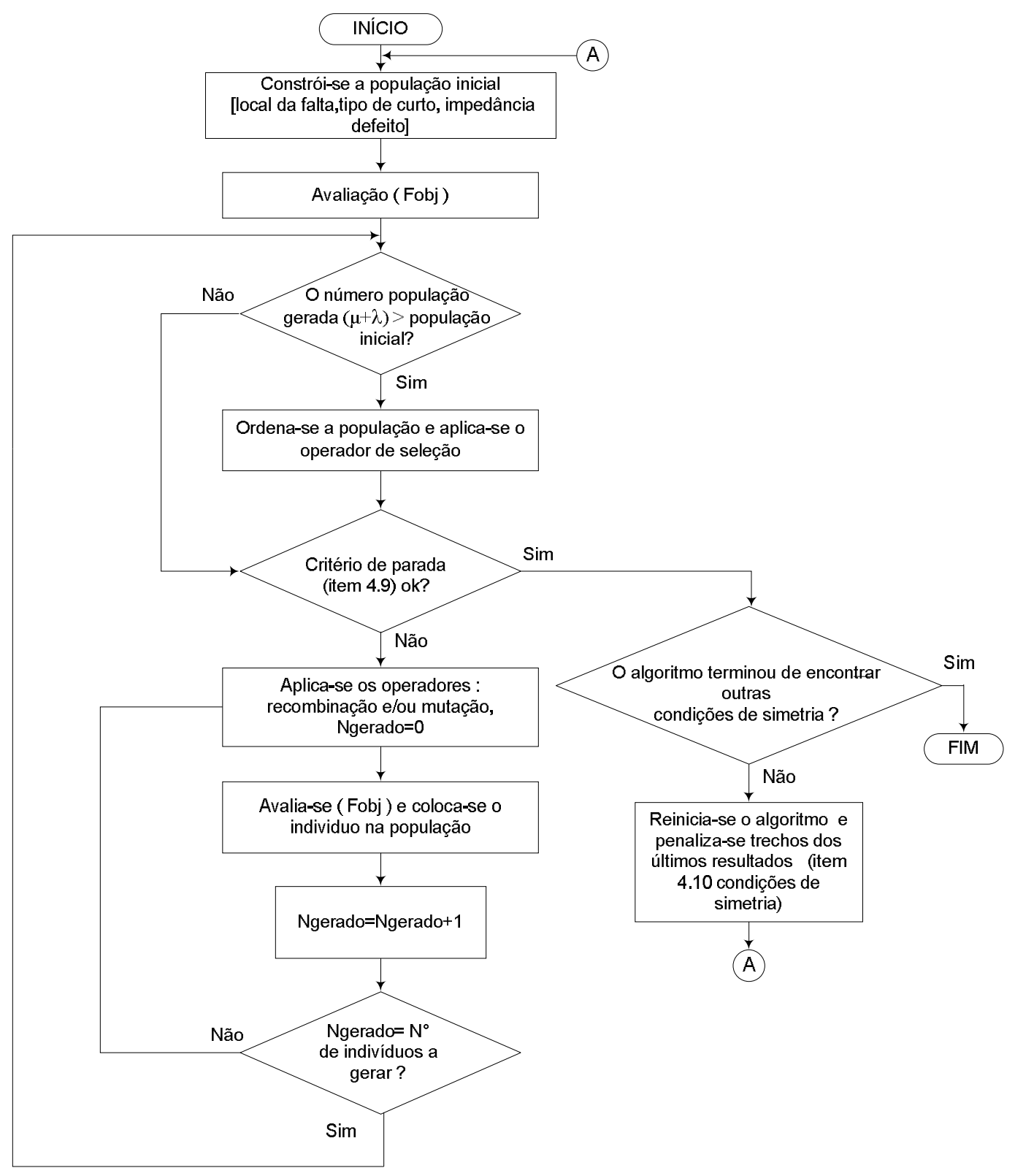

Figura 4.10 - Algoritmo 


\subsection{Simetria}

Um fato observado em redes de médio e grande porte é a simetria de locais de falta ilustrada na Figura 4.11, ou seja, aquelas condições de falta cujo valor da função objetivo é muito próximo para as barras onde se têm instalados medidores. Esta característica torna o problema de Estimação de VTCDs mais difícil para solucionar.

Quando se apresenta casos de simetria numa rede elétrica, o método apresentado de localização de faltas pode determinar locais prováveis de falta, com distâncias físicas entre estes locais muito grandes.

Sob o ponto de vista da estimação, os casos de simetria podem produzir erros grosseiros: várias condições de curto-circuito produzem os mesmos valores de tensões em certas barras (dos medidores), mas não necessariamente em outras barras (de estimação).

Neste cenário, são propostas estratégias e medidas para determinar e reduzir os casos de simetria, tais como:

- Analisar o banco de dados para avaliar se o trecho que contém o local de falta apresenta outro trecho paralelo (entre as mesmas barras), constatando-se uma condição de simetria, como ilustra a Figura 4.11.

- Com uma realocação ótima dos medidores é possível reduzir o número de condições de simetria, como será descrito no Capítulo 5.

- Alguns equipamentos de medição, além de registrar valores das tensões, também registram valores de correntes nos respectivos canais de medição. Esta informação é muito útil e rica para o processo de otimização, pois na medida em que o algoritmo se aproxima da condição de curto-circuito procurada, se calcula a distância entre valores de correntes lidos e registrados utilizando o método dos Mínimos Quadrados. Se este valor é grande, penaliza-se a função objetivo. Isso ajuda a melhorar a eficiência e precisão da metodologia, mesmo para as condições onde não se apresenta simetria. Este critério foi introduzido para garantir uma das características principais dos métodos de otimização, qual seja, a diversidade (num começo da busca), desta forma o risco de cair em uma solução local é menor.

- Para aqueles casos que não forem solucionados através dos procedimentos mencionados, realiza-se uma análise após a localização da falta sobre a atuação de relés, desde que esta informação esteja disponível. 


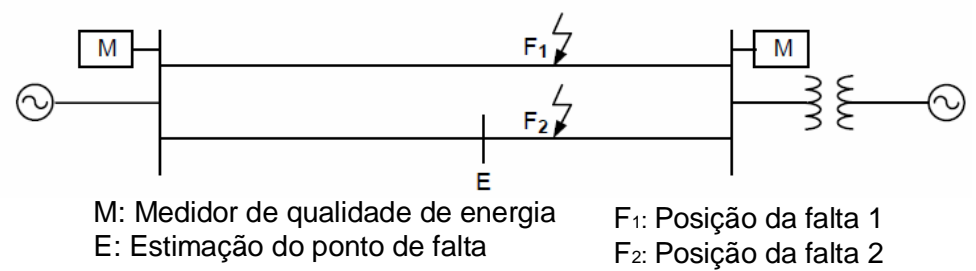

Figura 4.11 - Condições de simetria

É necessário salientar que uma vez que o algoritmo converge para uma solução (local de falta, impedância de falta, tipo de falta), o método é reiniciado restringindo o trecho ao qual pertence o local de falta encontrado. Em outras palavras, cada vez que algum indivíduo da população atual contenha esse trecho, a função objetivo dele é penalizada, com a finalidade de encontrar outras condições que gerem simetria, ou seja, outra condição de falta cujo valor da função objetivo seja igual ou muito próxima. A Figura 4.10 ilustra esta implementação, para encontrar condições simétricas. 


\section{$\overline{5 \text { - ALOCAÇÃO ÓTIMA DE MEDIDORES VISANDO A ESTIMAÇÃOO }}$ DE VARIAÇÕES DE TENSAO DE CURTA DURAÇÃO (VTCDS)}

Como já conceituada no Capítulo 1, a estimação de VTCDs consiste em determinar os valores da magnitude das tensões e duração do evento nas barras de interesse, a partir da ocorrência de uma falta elétrica. É uma condição para estimar esses valores que pelo menos um dos medidores instalados registre as VTCDs no instante da ocorrência desta falta. $\mathrm{Na}$ realidade, nem sempre as redes elétricas contam com um número suficiente de medidores para garantir um monitoramento adequado da rede toda, de maneira a permitir que todas as ocorrências (faltas elétricas) possam ser monitoradas.

Numa primeira tentativa para monitorar todas as barras, poderiam ser instalados medidores em cada uma das barras. Na prática, isto seria inviável devido aos custos ainda elevados dos equipamentos de medição. Além disso, este procedimento seria desnecessário, porque com um número menor de medidores instalados estrategicamente, pode-se monitorar toda a rede ou, em outras palavras, garantir a observabilidade da rede.

Neste sentido, calcular o número mínimo de medidores e onde eles devem ser instalados é o propósito do tema desenvolvido no presente capítulo.

Determinar a configuração ótima da instalação dos medidores com um número mínimo de medidores exige analisar explícita e/ou implicitamente todas as combinações possíveis de medidores para a rede analisada.

Solucionar este problema significaria resolver o seguinte sistema:

$$
\text { Minimizar } f=\sum_{i=1}^{n_{M}} V_{\text {Aloc }}(i)
$$

s.a.

$$
\begin{aligned}
& V_{\text {red }}(n) \neq 0 \rightarrow\left(n=1,2,3 \ldots \mathrm{n}^{\circ} \text { de defeitos }\right) \\
& V_{\text {Aloc }}(i) \in\{0,1\}
\end{aligned}
$$


onde:

$V_{\text {Aloc }}(i)$ é um vetor binário, que representa as posições (barras $i$ ) nas quais estão instalados $(=1)$ ou não $(=0)$ os medidores; $n_{M}$ é o número de barras; $V_{\text {red }}$ é um vetor, cujo tamanho é dado pelo número de defeitos (eventos $j$ ) considerados, em que cada posição $j$ representa o número de medidores sensibilizados naquele defeito.

A formulação 5.1 se enquadra num problema de otimização, podendo levar a uma explosão combinatória do número de configurações possíveis de alocação de medidores.

Foram desenvolvidos dois trabalhos para solucionar este problema de alocação ótima de medidores. Um deles tem como objetivo garantir o monitoramento para qualquer condição de curto-circuito, decorrente de uma falta em uma rede elétrica (GUERRA; KAGAN, 2010a). O segundo está relacionado com aquelas condições de curto-circuito que produzem "Simetria", tema apresentado no Capítulo 4. Dessa forma, a metodologia proposta tem como objetivo garantir o monitoramento de VTCDs em barras de interesse, minimizando o número de condições de curto-circuito que produzem simetria naquelas barras de interesse, onde se deseja estimar VTCDs (GUERRA; KAGAN, 2010b).

\subsection{Descrição da metodologia para solucionar o problema de Alocação Ótima de Medidores}

A metodologia desenvolvida para resolver o problema de Alocação Ótima de Medidores utiliza os conceitos da metaheurística "Busca em Vizinhança Variável" (em inglês Variable Neighborhood Search - VNS) (MLADENOVIC, 1995). A técnica consiste em fazer uma busca local combinada com uma busca global, utilizando estruturas de vizinhanças, o que permite intensificar a busca naquelas regiões promissoras. Através da mudança de estrutura de vizinhança, é possível sair dos ótimos locais, diversificando a busca. Os itens a seguir descrevem esta metodologia. 


\subsection{Busca em Vizinhança Variável}

A Busca em Vizinhança Variável (VNS), apresentada em Mladenovic (1995), é uma metaheurística baseada num princípio simples, qual seja mudar sistematicamente os parâmetros dentro de $\boldsymbol{k}$ estruturas de vizinhança.

As soluções que se encontram mediante um dos movimentos possíveis denominam-se vizinhas e constituem uma vizinhança. O conjunto de movimentos possíveis dá lugar a uma relação de vizinhança e estrutura de vizinhança. Para isso, a VNS utiliza uma combinação de buscas locais e globais. Nestes processos, as buscas não são informadas porque a solução atual (incumbente) não leva informação do passado e, por outro lado, o percurso pelo espaço de soluções é feito de forma parcial e aleatória, sendo esta estratégia a mais eficiente.

A construção de estruturas de vizinhança é fundamental no processo de busca, pois determina a qualidade do conjunto de movimentos aplicados, o qual enriquecerá a vizinhança. Com isso é possível realizar passos mais longos na aproximação ao ótimo procurado.

Existem outras questões relevantes para o êxito desse algoritmo, além da que se refere a articular às estruturas de vizinhança, tais como, a codificação utilizada, a avaliação da função objetivo e o critério de parada.

\subsubsection{Metodologia para solucionar o problema de Alocação Ótima de medidores utilizando VNS}

\subsubsection{Codificação}

É definido um vetor Alocação-Barra para indicar os pontos de instalação dos medidores (em quais barras devem ser instalados os medidores) como ilustra a Figura 5.1. Sua dimensão é dada pelo número de medidores a serem instalados. Para o problema, este pode ser considerado equivalente a um Vetor-Alocação $V_{\text {Aloc }}$, de igual tamanho ao número de barras, no qual, as barras em que estão instalados medidores são preenchidas por "l" e caso contrário " 0 ".

\begin{tabular}{|l|l|l|l|l|l|l|}
$\begin{array}{c}\text { Número de } \\
\text { barra }\end{array}$ & 15 & 20 & 85 & 102 & 50 & 17 \\
\hline
\end{tabular}

Figura 5.1 - Codificação de uma solução (Alocação-Barra) 


\subsubsection{Matriz de Observabilidade}

Para mapear o desempenho de um sistema elétrico frente às possíveis ocorrências de VTCDs no mesmo, é definida uma matriz com os valores das tensões em cada uma das barras, para cada defeito simulado (local de falta, impedância de defeito, tipo de falta). Essa matriz é definida considerando que cada linha representa uma condição de defeito, e que em cada coluna, são armazenados os valores das tensões de cada barra, como ilustra, a seguir a Tabela 5.1. Para preencher esta matriz, utiliza-se uma ferramenta computacional de análise de redes, em particular para estudo de curto-circuito, como a utilizada neste trabalho, denominada SINAP t\&d (SINAPSIS INOVAÇÃO EM ENERGIA).

Tabela 5.1 - Exemplo de Matriz de Tensão de Falta (p.u)

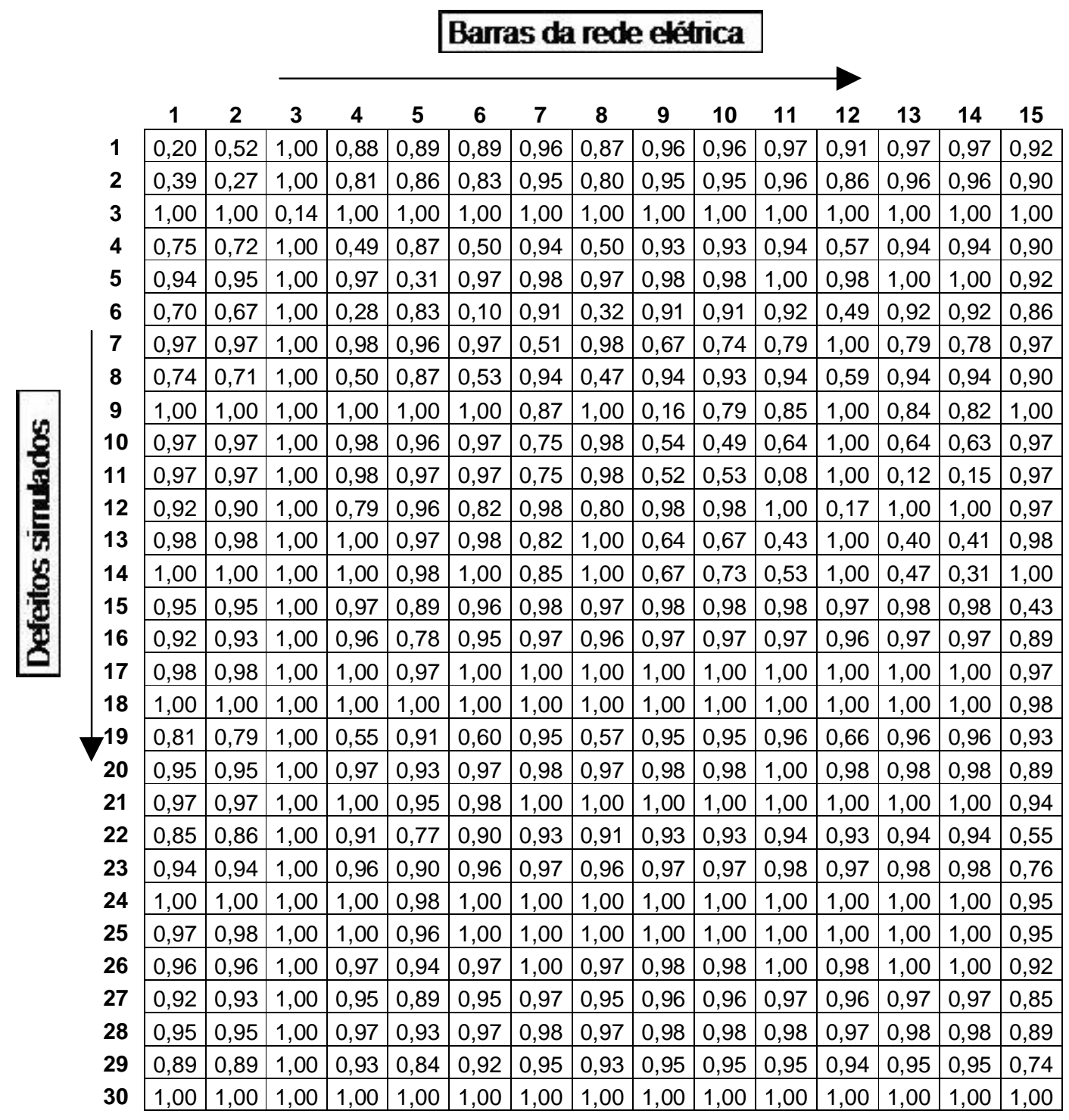


A fim de simplificar e tornar a avaliação mais objetiva, a partir dessa matriz definiu-se a Matriz de Observabilidade (MO), que é obtida fixando-se o valor da magnitude das tensões de falta a partir do qual se deseja que os medidores sejam sensibilizados.

Assim, para o caso de afundamentos de tensão, o nível de sensibilidade é $[0,1 \mathrm{pu}$; 0,9pu] (IEEE Std. 1346, 1998). As posições da matriz são preenchidas com “0”, caso o valor da tensão de falta seja superior a 0,9 e " 0 ”, caso contrario. Para elevações de tensão [1,1pu; $\infty$ ] (IEEE Std. 1346, 1998), as posições da matriz são preenchidas com '0', caso o valor da tensão de falta seja inferior a 1.1, e com "1", caso contrário. Um exemplo é ilustrado a seguir na Tabela 5.2.

Tabela 5.2 - Exemplo de Matriz de Observabilidade

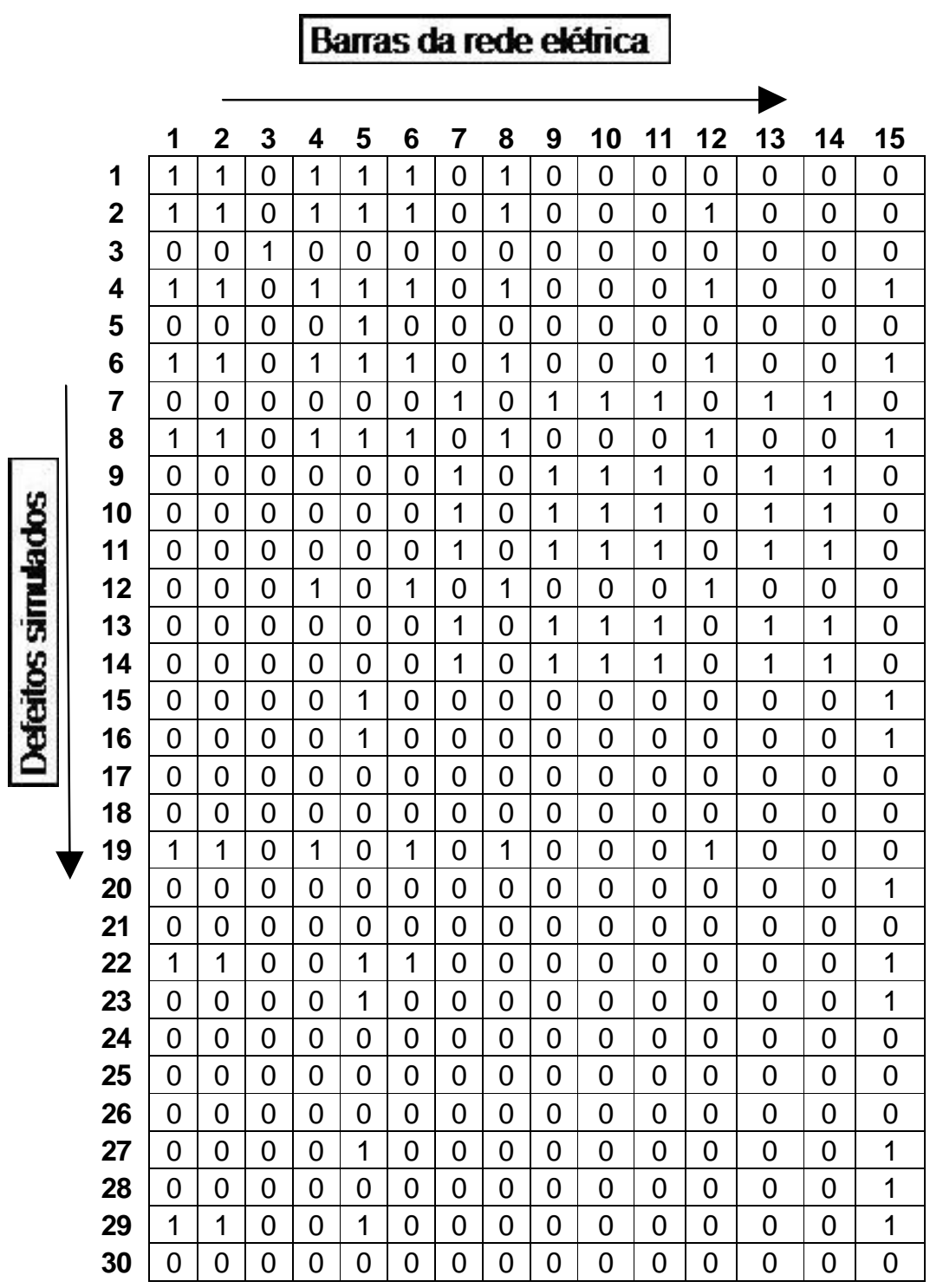




\subsubsection{Avaliação da Função Objetivo}

A função objetivo baseia-se no Vetor Redundância $V_{\operatorname{Re} d}$, mencionado anteriormente. Este vetor define o número de medidores sensibilizados para uma determinada condição de defeito. $\mathrm{O}$ vetor é determinado pela expressão 5.2 a seguir:

$$
V_{\mathrm{Re} d}=M O_{j i} x V_{\text {Aloc }}
$$

Como já mencionado no item 5.2.1.1, $V_{\text {Aloc }}$ é o Vetor-Alocação, que é preenchido com "1" se o medidor está alocado na barra correspondente ou " 0 " em caso contrário.

Assim, a expressão 5.2 resulta, que cada posição do $V_{\operatorname{Red}}$ contabiliza o número de medidores que, dispostos segundo $V_{\text {Aloc }}$, são capazes de monitorar uma condição de defeito correspondente à sua posição, isso é, cada posição de $V_{\operatorname{Re} d}$ indica o número de medidores sensibilizados para uma determinada condição de curto-circuito aplicada num determinado local do sistema.

À medida que se diminui a quantidade de valores iguais a zero no vetor $V_{\operatorname{Red}}$, tende-se a encontrar uma solução mais próxima daquela que garante o monitoramento da rede toda. Quando todos os elementos deste vetor forem não nulos (diferentes de “0”), garante-se o monitoramento de todas as condições de defeito consideradas, com certo grau de observabilidade.

Em algumas redes, pode-se encontrar mais de uma solução ótima, ou seja, o mesmo número de medidores, mas alocados em diferentes barras. Neste caso, o critério de avaliação é de forma a selecionar aquela alternativa na qual a somatória dos elementos $V_{\operatorname{Re} d}$ é o de maior redundância, ou seja, aquela solução que representa o máximo número de redundâncias nas situações de falta na rede analisada.

\subsubsection{Estruturas de Vizinhança}

No campo da otimização define-se como ótimo local da função a otimizar qualquer ponto $x$ para o qual existe uma vizinhança $N(x)$ tal que $x$ é ótimo nessa vizinhança. Então, o 
ótimo global pode ser obtido examinando todos os ótimos locais. Aquele que apresentar melhor valor da função objetivo resulta como ótimo global.

A partir deste conceito, pode-se definir uma vizinhança $N(x)$ para uma solução $x$ dentro de um espaço de soluções $S$, como uma função $N: S \rightarrow 2^{s}=\{x / y \subseteq S\}$ que associa a cada solução $x \in S$ um conjunto de configurações próximas de $x$ tal que cada $y$ será uma solução vizinha de $x$.

Considera-se uma solução que está mais próxima que outra, quando um menor número de barras de alocação dos medidores assume estados diferentes ao atual. Portanto, deve-se induzir uma distância $r$ definida sobre o espaço factível $S, r: S \times S \rightarrow R$, que permita avaliar a distância existente entre duas soluções quaisquer em $S$, como se ilustra na Figura 5.2. Nesta figura, $x$ representa uma solução ótima local e $y$ representa uma solução vizinha para uma determinada estrutura de vizinhança $N(x)$. O valor distância $r$ entre duas soluções aumenta, na medida em que incrementa $N(x)$ com relação a uma solução $x$. A partir dessa definição é possível obter as seguintes estruturas de vizinhança para uma solução qualquer de $x$ :

$$
N_{k}(x)=\left\{x^{\prime} \in S: r(x, y)=k\right\}, k=1, \ldots, n
$$

\section{Onde,}

$y$ é uma solução vizinha de $x$, e $r(x, y)=k$ é a estrutura de vizinhança.

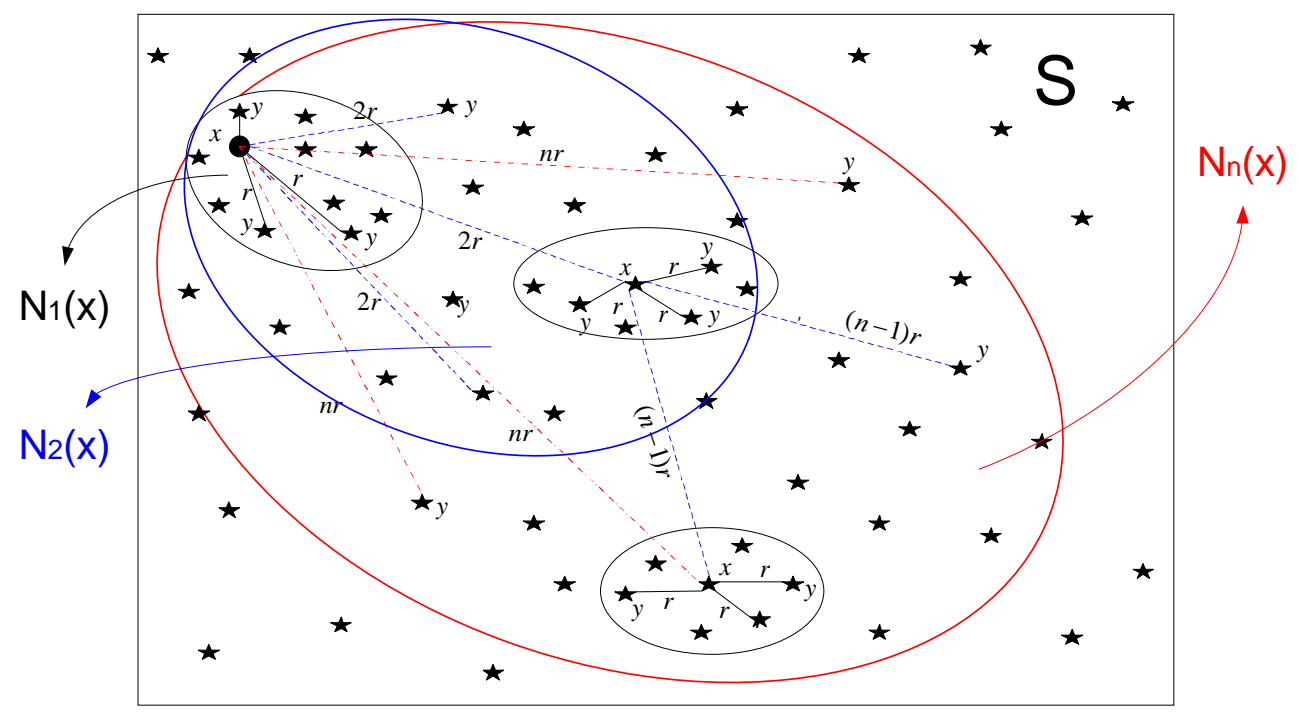

Figura 5.2 - Vizinhanças induzidas 
No problema de alocação ótima de medidores, considera-se um número definido de medidores instalados na rede. A mudança de posições (nas barras) dos medidores vai definir o universo do espaço de busca, ou seja, a combinação das barras onde possam estar alocados os medidores. Geralmente, esta combinação representa um valor muito elevado para redes de grande porte. Assim, será necessário estabelecer um critério de como gerar as estruturas de vizinhança e determinar a distância $r$.

\subsubsection{Geração de Estruturas de Vizinhança}

Em geral, as estruturas de vizinhança podem ser obtidas utilizando-se diferentes métricas ou distâncias induzidas no espaço de soluções factíveis $S$. Tais estruturas podem ser geradas utilizando as seguintes estratégias de seleção:

(i) seleção de heurísticas existentes,

(ii) alteração de parâmetros dos métodos existentes,

(iii) uso de k-mudança,

(iv) e divisão de vizinhança.

A estratégia adotada neste trabalho é através de $k$-mudança, como ilustra a Figura 5.3, que é a maneira mais fácil e natural de gerar estruturas de vizinhança. Ou seja, para uma configuração de $V_{\text {Aloc }}$, ao mudar um medidor da barra de alocação atual para outra se estará na primeira estrutura de vizinhança $N_{1}(x)$, ao mudar dois medidores, se estará na segunda estrutura de vizinhança $N_{2}(x)$ e assim sucessivamente.

Com esta estratégia de geração de vizinhanças, alguns problemas de otimização clássica foram resolvidos, como os problemas de localização $\rho$ - mediana e do Caixeiro Viajante (Traveling Salesman Problem - TSP) referenciados, respectivamente em Hansen; Mladenovic (1996) e Hansen; Mladenovic (1999).

\subsubsection{Ordenação da Vizinhança}

É obtida uma ordenação natural da vizinhança aumentando a distância $r$ existente entre a solução atual $x$ e outra configuração com solução $y$. Em outras palavras, quando se 
altera um maior número de medidores das suas respectivas barras alocadas, incrementa-se a distância $r$ e se estará mais distante da solução atual $x$. Este critério de ordenação faz com que o número de soluções vizinhas numa estrutura de vizinhança aumente ao passar à seguinte estrutura, ou seja, $\left|N_{1}(x)\right| \leq\left|N_{2}(x)\right| \leq, \ldots, \leq\left|N_{k \max }(x)\right|$.
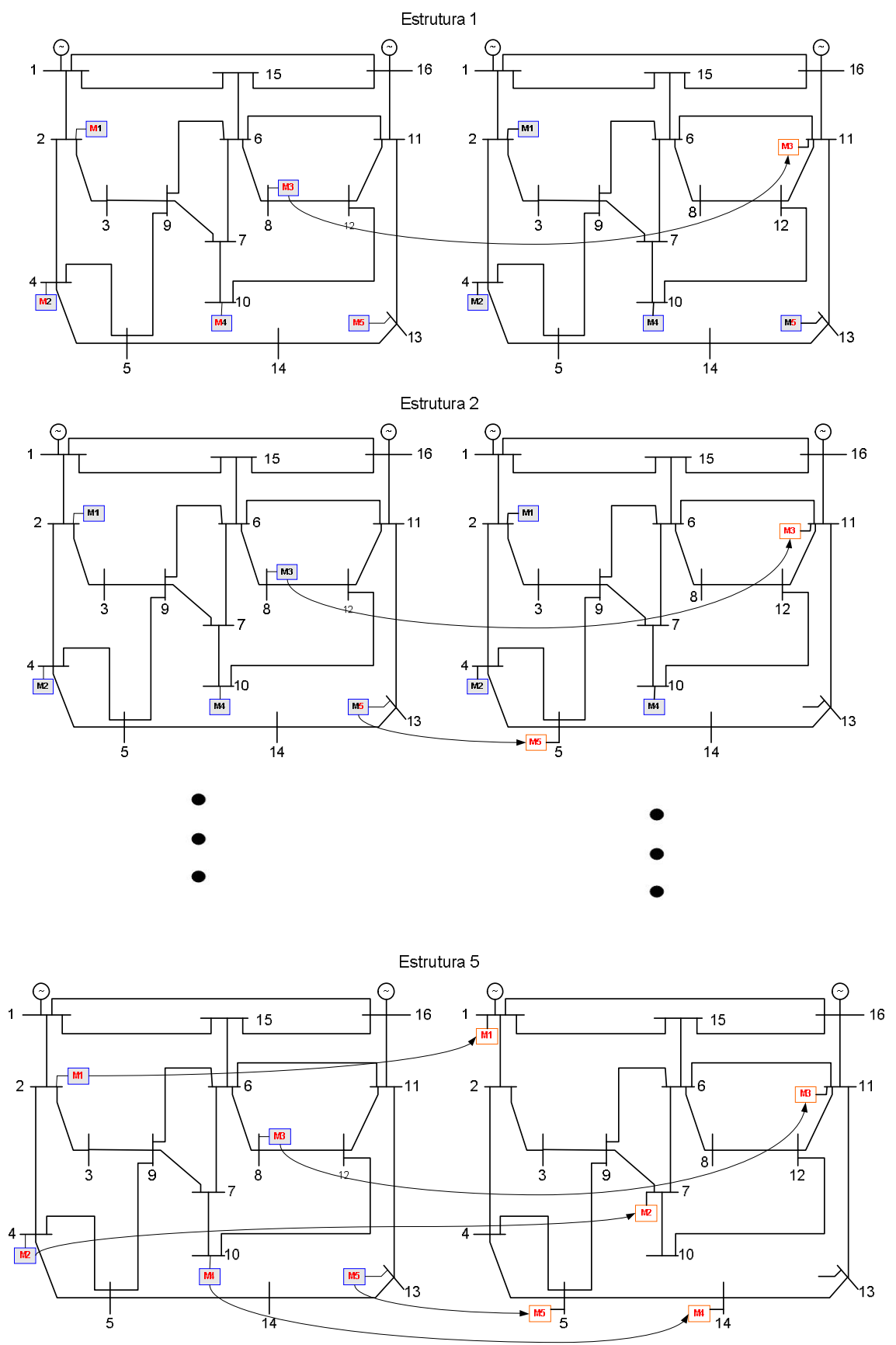

Figura 5.3 - Geração de estruturas de vizinhança através de k-mudança 


\subsubsection{Estratégias de Busca e Mudança da Vizinhança}

Utilizam-se estratégias com a finalidade de obter uma maior intensificação na busca nas regiões atrativas, onde se espera encontrar boas soluções. Este algoritmo também tem capacidade de explorar grande quantidade de zonas (diversificação), evitando que a busca se concentre numa determinada região do espaço de busca. Para isto, considera-se que a escolha seja realizada através de duas estratégias diferentes:

(i)

a busca Greedy ou a busca do melhor vizinho consiste em avaliar exaustivamente todas as configurações da vizinhança da solução atual, determinando qual das soluções avaliadas produz uma melhoria do valor da função objetivo atual;

(ii) a busca do primeiro melhor vizinho, que se caracteriza por avaliar as configurações da vizinhança até encontrar a primeira configuração vizinha, cujo valor da função objetivo seja melhor que a solução atual.

Por ter a metodologia duas fases importantes, a primeira ao se produzir a mudança de vizinhança (segundo nível de decisão) e, a segunda, quando se visitam diferentes soluções de uma mesma vizinhança (primeiro nível de decisão), foi escolhida a busca do primeiro melhor vizinho, que apresenta melhores resultados.

Para a mudança de estrutura de vizinhança, adotou-se percorrer de forma sistemática incrementando o valor de $k$, ou seja, começar com $k=1$ (forward), e quando não se pode melhorar em $N_{k}(x)$, faz-se $k=k+1$. Reinicia-se $k=1$ caso encontrar uma melhor solução, e considerar a solução encontrada como solução atual.

\subsubsection{Critério de Parada}

O critério de parada leva em conta certos indicadores de qualidade, tais como:

i. limite de número de iterações ou trocas,

ii. esforço computacional total,

iii. tempo computacional sem produzir uma melhora da melhor solução (incumbente). 
Para este problema, o indicador adotado foi o número de transições que não produz uma melhora entre a configuração visitada e a solução incumbente (melhor). Este critério se reflete no esforço computacional.

\subsubsection{Redução da Vizinhança}

Este aspecto é muito importante quando se trata de utilizar técnicas metaheurísticas, já que a maioria delas requer um esforço computacional considerável.

Um critério rudimentar para explorar a vizinhança de uma determinada estrutura seria de forma exaustiva, ou seja, percorrer o espaço de busca considerando uma ordenação implícita ou explícita de todas as posições (barras) dos medidores no espaço factível nessa estrutura $N_{k}(x)$. Esta estratégia de exploração poderá ser utilizada para redes de pequeno porte, sendo inviável para redes maiores.

Consequentemente será necessário aplicar estratégias de exploração nas estruturas de vizinhança, de modo a reduzir o número de soluções do espaço de busca. Pode-se fazer a exploração aplicando duas estratégias de exploração, quais sejam a parcial e a aleatória. A exploração parcial consiste em explorar somente parte do espaço de busca para obter uma visão de todo o espaço. Para isso, se estabelece critérios de probabilidade de como organizar a seleção dos medidores que participem da troca de posições (barras). A exploração aleatória consiste em explorar o espaço de soluções de forma dispersa, sempre que este espaço seja uniforme, ou seja, a distribuição de probabilidades de mudar as posições dos medidores seja equiprovável.

Para reduzir o espaço de busca, aplicou-se uma combinação parcial e aleatória para os diferentes níveis de estrutura de vizinhança.

\subsubsection{Implementação do Algoritmo VNS}

O processo de solução do algoritmo inicia-se com um número elevado (próximo ao número de barras) de medidores instalados aleatoriamente.

Uma vez definida a configuração inicial e todas as variáveis necessárias para o funcionamento do algoritmo processa-se uma busca local, ou seja, devem-se gerar os vizinhos 
desta configuração dentro da sua estrutura de vizinhança, realocando aleatoriamente um medidor em outra barra.

Na primeira estrutura de vizinhança, muda-se de posição um medidor e avalia-se a função objetivo. Este processo é feito para todos os medidores, o que representa no início do algoritmo uma porcentagem mínima das possibilidades. É determinado $V_{\operatorname{Re} d}$ para cada configuração visitada, que é comparado com $V_{\text {Red }}$ da solução atual. Se a configuração visitada é melhor que a solução atual, ou seja, se o número de zeros é maior no Vetor-Redundância $\left(V_{\operatorname{Re} d}\right)$ atual, esta configuração será a nova solução atual e a busca será reiniciada $\operatorname{com} k=1$. A outra possibilidade acontece quando não se encontra uma melhor solução. Então se passará à seguinte estrutura de vizinhança.

A ordem de transição das estruturas, como já foi mencionada, será sistemática com $k=k+1$. Assim, $k$ medidores são mudados aleatoriamente das suas respectivas barras. Caso seja encontrada uma melhora no processo de busca, volta-se à primeira estrutura de vizinhança $k=1$, reiniciando-se o processo de busca a partir de aquele ponto (melhor solução encontrada); do contrário, se o processo chegar a Nmax, passa-se à seguinte estrutura de vizinhança.

Quando, no processo de otimização se encontra $V_{\operatorname{Re} d}$ com valores não nulos, o algoritmo é reiniciado com uma unidade de medidores a menos, até encontrar uma configuração com um número mínimo de medidores e máxima redundância $V_{\operatorname{Re} d}$. A Figura 5.4 ilustra o algoritmo, sendo que: a variável $k$ representa estrutura de vizinhança (para o problema considerou-se kmax $=3$ ); Nmed é o número de medidores considerados; n é o número de soluções visitadas dentro de determinada estrutura de vizinhança (para o problema considerou-se $\mathrm{N}_{\max }=30 \%$ do $\mathrm{n}^{\circ}$ de barras). 
Capítulo 5 - Alocação Ótima de Medidores visando a Estimação de Variações de Tensão

66 de Curta Duração (VTCDs)

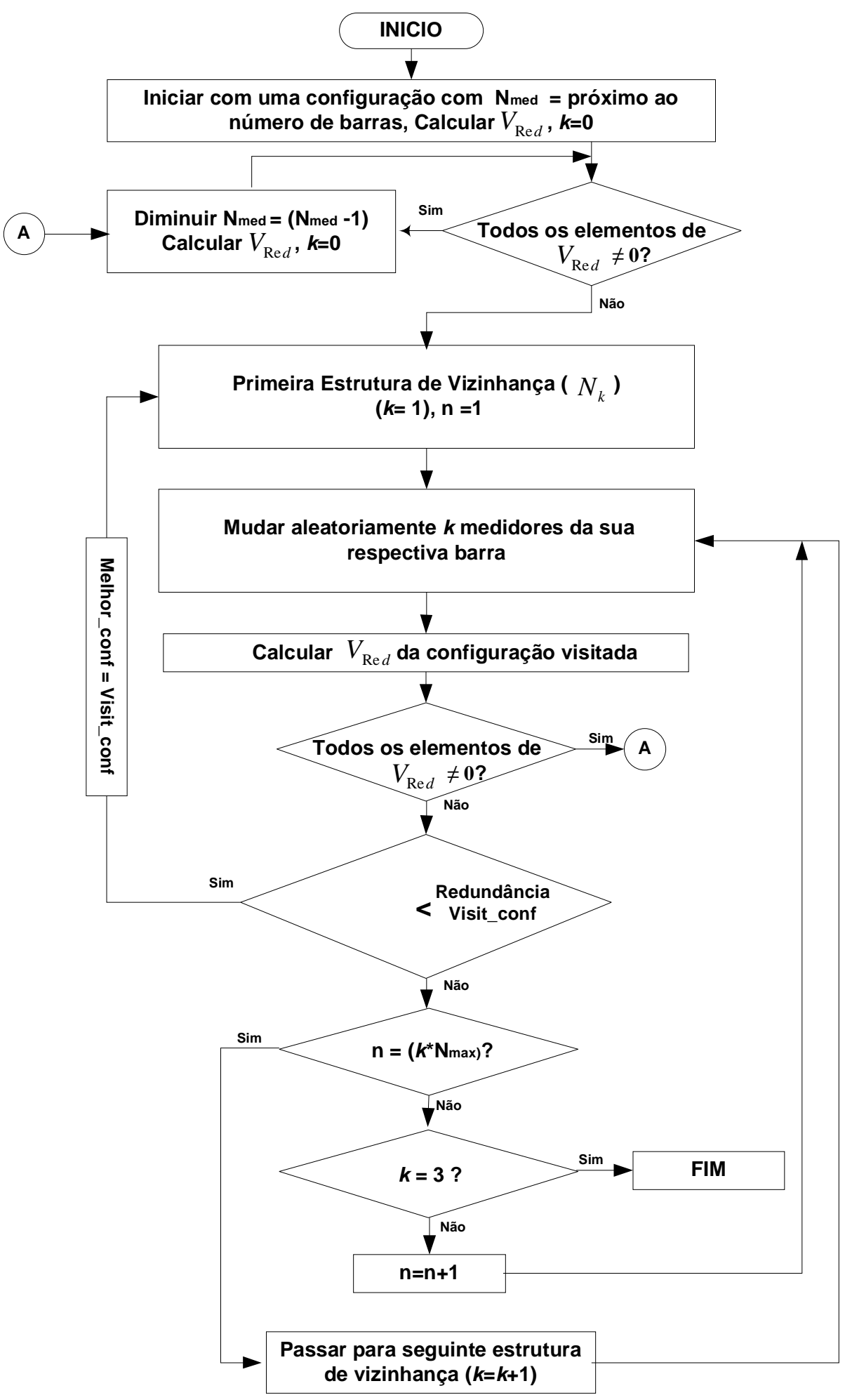

Figura 5.4 - Algoritmo para alocação de medidores (VNS) 


\subsection{Descrição da metodologia para resolver o problema de Alocação Ótima de Medidores considerando Simetria}

A solução do problema de alocação ótima de medidores, descrita no item 5.1, que utiliza a VNS, objetiva o monitoramento de condições de curto-circuito (defeitos) préestabelecidas. Observou-se no desenvolvimento deste trabalho a existência de condições de simetria, descrita no item 4.11, onde uma condição de curto-circuito pode produzir valores de tensões quase iguais ou muito próximas em algumas barras (aquelas onde estão instalados os medidores) e não necessariamente produzem valores quase iguais ou muito próximos em outras barras (aquelas que se pretende monitorar) do sistema. A existência desta característica pode trazer incerteza na estimação de VTCDs, ou seja, a estimação de VTCDs naquelas barras de monitoração podem conter erros grosseiros. Esta característica levou a desenvolver a metodologia proposta deste trabalho (Estratégias Evolutivas) para solucionar o problema de alocação ótima de medidores considerando condições de simetria.

Previamente, é necessário fazer algumas considerações ao respeito da estimação de VTCDs e das incertezas, sendo as seguintes:

- São chamados pontos de medição aquelas barras onde estão instalados os medidores;

- São chamados pontos de controle aquelas barras onde é necessário avaliar as VTCDs, por medição ou estimação;

- São chamados pontos de estimação aquelas barras onde é necessário avaliar as VTCDs por estimação, ou seja, não se têm instalados medidores;

- Se na ocorrência de algum defeito, o valor de tensão em um local de controle é menor que o valor limite de afundamento de tensão (0.9 pu), as características do defeito são consideradas para alocação ótima de medidores (item 5.3.1.2);

- $\quad \mathrm{Na}$ ocorrência de algum defeito que produz VTCDs em algum ponto de controle, pelo menos um dos medidores instalados deve registrar (observar) a falta (item 5.3.1.3);

- Deve-se verificar condições de simetria nos pontos de controle, examinando os valores calculados da tensão como consequência de algum defeito, considerando um valor de desvio pré-determinado (por exemplo, $5 \%$ ); 


\subsubsection{Metodologia para solucionar o problema de Alocação Ótima de medidores visando VTCDs utilizando EEs}

\subsubsection{Construção da População Inicial}

A população inicial representa um conjunto de soluções (indivíduos) para resolver o problema de alocação de medidores, que são representados por uma codificação descrita no item 5.2.1.1.

O critério adotado para construir a população inicial é de forma aleatória, com a finalidade de dotar ao algoritmo de diversidade no processo de otimização, ou seja, começar de forma dispersa.

\subsubsection{Matriz de Observabilidade e Matriz de Simetria}

De igual forma que a metodologia da $V N S$ desenvolvida no item 5.2. é definido o mesmo conceito de Matriz Observabilidade $M O$, que representa o desempenho do sistema de potência em avaliação, considerando os valores de tensões de falta em cada uma das barras de controle. A Tabela 5.3 ilustra um exemplo de $M O$, na qual se pretende monitorar 5 barras de controle. 
Tabela 5.3 - Exemplo de Matriz Observabilidade $M O$

\begin{tabular}{|c|c|c|c|c|c|}
\hline & \multicolumn{5}{|c|}{ Barras Monitoradas - VTCDs } \\
\hline & bar1 & bar2 & bar3 & bar4 & bar5 \\
\hline 1 & 0,956 & 0,615 & 0,927 & 0,978 & 0,950 \\
\hline 2 & 0,913 & 0,843 & 0,922 & 0,927 & 0,944 \\
\hline 3 & 0,913 & 0,848 & 0,979 & 0,954 & 0,993 \\
\hline 4 & 0,980 & 0,667 & 0,945 & 0,993 & 0,950 \\
\hline 5 & 0,915 & 0,670 & 0,997 & 0,931 & 0,925 \\
\hline 6 & 0,974 & 0,631 & 0,979 & 0,913 & 0,976 \\
\hline 7 & 0,948 & 0,607 & 0,903 & 0,936 & 0,991 \\
\hline 8 & 0,909 & 0,748 & 0,944 & 0,930 & 0,972 \\
\hline 9 & 0,915 & 0,819 & 0,944 & 0,986 & 0,958 \\
\hline 10 & 0,910 & 0,665 & 0,918 & 0,960 & 0,935 \\
\hline 11 & 0,970 & 0,768 & 0,925 & 0,939 & 0,975 \\
\hline 12 & 0,938 & 0,838 & 0,980 & 0,712 & 0,938 \\
\hline 13 & 0,906 & 0,815 & 0,965 & 0,975 & 0,908 \\
\hline 14 & 0,974 & 0,820 & 1,000 & 0,988 & 0,944 \\
\hline 15 & 0,929 & 0,661 & 0,979 & 0,962 & 0,907 \\
\hline 16 & 0,938 & 0,757 & 0,947 & 0,905 & 0,923 \\
\hline 17 & 0,908 & 0,751 & 0,991 & 0,942 & 0,998 \\
\hline 18 & 0,936 & 0,611 & 0,953 & 0,947 & 0,995 \\
\hline 19 & 0,985 & 0,616 & 0,983 & 0,963 & 0,965 \\
\hline 20 & 0,929 & 0,684 & 0,973 & 0,927 & 0,921 \\
\hline 21 & 0,893 & 0,984 & 0,920 & 0,910 & 0,922 \\
\hline 22 & 0,795 & 0,996 & 0,938 & 0,991 & 0,904 \\
\hline 23 & 0,694 & 0,997 & 0,959 & 0,993 & 0,995 \\
\hline 24 & 0,742 & 0,996 & 0,952 & 0,916 & 0,973 \\
\hline 25 & 0,860 & \begin{tabular}{|l|}
0,974 \\
\end{tabular} & 0,969 & 0,914 & 0,922 \\
\hline
\end{tabular}

\begin{tabular}{|c|c|c|c|c|c|}
\hline & \multicolumn{5}{|c|}{ Barras Monitoradas - VTCDs } \\
\hline & bar1 & bar2 & bar3 & bar4 & bar5 \\
\hline 26 & 0,892 & 0,902 & 0,942 & 0,986 & 0,961 \\
\hline 27 & 0,768 & 0,938 & 0,945 & 0,940 & 0,911 \\
\hline 28 & 0,857 & 0,972 & 0,991 & 0,906 & 0,941 \\
\hline 29 & 0,604 & 0,910 & 0,970 & 0,933 & 0,923 \\
\hline 30 & 0,691 & 0,912 & 0,949 & 0,930 & 0,926 \\
\hline 31 & 0,692 & 0,974 & 0,928 & 0,906 & 0,995 \\
\hline 32 & 0,743 & 0,928 & 0,923 & 0,905 & 0,993 \\
\hline 33 & 0,700 & 0,932 & 0,916 & 0,977 & 0,975 \\
\hline 34 & 0,672 & 0,960 & 0,971 & 0,908 & 0,933 \\
\hline 35 & 0,763 & 0,951 & 0,982 & 0,966 & 0,977 \\
\hline 36 & 0,820 & 0,902 & 0,984 & 0,915 & 1,000 \\
\hline 37 & 0,743 & 0,961 & 0,952 & 0,994 & 0,817 \\
\hline 38 & 0,818 & 0,995 & 0,945 & 0,979 & 0,618 \\
\hline 39 & 0,722 & 0,915 & 0,985 & 0,983 & 0,874 \\
\hline 40 & 0,774 & 0,967 & 0,922 & 0,933 & 0,810 \\
\hline 41 & 0,908 & 0,906 & 0,601 & 0,719 & 0,746 \\
\hline 42 & 0,934 & 0,940 & 0,808 & 0,700 & 0,742 \\
\hline 43 & 0,912 & 0,946 & 0,696 & 0,697 & 0,786 \\
\hline 44 & 0,987 & 0,968 & 0,805 & 0,689 & 0,615 \\
\hline 45 & 0,910 & 0,990 & 0,692 & 0,933 & 0,870 \\
\hline 46 & 0,934 & 0,942 & 0,602 & 0,907 & 0,924 \\
\hline 47 & 0,917 & 0,936 & 0,693 & 0,962 & 0,933 \\
\hline 48 & 0,906 & 0,933 & 0,641 & 0,948 & 0,973 \\
\hline 49 & 0,961 & 0,951 & 0,621 & 0,956 & 0,903 \\
\hline 50 & 0,941 & 0,909 & 0,712 & 0,955 & 0,989 \\
\hline
\end{tabular}

Também é definida a Matriz Simetria $M S$ de igual tamanho ao $M O$, que agrupa todas as condições de simetria nos pontos de controle. Esta matriz representa o grau de incerteza para a estimação de VTCDs, ou seja, quanto mais condições de simetria houver, mais forte será o seu grau. Como exemplo, apresenta-se a Tabela 5.4, construída com desvio de 0,01 pu. (5\% do valor nominal). Nesta tabela, todos os pontos de controle possuem condições de simetria. O ponto de controle bar 1 apresenta 5 condições de simetria 1, 2, 3, 4 e 5; das quais, os defeitos nas linhas 23, 30 e 31 pertencem à condição de simetria 1, os defeitos nas linhas 24 e 32 à condição 2, os defeitos nas linhas 27 e 35 à condição 3, os defeitos nas linhas 36 e 38 à condição 4 e os defeitos nas linhas 21 e 26 à condição 5. Isto pode ser conferido na Tabela $5.3(M O)$. 
Tabela 5.4 - Exemplo de Matriz Simetria $M O$

\begin{tabular}{|c|c|c|c|c|c|c|}
\hline & \multicolumn{5}{|c|}{$\begin{array}{c}\text { Barras Monitoradas - } \\
\text { VTCDs }\end{array}$} \\
\hline & & bar1 & bar2 & bar3 & bar4 & bar5 \\
\hline \multirow{25}{*}{ 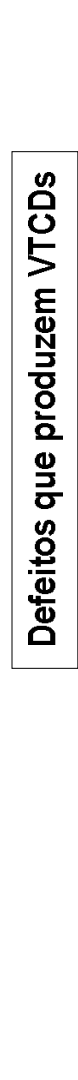 } & 1 & 0 & 1 & 0 & 0 & 0 \\
\hline & 2 & 0 & 5 & 0 & 0 & 0 \\
\hline & 3 & 0 & 5 & 0 & 0 & 0 \\
\hline & 4 & 0 & 2 & 0 & 0 & 0 \\
\hline & 5 & 0 & 2 & 0 & 0 & 0 \\
\hline & 6 & 0 & 0 & 0 & 0 & 0 \\
\hline & 7 & 0 & 0 & 0 & 0 & 0 \\
\hline & 8 & 0 & 0 & 0 & 0 & 0 \\
\hline & 9 & 0 & 4 & 0 & 0 & 0 \\
\hline & 10 & 0 & 2 & 0 & 0 & 0 \\
\hline & 11 & 0 & 0 & 0 & 0 & 0 \\
\hline & 12 & 0 & 0 & 0 & 2 & 0 \\
\hline & 13 & 0 & 4 & 0 & 0 & 0 \\
\hline & 14 & 0 & 0 & 0 & 0 & 0 \\
\hline & 15 & 0 & 2 & 0 & 0 & 0 \\
\hline & 16 & 0 & 3 & 0 & 0 & 0 \\
\hline & 17 & 0 & 3 & 0 & 0 & 0 \\
\hline & 18 & 0 & 1 & 0 & 0 & 0 \\
\hline & 19 & 0 & 1 & 0 & 0 & 0 \\
\hline & 20 & 0 & 0 & 0 & 0 & 0 \\
\hline & 21 & 5 & 0 & 0 & 0 & 0 \\
\hline & 22 & 0 & 0 & 0 & 0 & 0 \\
\hline & 23 & 1 & 0 & 0 & 0 & 0 \\
\hline & 24 & 2 & 0 & 0 & 0 & 0 \\
\hline & 25 & 0 & 0 & 0 & 0 & 0 \\
\hline
\end{tabular}

\begin{tabular}{|c|c|c|c|c|c|c|}
\hline & \multicolumn{5}{|c|}{$\begin{array}{c}\text { Barras Monitoradas - } \\
\text { VTCDs }\end{array}$} \\
\hline & & bar1 & bar2 & bar3 & bar4 & bar5 \\
\hline \multirow{25}{*}{ 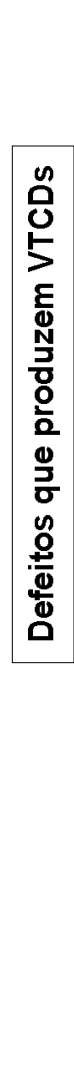 } & 26 & 5 & 0 & 0 & 0 & 0 \\
\hline & 27 & 3 & 0 & 0 & 0 & 0 \\
\hline & 28 & 0 & 0 & 0 & 0 & 0 \\
\hline & 29 & 0 & 0 & 0 & 0 & 0 \\
\hline & 30 & 1 & 0 & 0 & 0 & 0 \\
\hline & 31 & 1 & 0 & 0 & 0 & 0 \\
\hline & 32 & 2 & 0 & 0 & 0 & 0 \\
\hline & 33 & 0 & 0 & 0 & 0 & 0 \\
\hline & 34 & 0 & 0 & 0 & 0 & 0 \\
\hline & 35 & 3 & 0 & 0 & 0 & 0 \\
\hline & 36 & 4 & 0 & 0 & 0 & 0 \\
\hline & 37 & 2 & 0 & 0 & 0 & 3 \\
\hline & 38 & 4 & 0 & 0 & 0 & 1 \\
\hline & 39 & 0 & 0 & 0 & 0 & 0 \\
\hline & 40 & 0 & 0 & 0 & 0 & 3 \\
\hline & 41 & 0 & 0 & 1 & 2 & 2 \\
\hline & 42 & 0 & 0 & 3 & 1 & 2 \\
\hline & 43 & 0 & 0 & 2 & 1 & 0 \\
\hline & 44 & 0 & 0 & 3 & 0 & 1 \\
\hline & 45 & 0 & 0 & 2 & 0 & 0 \\
\hline & 46 & 0 & 0 & 1 & 0 & 0 \\
\hline & 47 & 0 & 0 & 2 & 0 & 0 \\
\hline & 48 & 0 & 0 & 0 & 0 & 0 \\
\hline & 49 & 0 & 0 & 0 & 0 & 0 \\
\hline & 50 & 0 & 0 & 0 & 0 & 0 \\
\hline
\end{tabular}

\subsubsection{Avaliação da Função Objetivo}

É definido o mesmo vetor redundância $V_{\text {Red }}$ para avaliar parte da função objetivo, desenvolvido no item 5.2.1.3. Este vetor define o número de medidores sensibilizados para uma determinada condição de defeito.

Por outro lado, é possível que, para uma determinada configuração de medidores $V_{\text {Aloc }}$, existam condições de falta que produzem valores de tensão quase iguais ou muito próximos nos pontos de controle. Para avaliar esta característica, é definida a seguinte expressão:

$$
\text { Minimizar_ } F O=\left(F_{1} * N_{\text {defmedição }}\right)+\left(F_{2} * N_{\text {defcontrol e }}\right)
$$


onde $N_{\text {defmedição }}, N_{\text {defcontrole }}$ são os números das condições de faltas que produzem valores de tensão quase iguais ou muito próximos (simetria) nos pontos de medição e nos pontos de controle respectivamente. $F_{1}$ e $F_{2}$ são fatores de peso dos critérios de simetria de pontos de medição e pontos de estimação. Para o problema $F_{2}>F_{1}$, ou seja, o principal objetivo é monitorar as VTCDs nos pontos de controle.

À medida que se diminui a quantidade de valores iguais a zero no vetor $V_{\operatorname{Re} d}$, tende-se a encontrar uma solução mais próxima daquela que garante o monitoramento de todas as condições de curto-circuito. Quando todos os elementos deste vetor são não nulos, a solução garante o monitoramento de todas as condições de curto-circuito que causam VTCDs nos pontos de controle, e se avaliará a expressão 5.3. Caso contrário, não será considerada a equação 5.3, até que seja encontrada uma condição que garanta o monitoramento de todas as condições de curto-circuito que produzem VTCDs.

\subsubsection{Recombinação}

Por ser este um operador secundário, é definida previamente uma taxa de recombinação baixa. Optou-se por utilizar uma recombinação intermediária local modificada, de modo, a sortear um número binário [0-1] para $a$, e aplicam-se as equações 3.7 e 3.8 para cada posição dos atributos e desvios nos indivíduos selecionados. Desta forma, a informação genética do indivíduo gerado (filho) é herdada dos indivíduos pais, como ilustra a Figura 5.5.

\begin{tabular}{l|l|l|l|l|l|l|}
\hline Individuo 1 & 15 & 17 & 20 & 50 & 73 & 88 \\
\hline Individuo 2 & 18 & 29 & 44 & 57 & 80 & 87 \\
\hline
\end{tabular}

(a) pais

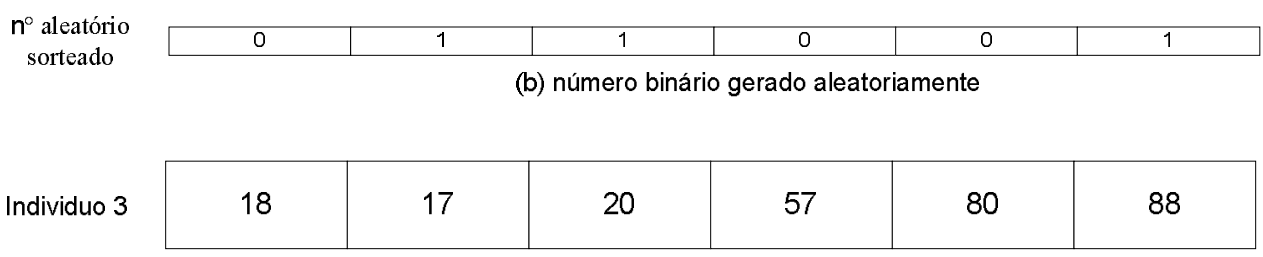

(c) filho

Figura 5.5 - Operador Recombinação - Alocação ótima de medidores 


\subsubsection{Mutação}

Como já mencionado no Capítulo 3, a mutação representa o principal operador da evolução. A sua correta aplicação e respectivas estratégias são imprescindíveis para o sucesso do algoritmo. O número de mutações é definido de forma a controlar a velocidade de evolução em cada geração. Sendo assim, cada indivíduo gera " $m$ ” indivíduos.

A equação 3.9 é utilizada para aplicar este operador, onde o valor do desvio padrão $\sigma$ será fixado para cada indivíduo. No processo de evolução, estes vão se adaptando, aumentando ou diminuindo, utilizando o conceito de auto-adaptação descrito no item 3.2.5.1.

De forma similar à estratégia apresentada no Capítulo 4, para resolver o problema de Estimação de VTCDs é construída uma lista de barras ordenadas para cada posição do medidor (atributo), com intuito de guiar a busca no espaço de soluções. Como exemplo ilustrativo, na Tabela 5.5 é construída uma lista ordenada por camadas para a barra 8 da rede mostrada na Figura 4.2. Esta lista fornece uma visão de distâncias entre uma barra (local de instalação do medidor) e as demais barras.

Tabela 5.5 - Exemplo de lista ordenada - Mutação

\begin{tabular}{|c|c|}
\hline Barra & Camada \\
\hline 8 & \\
\hline 6 & 1 \\
\hline 12 & 1 \\
\hline 9 & 2 \\
\hline 11 & 2 \\
\hline 15 & 2 \\
\hline 7 & 2 \\
\hline 10 & 2 \\
\hline 3 & 3 \\
\hline 5 & 3 \\
\hline 16 & 3 \\
\hline 1 & 3 \\
\hline 13 & 3 \\
\hline 2 & 4 \\
\hline 4 & 4 \\
\hline 14 & 4 \\
\hline
\end{tabular}




\subsubsection{Seleção}

Este processo tem por objetivo copiar indivíduos de uma geração para outra, de modo que aqueles indivíduos mais adaptados tenham maior probabilidade de se reproduzirem nas gerações futuras.

O método escolhido foi baseado na roleta descrito em (KAGAN et al., 2009b). Assim, ao girar a roleta, a probabilidade de cada indivíduo ser selecionado será diretamente proporcional à função objetivo. Este procedimento garante que aqueles indivíduos mais ajustados tenham maior probabilidade de serem reproduzidos na geração posterior.

\subsubsection{Critério de Parada}

O critério de parada utilizado foi o número de gerações que não produz melhora do indivíduo mais adaptado (função de aptidão). Este critério se reflete no esforço computacional.

\subsubsection{Implementação do Algoritmo EEs}

Detalha-se a seguir o processo de solução do algoritmo:

Passo 1: Constrói-se a Matriz de Observabilidade (MO) e a Matriz Simetria (MS) utilizando uma ferramenta computacional de cálculo de curto-circuito, na qual são calculadas as tensões nos pontos de controle e de medição para cada condição de falta. Nesta etapa são definidas as barras a serem monitoradas (pontos de controle). Só aquelas condições de curtocircuito que geram VTCDs nessas barras serão consideradas nas matrizes $M O$ e $M S$. Este processo é realizado uma única vez.

Passo 2: O algoritmo começa com um número elevado de medidores, próximo ao número de barras. Constrói-se a população inicial de indivíduos de forma aleatória, em seguida, avalia-se a função aptidão de cada indivíduo.

Passo 3: Uma vez construída a população, ordena-se de acordo com a sua função de aptidão em ordem crescente. Em seguida são aplicados os operadores de Mutação e Recombinação descritos nos itens 5.3.1.5 e 5.3.1.6 respectivamente. Uma vez gerados estes indivíduos, é aplicado o operador de Seleção. 
Passo 4: Quando é encontrado $V_{\text {Red }}$ com valores não nulos (diferentes de zero), se garante a Observabilidade dos defeitos considerados em $M O$. Cada vez que isto acontece, deve-se avaliar a função objetivo dada pela equação 5.3.

Depois de encontrar um $V_{\text {Aloc }}$ que garante a observabilidade, deve-se reduzir o número de medidores, até encontrar uma configuração $V_{A l o c}$ (com mínimo número de medidores) que garanta a observabilidade da $M O$. Finalmente, considera-se que o algoritmo converge (critério de parada) à solução procurada, quando a melhor solução da população atual não melhorar durante certo número de gerações pré-definidas. O fluxograma é ilustrado na Figura 5.6 


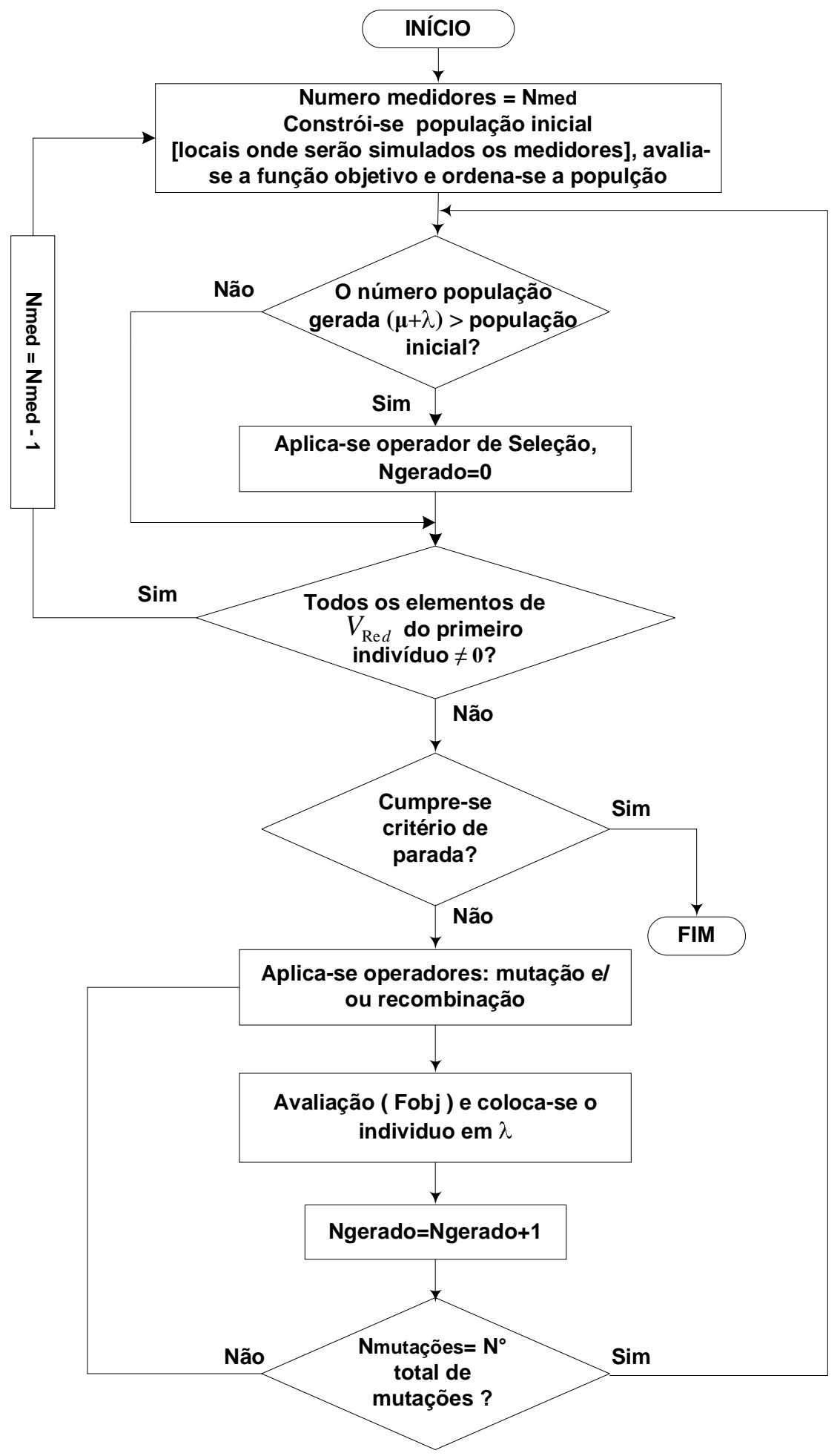

Figura 5.6 - Algoritmo para alocação de medidores (EEs) 


\section{6 - RESULTADOS}

A primeira parte deste capítulo visa apresentar os resultados obtidos na aplicação da metodologia adotada para resolver o problema de alocação ótima de medidores, com intuito de utilizá-los na aplicação do estimador de VTCDs em pontos específicos dos sistemas elétricos.

Na segunda parte do desenvolvimento do capítulo, apresentam-se os resultados e a análise da metodologia Estratégias Evolutivas para resolver o problema de estimação de VTCDs no instante da ocorrência (falta elétrica). Para esta tarefa, foi utilizada uma plataforma computacional, chamada Sinap t\&d, que realiza simulações e análises de sistemas elétricos de potência.

\subsection{Resultados da Metodologia de Alocação Ótima de Medidores}

Com a finalidade de avaliar as metodologias desenvolvidas no Capítulo 5, aplicam-se inicialmente os modelos de alocação ótima de medidores a um sistema de 30 barras do IEEE, averiguando-se a viabilidade das metodologias. Em seguida, foram testadas duas redes de maior porte, uma de 57 e outra de 118 barras do IEEE, para posterior aplicação no estimador de VTCDs em sistemas elétricos.

\subsubsection{Sistema de 30 barras}

As metodologias desenvolvidas no Capítulo 5 foram aplicadas, inicialmente, numa rede de 30 barras IEEE, ilustrada na Figura 6.1, com intuito de avaliar a viabilidade da aplicação dos algoritmos propostos.

Na primeira metodologia utilizada, denominada "Alocação Ótima de Medidores utilizando Busca em Vizinhança Variável", foram consideradas 720 condições de curtocircuito (monofásicas com valor de impedância de defeito nulo) e 20 medidores como solução inicial. A partir desta solução, o algoritmo encontrou 6 medidores como número mínimo para 
garantir o monitoramento da rede. Uma possível configuração da alocação sugeriu a instalação de equipamentos nas barras: bar4, bar5, bar11, bar12, bar13 e bar29 como ilustrado na Figura 6.1 (elipses azuis). Os resultados foram encontrados na segunda estrutura de vizinhança.

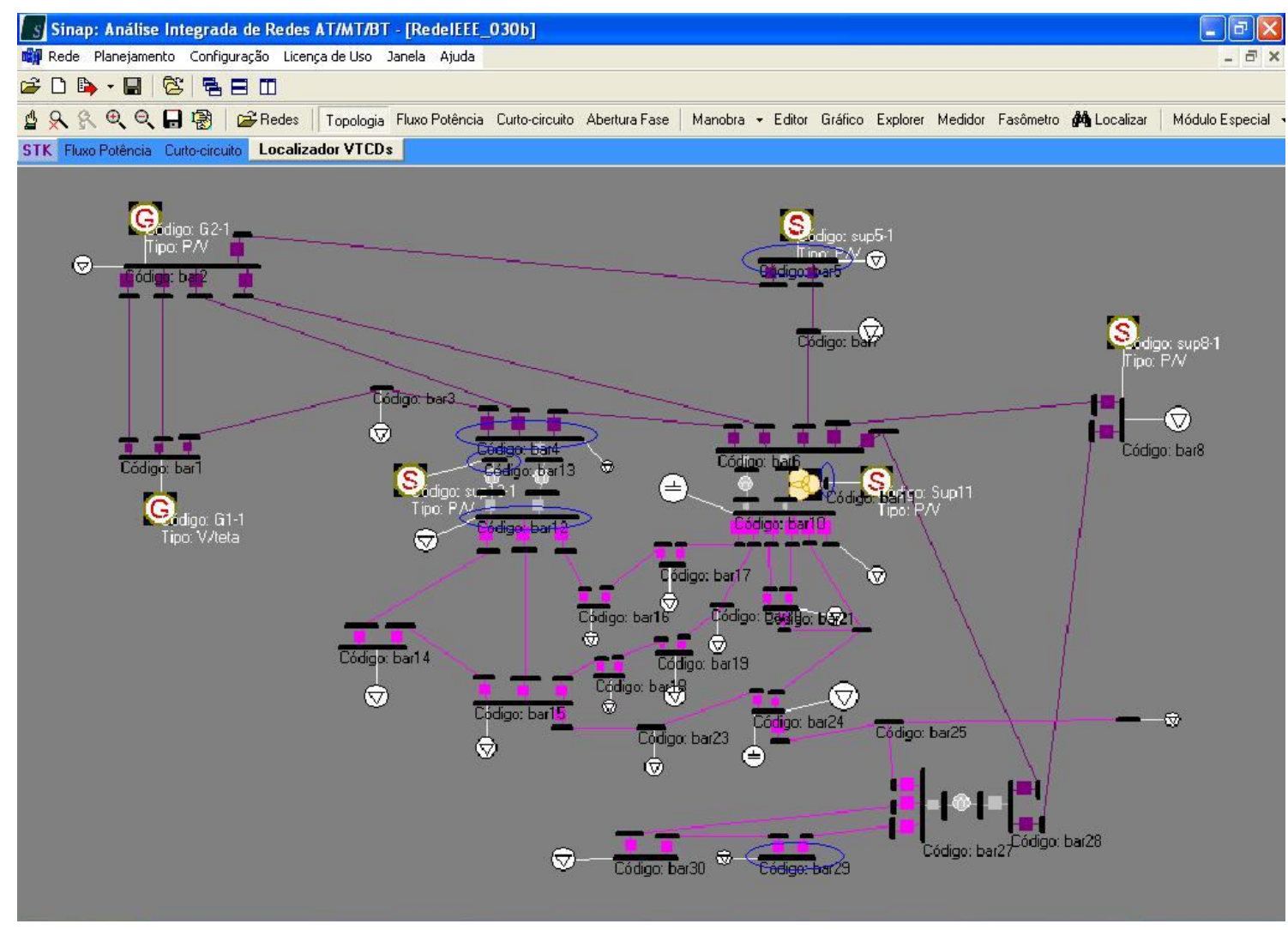

Figura 6.1 - Configuração ótima de medidores (6 medidores) - 30 barras

Num segundo teste, considerou-se o monitoramento restrito a certas condições de curto-circuito (faltas monofásicas com impedância de falta nula), cujos resultados ilustram-se na Tabela 6.1. Depreende-se desta tabela que o algoritmo encontrou um número mínimo de medidores igual a 3 em diferentes configurações, sendo a primeira delas a melhor, pois satisfaz a hipótese: "O monitoramento é melhor, quanto maior for o número de medidores sensibilizados para monitorar os locais de falta”. Nesse sentido, na primeira configuração, 521 locais de falta são monitorados por um só medidor, 105 locais de falta são monitorados por 2 medidores e 94 são monitorados por 3 medidores. Nos outros casos (soluções), nota-se um número menor de locais de falta com sensibilização nos 3 medidores. 
Para visualizar os resultados, a Figura 6.2 ilustra as barras correspondentes às configurações da tabela 6.1 , sendo a primeira solução representada por elipses da cor vermelha, a segunda solução por elipses da cor azul e terceira solução por elipses de cor preta.

Tabela 6.1 - Resultados Alocação Ótima de Medidores utilizando VNS - 30 barras IEEE

\begin{tabular}{|l|c|c|c|c|}
\hline \multirow{2}{*}{$\begin{array}{c}\text { Configurações de } \\
\text { medidores }\end{array}$} & \multicolumn{3}{|c|}{$\begin{array}{c}\mathbf{n}^{\circ} \text { de faltas sensibilizadas em } \mathbf{N m} \\
\text { medidores }\end{array}$} & $\begin{array}{c}\mathbf{N}^{\circ} \text { de } \\
\text { locais de } \\
\text { falta } \\
\text { simulados }\end{array}$ \\
\cline { 2 - 4 } & $\mathbf{N m = 1}$ & $\mathbf{N m = 2}$ & $\mathbf{N m = 3}$ & 720 \\
\hline bar1,bar5, bar17 & 521 & 105 & 94 & 720 \\
\hline bar1, bar2,bar29 & 535 & 107 & 78 & 720 \\
\hline bar2, bar6, bar29 & 548 & 168 & 4 & \\
\hline
\end{tabular}

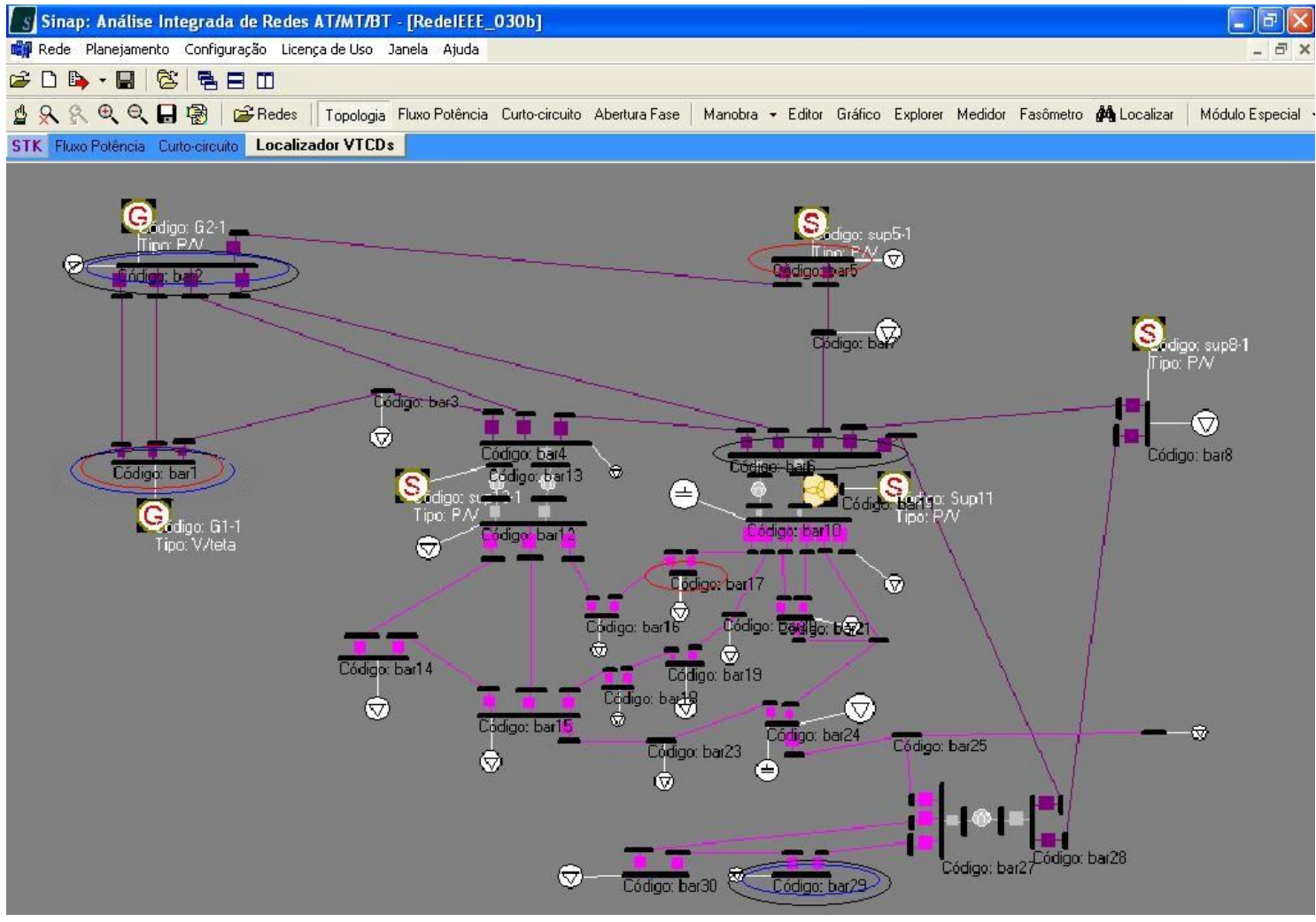

Figura 6.2 - Configuração ótima de medidores visando Faltas monofásicas (impedância de falta nula) - 30 barras

A segunda metodologia desenvolvida, denominada "Alocação Ótima de Medidores visando ao monitoramento de VTCDs utilizando Estratégias Evolutivas", considera as incertezas (simetrias) na estimação de VTCDs e restrições quanto ao número de barras monitoradas. Considerou-se um total de 10 barras de controle, ilustradas na Figura 6.3 (barras 
da cor azul): bar10, bar16, bar17, bar20, bar21, bar23, bar24, bar25, bar27 e bar29. Para obter as condições de curto-circuito (defeitos) na rede avaliada, foram simulados curtos-circuitos a cada $1 \mathrm{~km}$ de linha, totalizando 720 condições de curto-circuito, dos quais somente 647 provocam VTCDs nas barras de controle. Por outro lado, para encontrar o resultado procurado, foi necessário utilizar em média 80 gerações. Os resultados são ilustrados na Tabela 6.2.

Tabela 6.2 - Resultados - Alocação Ótima de Medidores utilizando EEs - 30 barras IEEE

\begin{tabular}{|l|c|c|c|c|}
\hline $\begin{array}{c}\text { Configuração de } \\
\text { medidores }\end{array}$ & F.O. & $\begin{array}{c}\mathbf{N}^{\circ} \text { de } \\
\text { medidores }\end{array}$ & $\begin{array}{c}\mathbf{N}^{\circ} \text { de simetrias } \\
\text { (barras de } \\
\text { medição) }\end{array}$ & $\begin{array}{c}\mathbf{N}^{\circ} \text { de simetrias } \\
\text { (barras de } \\
\text { controle) }\end{array}$ \\
\hline bar11 bar18 & 0.00 & 2 & 0 & 0 \\
\hline & 0.00 & 2 & 0 & 0 \\
\hline bar19 bar27 & 52,6 & 2 & 6 & 65 \\
\hline bar1 bar9 bar21 & 0.00 & 3 & 0 & 0 \\
\hline
\end{tabular}

Depreende-se dos resultados desta tabela que o algoritmo encontrou o número mínimo de medidores igual a 2 (duas primeiras configurações) com uma função objetivo igual a zero; tais soluções não apresentam simetrias tanto para as barras de medição quanto para as barras de controle. Uma das diferenças entre a primeira e a segunda configuração é que um dos medidores compreendidos na segunda configuração (bar17) está alocado numa barra de medição (barra que possui medidor), o que melhoraria a exatidão dos valores estimados nessa mesma barra. Por outro lado, a terceira configuração desta tabela apresenta seis condições de curto-circuito com simetria relativas às barras de medição. Estas, por sua vez, levam a 65 condições de simetria vistas pelas barras de controle. As três primeiras configurações encontradas nesta tabela são apresentadas na Figura 6.3, sendo, a primeira configuração representada por elipses de cor vermelha, a segunda configuração por elipses de cor amarela e a terça configuração por elipses de cor preta.

Finalmente, dos resultados obtidos, entende-se que, mesmo em redes de menor porte, como a rede testada de 30 barras, foi necessário restringir a alocação de medidores para monitorar um grupo de barras de estimação de VTCDs. 


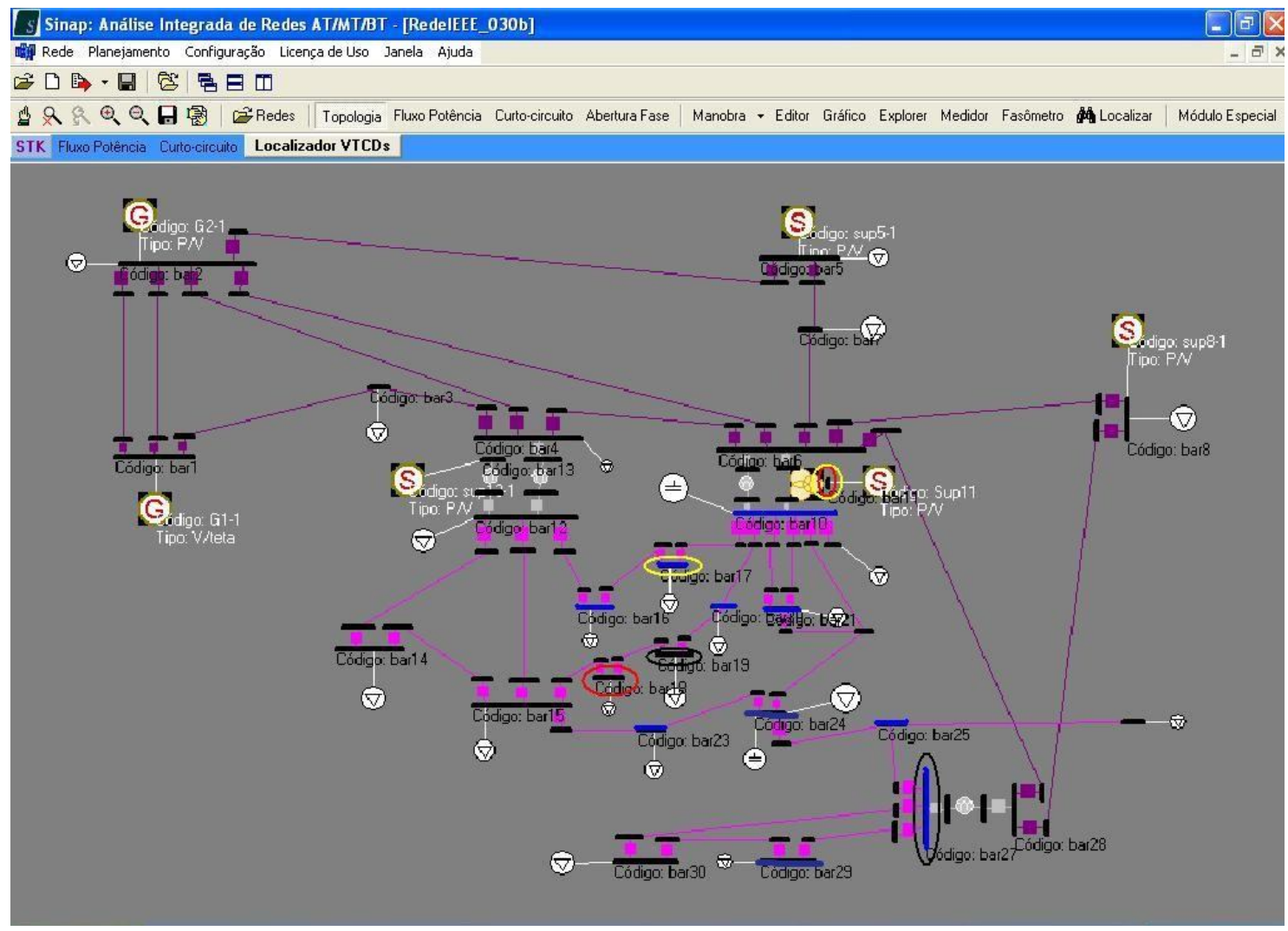

Figura 6.3 - Configuração ótima de medidores visando VTCDs ( faltas monofásicas e impedância de defeito nula) - 30 barras

\subsubsection{Sistema de 57 e 118 barras}

No intuito de avaliar a potencialidade das metodologias propostas, foram também analisadas outras duas redes do IEEE, uma delas de 57 barras e a outra de 118 barras, ilustradas na Figura 6.4 e na Figura 6.5 respectivamente. Nestas redes foi necessário restringir a monitoração de VTCDs para um número de barras de controle e/ou número de condições de falta.

Para a rede de 57 barras, foram consideradas duas restrições: número de barras monitoradas (barras de controle) igual a 12, que representa uma região da rede, conforme a Figura 6.4 (elipse azul) e, o tipo de falta, monofásico com impedância de falta nula. Já para a rede de 118 barras considerou-se a restrição de um número fixo de medidores, sendo este cenário mais próximo à realidade, em que as empresas concessionárias possuem nas suas redes um número definido de medidores. Deseja-se, porém, determinar onde estes devem ser instalados para monitorar a maior quantidade de condições de curto-circuito que geram VTCDs num grupo de barras de estimação. 
Dos resultados mostrados na Tabela 6.3, pode-se observar que o total de condições de curto-circuito consideradas foi, respectivamente, 1360 e 4080 para as redes avaliadas (57 e 118 barras), das quais, 1106 e 1963 condições de curto-circuito respectivamente produzem VTCDs nas barras de controle. Observa-se também, nesta tabela, que o algoritmo encontrou um número mínimo de medidores, sob as condições estabelecidas, igual a 4 medidores (rede de 57 barras). Já para a rede de 118 barras, o algoritmo encontrou para os 5 medidores fixados uma configuração de posições (barras alocadas) dos medidores, a qual não permite observar (sensibilizar medidores) em 180 condições de falta.

Para as redes avaliadas, a Figura 6.4 e a Figura 6.5 ilustram a região monitorada (elipse grande) formada por barras de controle (barras cor azul) e a posição dos medidores, isto é, onde estes devem ser instalados (elipses pequenas de cor vermelha).

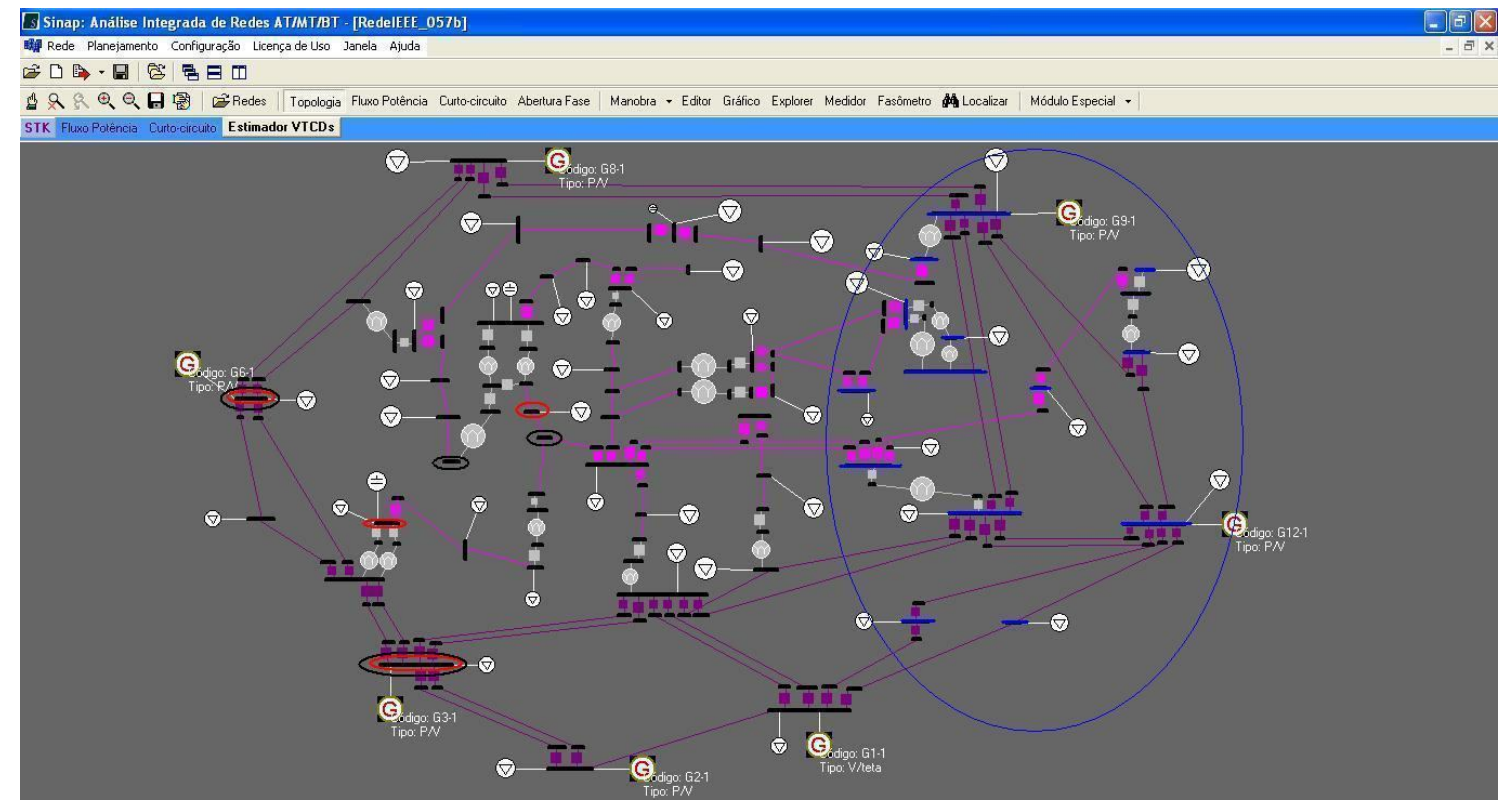

Figura 6.4 - Alocação ótima de medidores (Faltas monofásicas) visando VTCDs - 57 barras IEEE 


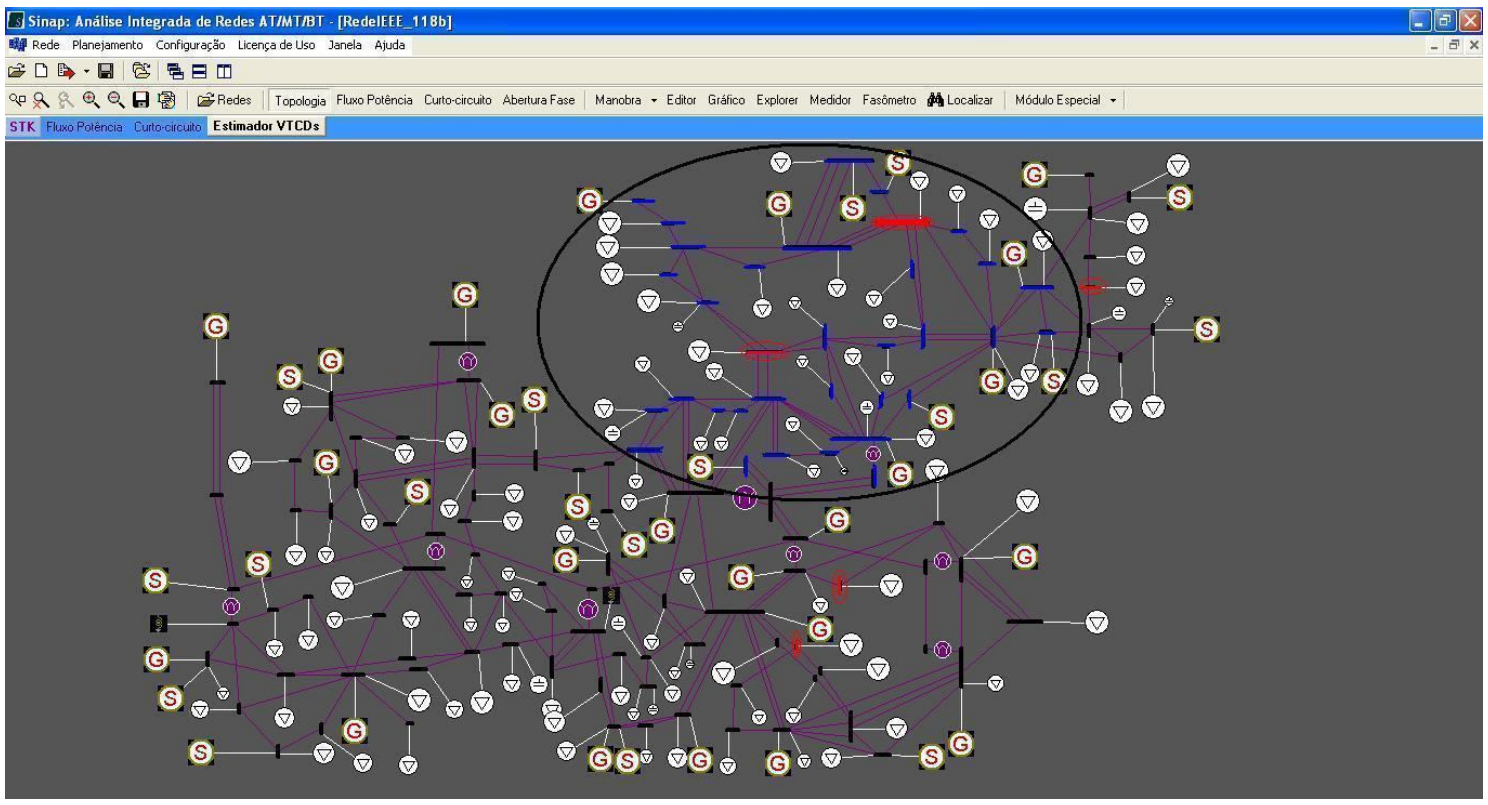

Figura 6.5 - Alocação ótima de medidores (Faltas monofásicas) visando VTCDs - 118 barras IEEE

Tabela 6.3 - Resultados - Alocação Ótima de Medidores utilizando EEs (Faltas monofásicas)

\begin{tabular}{|c|c|c|}
\hline & Rede -57 barras & Rede - 118 barras \\
\hline Condições estabelecidas & $\begin{array}{l}\text { * } N^{\circ} \text { de barras de } \\
\text { estimação } \\
\text { * Tipo de falta, monofásico } \\
\text { com impedância de falta } \\
\text { nula }\end{array}$ & $\begin{array}{l}\text { * } N^{\circ} \text { de barras de estimação } \\
\text { * Tipo de falta, monofásico com } \\
\text { impedância de falta nula } \\
\text { * } N^{\circ} \text { de medidores fixo }\end{array}$ \\
\hline Função objetivo & $\begin{array}{c}\text { Minimizar o } \mathrm{N}^{\circ} \text { de } \\
\text { medidores, e minimizar } \mathrm{N}^{\circ} \\
\text { de simetrias }\end{array}$ & $\begin{array}{l}\text { Maximizar a observabilidade de } \\
\text { um } N^{\circ} \text { de medidores fixos }\end{array}$ \\
\hline $\mathrm{N}^{\circ}$ de medidores (solução inicial) & 20 & $\begin{array}{ll}-------- \\
\end{array}$ \\
\hline № fixo de medidores & --------- & 5 \\
\hline $\mathrm{N}^{\circ}$ de barras de estimação & 14 & 34 \\
\hline Barras de estimação & $\begin{array}{c}\text { bar16 bar17 bar12 bar13 } \\
\text { bar } 55 \text { bar49 bar50 bar51 } \\
\text { bar9 bar10 bar11 bar41 } \\
\text { bar42 bar43 }\end{array}$ & $\begin{array}{c}\text { bar84 bar50 bar51 bar58 bar52 } \\
\text { bar98 bar95 bar97 bar67 bar108 } \\
\text { bar109 bar89 bar88 bar92 bar101 } \\
\text { bar102 bar93 bar90 bar36 bar35 } \\
\text { bar47 bar43 bar10 bar25 bar111 } \\
\text { bar87 bar26 bar65 bar5 bar37 } \\
\text { bar113 bar24 bar68 bar71 }\end{array}$ \\
\hline $\mathrm{N}^{\circ}$ de condições de faltas avaliadas & 1360 & 4080 \\
\hline $\mathrm{N}^{\circ}$ de condições que geram VTCDs & 1106 & 1963 \\
\hline $\mathrm{N}^{\circ}$ de medidores encontrados (Solução) & 4 & --------- \\
\hline Configuração de medidores encontrada & bar3 bar6 bar18 bar23 & Bar51 bar67 bar82 bar92 bar108 \\
\hline $\begin{array}{l}\text { F.O. } \\
\end{array}$ & 0,0625 & 0,02778 \\
\hline $\begin{array}{c}\mathrm{N}^{\circ} \text { de condições de curto-circuito não } \\
\text { observadas }\end{array}$ & 0 & 180 \\
\hline $\mathrm{N}^{\circ}$ de simetrias (barras de controle) & 4 & --------- \\
\hline $\mathrm{N}^{\circ}$ de simetrias (barras de estimação) & 29 & ---------- \\
\hline
\end{tabular}




\subsection{Resultados da Metodologia de Estimação de VTCD}

Nesta segunda parte deste capítulo, apresentam-se os resultados e a análise da metodologia Estratégias Evolutivas para resolver o problema de estimação de VTCDs.

Como já mencionado anteriormente, a metodologia foi implementada numa plataforma computacional, chamada Sinap t\&d, que realiza simulações e análises de sistemas elétricos de potência.

Inicialmente, foi utilizada uma rede de 14 barras do IEEE, com a finalidade de analisar a viabilidade da aplicação da metodologia proposta. Em seguida, foram empregadas redes de 30 e 57 barras do IEEE e, finalmente, utilizada uma rede complexa de 118 barras do IEEE.

A metodologia considerou dois tipos de parâmetros:

(i) aqueles que durante todo o processo de otimização se mantém constantes (fixos) e,

(ii) aqueles que durante esse processo vão mudando (variáveis).

Os parâmetros fixos considerados são:

- Taxa de falta;

- Número de indivíduos da população;

- Número de mutações por indivíduo;

- Taxa de Recombinação;

- Passo (desvio) de mutação inicial;

- Critério de Seleção adotado $(\mu+\lambda)$-EE;

- Método de mutação utilizando o conceito de auto-adaptação e mutações correlacionadas;

- Método de recombinação adotado Intermediaria Global (média aritmética dos atributos).

Os parâmetros variáveis considerados são:

- Desvios (passos) dos parâmetros que representam o indivíduo;

- Direções preferenciais entre variáveis ou atributos que representam o indivíduo. 
Como forma de avaliar a sensibilidade do algoritmo frente às variações de alguns valores dos parâmetros fixos mencionados acima, foram realizadas variações dos valores destes parâmetros, de forma a determinar uma condição de falta mais próxima à condição procurada.

Por outro lado, com intuito de avaliar eficiência e robustez do algoritmo proposto, foi aplicado um Algoritmo Genético (AG) ao problema deste trabalho, de modo a comparar certas características, tais como: precisão, velocidade de convergência entre outras. Esta implementação é descrita no Anexo A.

\subsubsection{Sistema de 14 barras IEEE}

Como primeira análise, foi utilizada uma rede de 14 barras apresentada na Figura 6.6, objetivando avaliar a viabilidade da implementação da metodologia. As características desta rede estão ilustradas na Tabela 6.4. O número considerado de medidores foi $2 \mathrm{em}$ barras aleatoriamente selecionadas, com valores dos parâmetros iniciais ilustrados na Tabela 6.5.

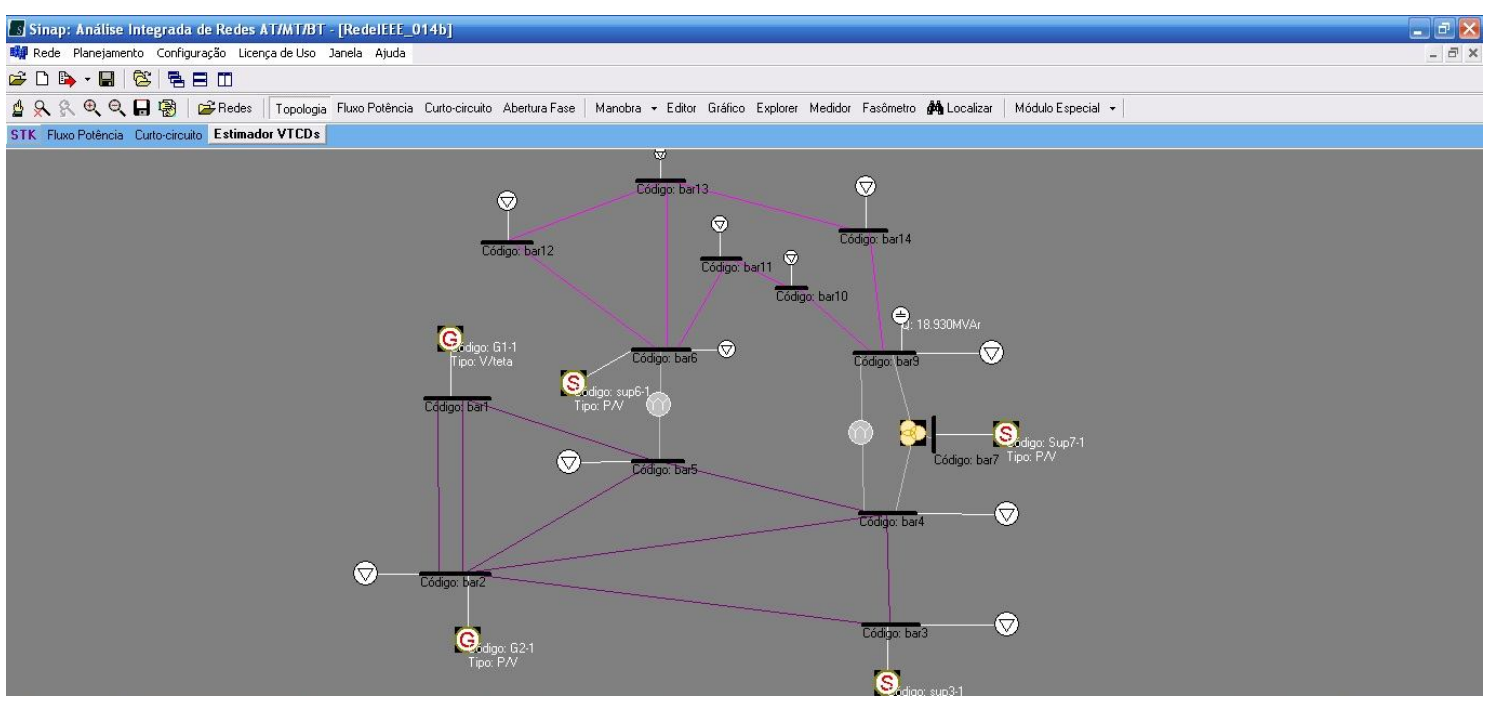

Figura 6.6 - Sistema de 14 barras do IEEE 
Tabela 6.4 - Características - 14 barras IEEE

\begin{tabular}{|l|c|}
\hline \multicolumn{1}{|c|}{ Item } & Quantidade \\
\hline Número de trechos & 17 \\
\hline Número de geradores & 2 \\
\hline Número de suprimentos & 3 \\
\hline Número de capacitores & 1 \\
\hline Número de reatores & 0 \\
\hline Número de transformadores 2 enrolamentos & 2 \\
\hline Número de transformadores 3 enrolamentos & 1 \\
\hline Níveis de tensão $-\mathrm{kV}$ & $138 ; 88 ; 69$ \\
\hline Tamanho da rede $-\mathrm{km}$ & 170 \\
\hline Comprimento de cada trecho $-\mathrm{km}$ & 10 \\
\hline
\end{tabular}

Tabela 6.5 - Parâmetros iniciais para a rede de 14 barras IEEE

\begin{tabular}{|l|r|}
\hline \multicolumn{1}{|c|}{ Parâmetros } & \multicolumn{1}{|c|}{ Valores } \\
\hline Fixos: & 0,05 \\
\hline Taxa de Recombinação & \\
\hline Variáveis: & $20 ; 30 ; 50 ; 100$ \\
\hline Número de indivíduos da população & $1 ; 2$ \\
\hline Número de mutações por indivíduo & 0,$01 ; 0,02 ; 0,05 ; 0,1$ \\
\hline Passo $\sigma$ inicial &
\end{tabular}

Os valores apresentados na Tabela 6.5 foram fixados com intuito de analisar o desempenho e sensibilidade da metodologia. A variação dos valores de alguns parâmetros fixos gera maior sensibilidade ao algoritmo na busca da solução. Entendendo-se assim, as Figuras 6.7 e 6.8 ilustram o comportamento desses parâmetros $\left(\mathrm{n}^{\circ}\right.$ de indivíduos da população e passo inicial porcentual). Na teoria desenvolvida no Capítulo 3, menciona-se que o ajuste do desvio (passo) inicial de mutação $\sigma$ (para local de falta e para impedância de falta) indica a distância entre o indivíduo pai e o indivíduo filho dentro do espaço de busca. Um valor inicial elevado deste parâmetro $\boldsymbol{\sigma}$ poderá introduzir muita variação sobre as populações e o algoritmo pode convergir em um ótimo local. Já valores muitos pequenos de $\boldsymbol{\sigma}$ implicariam em variações muito pequenas nos indivíduos filhos, diminuindo a velocidade de convergência do algoritmo. Esta afirmação pode ser percebida na Figura 6.8, onde um valor inicial alto para $\sigma$ leva a uma convergência rápida; por outro lado, um valor pequeno para $\sigma$ leva a uma convergência demorada para o sistema testado. 


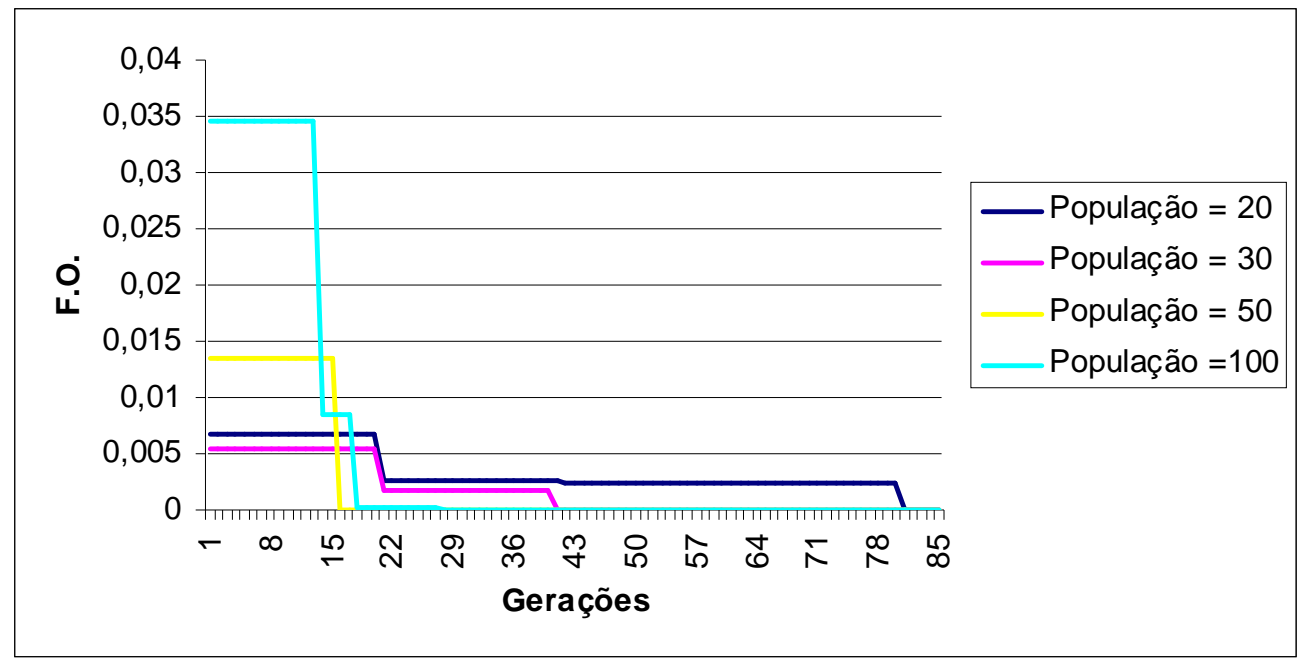

Figura 6.7 - Evolução variação do Tamanho da População e do número de Mutações por Indivíduo

Um indicador importante para avaliar a eficiência da metodologia é a taxa de convergência, que representa a quantidade porcentual das tentativas de executar o algoritmo e obter sucesso (encontrar a condição de falta mais próxima à procurada). Na Tabela 6.6 ilustram-se os resultados para esta rede nos cenários considerados.

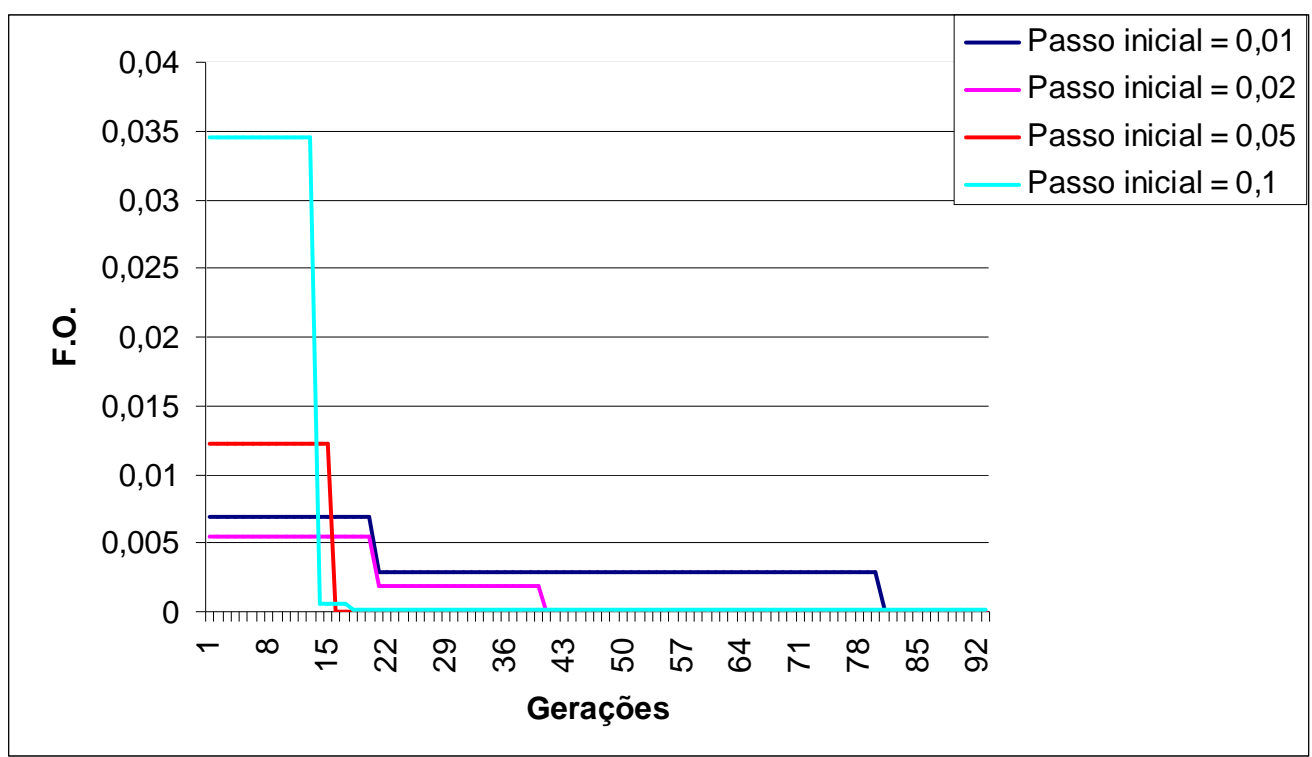

Figura 6.8 - Evolução do algoritmo frente aos valores iniciais de $\sigma$ (local de falta e impedância de defeito) - 14 barras IEEE 
Tabela 6.6 - Resultados da avaliação 14 barras IEEE (utilizando Alocação Ótima de Medidores)

\begin{tabular}{|l|c|}
\hline \multicolumn{1}{|c|}{ Características } & Valores \\
\hline Número de medidores & 2 unidades \\
\hline Barras instaladas medidores & bar6, bar9 \\
\hline Taxa de convergência & $98 \%$ \\
\hline Erro médio local de falta em km & 0,16 \\
\hline Erro médio de impedância de falta em $\Omega$ & 1,50 \\
\hline Erro médio do valor do módulo nas barras em p.u. & 0,001 \\
\hline
\end{tabular}

Os valores referentes aos erros mostrados na Tabela 6.6 são a média dos erros dos valores obtidos (de $98 \%$ do total de testes) e do valor real simulado.

A Tabela 6.7 ilustra três locais de falta conhecidos, simulados e seus respectivos resultados. Para cada falta, a primeira linha representa a condição conhecida e a segunda linha o local de falta obtido pelo algoritmo proposto. Os erros referem-se à distância calculada entre o local de falta obtido e o local da falta conhecido.

A Figura 6.9 ilustra o perfil das tensões naquelas barras onde se produz VTCDs, como consequência da primeira condição de curto-circuito (maior erro de impedância) da Tabela 6.7, bem como os valores determinados através da estimação de VTCDs para a mesma condição de curto-circuito.

Por ser este sistema de comprimento igual a $170 \mathrm{~km}$, o algoritmo encontrou todas as condições de curto-circuito procuradas e valores estimados nas barras da rede com erros que podem ser considerados muito baixos.

Tabela 6.7 - Resultados 14 barras IEEE

\begin{tabular}{|l|r|r|r|r|r|r|}
\hline $\begin{array}{c}\text { Nome do } \\
\text { trecho }\end{array}$ & $\begin{array}{c}\text { Distância do } \\
\text { extremo do } \\
\text { trecho ao } \\
\text { ponto de falta } \\
(\mathbf{k m})\end{array}$ & Tipo de falta & $\begin{array}{c}\text { Impedância de } \\
\text { defeito }\end{array}$ & F.o. & $\begin{array}{c}\text { Erro } \\
\mathbf{( k m )}\end{array}$ & $\begin{array}{c}\text { Erro } \\
(\Omega)\end{array}$ \\
\hline LST1213-1 & 4,37 & DuasFasesTerra & 10,69 & Local da falta & & \\
\hline LST1213-1 & 4,37 & DuasFasesTerra & 8,91 & $2,1984 \mathrm{E}-01$ & 0 & 1,78 \\
\hline LT45-1 & 5,37 & FaseTerralmpedância & 3,69 & Local da falta & & \\
\hline LT45-1 & 5,55 & FaseTerralmpedância & 2,35 & $2,1984 \mathrm{E}-01$ & 0,18 & 1,34 \\
\hline LT12-1 & 2,37 & Trifásico & 0 & Local da falta & & \\
\hline LT12-1 & 2,52 & Trifásico & 0 & $2,1984 \mathrm{E}-01$ & 0,15 & ----- \\
\hline
\end{tabular}




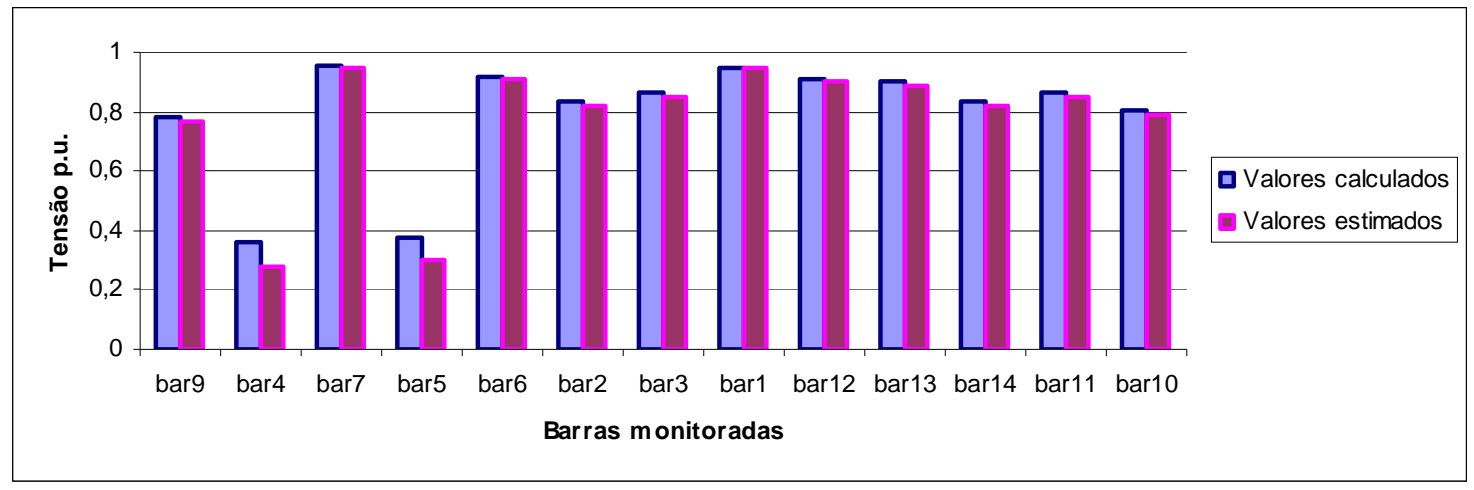

Figura 6.9 - Perfil de tensões nas barras afetadas por VTCDs (14 barras IEEE)

\subsubsection{Sistema de 30 barras IEEE}

Uma segunda rede, ilustrada na Figura 6.10, foi utilizada para avaliar a metodologia proposta, cujas características estão indicadas na Tabela 6.8. Para obter os resultados esperados em qualquer condição de falta (tipo de falta, local de falta e impedância de defeito), foi necessário ajustar os parâmetros próprios da metodologia.

Para monitorar as condições de curto-circuito, foi necessário instalar na rede três equipamentos de medição, dos quais foram habilitados dois canais de corrente, conforme a Tabela 6.10. Este número de medidores foi determinado utilizando o módulo de "Alocação Ótima de Medidores" apresentado no item 6.1.

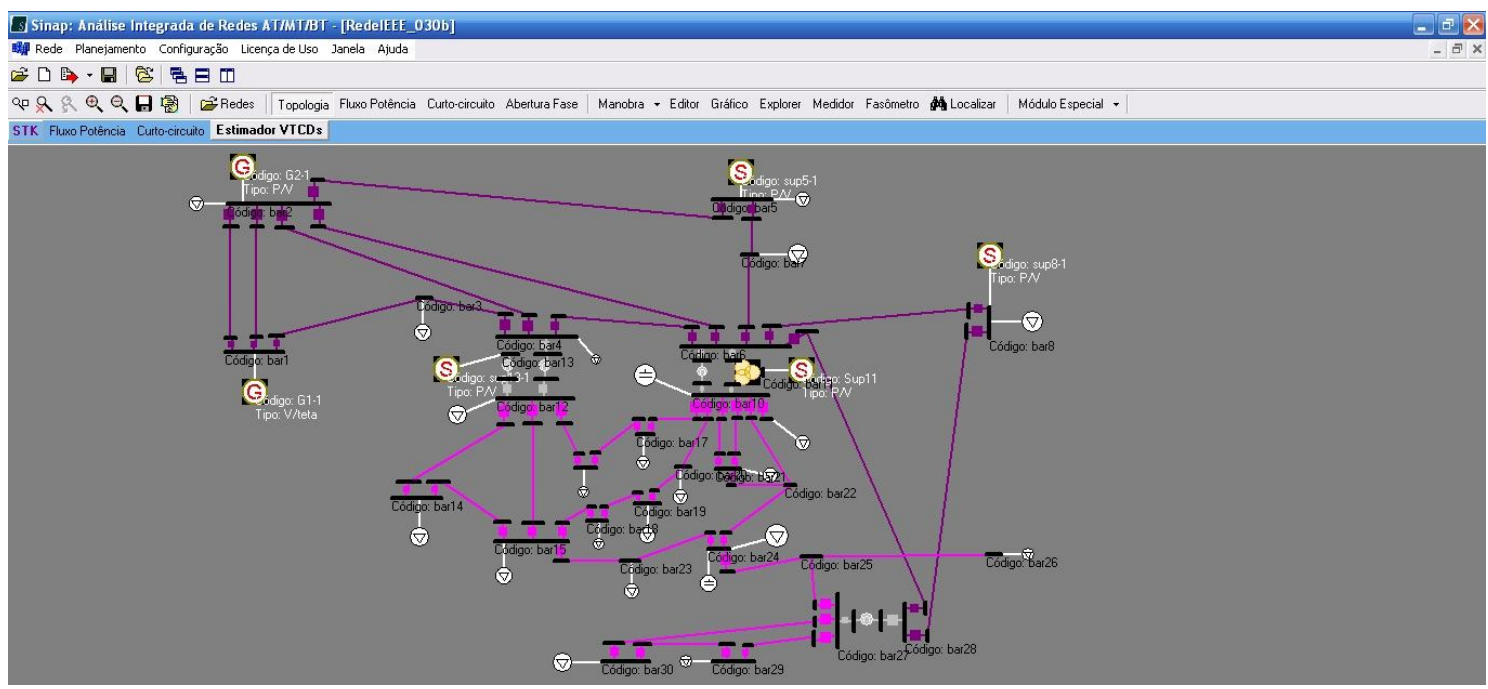

Figura 6.10 - Sistema de 30 barras do IEEE 
Tabela 6.8 - Características - 30 barras IEEE

\begin{tabular}{|l|c|}
\hline \multicolumn{1}{|c|}{ Item } & Quantidade \\
\hline Número de trechos & 36 \\
\hline Número de geradores & 2 \\
\hline Número de suprimentos & 4 \\
\hline Número de capacitores & 2 \\
\hline Número de reatores & 0 \\
\hline Número de transformadores 2 enrolamentos & 4 \\
\hline Número de transformadores 3 enrolamentos & 1 \\
\hline Níveis de tensão - kV & $132 ; 33 ; 11$ \\
\hline Tamanho da rede - km & 360 \\
\hline
\end{tabular}

Tabela 6.9 - Parâmetros iniciais 30 barras IEEE

\begin{tabular}{|l|r|}
\hline \multicolumn{1}{|c|}{ Parâmetros } & \multicolumn{1}{c|}{ Valores } \\
\hline Fixos: & 0,05 \\
\hline Taxa de Recombinação & \\
\hline Variáveis: & $30 ; 50 ; 80 ; 100$ \\
\hline Número de indivíduos da população & $1 ; 2$ \\
\hline Número de mutações por indivíduo & \\
\hline Passo de mutação inicial & 0,$01 ; 0,02 ; 0,05 ; 0,1$ \\
\hline
\end{tabular}

As variações dos parâmetros mostrados na Tabela 6.9 levaram a um comportamento parecido ao da rede de 14 barras do IEEE. Ou seja, um passo inicial $\sigma$ (local de falta e impedância de falta) maior e um tamanho de população fixo leva ao algoritmo a uma convergência rápida, de forma que o risco para uma solução ótima local é maior se comparada com um desvio inicial menor, onde a convergência é mais demorada e a probabilidade de encontrar a solução procurada é maior, como ilustra a Figura 6.11.

Os indicadores de eficiência mostrados na Tabela 6.10 foram calculados de forma similar aos da rede de 14 barras, anteriormente avaliada. A "taxa de convergência" é menor que para uma rede de menor porte. Este comportamento é mais presente na medida em que a complexidade da rede aumenta. 


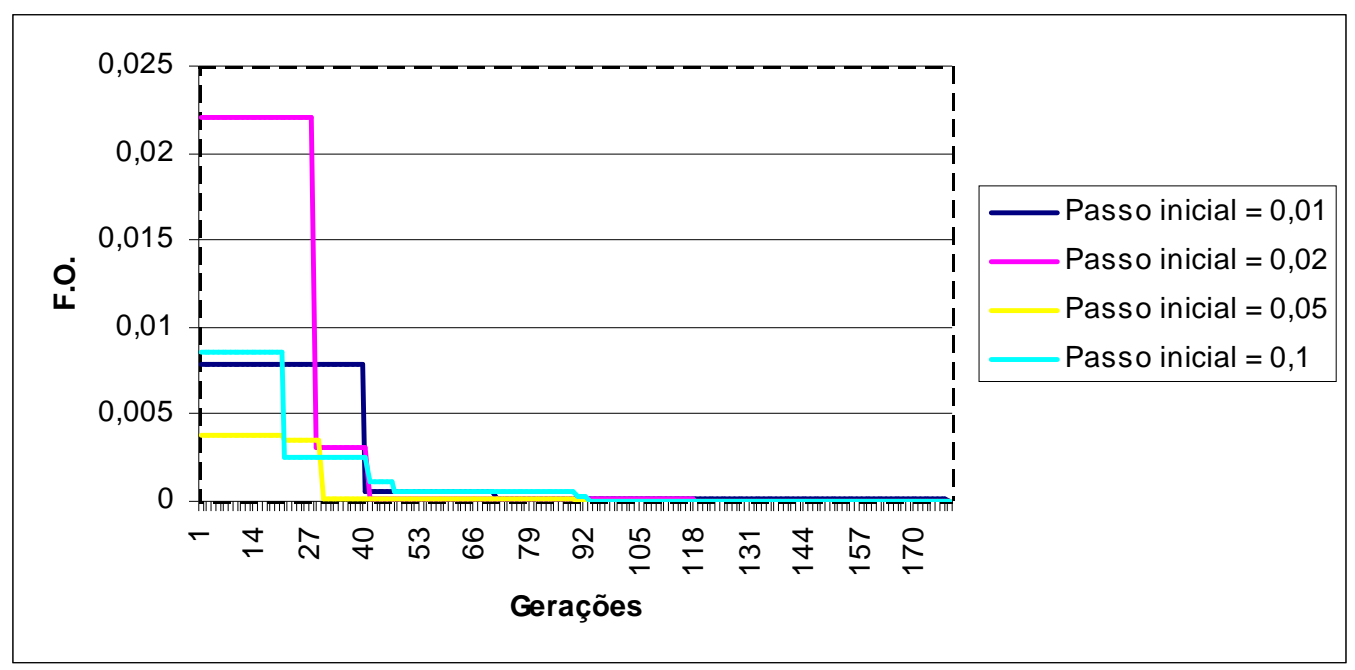

Figura 6.11 - Evolução do algoritmo frente aos valores iniciais de $\sigma$ (local de falta e impedância de defeito) - 30 barras IEEE

Tabela 6.10 - Resultados da avaliação 30 barras IEEE (utilizando alocação ótima de medidores)

\begin{tabular}{|l|c|}
\hline \multicolumn{1}{|c|}{ Características } & Valores \\
\hline Número de medidores & 3 unidades \\
\hline Barras instaladas medidores & bar1, bar5, bar17 \\
\hline Canais de corrente & LT13-1(fase A), LT57-1 (fase C) \\
\hline Taxa de convergência & 0,30 \\
\hline $\begin{array}{l}\text { Erro médio de distância de falta } \\
\text { expressado em km }\end{array}$ & 2,7 \\
\hline $\begin{array}{l}\text { Erro médio de impedância de falta } \\
\text { expressado em } \Omega\end{array}$ & 0,02 \\
\hline $\begin{array}{l}\text { Erro médio do valor do módulo nas } \\
\text { barras de estimação em p.u. }\end{array}$ & 0 \\
\hline
\end{tabular}

A Tabela 6.11, apresenta os resultados de três simulações feitas aleatoriamente. $\mathrm{Na}$ Figura 6.12 é apresentado o perfil dos valores das tensões calculadas e estimadas em todas as barras para a falta.

Tabela 6.11 - Resultados 30 barras IEEE

\begin{tabular}{|l|r|r|r|r|r|r|}
\hline $\begin{array}{c}\text { Nome do } \\
\text { trecho }\end{array}$ & $\begin{array}{c}\text { Distância } \\
\text { do extremo } \\
\text { do trecho } \\
\text { ao ponto de } \\
\text { falta (km) }\end{array}$ & Tipo de falta & $\begin{array}{c}\text { Impedância } \\
\text { de defeito }\end{array}$ & F.o. & $\begin{array}{c}\text { Erro } \\
(\mathbf{k m})\end{array}$ & $\begin{array}{c}\text { Erro } \\
(\Omega)\end{array}$ \\
\hline LT628-1 & 6,75 & FaseTerralmpedância & 11,25 & Local da falta & & \\
\hline LT628-1 & 7,00 & FaseTerralmpedância & 11,16 & $2,1984 \mathrm{E}-01$ & 0,25 & 0,09 \\
\hline LST1214-1 & 3,46 & FaseTerralmpedância & 15,3 & Local da falta & & \\
\hline LST1214-1 & 3,50 & FaseTerralmpedância & 16,46 & $4,3524 \mathrm{E}-01$ & 0,04 & 1,16 \\
\hline LST1215-1 & 7,25 & Trifásica & 0 & Local da falta & & \\
\hline LST1215-1 & 7,00 & Trifásica & 0 & $2,6252 \mathrm{E}+00$ & 0,25 & $-\cdots$ \\
\hline
\end{tabular}




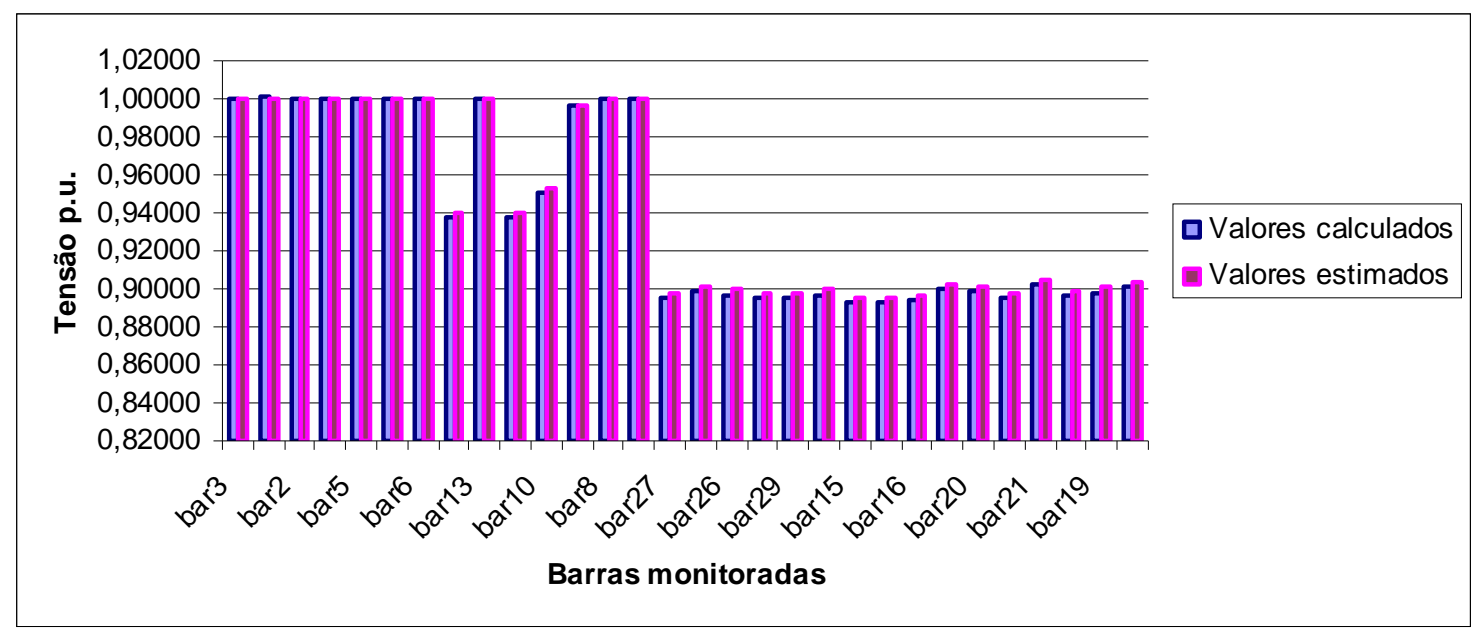

Figura 6.12 - Perfil de tensões nas barras (30 barras IEEE)

No intuito de avaliar a eficiência da metodologia, esta foi comparada com uma aplicação por $A G$. A Figura 6.13 ilustra o comportamento das EEs e dos $A G s$, mostrando a convergência para uma condição de curto-circuito, que representa o desempenho das duas metodologias. Observa-se que a convergência das EEs é mais rápida comparada com os AGs, o que se deve às estratégias próprias das metodologias.

A Tabela 6.12 ilustra os resultados das EEs e $A G s$, visando aos erros na localização de falta e na estimação de VTCDs. Os resultados obtidos demonstram uma maior exatidão das EEs para a rede avaliada.

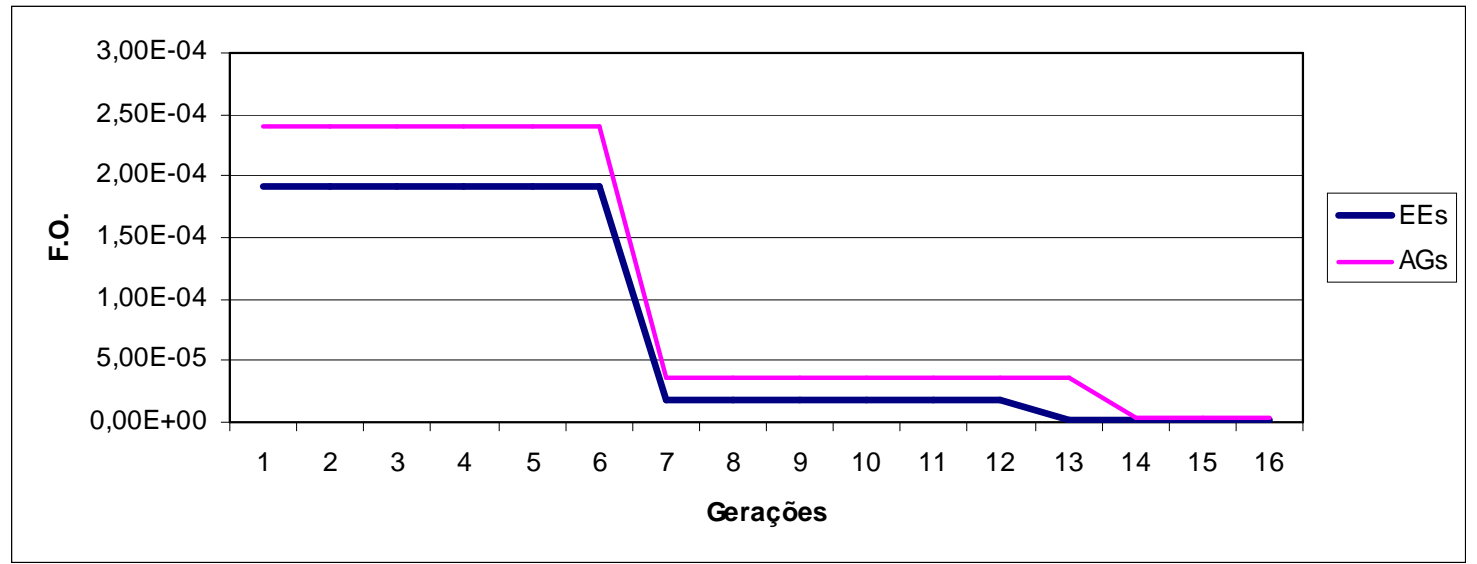

Figura 6.13 - Comparação do comportamento de convergência entre EEs e AGs (30 barras IEEE) 
Tabela 6.12 - Comparação dos resultados entre EEs e AGs (30 barras IEEE)

\begin{tabular}{|l|c|c|}
\hline \multicolumn{1}{|c|}{ Metodologia utilizada } & $\begin{array}{c}\text { Estratégias Evolutivas } \\
\text { EEs }\end{array}$ & $\begin{array}{c}\text { Algoritmos Genéticos } \\
\text { AGs }\end{array}$ \\
\hline $\begin{array}{l}\text { Número de condições de curto- } \\
\text { circuito simuladas }\end{array}$ & 50 & 50 \\
\hline Taxa de convergência & $93 \%$ & $90 \%$ \\
\hline $\begin{array}{l}\text { Erro médio de distância de falta } \\
\text { expressado em km }\end{array}$ & 0,30 & 0,80 \\
\hline $\begin{array}{l}\text { Erro médio de impedância de } \\
\text { falta expressado em } \Omega\end{array}$ & 2,7 & 3,50 \\
\hline $\begin{array}{l}\text { Erro médio do valor do módulo } \\
\text { das tensões nas barras em p.u. }\end{array}$ & 0,002 & 0,007 \\
\hline
\end{tabular}

\subsubsection{Sistema de 57 barras do IEEE}

Uma terceira rede teste do IEEE, com 57 barras, ilustrada na Figura 6.14, foi utilizada para avaliar a metodologia proposta, cujas características estão indicadas na Tabela 6.13.

Os valores dos parâmetros para iniciar o algoritmo estão ilustrados na Tabela 6.14. Foram consideradas faixas para os diferentes parâmetros com a finalidade de avaliar a sensibilidade do algoritmo.

Foram considerados dois cenários, o primeiro considerando 6 medidores instalados aleatoriamente na rede, tendo como premissa que o Estimador só é executado na condição de pelo menos um dos medidores registrar as VTCDs. No segundo cenário, foram considerados os resultados do módulo de alocação ótima de medidores, destacados no item 6.1.2, em que a estimação fica restrita a um número de barras (de controle) igual a 14 dentro de uma região da rede elétrica conforme a Figura 6.4, para falta monofásica com impedância de falta nula. 


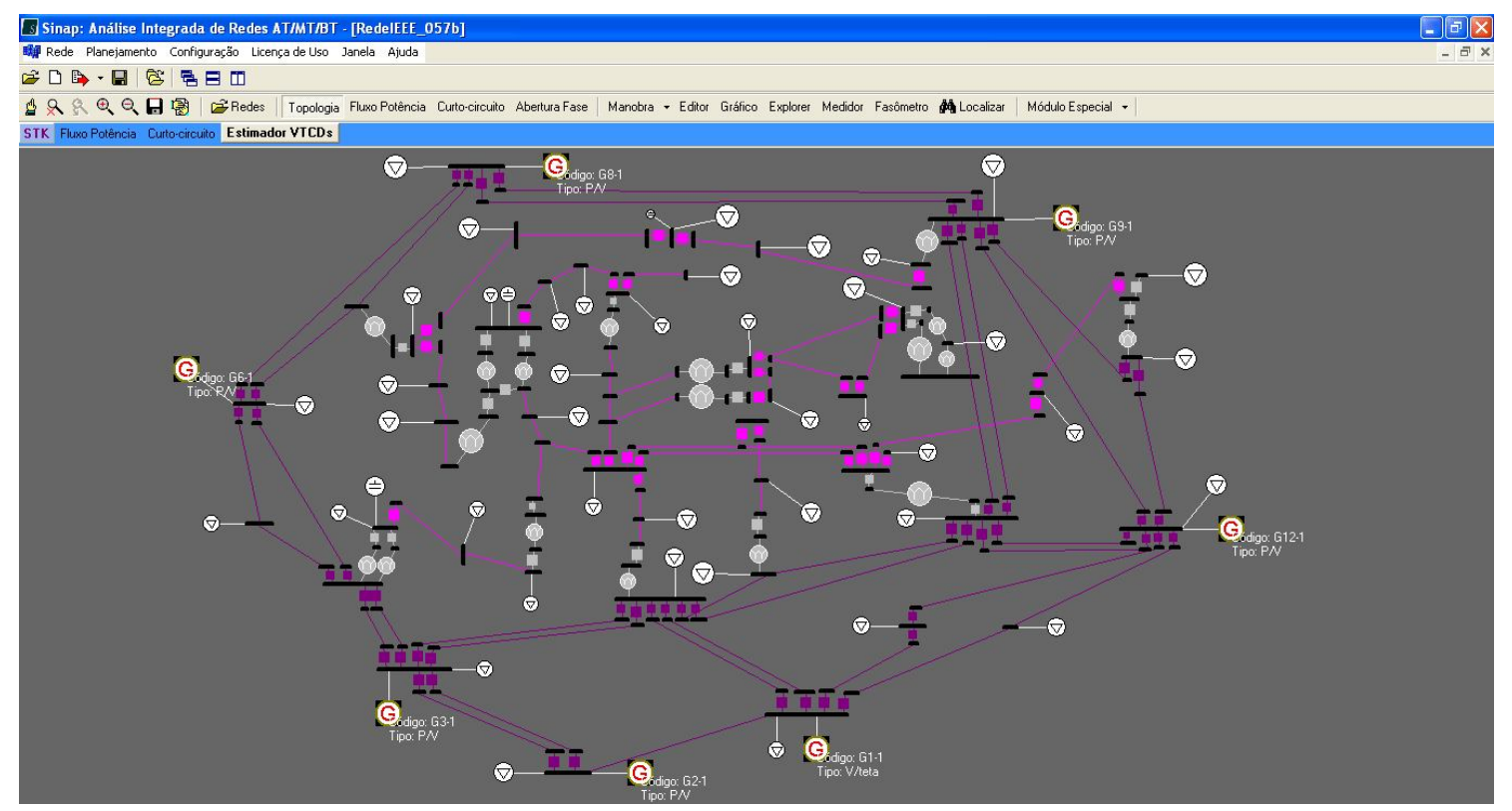

Figura 6.14 - Sistema de 57 barras do IEEE

Tabela 6.13 - Características - 57 barras IEEE

\begin{tabular}{|l|c|}
\hline \multicolumn{1}{|c|}{ Item } & Quantidade \\
\hline Número de trechos & 68 \\
\hline Número de geradores & 7 \\
\hline Número de suprimentos & 0 \\
\hline Número de capacitores & 3 \\
\hline Número de reatores & 0 \\
\hline Número de transformadores 2 enrolamentos & 18 \\
\hline Número de transformadores 3 enrolamentos & 0 \\
\hline Níveis de tensão $-\mathrm{kV}$ & $138 ; 88 ; 69 ; 34.5$ \\
\hline Tamanho da rede $-\mathrm{km}$ & 680 \\
\hline
\end{tabular}

Tabela 6.14 - Parâmetros iniciais 57 barras IEEE

\begin{tabular}{|l|r|}
\hline \multicolumn{1}{|c|}{ Parâmetros } & \multicolumn{1}{|c|}{ Valores } \\
\hline Taxa de falta & 1 falta/ano \\
\hline Taxa de Recombinação & 0,05 \\
\hline Número de indivíduos da população & $30 ; 50 ; 80$ \\
\hline Número de mutações por indivíduo & $1 ; 2 ; 4$ \\
\hline Passo de mutação inicial & 0,$01 ; 0,03 ; 0,08$ \\
\hline
\end{tabular}


Segundo a metodologia desenvolvida, além de canais para registrar valores de tensão, podem ser utilizados os canais para registrar valores de correntes. Isso dotou o algoritmo de maior precisão em encontrar o local de falta, inclusive, em alguns casos onde se apresentava simetria, ajudando a identificar o local (trecho) de falta real. Para esta rede, foram habilitados dois canais de corrente mostrados na Tabela 6.15.

Como mencionado no Capítulo 4, esses valores (de correntes) só foram utilizados depois de certo número de gerações, com intuito de garantir a diversificação nas primeiras gerações e depois direcionar a busca naquelas regiões mais promissórias do espaço de busca, de forma a penalizar a função principal (distância entre valores de tensão lidos e calculados) utilizando a função de penalização, que é calculada pelo mesmo critério da função objetivo, mas utilizando valores de correntes. Para este sistema, foi aplicada a penalização depois das primeiras dezenas de gerações (8 a 10 dezenas). Esta faixa de valores foi obtida através de simulações, cujo comportamento pode ser observado na Figura 6.17 para os primeiros resultados mostrados na Tabela 6.17 .

Considera-se também uma faixa de valores da Tabela 6.14 para avaliar a sensibilidade (Figura 6.15) do algoritmo, dadas às variações de alguns parâmetros.

Na Figura 6.15 o tamanho dos círculos representa o desvio de convergência, isto é, quanto menor o diâmetro, o algoritmo encontra soluções mais próximas à procurada, caso contrário as soluções estarão mais distantes entre si.

A partir de uma configuração inicial de parâmetros: tamanho da população igual a 30; passo inicial igual 0,03 e; $\mathrm{n}^{\circ}$ de mutações igual a 2 , foi alterado um dos valores dos parâmetros, aumentando ou diminuindo o valor destes parâmetros. A variação de cada parâmetro é representada por círculos da mesma cor. Foram criados 6 novos círculos, observando-se que, a maior variação nos eixos se obtém incrementando o passo inicial, ou seja, o desvio de convergência aumenta e o algoritmo tende a encontrar soluções locais com menor número de gerações. Por outro lado, ao diminuir o valor do passo inicial o algoritmo tende a encontrar soluções com menor desvio de convergência utilizando um maior número de gerações.

Com a finalidade de combinar valores dos parâmetros, mais uma vez foi alterado o valor do parâmetro mais sensível. Por exemplo, na seguinte configuração: tamanho da população igual a 50; passo inicial igual $\mathbf{0 , 0 1}$ e; $\mathrm{n}^{\circ}$ de mutações igual a 2 (círculo vermelho), foi alterado o valor do passo inicial de 0,03 para 0,01 . Seguindo essa tendência, altera-se o 
tamanho da população de 50 para 30. Desta forma tenta-se ajustar os valores dos parâmetros para que o algoritmo encontre os resultados procurados.

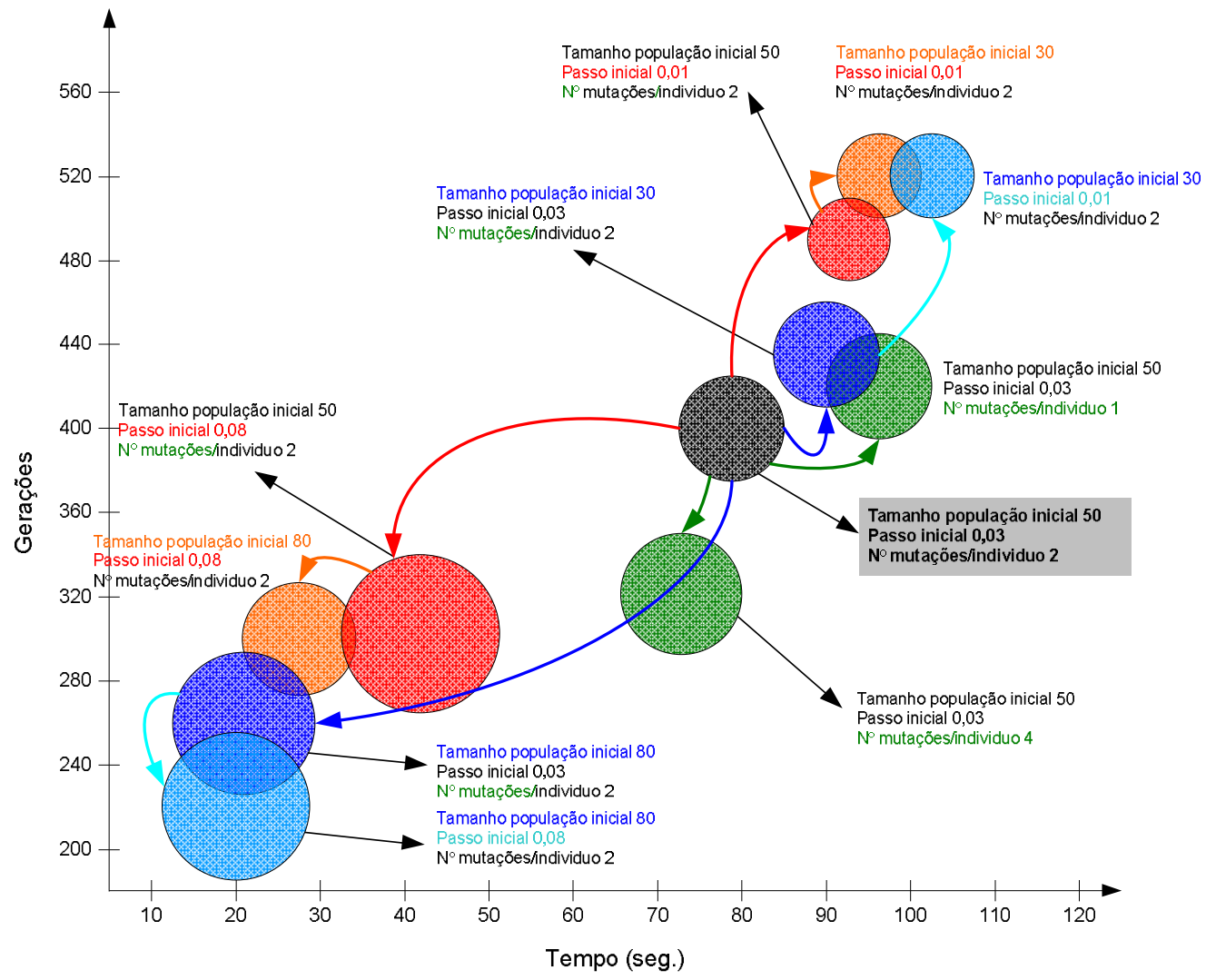

Figura 6.15 - Evolução do algoritmo frente à variação dos parâmetros (57 barras IEEE)

Por outro lado, dos resultados mostrados na Tabela 6.15 observa-se que a "taxa de convergência" diminui em relação às redes já testadas, devido a maior complexidade desta rede. Este fato está associado ao aparecimento de condições de curto-circuito com simetrias conceituadas no Capítulo 4. 
Tabela 6.15 - Resultados da avaliação 57 barras IEEE

\begin{tabular}{|l|c|c|c|c|}
\hline \multicolumn{1}{|c|}{$\begin{array}{c}\text { Características e Parâmetros de } \\
\text { avaliação }\end{array}$} & \multicolumn{4}{c|}{ Valores } \\
\hline Número de medidores & \multicolumn{4}{c|}{6 unidades } \\
\hline Barras instaladas medidores & $\begin{array}{l}\text { bar4, bar11, bar15, bar17, } \\
\text { bar34, bar47 }\end{array}$ \\
\hline Canais de corrente & $\begin{array}{l}\text { Trecho LT1731-1 (fase A) } \\
\text { Trecho LT4056-1 (fase C) }\end{array}$ \\
\hline \multirow{2}{*}{ Taxa de convergência em \% } & $3 F$ & $2 F$ & $1 F T$ & $2 F T$ \\
\cline { 2 - 6 } & 95 & 90 & 80 & 80 \\
\hline $\begin{array}{l}\text { Erro médio de distância de falta } \\
\text { expressado em km }\end{array}$ & $3 F$ & $2 F$ & $1 F T$ & $2 F T$ \\
\hline \multirow{2}{*}{ Erro médio de impedância de falta em $\Omega$} & 0,80 & 0,90 & 1,10 & 1,30 \\
\hline & $3 F$ & $2 F$ & $1 F T$ & $2 F T$ \\
\hline Erro médio do valor do módulo das & 0 & 0 & 7,00 & 6,50 \\
\hline tensões nas barras em p.u. & \multicolumn{5}{|c|}{0,015} \\
\hline
\end{tabular}

A Figura 6.16 ilustra algumas condições de simetria encontradas, cujos resultados estão na Tabela 6.16. Na primeira condição, o local de falta com condição de simetria está fisicamente distante (cor vermelha) do local procurado e, na segunda, o local de falta encontra-se num trecho paralelo (cor azul), como ilustra a Figura 6.16. Para encontrar as possíveis soluções com simetria foi necessário aplicar as estratégias detalhadas no Capítulo 4. A Tabela 6.17 ilustra também os resultados para quatro condições de curtos-circuitos, onde os erros representam a distância entre valores determinados e os valores da condição de falta procurada.

Tabela 6.16 - Condições de curto-circuito com simetria (57 barras IEEE ) - medidores instalados aleatoriamente

\begin{tabular}{|c|c|c|c|c|c|}
\hline $\begin{array}{c}\text { Nome do } \\
\text { trecho }\end{array}$ & $\begin{array}{c}\text { Distância } \\
\text { do extremo } \\
\text { do trecho } \\
\text { ao ponto de } \\
\text { falta (km) }\end{array}$ & Tipo de falta & $\begin{array}{c}\text { Impedância } \\
\text { de defeito } \\
(\Omega)\end{array}$ & F.o. & Observações \\
\hline LST4445-1 & 8,36 & FaseTerralmpedância & 10,9 & Local da falta & \\
\hline LST4445-1 & 8,1 & FaseTerralmpedância & 5,32 & $6,57 \mathrm{E}-15$ & \\
\hline LST4748-1 & 5,7 & FaseTerralmpedância & 8,48 & $8,98 \mathrm{E}-20$ & Trecho Distante \\
\hline LT89-1 & 7,93 & FaseTerralmpedância & 3,89 & Local da falta & \\
\hline LT89-1 & 8,20 & FaseTerralmpedância & 1,85 & 0,0000779 & \\
\hline LT89-2 & 8,80 & FaseTerralmpedância & 5,31 & 0,0000971 & Trecho Paralelo \\
\hline
\end{tabular}




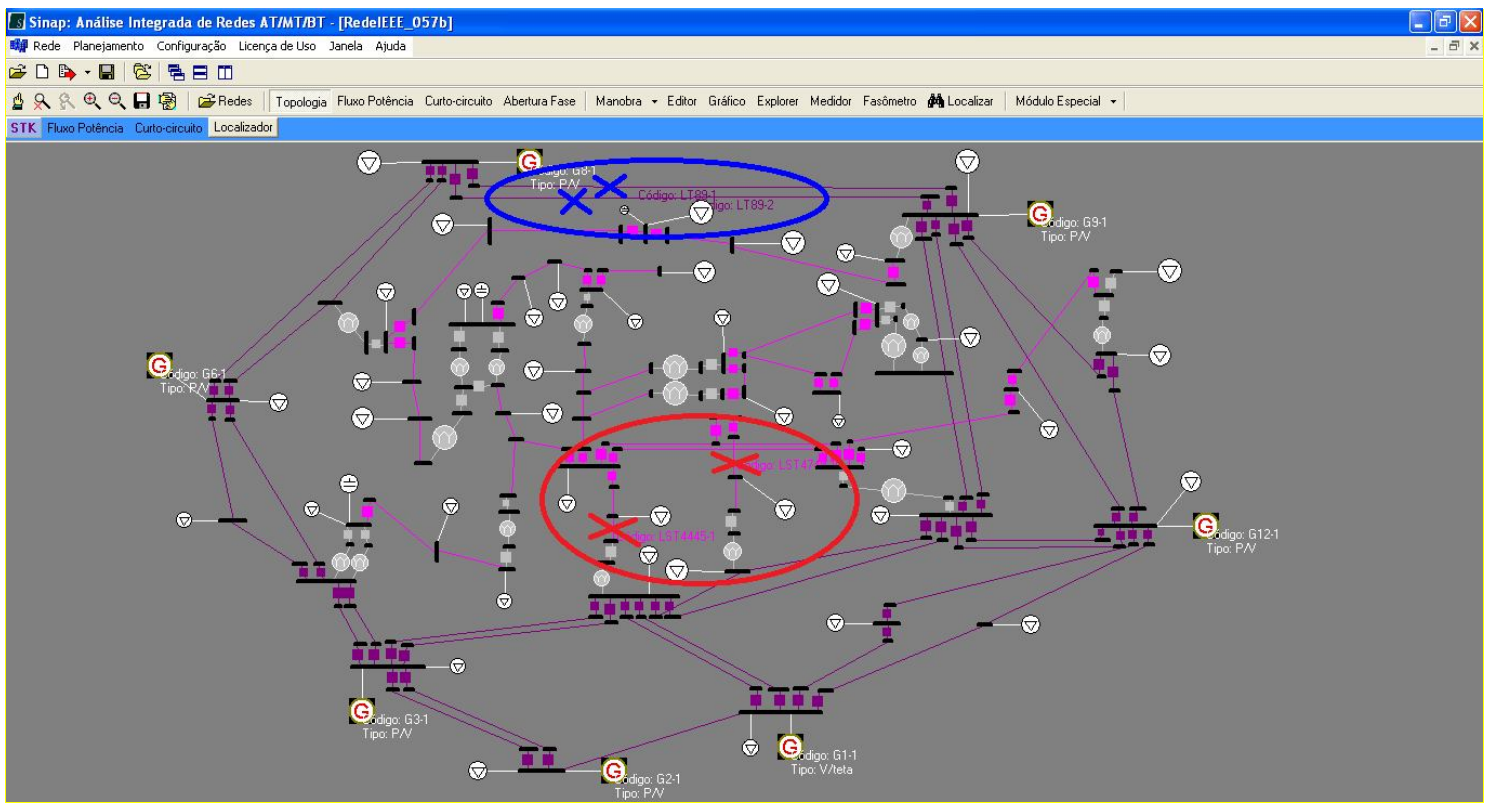

Figura 6.16 - Casos de simetria (57 barras IEEE)

Para avaliar a eficiência da metodologia desta rede, comparou-se os resultados com modelo baseado em AGs. A convergência para uma dada condição de curto-circuito é apresentada na Figura 6.18. Observa-se que nos AGs a convergência é muito mais demorada, mesmo quando ambas metodologias encontram soluções muito próximas à procurada. Em alguns casos, os AGs não encontram a solução procurada, caindo provavelmente em ótimos locais. A Tabela 6.18 apresenta os resultados que quantificam as diferenças entre as EEs e os AGs.

Tabela 6.17 - Resultados 57 barras IEEE - medidores instalados aleatoriamente

\begin{tabular}{|l|r|c|r|r|r|r|}
\hline $\begin{array}{c}\text { Nome do } \\
\text { trecho }\end{array}$ & $\begin{array}{c}\text { Distância } \\
\text { do extremo } \\
\text { do trecho } \\
\text { ao ponto de } \\
\text { falta } \mathbf{( k m )}\end{array}$ & Tipo de falta & $\begin{array}{r}\text { Impedância } \\
\text { de defeito }(\boldsymbol{\Omega})\end{array}$ & F.o. & $\begin{array}{c}\text { Erro } \\
\text { Distância } \\
\mathbf{( k m )}\end{array}$ & $\begin{array}{c}\text { Erro } \\
\text { Impedância } \\
(\boldsymbol{\Omega})\end{array}$ \\
\hline LT1012-1 & 7,36 & Trifásica & 0,00 & Local da falta & & \\
\hline LT1012-1 & 7,41 & Trifásica & 0,00 & 0,0000068670 & 0,05 & 0,0000 \\
\hline LST3640-1 & 1,36 & DuasFasesTerra & 10,36 & Local da falta & & \\
\hline LST3640-1 & 1,41 & DuasFasesTerra & 0,42 & 0,0000006734 & 0,05 & 9,94 \\
\hline LT12-1 & 6,36 & FaseTerralmpedância & 4,36 & Local da falta & & \\
\hline LT12-1 & 5,90 & FaseTerralmpedância & 5,60 & 0,0000430000 & 0,46 & 1,24 \\
\hline LST3844-1 & 2,36 & FaseTerralmpedância & 18,36 & Local da falta & & \\
\hline LST3844-1 & 2,10 & FaseTerralmpedância & 3,27 & 0,0000000000 & 0,26 & 15,09 \\
\hline
\end{tabular}




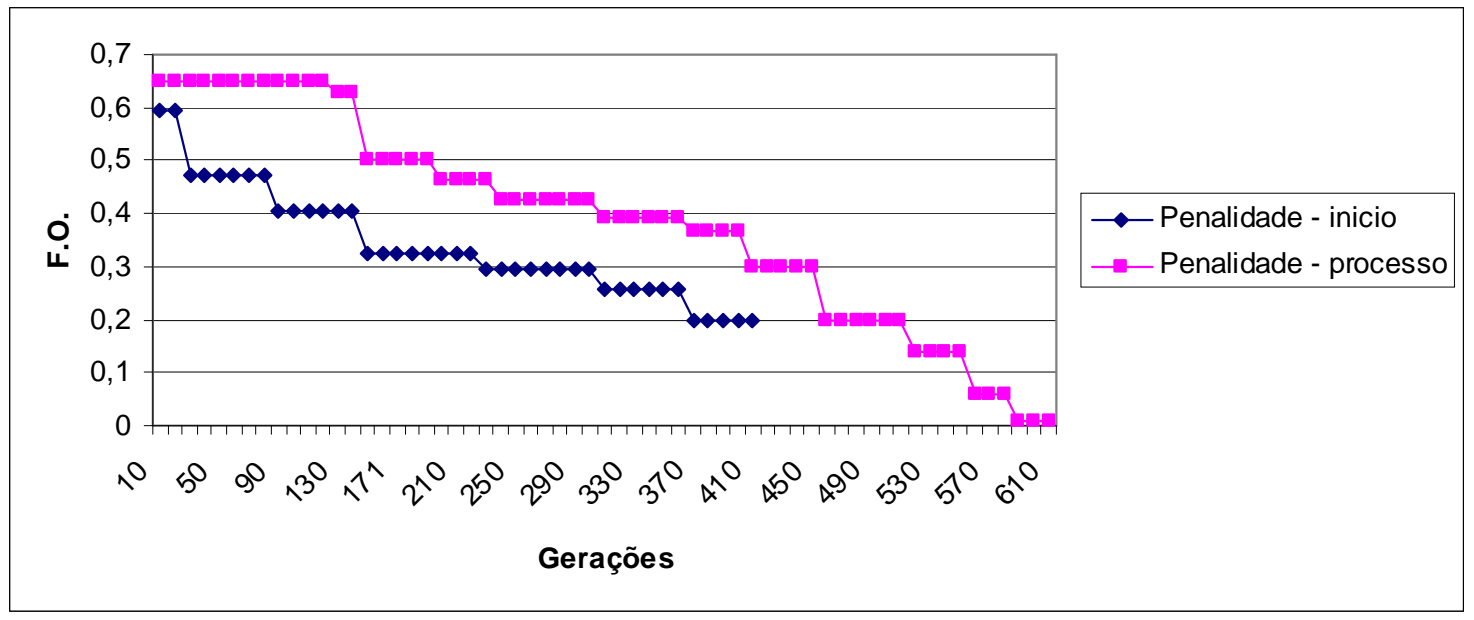

Figura 6.17 - Evolução do algoritmo considerando penalização da função objetivo depois da $100^{\circ}$ geração $^{\circ}$ (57 barras IEEE) - medidores instalados aleatoriamente

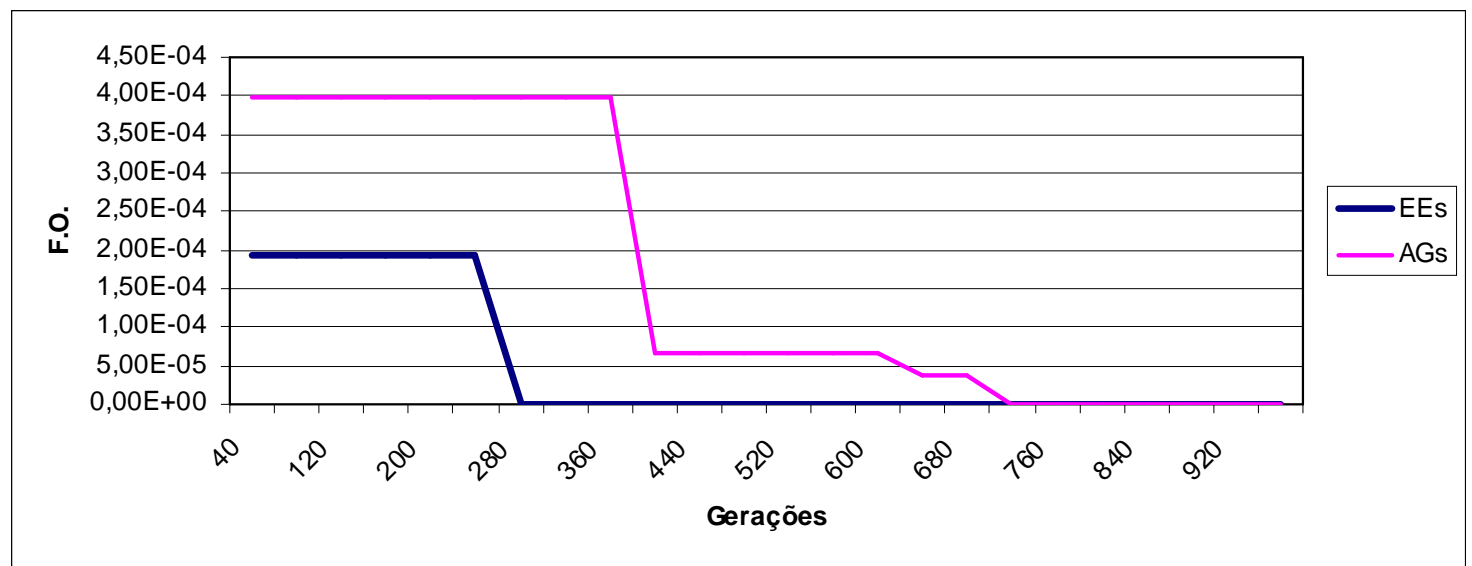

Figura 6.18 - Comparação do comportamento de convergência entre EEs e AGs (57 barras IEEE)

Tabela 6.18 - Comparação dos resultados entre EEs e AGs (57 barras IEEE) - medidores instalados aleatoriamente

\begin{tabular}{|c|c|c|}
\hline Metodologia utilizada & $\begin{array}{c}\text { Estratégias Evolutivas } \\
\text { EEs }\end{array}$ & $\begin{array}{c}\text { Algoritmos Genéticos } \\
\text { AGs }\end{array}$ \\
\hline Número de locais simulados & 50 & 50 \\
\hline Taxa de convergência & 88 & 60 \\
\hline $\begin{array}{c}\text { Erro médio de distância de falta } \\
\text { expressado em km }\end{array}$ & 1,10 & 6,00 \\
\hline $\begin{array}{c}\text { Erro médio de impedância de } \\
\text { falta expressado em } \Omega\end{array}$ & 2,8 & 10,0 \\
\hline $\begin{array}{c}\text { Erro médio do valor do módulo } \\
\text { das tensões nas barras em p.u. }\end{array}$ & 0,015 & 0,1 \\
\hline
\end{tabular}


Depois de determinar os valores das condições de falta (local de falta, impedância de defeito e tipo de falta), estimam-se os valores das tensões nas barras do sistema, para o qual se simulou 50 condições de curto-circuito cujos resultados são ilustrados na Figura 6.19, vislumbrando-se o erro médio dos valores das tensões em p.u. para cada barra. Depreende-se destes resultados que os valores dos erros são baixos.

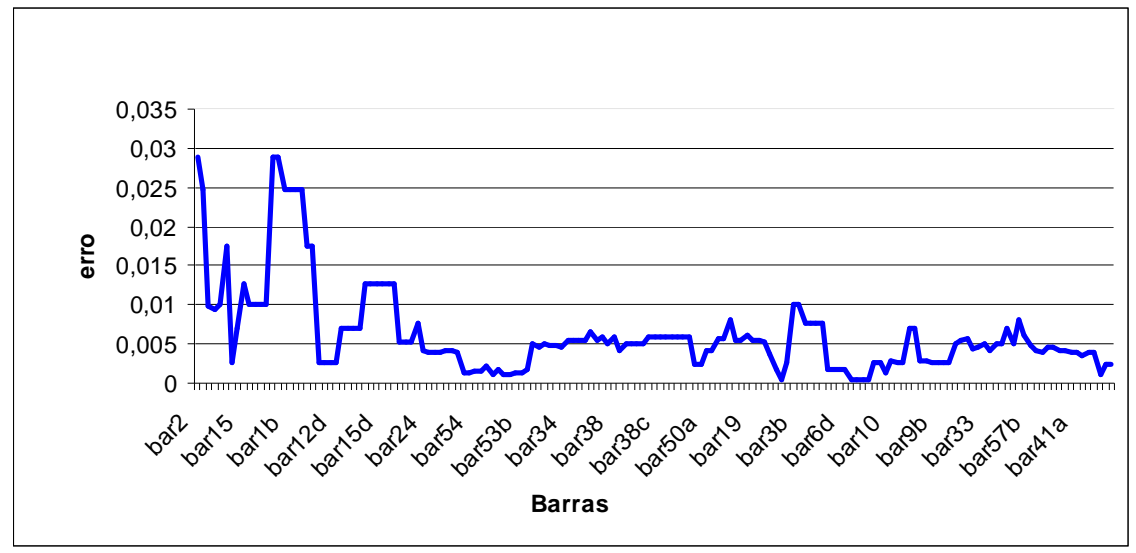

Figura 6.19 - Perfil de erros na estimação de VTCDs (57 barras IEEE) - medidores instalados aleatoriamente

Para aqueles casos de simetria, conforme a Tabela 6.16 (primeiro resultado fisicamente longe) observa-se que, para poucas barras os erros são muito elevados comparados com as demais barras da rede, as quais possuem erros muito baixos, como demonstrados na Figura 6.20.

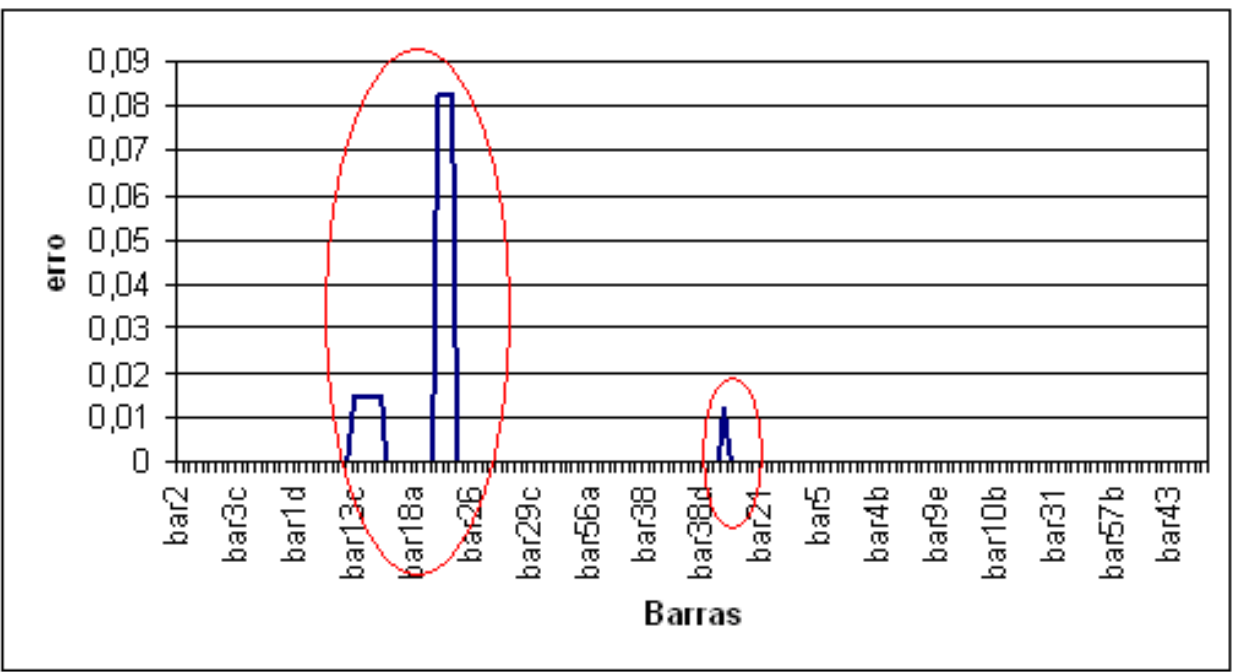

Figura 6.20 - Perfil de erros médios na estimação de VTCDs - Simetria (57 barras IEEE) - medidores instalados aleatoriamente 
Na Figura 6.21 ilustra-se o perfil dos valores das tensões reais e estimadas para uma determinada condição de curto-circuito.

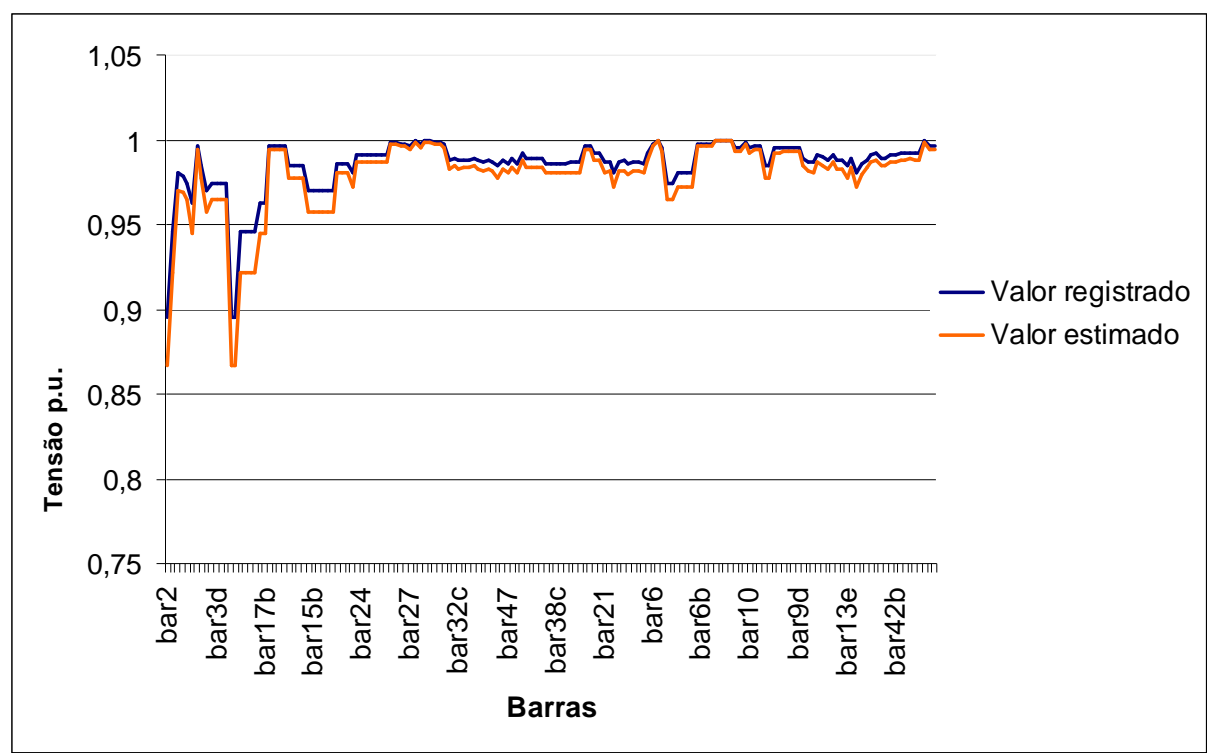

Figura 6.21 - Perfil dos valores médios das tensões nas barras (57 barras IEEE) - medidores instalados aleatoriamente

Salienta-se que a análise e os resultados mostrados para a rede avaliada consideraram 6 medidores instalados aleatoriamente na rede. Este número de medidores é insuficiente para monitorar toda a rede, sendo necessário utilizar os resultados obtidos no item 6.1 (Alocação Ótima de Medidores).

A alocação foi condicionada a monitorar VTCDs em um determinado número de barras (14 barras) e tipo de falta (monofásico com impedância de defeito nula). Para estas condições, a Tabela 6.19 ilustra os resultados de 3 simulações feitas aleatoriamente. No primeiro, os valores das tensões calculados e estimados nas barras monitoradas estão muito próximos, conforme se observa na Figura 6.22. 
Tabela 6.19 - Resultados 57 barras IEEE utilizando módulo de alocação ótima de medidores

\begin{tabular}{|l|r|l|r|r|r|r|}
\hline $\begin{array}{c}\text { Nome do } \\
\text { trecho }\end{array}$ & $\begin{array}{c}\text { Distância do } \\
\text { extremo do } \\
\text { trecho ao } \\
\text { ponto de falta } \\
(\mathbf{k m})\end{array}$ & Tipo de falta & $\begin{array}{c}\text { Impedância } \\
\text { de defeito } \\
(\boldsymbol{\Omega})\end{array}$ & F.o. & $\begin{array}{c}\text { Erro } \\
\text { Distância } \\
(\mathbf{k m})\end{array}$ & $\begin{array}{c}\text { Erro } \\
\text { Impedância } \\
(\boldsymbol{\Omega})\end{array}$ \\
\hline LT1315-1 & 5,89 & FaseTerralmpedância & 0,00 & Local da falta & & \\
\hline LT1315-1 & 5,77 & FaseTerralmpedância & 2,21 & 0,000000064 & 0,12 & $-2,21$ \\
\hline LST3849-1 & 2,89 & FaseTerralmpedância & 0,00 & Local da falta & & \\
\hline LST3849-1 & 2,29 & FaseTerralmpedância & 10,49 & 0,000664556 & 0,60 & $-10,49$ \\
\hline LT12-1 & 5,12 & FaseTerralmpedância & 0,00 & Local da falta & & \\
\hline LT12-1 & 5,08 & FaseTerralmpedância & 1,31 & 0,000000067 & 0,04 & $-1,31$ \\
\hline
\end{tabular}

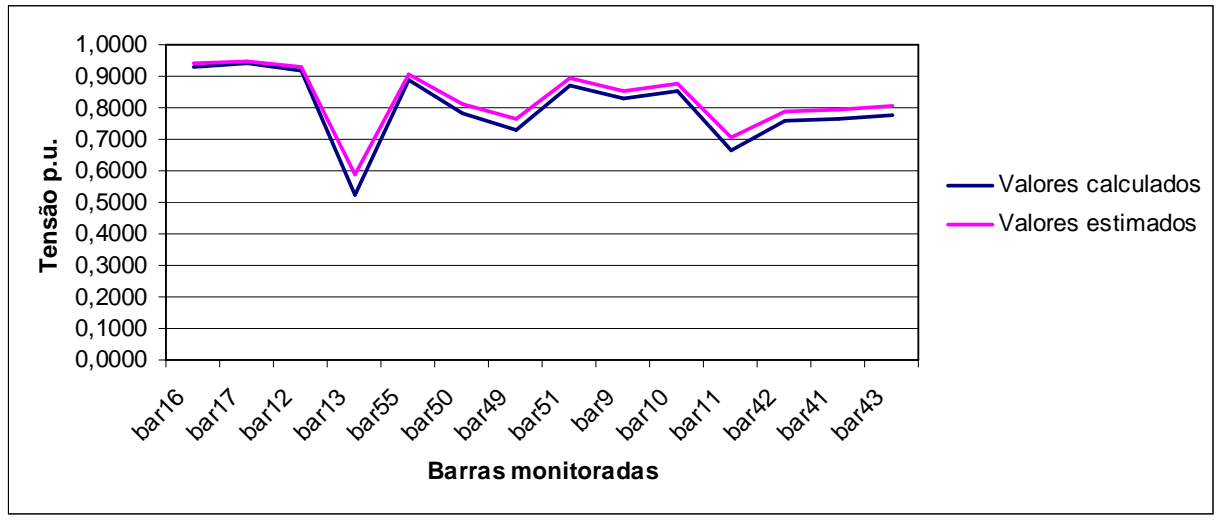

Figura 6.22 - Perfil dos valores das tensões nas barras monitoradas (57 barras IEEE) utilizando módulo de alocação ótima de medidores

\subsubsection{Sistema de 118 barras IEEE}

Finalmente, foi utilizada uma rede mais complexa (Figura 6.23) para avaliar a potencialidade da metodologia proposta considerando dois cenários: (i) 6 medidores instalados aleatoriamente, sendo dois deles habilitados para registrar valores de corrente (dois canais); e (ii) outro cenário, utilizando o módulo de alocação ótima de medidores, onde o número de medidores instalados se restringiu a 5, de forma a maximizar o monitoramento para 34 barras de estimação (item 6.1). As características desta rede estão indicadas na Tabela 6.20 . 


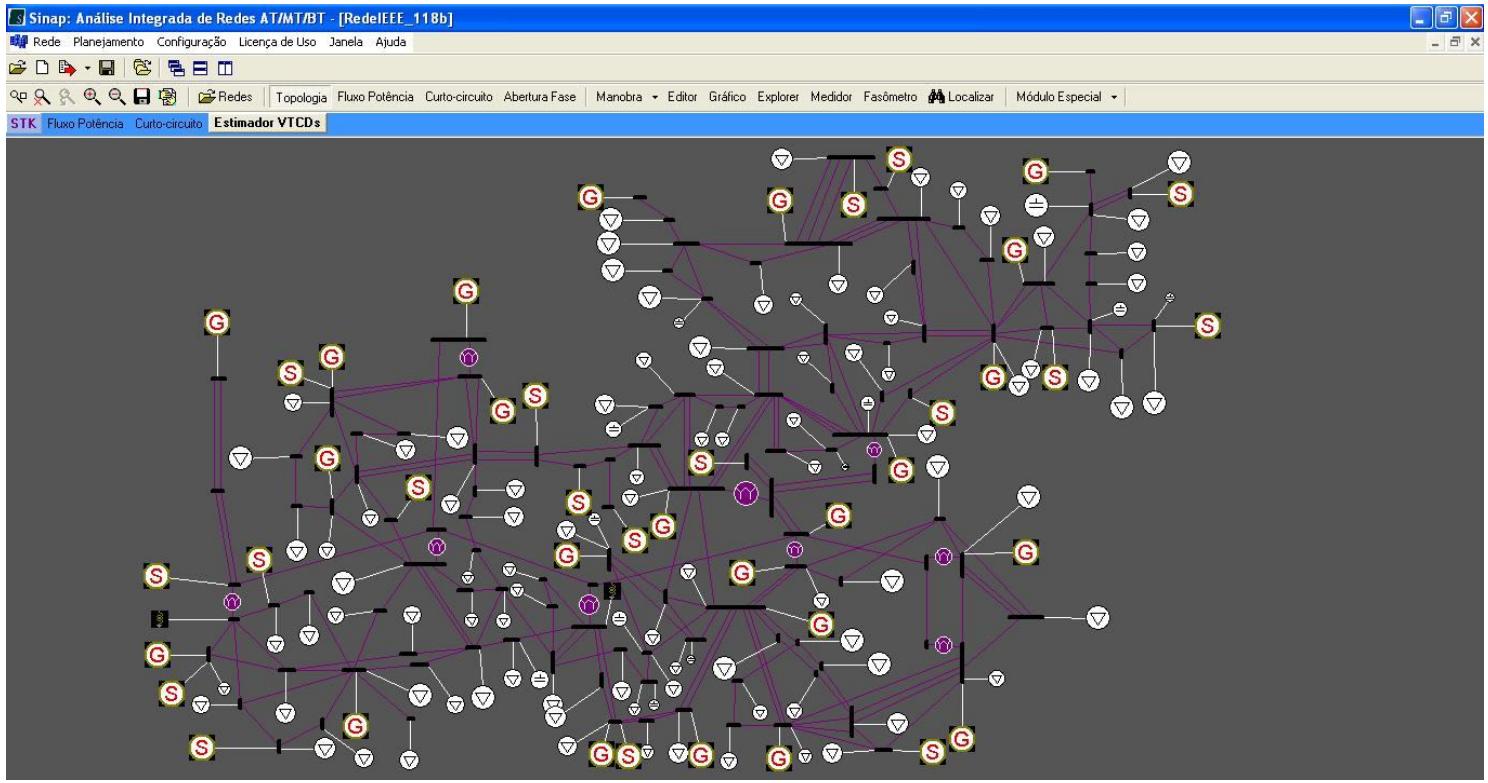

Figura 6.23 - Sistema de 118 barras IEEE

Tabela 6.20 - Características - 118 barras IEEE

\begin{tabular}{|l|c|}
\hline \multicolumn{1}{|c|}{ Item } & Quantidade \\
\hline Número de trechos & 204 \\
\hline Número de geradores & 23 \\
\hline Número de suprimentos & 18 \\
\hline Número de capacitores & 12 \\
\hline Número de reatores & 2 \\
\hline Número de transformadores 2 enrolamentos & 9 \\
\hline Número de transformadores 3 enrolamentos & 0 \\
\hline Níveis de tensão - kV & $230 ; 138$ \\
\hline Tamanho da rede - km & 2040 \\
\hline
\end{tabular}

Os valores dos parâmetros próprios da metodologia estão apresentados na Tabela 6.21. Estes valores também foram determinados de forma intuitiva através de simulações, com a finalidade de localizar qualquer condição de curto-circuito.

Similarmente às redes já testadas, avaliou-se o comportamento da sensibilidade do algoritmo frente a alguns parâmetros, conforme indicado na Figura 6.24. 
Tabela 6.21 - Parâmetros iniciais 118 barras IEEE

\begin{tabular}{|l|r|}
\hline \multicolumn{1}{|c|}{ Parâmetros } & \multicolumn{1}{|c|}{ Valores } \\
\hline Taxa de falta & 1 falta/ano \\
\hline Taxa de Recombinação & 0,05 \\
\hline Número de indivíduos da população & $30 ; 50 ; 80$ \\
\hline Número de mutações por indivíduo & $1 ; 2 ; 4$ \\
\hline Passo de mutação inicial & 0,$03 ; 0,05 ; 0,08$ \\
\hline
\end{tabular}

Na Figura 6.24 o tamanho dos círculos representa o desvio de convergência: quanto menor o diâmetro o algoritmo encontra soluções mais próximas à real. Caso contrário, as soluções encontradas estão mais longe do objetivo.

Similarmente a rede de 57 barras analisada, é construída uma ordem de combinações entre os valores dos parâmetros fixos do algoritmo. A partir de uma configuração inicial de parâmetros: tamanho da população igual a 50; passo inicial igual 0,05 e; $\mathrm{n}^{\circ}$ de mutações igual a 2, foi alterado um dos valores dos parâmetros, aumentando ou diminuindo de valor (círculo da mesma cor). Foram criados 6 novos círculos, observando-se maiores variações nos eixos ao alterar o passo inicial e o tamanho da população, ou seja, o desvio de convergência aumenta quando o passo inicial aumenta e o tamanho da população aumenta, levando a busca para ótimos locais. Por outro lado, quando se diminui o valor do passo inicial e diminui o tamanho da população o algoritmo tende a encontrar soluções com menor desvio de convergência utilizando um maior número de gerações.

Com a finalidade de combinar valores dos parâmetros, mais uma vez foi alterado o valor do parâmetro mais sensível. Por exemplo, na seguinte configuração: tamanho da população igual a 30; passo inicial igual 0,05 e; $n^{\circ}$ de mutações igual a 2 (círculo vermelho), foi alterado o valor do tamanho da população de 50 para 30 (círculo azul claro). Seguindo essa tendência, altera-se o valor do passo inicial de 0,05 para 0,03. Desta forma tenta-se ajustar os valores dos parâmetros para que o algoritmo encontre os resultados procurados. 


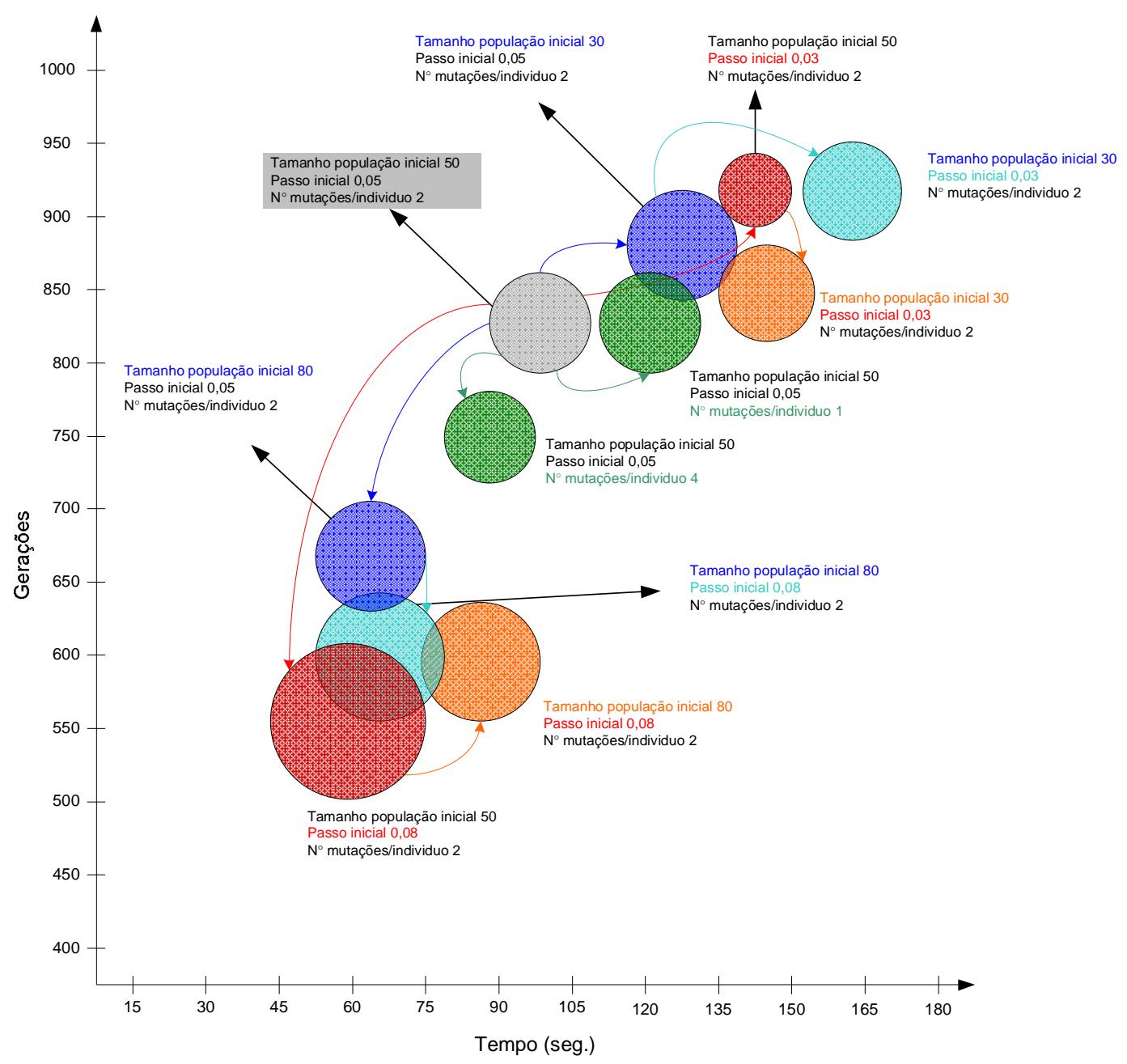

Figura 6.24 - Evolução do processo de evolução frente aos parâmetros próprios (118 barras IEEE)

Nesta rede, verifica-se maior frequência de casos de simetria devido à complexidade $\mathrm{e}$ configuração própria da rede (fortemente em malha). Para resolver esta característica, que torna o problema mais complexo ainda, foi necessário processar o algoritmo inúmeras vezes, de modo a penalizar a função objetivo encontrada na tentativa anterior, com a finalidade de encontrar outra condição de curto-circuito. Em seguida, comparam-se os valores das respectivas funções objetivos. Desta forma, o algoritmo encontrou locais de falta prováveis conforme ilustra a Tabela 6.22. Como exemplo, nesta tabela, mostram-se duas condições de simetria. A primeira delas com locais de falta muito distantes fisicamente (elipse da cor vermelha) e a segunda com local de falta contido em um trecho paralelo (elipse da cor azul) como ilustra a Figura 6.25. 
Com a utilização dos canais de corrente, a metodologia encontrou resultados mais próximos aos procurados. Em muitos casos possibilitou o sucesso na busca, e o número de casos, nos quais se apresentava condições de simetria diminuiu.

A Tabela 6.23 ilustra os erros médios calculados para 50 condições de curto-circuito. Os valores dos erros da impedância de falta podem ser considerados maiores em relação aos valores dos erros dos locais de falta. Como mencionado anteriormente, para atividades de manutenção preventiva e corretiva é mais importante o local de falta, pois reduziria os tempos de restauração da energia frente às faltas elétricas.

Tabela 6.22 - Condições de curto-circuito com simetria (118 barras IEEE)

\begin{tabular}{|c|c|c|c|c|c|c|}
\hline $\begin{array}{c}\text { Nome do } \\
\text { trecho }\end{array}$ & $\begin{array}{c}\text { Distância do } \\
\text { extremo do trecho } \\
\text { ao ponto de falta } \\
\mathbf{( k m )}\end{array}$ & Tipo de falta & $\begin{array}{c}\text { Impedância } \\
\text { de defeito } \\
(\boldsymbol{\Omega})\end{array}$ & F.o. & $\begin{array}{c}\text { F.o } \\
\text { Correntes }\end{array}$ & Observação \\
\hline LT4549-1 & 3,56 & FaseTerralmpedância & 15,9 & Local da falta & & \\
\hline LT4549-1 & 3,01 & FaseTerralmpedância & 5,34 & 0,0009 & 0,89000 & Trecho \\
\hline LT4950-1 & 0,60 & FaseTerralmpedância & 2,23 & 0,0001 & 1,65000 & diferente \\
\hline LT100103-1 & 2,21 & Trifásico & 0,00 & Local da falta & & \\
\hline LT100103-2 & 8,06 & Trifásico & 0,00 & 0,0001 & 116,1960 & Trecho paralelo \\
\hline LT100103-1 & 1,90 & Trifásico & 0,00 & 0,0009 & 220,8900 & \\
\hline
\end{tabular}

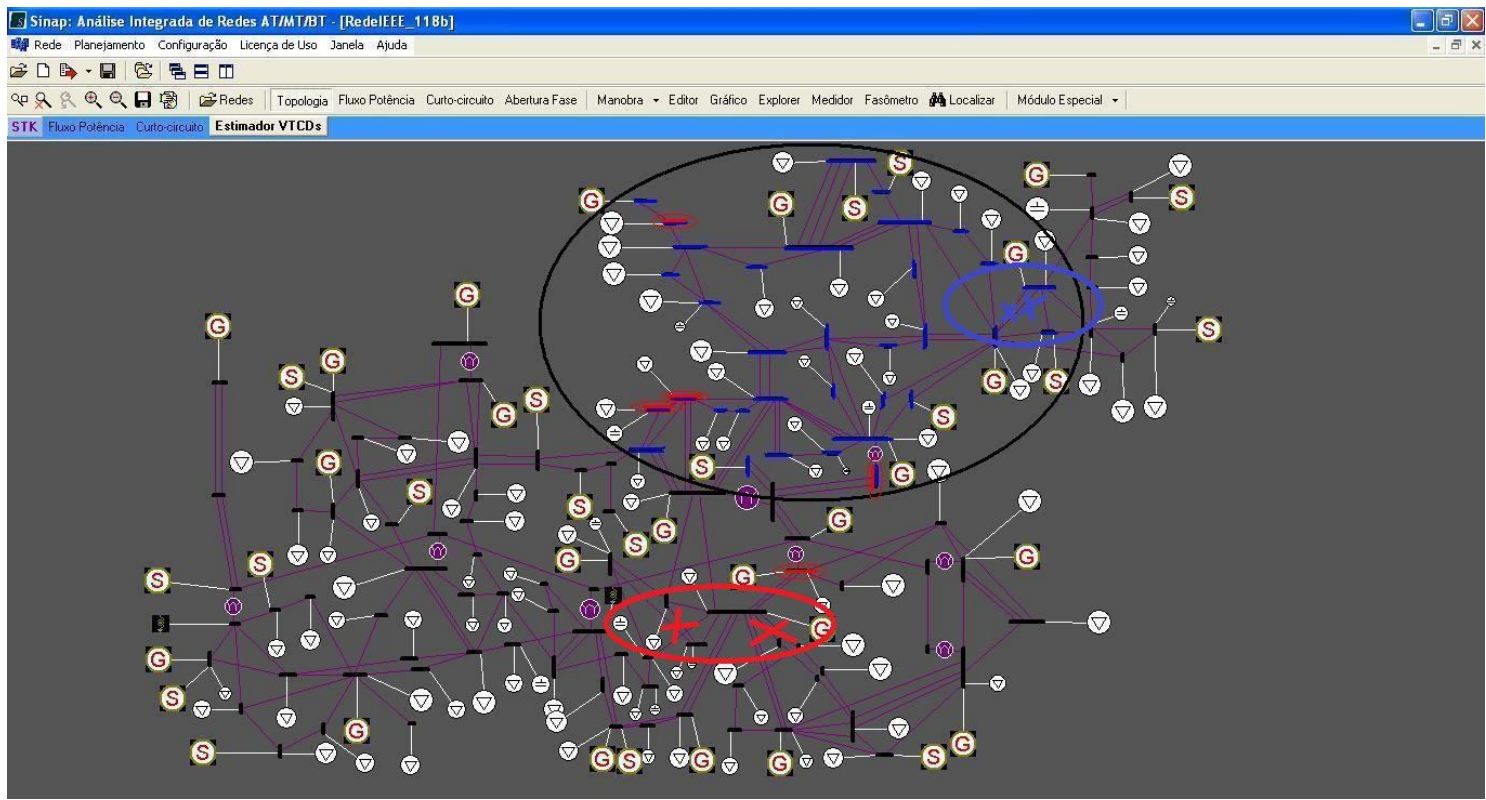

Figura 6.25 - Casos de simetria (118 barras do IEEE) 
Tabela 6.23 - Resultados da avaliação 118 barras IEEE

\begin{tabular}{|l|c|c|c|c|}
\hline \multicolumn{1}{|c|}{ Características } & \multicolumn{4}{c|}{ Valores } \\
\hline Número de medidores & \multicolumn{4}{c|}{6 unidades } \\
\hline Barras instaladas medidores & $\begin{array}{l}\text { Bar31, bar33, bar64, bar45, } \\
\text { bar96, bar103 }\end{array}$ \\
\hline \multirow{2}{*}{ Canais de corrente } & $\begin{array}{l}\text { Trecho LT712-1 (fase A) } \\
\text { Trecho LT100103-2 (fase C) }\end{array}$ \\
\hline \multirow{2}{*}{ Taxa de convergência } & $3 F$ & $2 F$ & $1 F T$ & $2 F T$ \\
\cline { 2 - 6 } & 95 & 90 & 77 & 75 \\
\hline \multirow{2}{*}{$\begin{array}{l}\text { Erro médio de distância de falta } \\
\text { expressado em km }\end{array}$} & $3 F$ & $2 F$ & $1 F T$ & $2 F T$ \\
\hline $\begin{array}{l}\text { Erro médio de impedância de falta } \\
\text { expressado em } \Omega\end{array}$ & 0,9 & 1,2 & 2,0 & 1,8 \\
\hline $\begin{array}{l}\text { Erro médio do valor do módulo das } \\
\text { tensões nas barras em p.u. }\end{array}$ & $3 F$ & $2 F$ & $1 F T$ & $2 F T$ \\
\cline { 2 - 6 } & 0 & 0 & 5,60 & 8,0 \\
\hline
\end{tabular}

A Tabela 6.24 ilustra os resultados para cinco condições de curto-circuito simuladas, observando-se valores dos erros menores a $2,32 \mathrm{~km}$ e $8,22 \Omega$, que estão dentro da média encontrada de todas as condições executadas.

A Tabela 6.25 ilustra os resultados considerando valores dos fasores das tensões (registrados pelos medidores), dos quais se depreende melhor exatidão do que os resultados mostrados na Tabela 6.24

Tabela 6.24 - Resultados 118 barras IEEE - medidores instalados aleatoriamente

\begin{tabular}{|l|r|r|r|r|r|r|r|}
\hline $\begin{array}{c}\text { Nome } \\
\text { trecho }\end{array}$ & $\begin{array}{c}\text { Distância do } \\
\text { extremo do } \\
\text { trecho ao } \\
\text { ponto de } \\
\text { falta (km) }\end{array}$ & Tipo de falta & $\begin{array}{c}\text { Impedância } \\
\text { de defeito } \\
(\mathbf{\Omega})\end{array}$ & $\begin{array}{c}\text { F.o. } \\
\text { Tensões }\end{array}$ & $\begin{array}{c}\text { F.o } \\
\text { Correntes }\end{array}$ & $\begin{array}{c}\text { Erro } \\
\text { Distância } \\
\text { (Km) }\end{array}$ & $\begin{array}{c}\text { Erro } \\
\text { Impedância } \\
\text { (ohm) }\end{array}$ \\
\hline LT1731-1 & 7,36 & FaseTerralmpedância & 5,90 & Local da falta & & & \\
\hline LT1731-1 & 8,69 & FaseTerralmpedância & 5,31 & 0,0000068 & 0,0606 & 1,3300 & 0,5900 \\
\hline LT1533-1 & 3,56 & FaseTerralmpedância & 3,90 & Local da falta & & & \\
\hline LT1533-1 & 3,80 & FaseTerralmpedância & 4,27 & 0,0002038 & 2,5500 & 0,2400 & 0,3700 \\
\hline LT3337-1 & 6,98 & FaseTerralmpedância & 13,45 & Local da falta & & & \\
\hline LT3337-1 & 9,3 & FaseTerralmpedância & 5,23 & 0,0007410 & 29,730 & 2,3200 & 8,2200 \\
\hline LT3337-1 & 6,98 & Trifásico & 0,00 & Local da falta & & & \\
\hline LT3337-1 & 7,40 & Trifásico & 0,00 & 0,0001398 & 2,3400 & 0,4200 & 0,0000 \\
\hline LT6364-1 & 3,56 & FaseTerralmpedância & 3,90 & Local da falta & & & \\
\hline LT6364-1 & 5,67 & FaseTerralmpedância & 2,88 & 0,0033377 & 16,000 & 2,1100 & 1,0200 \\
\hline LT6364-1 & 4,90 & FaseTerralmpedância & 1,53 & 0,0187500 & 0,0766 & 1,3400 & 2,3700 \\
\hline
\end{tabular}


Tabela 6.25 - Resultados 118 barras IEEE (considerando valores fasoriais registrados pelos medidores)

\begin{tabular}{|l|r|r|r|r|r|r|r|}
\hline $\begin{array}{c}\text { Nome } \\
\text { trecho }\end{array}$ & $\begin{array}{c}\text { Distância do } \\
\text { extremo do } \\
\text { trecho ao } \\
\text { ponto de } \\
\text { falta (km) }\end{array}$ & Tipo de falta & $\begin{array}{c}\text { Impedância } \\
\text { de defeito } \\
(\mathbf{\Omega})\end{array}$ & $\begin{array}{c}\text { F.o. } \\
\text { Tensões }\end{array}$ & $\begin{array}{c}\text { F.o } \\
\text { Correntes }\end{array}$ & $\begin{array}{c}\text { Erro } \\
\text { Distância } \\
\text { (Km) }\end{array}$ & $\begin{array}{c}\text { Erro } \\
\text { Impedância } \\
\text { (ohm) }\end{array}$ \\
\hline LT1731-1 & 7,36 & FaseTerralmpedância & 5,90 & Local da falta & & & \\
\hline LT1731-1 & 7,97 & FaseTerralmpedância & 5,43 & 0,00000041 & 0,000634 & 0,610 & 0,470 \\
\hline LT1533-1 & 3,56 & FaseTerralmpedância & 3,90 & Local da falta & & & \\
\hline LT1533-1 & 3,68 & FaseTerralmpedância & 4,05 & 0,00001008 & 1,9087 & 0,120 & 0,150 \\
\hline LT3337-1 & 6,98 & FaseTerralmpedância & 13,45 & Local da falta & & & \\
\hline LT3337-1 & 8,23 & FaseTerralmpedância & 7,87 & 0,0000643 & 24,056 & 1,250 & 5,580 \\
\hline LT3337-1 & 6,98 & Trifásico & 0,00 & Local da falta & & & \\
\hline LT3337-1 & 7,29 & Trifásico & 0,00 & 0,0000234 & 2,100 & 0,310 & 0,000 \\
\hline LT6364-1 & 3,56 & FaseTerralmpedância & 3,90 & Local da falta & & & \\
\hline LT6364-1 & 4,37 & FaseTerralmpedância & 3,00 & 0,0006476 & 12,567 & 0,810 & 0,90 \\
\hline LT6364-1 & 4,85 & FaseTerralmpedância & 1,99 & 0,0005454 & 0,00523 & 1,290 & 1,910 \\
\hline
\end{tabular}

O método por EEs foi comparado com o $A G$. Os resultados encontram-se na Tabela 6.26. Os resultados mostram que as EEs apresentam maior eficiência frente aos AGs. Para os casos onde ambos os algoritmos determinaram a condição de curto-circuito procurada, a convergência das EEs foi muito mais rápida. Para os casos de simetria, as EEs encontraram condições de falta com um valor de função objetivo menor e, em muitos casos, os AGs encontram soluções com valores da função objetivo muito elevados.

Tabela 6.26 - Comparação dos resultados entre EEs e AGs (118 barras IEEE)

\begin{tabular}{|l|c|c|}
\hline \multicolumn{1}{|c|}{ Metodologia utilizada } & $\begin{array}{c}\text { Estratégias Evolutiva } \\
\text { EEs }\end{array}$ & $\begin{array}{c}\text { Algoritmos Genéticos } \\
\text { AGs }\end{array}$ \\
\hline Número de locais simulados & 50 & 50 \\
\hline Taxa de convergência & 90 & 40 \\
\hline $\begin{array}{l}\text { Erro médio de distância de falta } \\
\text { expressado em km }\end{array}$ & 2,00 & 10,00 \\
\hline $\begin{array}{l}\text { Erro médio de impedância de } \\
\text { falta expressado em } \Omega\end{array}$ & 5,1 & 15,0 \\
\hline
\end{tabular}

A Figura 6.26 ilustra o comportamento dos algoritmos para uma condição de curtocircuito. 


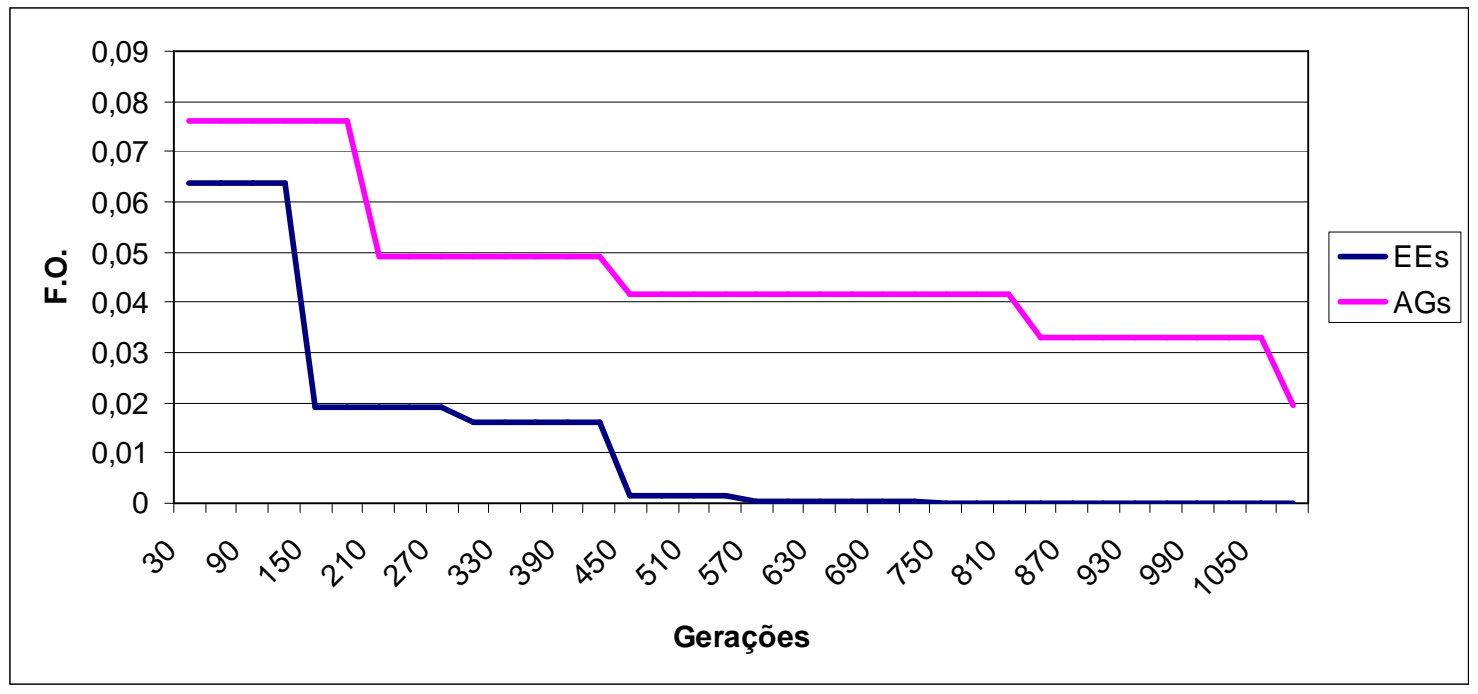

Figura 6.26 - Comparação do comportamento de convergência entre EEs e AGs (118 barras IEEE)

Similarmente às redes já avaliadas, estimaram-se valores das tensões nas barras afetadas por VTCDs, com a simulação de 50 condições de curto-circuito. A Figura 6.27 ilustra o erro médio em p.u. para cada barra. Depreende-se destes resultados, que os valores dos erros são baixos, menores a 0,03 p.u. Para os casos de simetria os erros são elevados, chegando a mais de 0,1 p.u. para algumas barras, como ilustra a Figura 6.28.

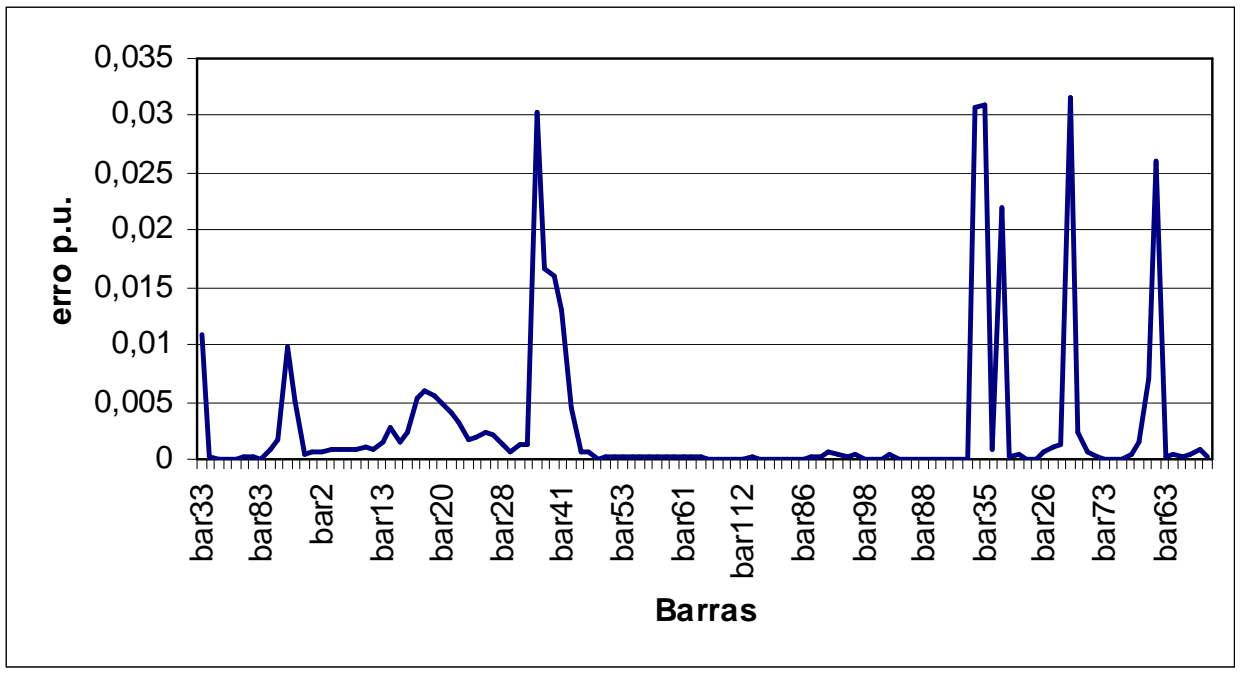

Figura 6.27 - Perfil de erros médios na estimação de VTCDs (118 barras IEEE) 


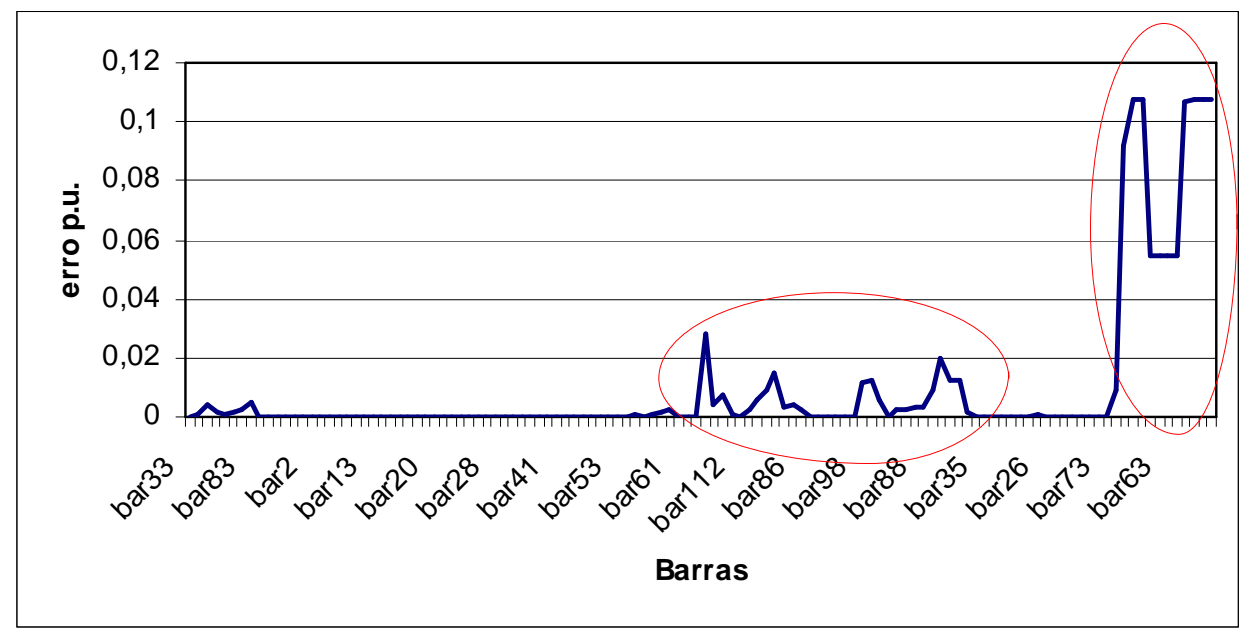

Figura 6.28 - Perfil de erros médios na estimação de VTCDs - com Simetria (118 barras IEEE)

A Figura 6.29 ilustra o perfil dos valores das tensões reais e estimadas para a primeira solução da Tabela 6.24. Na Figura 6.30 ilustra-se o perfil dos valores das tensões para condições de simetria. Pode-se verificar, nesta última figura, que os valores dos erros são elevados, chegando a 0,1 p.u. para algumas barras.

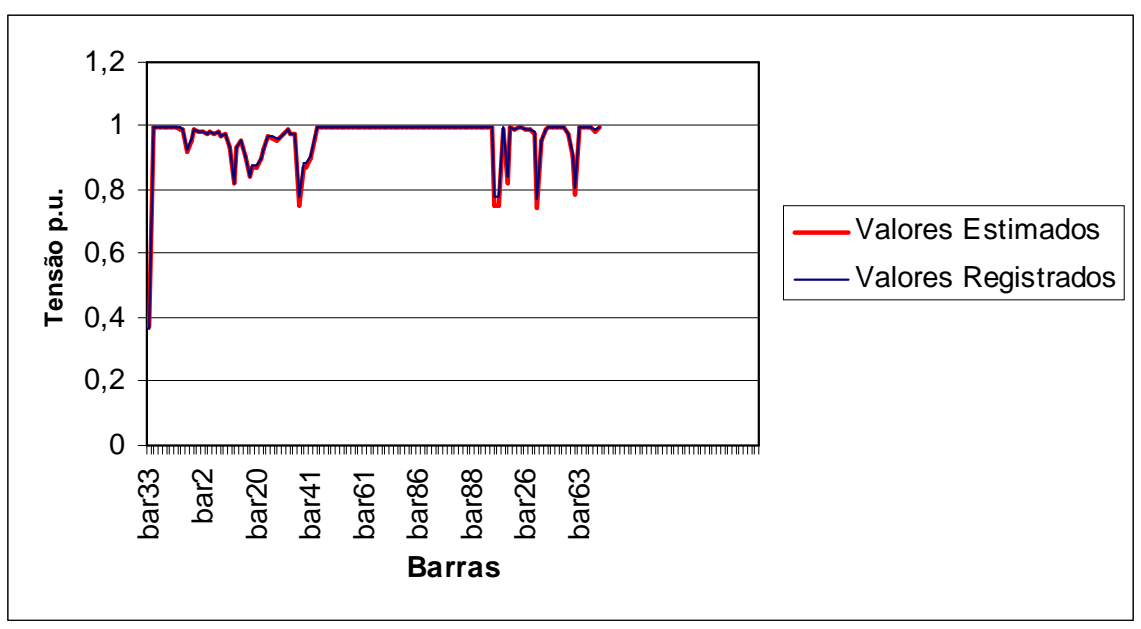

Figura 6.29 - Perfil dos valores médios das tensões nas barras (118 barras IEEE) 


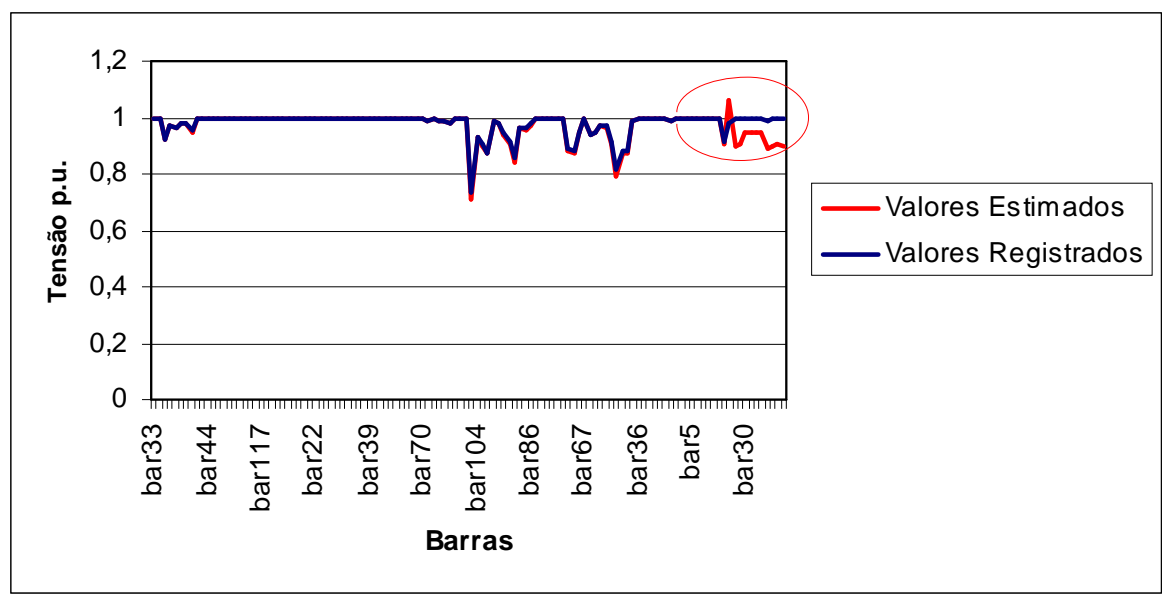

Figura 6.30 - Perfil dos valores médios das tensões nas barras -Simetria (118 barras IEEE)

No item 6.1 é determinada a alocação para um número fixo de medidores (5 medidores) de modo a maximizar o monitoramento de uma região (grupo de consumidores). Considerando os resultados apresentados na Tabela 6.3, de um total de 4080 condições de curto-circuito, é necessário monitorar 1963 condições de curto-circuito (produzem VTCDs na região escolhida). Uma configuração de 5 medidores instalados aleatoriamente na rede registra 150 condições de curto-circuito das 1963 necessárias para monitorar a região escolhida.

A Tabela 6.27 apresenta os resultados para três simulações, considerando os resultados da alocação ótima de medidores indicados na Tabela 6.3. A Figura 6.31 mostra o perfil dos valores das tensões registradas e estimadas nas barras monitoradas.

Tabela 6.27 - Resultados 118 barras IEEE utilizando módulo de alocação ótima de medidores

\begin{tabular}{|c|r|r|r|r|r|c|}
\hline $\begin{array}{c}\text { Nome do } \\
\text { trecho }\end{array}$ & $\begin{array}{c}\text { Distância do } \\
\text { extremo do } \\
\text { trecho ao } \\
\text { ponto de } \\
\text { falta (km) }\end{array}$ & Tipo de falta & $\begin{array}{r}\text { Impedância } \\
\text { de defeito }(\boldsymbol{\Omega})\end{array}$ & F.o. & $\begin{array}{c}\text { Erro } \\
\text { Distância } \\
\mathbf{( k m )}\end{array}$ & $\begin{array}{c}\text { Erro } \\
\text { Impedância } \\
(\Omega)\end{array}$ \\
\hline LT92100-1 & 3,85 & FaseTerralmpedância & 0,00 & Local da falta & & \\
\hline LT92100-1 & 3,88 & FaseTerralmpedância & 0,000345 & $4,465 E-08$ & 0,03 & $-0,000345$ \\
\hline LT103110-1 & 5,37 & FaseTerralmpedância & 0,00 & Local da falta & & \\
\hline LT103110-1 & 5,25 & FaseTerralmpedância & 0,00 & 0,000006687 & 0,12 & -- \\
\hline LT9496-1 & 6,23 & FaseTerralmpedância & 0.00 & Local da falta & & \\
\hline LT9496-1 & 5,17 & FaseTerralmpedância & 0,074903 & 0,0000000876 & 1,06 & $-0,074903$ \\
\hline
\end{tabular}




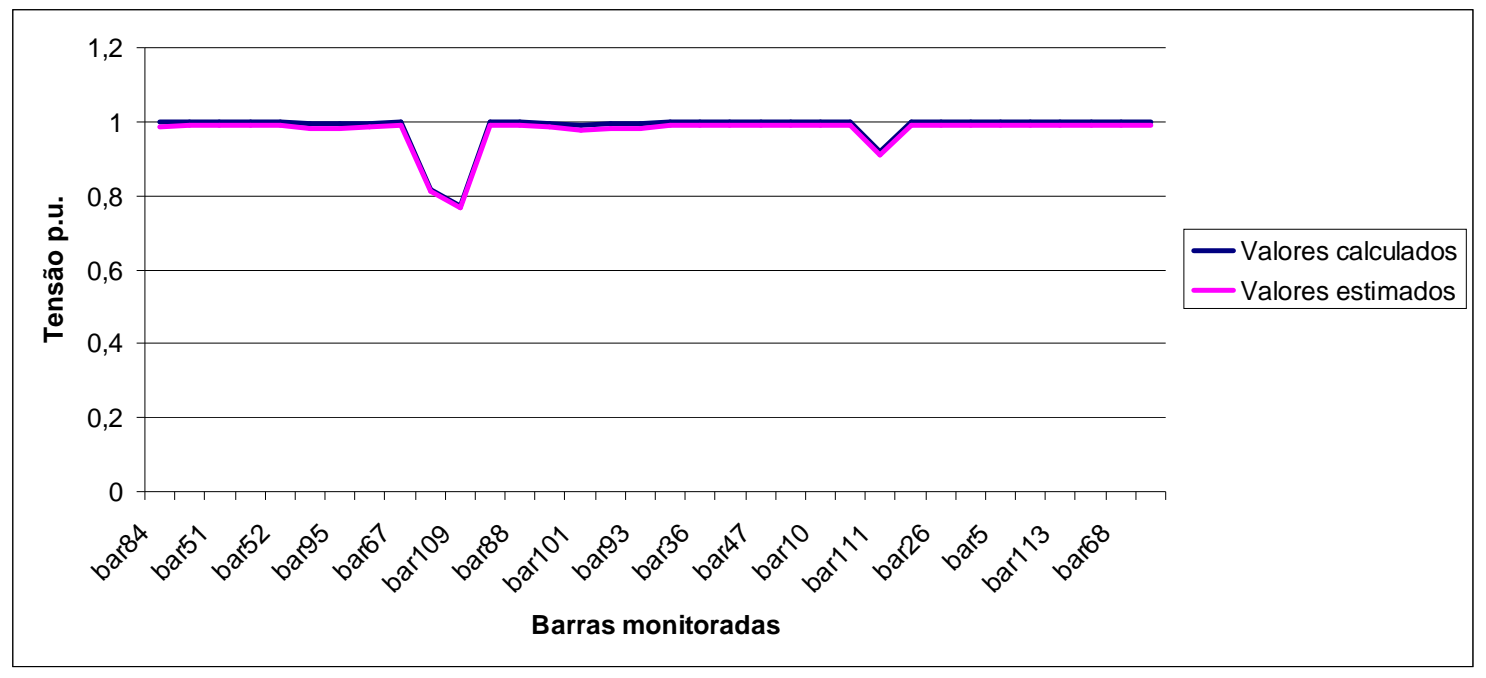

Figura 6.31 - Perfil dos valores das tensões nas barras monitoradas (118 barras IEEE) 


\section{7 - CONCLUSÕES}

Nesta tese foi apresentada uma metodologia para solucionar o problema de estimação de VTCDs provocadas por faltas em sistemas elétricos de potência. Esta metodologia baseiase em Estratégias Evolutivas (EEs), parte da família dos Algoritmos Evolutivos.

Numa primeira etapa foi realizada uma revisão da bibliografia, encontrando-se poucos trabalhos que solucionam o problema da estimação de VTCDs, e muitos que tratam de localização de faltas, agrupando-se basicamente em dois grandes grupos de métodos: (i) métodos que se baseiam na técnica de ondas trafegantes e (ii) métodos que se baseiam na técnica de medição de tensões e correntes em regime permanente. O primeiro grupo de métodos utiliza a informação referente à forma de onda das grandezas (tensão e corrente) elétricas. Este trabalho se enquadra no segundo grupo, ou seja, utiliza valores de tensões e correntes lidos nos equipamentos de medição instalados em algumas barras das redes elétricas.

\section{Filosofia da metodologia:}

As EEs se baseiam em princípios que governam a evolução da vida utilizando níveis avançados de desenvolvimento, que são determinados pelos conceitos da seleção natural e o

processo de sobrevivência dos indivíduos, permitindo desenvolver conceitos de adaptabilidade evolutiva presentes na natureza.

Esse processo começa com a construção de uma população inicial de indivíduos, onde cada indivíduo representa um local de falta, tipo de falta e impedância de defeito. Associado a estes atributos estão: o desvio inicial (passo) e os ângulos de rotação dos parâmetros (local de falta e impedancia de defeito), que são fundamentais para o sucesso da metodologia implementada. Estes indivíduos são submetidos aos operadores de Recombinação e/ou Mutação Correlacionada, sobrevivendo aqueles que estão mais adaptados através da seleção.

Um conceito utilizado foi o de auto-adaptabilidade, que permite o controle da velocidade de convergência, de modo a intensificar a busca naquelas regiões mais promissórias do espaço de soluções e diversificar a busca evitando cair em ótimos locais. 


\section{Condições de Simetria:}

Para que a metodologia determine o local de falta e o valor da impedância de defeito é necessário que no mínimo um medidor instalado na rede observe a falta, com valores de tensão maiores a 1,10 p.u. (elevações) ou inferiores a 0,90 p.u (afundamentos).

Como consequência dessa restrição (observação da falta), foi necessário a implementação de um módulo "Alocação Ótima de Medidores de Qualidade de Energia utilizando Busca em Vizinhança Variável" (GUERRA; KAGAN, 2010a). Para redes de menor porte o algoritmo determinou um número que na prática seria viável. No entanto, para redes de maior porte este número de medidores foi elevado. Alguns critérios foram sugeridos para viabilizar a monitoração, como prioridade de regiões (barras) de estimação, condições de curto-circuito, número limitado de medidores, dentre outras.

Dos resultados nas simulações feitas em redes de meio e grande porte, depreende-se alguns casos de "simetria". Sendo estes de dois tipos: aqueles em que o local de simetria está coompreendido em um trecho paralelo e em outros casos quando estão fisicamente distantes. A metodologia implementada considerou estas condições, utilizando estratégias adequadas para determinar os locais mais prováveis de falta.

Alguns casos de simetria trazem muitas vezes erros groseiros na estimação de VTCDs. Com a finalidade de reduzir estes erros e o número de casos de simetria, foi desenvolvido um módulo denominado "Alocação Ótima de Medidores de Qualidade de Energia visando monitoramento de VTCDs utilizando Estratégias Evolutivas" (GUERRA; KAGAN, 2010b), no qual, o algoritmo é executado um número necessário de vezes, desconsiderando (penalizando a função objetivo) os trechos que contém os resultados (local de falta) nas execuções anteriores do algoritmo.

\section{Resultados:}

Foram utilizadas 4 redes teste do IEEE, duas delas de menor porte, 14 e 30 barras, outra de porte médio, 57 barras e finalmente, uma de maior porte, 118 barras, com a finalidade de avaliar a potencialidade da metodologia.

Para as redes testadas, foram realizadas análises de sensibilidade, variando alguns parâmetros próprios da metodologia com a finalidade de calibrá-los, de modo a encontrar os resultados esperados. Destes gráficos, são destacados alguns parâmetros que afetam mais a sensibilidade da metodologia, como é o passo inicial (desvio) dos atributos (local de falta, 
impedância de falta) e, com menor sensibilidade, o número de mutações por indivíduo e o número de indivíduos da população.

Os resultados mostraram a potencialidade do algoritmo apresentando erros na localização de falta, em média, de 2,0 km para local de falta e 5,1 $\Omega$ para impedância de falta na rede de maior complexidade (118 barras). E, na estimação, das tensões durante a falta elétrica erros menores a 0,02 p.u. para a rede de 118 barras. Este erro na tensão não compromete o cálculo dos indicadores de qualidade, por exemplo o SARFI, para as barras de estimação.

\section{Comparação com outra metodologia:}

Com a finalidade de comparar a eficiência da metologia deste trabalho de doutorado, foi implementado outro algoritmo de otimização, baseado em Algoritmos Genéticos AGs, amplamente utilizados na área da otimização.

O algoritmo implementado foi baseado nos princípios básicos dos AGs, utilizando os operadores próprios como seleção, recombinação e mutação.

Foram ilustrados gráficos de desempenho e tabelas dos resultados obtidos nas simulações. Desses resultados, entende-se que as EEs encontram melhores resultados na precisão e taxa de convergência.

\section{Contribuições do trabalho:}

A principal contribuição deste trabalho é a aplicação das EEs como uma ferramenta poderosa para a solução do problema de estimação de VTCDs, devido às faltas elétricas que ocorrem num sistema elétrico de potência.

No processo de otimização, a busca dentro do espaço de soluções é guiada através da construção de uma lista ordenada de trechos, proposta neste trabalho, que dá uma visão de Distância Euclidiana entre as características principais de falta. Esta lista é principalmente utilizada na aplicação do operador mutação, de importância ímpar para as EEs.

Com o objetivo de melhorar a estimação de VTCDs face às limitações orçamentárias (número limitado de medidores de qualidade), também foram implementadas duas metodologias para resolver o problema de alocação ótima de medidores, como as EEs e a Busca em Vizinhança variável (VNS). Os resultados assim obtidos podem ser utilizados para definição da aquisição e locais de instalação de medidores tendo por objetivo melhores resultados para a solução do problema de estimação de VTCDs.

Com a implementação destas ferramentas, é possível atingir: 
- Localização de faltas: (i) determinar local de falta frente a uma falta elétrica, o que traz uma redução do tempo de restabelecimento da energia. (ii) melhoria dos índices de qualidade de energia como DEC e DIC, permitindo elaborar planos de manutenção preventiva para melhorar estes índices.

- Estimação de VTCDs: estimar as magnitudes dos valores das tensões em barras de interesse no momento da ocorrência da falta elétrica, auxiliando a identificação das áreas de risco para um determinado grupo de consumidores que possuam cargas sensíveis.

- Elaborar planos de manutenção preventiva, de modo a reduzir índices de qualidade de energia relativos às VTCDs (p. ex., SARFI).

- Introduzir medidas de automação para implementar a metodologia desenvolvida, utilizando o conceito de rede inteligente (Smart Grid).

\subsection{Trabalhos futuros}

Para desenvolvimentos futuros deste trabalho, dentre outros aspectos, propõe-se que sejam pesquisados e tratados os seguintes aspectos do problema:

- Utilizar informação proveniente de dispositivos de seccionamento e proteção instalados no sistema elétrico. Isto ajudaria a diminuir o espaço de busca, o que reduziria os erros produzidos por algumas condições de curto-circuito que geram condições de simetria.

- A implementação desta metodologia em alguma empresa concessionária, possibilitaria os seguintes estudos:

- Estabelecer áreas de risco frente às VTCDs, para depois tomar medidas necessárias objetivando a diminuição e até eliminação destes riscos, como: aprimorar tarefas de manutenção preventiva, reconfigurar a rede visando este aspecto, entre outros.

- Construir sistema de gestão da qualidade, com informações estatísticas mais precisas como: taxas de falta, indicadores de Qualidade de Energia (DEC, FEC), estimação de frequência de VTCDs para aqueles consumidores que não possuem equipamentos de medição. 
- Estudos de planejamento de expansão considerando índices de qualidade de energia relativos às VTCDs.

- Estudo prévio de sincronismo de equipamentos de medição e proteção e, desenvolver um administrador da informação proveniente destes equipamentos. Com estes recursos pode-se implementar o estimador de VTCDs e fazer outros estudos relacionados à qualidade de energia. 


\section{REFERÊNCIAS BIBLIOGRÁFICAS}

AGENCIA NACIONAL DE ENERGIA ELÉTRICA (ANEEL). Procedimentos de distribuição de energia elétrica no sistema elétrico nacional - PRODIST. Módulo 8, Qualidade da Energia Elétrica, 2007.

ARRUDA, E.F.; KAGAN, N.; RIBEIRO, P.F. Harmonic distortion state estimation using an evolutionary stategy. IEEE Transactions on Power Delivery, v. 25, n. 2, p: 831-842, 2010.

BACK, T.; SCHWEFEL, H.P. Evolutionary computation: an overview. In: Proceedings of the third IEEE Conference on Evolutionary Computation, p. 20-29, 1996.

BACK, T.; FOGEL, D.B.; MICHALEWICZ, Z. Evolutionary computation 1: basic algorithms and operators. Institute of Physics Publishing (IOP), 2000.

BÄCK, T.; HOFFMEISTER, F.; SCHWEFEL, H.P. A survey of evolution strategies. In: Proceeding of the $4^{\text {th }}$ International Conference on Genetic Algorithms, San Diego, CA, In Morgan Kaufmann Publishers (Ed.) p. 2-9, 1991.

CEBRIAN, A.J.C. Metodologias para avaliação de Riscos e dos Custos de Interrupções em Processos causados por Faltas em Sistemas de Distribuição de Energia Elétrica. Tese de doutorado - USP, Março 2008.

DAVID, B. FOGEL Evolutionary computation: toward a new philosophy of machine intelligence. 2.nd ed. New York, IEEE Press, 1995.

EPRI - Reliability Benchmarking Methodology - RBM software tools user's guide - RBM Index Calculation Module and Power Quality State Estimation Manager. - Version 2.0 February/1998.

GUERRA, W.; KAGAN, N. Alocação ótima de medidores de qualidade de energia utilizando busca em vizinhança variável. In: Simpósio Brasileiro de Sistemas Elétricos, SBSE-2010, Belém 2010a. 
GUERRA, W.; KAGAN, N. Alocação otima de medidores de qualidade de energia visando monitoramento de VTCDs utilizando estratégias evolutivas. In: Latin América IEEE, São Paulo, 2010b.

HONG, H.W.; COLWELL, D.H. Intelligent system identifies and locates transmission faults. IEEE Computer Applications in Power, v. 10, p. 31-35, 1997.

HANSEN, P.; MLADENOVIC, N. An introduction to variable neighborhood search. IEEE Transaction and Automatic Control, v. 41, n. 3, p. 358-367, 1996.

HANSEN, P.; MLADENOVIC, N. An introduction to variable neighborhood search. In: Advances and Trends in Local Search Paradigms for Optimization. Dordrech: [s.n.], p. 433-458, 1999.

IEEE Std. 1159. IEEE recommended practice for monitoring electric power quality, 1995.

IEEE 1159.2 Working Group. Task force on characterization of a power quality event given an adequately sampled set of digital data point. In: Power Quality Event Characterization, Last Update August 24, 1999. http://grouper.ieee.org/groups/1159/2.

IEEE Std. 1346. IEEE recommended practice for evaluating electric power system compatibility with electronic process equipment. New York: 1998.

JOHNS, A.T.; JAMALI, S. Accurate fault location technique for power transmission lines. IEEE Proceedings Generation, Transmission and Distribution, v. 137, n. 6, p. 345-402, 1990a.

JOHNS, A.T.; JAMALI, S. Accurate fault location in the power transmission line using support vector machine approach. Generation, Transmission and Distribution, IEE Proceedings C, v: 137, p. 395-402, 1990 b.

KAGAN, N.; ROBBA, E. J.; SCHMIDT, H. P. Estimação de indicadores de qualidade da energia elétrica. São Paulo: Edgard Blucher, 2009a.

KAGAN, N.; SCHMIDT, H. P.; OLIVEIRA, C. B.; KAGAN, H. Métodos de otimização aplicados a sistemas elétricos de potência. São Paulo: Edgard Blucher, 2009b.

KAWADY, T.; STENZEL, J. Investigation of practical problems for digital fault location algorithms based on EMTP simulation. In: Transmission and Distribution Conference and Exhibition 2002: Asia Pacific. IEEE/PES, v.1, p. 118-123, Japan, 2002. 
KEZUNOVIC, M.; LUO, S.; SEVCIK, D.R. A novel method for transmission network fault location using genetic algorithms and sparse field recordings. IEEE Power Engineering Society Summer Meeting, v: 3, p. 1101-1106, 2002.

KWANG, Y. LEE; FRANK, F. YANG. Optimal reactive power planning using evolutionary algorithms: a comparative study for evolutionary programming, evolutionary strategy, genetic algorithm, and linear programming. IEEE Transactions on Power Systems, v: 13, n. 1, p. 101-108, 1998.

LEDESMA, A.T.P. Estimação de estado da rede durante variações de tensão de curta duração para o monitoramento de qualidade de energia elétrica. Dissertação (Teses de mestrado) - USP, Março 2004.

MAGELE, C. Evolution strategies and optimization. In: IGTE Graz University of Technology, Áustria, 2001.

MANTOVANI, J.R.S. Cálculo de fluxo de carga e curto-circuito em redes de distribuição de energia elétrica. Relatório do Projeto de Pesquisa, São Paulo, 2001.

MLADENOVIC, N. Variable neighborhood algorithm: a new metaheuristic for combinatorial optimization. In: Abstracts of papers presented at Optimization Days, p. 112, Montréal, 1995.

PEREIRA, R.A.F.; DA SILVA, L.G.W.; KEZUNOVIC, M.; MANTOVANI J.R.S. Improved fault location on distribution feeders based on matching during-fault voltage sags. IEEE Transactions on Power Delivery, IEEE Delivery, v: 24, n. 2, p. 831-842, 2009.

RECHENBERG, I. Cybernetic Solution Path of an Experimental Problem. In Royal Aircraft Establishment. Translation n. 1122, B.F. Toms, Trans., Farnborough, UK, 1965.

RECHENBERG, I. Evolutionstrategies: optimierung technischer systeme nach prinzipien der biologischen evolution. Stuttgart: Fromman-Holzboog Verlag, 1973.

SCHWEFEL, H.P. Kybernetische evolution als strategie der experimentellen forschung in der strömungstechnik. Diploma thesis - Technical University of Berlim, Março, 1965.

SCHWEFEL, H.P. Numerical optimization of computer models. $3^{\text {rd }}$. ed. Chichester, USA, Wiley, 1981. 
SCHWEFEL, H.P. Collective phenomena in evolutionary systems. In: Preprints of the 31st Annual Meeting of the International Society for General Systems Research, p. 10251033, Budapeste, 1987.

SCHWEFEL, H.P. Evolution and optimum seeking. New York, Wiley, 1995.

SCHWEFEL, H.P.; RUDOLPH, G. Contemporary evolution strategie. In: F. Morán, A. Morelo, and P. Chacon (eds.), Advances in Artificial Life, 3rd International Conference on Artificial Life, v. 929 of Lecture Notes in Artificial Intelligence, p. 893-907, Berlim, Springer, 1995.

SOUSA, J.C.S.; RODRIGUES, A.M.P.; SCHILLING, M.T.; COUTO FILHO, M.B. Fault location in electrical power systems using intelligent systems techniques. IEEE Transactions on Power Delivery, v. 16, n. 1, p. 59-67, 2001.

SINAPSIS INOVAÇÃO EM ENERGIA Sinap T\&D - sistema de análise integrada AT/MT/BT. http://www.sinapsisenergia.com. Acesso em Maio 2011.

TETTAMANZI, A.; TOMASSINI, M. Soft computing integrating evolutionary, neural, and fuzzy systems. Springer, Verlag, 2001.

WANG, B.; XU, W.; PAN, Z. Voltage sag state estimation for power distribution systems. IEEE Transactions on Power System, v.20, n. 2, p. 806-812, 2005.

YUAN, L. Fault location using sparse voltage measurements. In: Power Symposium, 2007. NAPS '07. 39th North American, p. 7-12, 2007.

ZIJAD, G.; ALI, A. Fault location using voltage measurements. IEEE Transactions On Power Delivery, v. 17, n. 2, p. 441-445, 2002.

ZBIGNIEW, MICHALEWICZ Genetic algorithms+data structures=evolution programs. 3rd. ed. USA, Springer, 1996. 


\section{ANEXO A - ALGORITMOS GENÉTICOS}

Como já mencionado no Capítulo 3 - os AGs e as EEs formam parte da família da Computação Evolutiva tendo uma similaridade nos operadores de evolução, mas com diferente sequência de aplicação (principio de evolução) e estratégias próprias dos operadores de evolução ilustradas na Tabela 3.1 e na Figura 3.1.

Com intuito de comparar o comportamento do desempenho das EEs para resolver o problema de Estimação de VTCDs, neste trabalho, foi necessário desenvolver um algoritmo básico empregando os AGs. Este algoritmo é detalhado a seguir:

Codificação: Um indivíduo é representado através de uma cadeia de string binário como ilustra a Figura A.1. A primeira parte corresponde ao local de falta (número real) e a segunda a impedância de falta (número real).

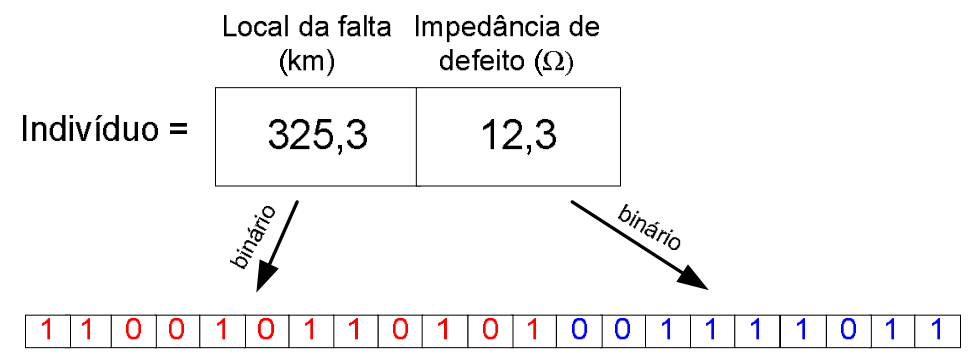

Figura A.1 - Codificação de indivíduo (AGs)

Para representar um número real com $n$ casas decimais numa base binária, o número será multiplicado por $10^{n}$ para obter um número inteiro; adotando $n=1$, de modo a facilitar a codificação. O tamanho do string dependerá do tamanho da rede, ou seja, se $m$ representa o comprimento da rede em $\mathrm{km}$., deve ser cumprir $2^{d-1}<m * 10 \leq 2^{d}$, onde $d$ é tamanho do string. Números pequenos só utilizarão alguns bits, nesses casos será preenchido por zeros do 
lado esquerdo da codificação. Um exemplo disso pode ser observado na Figura A.1. A quantidade de bits para representar a impedância de falta é 9. Sendo que, o valor de 12,3 é expressado em 7 bits, porém os bits do lado esquerdo ( 2 espaços) são preenchidos por zeros.

Avaliação da função objetivo: É utilizado o mesmo critério adotado nas EEs, ou seja, calculando a distância entres os valores das tensões lidas pelos medidores e os obtidos das simulações (empregando a regra de mínimos quadrado), para isso é utilizada a equação 4.1 .

População inicial: Para construir a população inicial são utilizados os mesmos critérios que as EEs, descritos no item 4.4.

Seleção: Através deste operador, os indivíduos da população serão submetidos aos operadores de Cruzamento e/ou Mutação. O critério adotado é o método da Roleta (KAGAN et al., 2009b), também implementado para esta metodologia (AGs).

Cruzamento: Como já mencionado, a recombinação representa o principal operador de evolução dos AGs. Ele opera sobre pares de string escolhidos aleatoriamente, ilustrado na Figura A.2. Nem todos os pares de string passam pela operação de cruzamento, o que é controlado através de uma taxa de cruzamento $p_{c}$. Os indivíduos que não cruzam são copiados para a nova população, sem ocorrências de troca de informações (material genético). Em geral esta taxa é mantida entre 0,8 e 0,9 . 


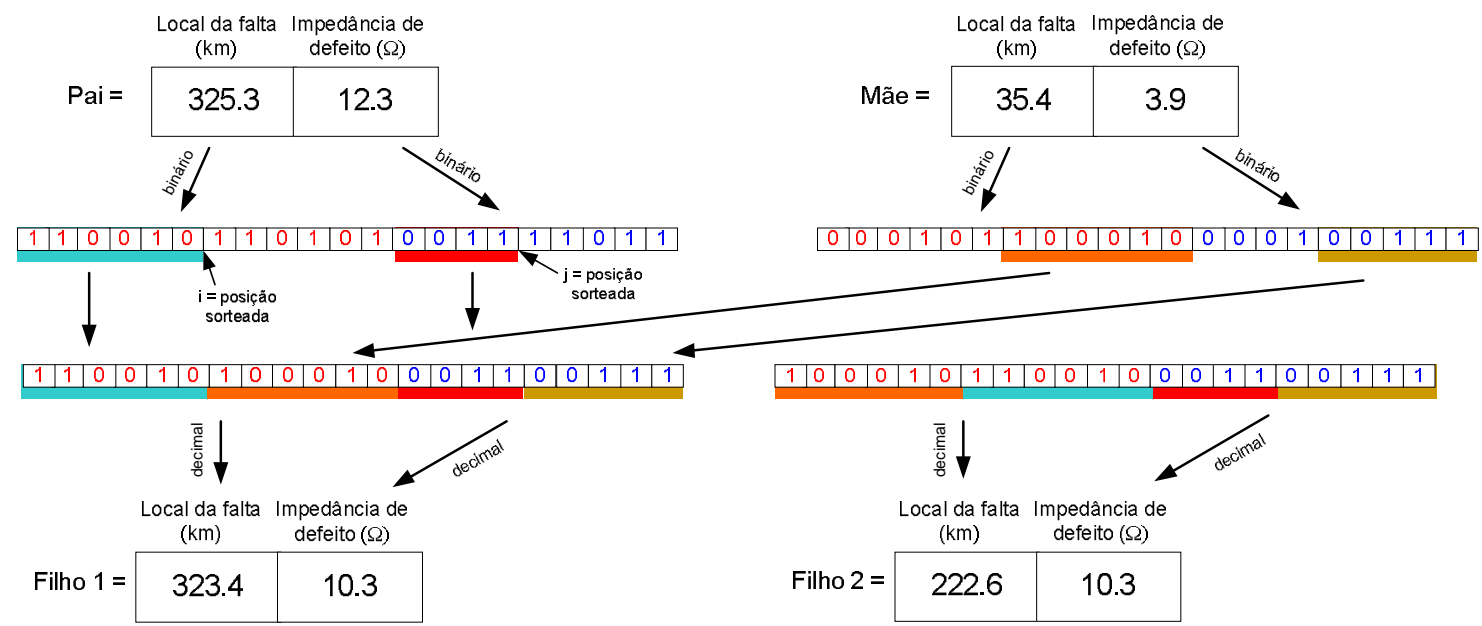

Figura A.2 - Operador Cruzamento (AGs)

Mutação: Este operador simplesmente altera ocasionalmente o valor de um bit de um string da nova população criada a partir dos outros operadores, ou seja, se o valor do bit vale "1", o operador o altera para "0”, e vice-versa.

Define-se, a priori, uma Taxa de Mutação $p_{c}$ por exemplo, igual a 0,01. Em seguida é sorteado um número aleatório entre 0 e 1 (com distribuição uniforme) para cada bit. Se o valor sorteado é menor que $p_{c}$, altera-se o bit (KAGAN et al., 2009b). Neste exemplo, uma mutação seria feita a cada 100 cruzamentos. Na Figura A.3 é ilustrada a aplicação deste operador. A ocorrência de mutação no $9^{\circ}$ bit altera o valor do bit de "0" para " 1 ". 


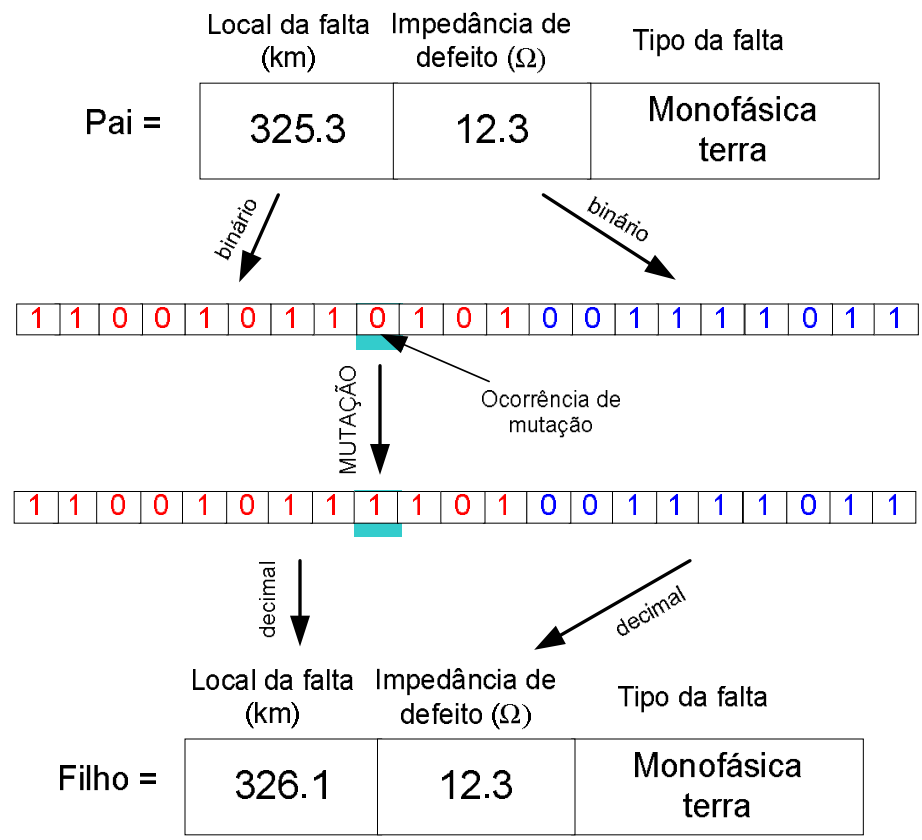

Figura A.3 - Operador Mutação (AGs)

Critério de convergência: É analisado o valor da função objetivo do melhor indivíduo (incumbente) da população atual. Se este não tem uma melhoria na avaliação durante um número fixo de gerações, é considerado que o processo convergiu. Caso contrário, o processo continua. O algoritmo é mostrado na Figura A.4. 


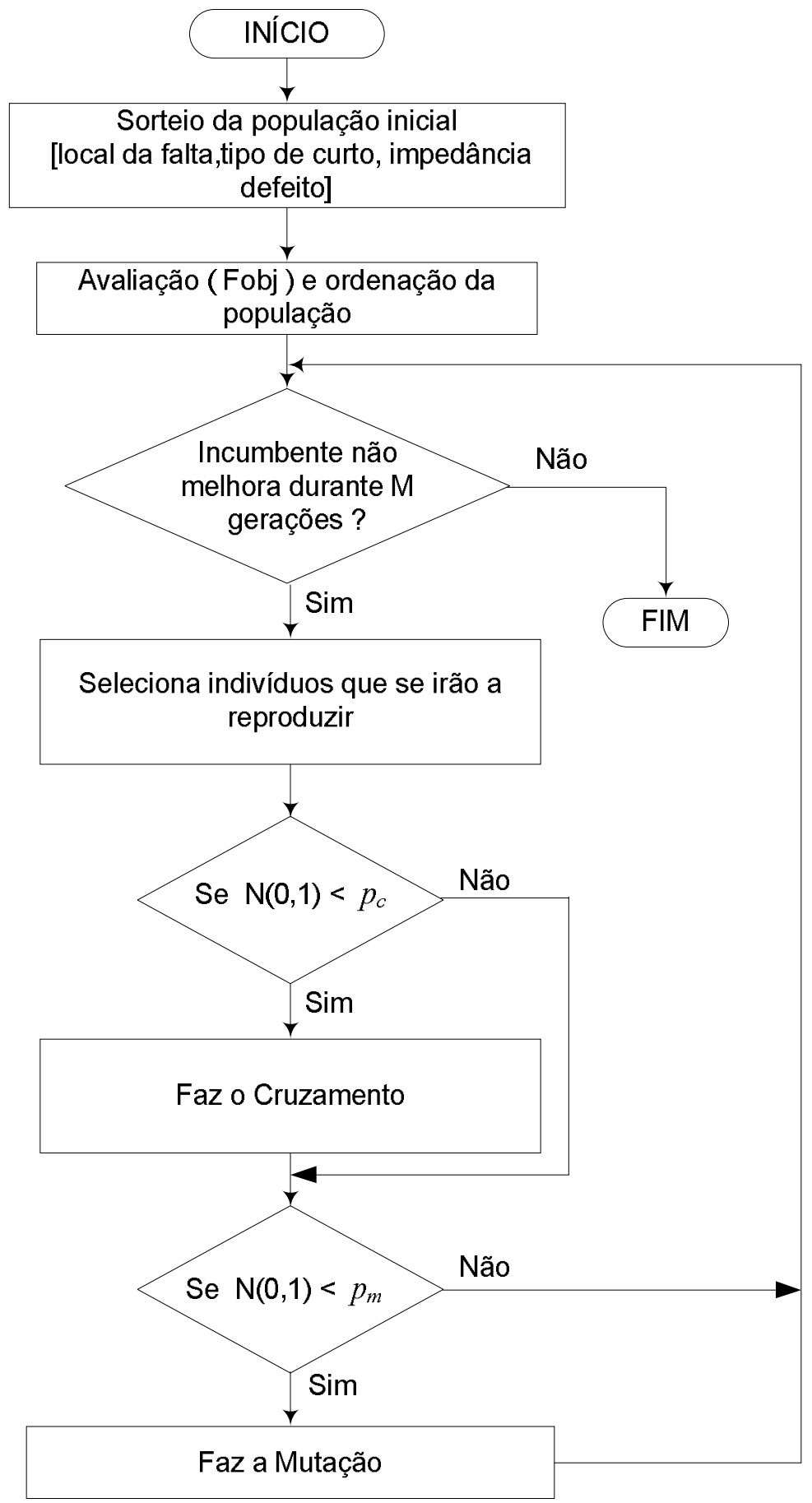

Figura A.4 - Algoritmo (AGs) 


\section{ANEXO B - CÁLCULO DE CURTO-CIRCUITO}

Para faltas desequilibradas em redes trifásicas, a complexidade envolvida na análise do Curto-Circuito para sistemas desequilibrados pode ser consideravelmente reduzida utilizandose o método das componentes simétricas. A grande vantagem deste método é a decomposição das correntes e tensões de fase, assimétricas, em um conjunto de componentes com características simétricas (MANTOVANI, 2001).

Considerando-se $I_{A}, I_{B}$ e $I_{C}$ como sendo três correntes de fase desequilibradas, por definição, pode-se decompô-las em nove novos componentes, de acordo com o conjunto de equações a seguir:

$$
\begin{aligned}
& I_{A} \equiv I_{A 0}+I_{A 1}+I_{A 2} \\
& I_{B} \equiv I_{B 0}+I_{B 1}+I_{B 2} \\
& I_{C} \equiv I_{C 0}+I_{C 1}+I_{C 2}
\end{aligned}
$$

Para que o conjunto de equações (B.1) tenha solução única, é necessário impor as seguintes restrições adicionais aos componentes deste conjunto de equações, como, por exemplo, as do conjunto de equações a seguir:

$$
\begin{gathered}
I_{A}=I_{A 1}+I_{A 2}+I_{A 0} \\
I_{B}=\alpha^{2} I_{A 1}+\alpha I_{A 2}+I_{A 0} \\
I_{C}=\alpha I_{A 1}+\alpha^{2} I_{A 2}+I_{A 0}
\end{gathered}
$$

Sendo $\alpha \equiv e^{j 120^{0}}$ : A equação a seguir, corresponde ao conjunto de equações (B.2) escrito na forma matricial: 


$$
I_{p}=T I_{s}
$$

Sendo a matriz:

$T \equiv\left[\begin{array}{ccc}1 & 1 & 1 \\ 1 & \alpha^{2} & \alpha \\ 1 & \alpha & \alpha^{2}\end{array}\right]$

denominada matriz de transformação de componentes simétricas. Os vetores correntes:

$I_{p} \equiv\left[\begin{array}{l}I_{A} \\ I_{B} \\ I_{C}\end{array}\right]$

E:

$I_{s} \equiv\left[\begin{array}{c}I_{A 0} \\ I_{A 1} \\ I_{A 2}\end{array}\right]$ ou, para simplificar ${ }^{2} \quad I_{s} \equiv\left[\begin{array}{c}I_{0} \\ I_{1} \\ I_{2}\end{array}\right]$

representam as correntes de fase e os componentes simétricos, respectivamente. Invertendo-se a equação (B.3), obtém-se:

$$
I_{s}=T^{-1} I_{p}
$$

Sendo:

$$
T^{-1}=\frac{1}{3}\left[\begin{array}{ccc}
1 & 1 & 1 \\
1 & \alpha & \alpha^{2} \\
1 & \alpha^{2} & \alpha
\end{array}\right]
$$

\footnotetext{
${ }^{2}$ Deve-se lembrar sempre que os componentes $I_{0}$ e $I_{1}, I_{2}$ referem-se à fase A.
} 
Os vetores do conjunto de equações a seguir:

$$
V_{p} \equiv\left[\begin{array}{c}
V_{A} \\
V_{B} \\
V_{C}
\end{array}\right] \text { e } V_{s} \equiv\left[\begin{array}{c}
V_{A 0} \\
V_{A 1} \\
V_{A 2}
\end{array}\right] \text { ou para simplificar } V_{s} \equiv\left[\begin{array}{c}
V_{0} \\
V_{1} \\
V_{2}
\end{array}\right]
$$

representam as tensões de fase e os componentes simétricos da tensão, respectivamente. Aplicando-se a transformação aos fasores de tensão, tem-se:

$$
\begin{aligned}
& V_{p}=T V_{s} \\
& V_{s}=T^{-1} V_{p}
\end{aligned}
$$

Conforme o tipo de falta, são estabelecidos condições de contorno nos pontos de falta. A partir destas condições, determinam-se uma forma conveniente de interligar as redes de seqüência de modo a satisfazer as restrições, gerando um circuito equivalente para o defeito, que possibilita obter as correntes e tensões de seqüência resultantes da falta. Os valores de fase são obtidos pela transformação das componentes simétricas.

As tensões de seqüência na barra de falta (barra i) são obtidas por:

$$
V_{i}^{s}=V_{i}^{s '}-z_{i i}^{s} I_{f_{i}}^{s}
$$

Em que: $s \in\{0,1$ e 2$\}$, índices referentes às seqüências zero, positiva e negativa respectivamente.

As tensões de seqüência em outras barras da rede (barra genérica k) resultantes da falta no ponto i são obtidas de:

$$
V_{k}^{s}=V_{k}^{s}-z_{i k}^{s} I_{f_{i}}^{s}
$$

Para redes trifásicas simétricas com cargas bastante equilibradas, as tensões pré-faltas de seqüências negativas e zero podem ser desprezadas.

As impedâncias $z_{i i}^{s}$ e $z_{i k}^{s}$ são elementos da matriz de impedâncias nodais, que podem ser obtidas da inversão da matriz de admitâncias nodais, para cada seqüência (MANTOVANI, 2001): 


$$
\left[Z^{s}\right]=\left[Y^{s}\right]^{-1}
$$

\section{Em que:}

$\left[Y^{s}\right]=\left[\begin{array}{ccccc}y_{11}^{s} & \cdot & \cdot & \cdot & y_{1 n}^{s} \\ \cdot & \cdot & \cdot & \cdot & \cdot \\ \cdot & \cdot & \cdot & \cdot & \cdot \\ \cdot & \cdot & \cdot & \cdot & \cdot \\ y_{n 1}^{s} & \cdot & \cdot & \cdot & y_{n n}^{s}\end{array}\right]$

$y_{i i}^{s}=\sum_{k \neq i} Y_{i k}^{s}$

$$
y_{i k}^{s}=-Y_{i k}^{s}
$$

onde $Y_{i k}^{s}$ representa a admitância entre barras como ilustra a Figura B.1. Os elementos da diagonal principal correspondem à soma de todas as admitâncias conectadas àquela respectiva barra. Já os elementos fora da diagonal principal correspondem ao negativo da admitância conectadas entre as barras.

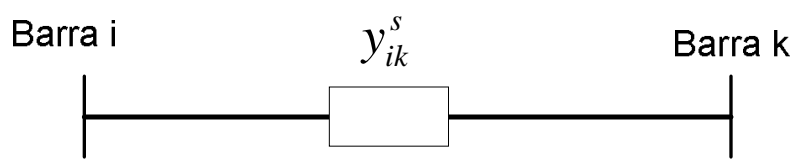

Figura B.1 - Representação de uma linha elétrica

A forma expandida da matriz de impedâncias nodais é obtida pelo inverso da matriz $Y^{s}$.

$\left[Z^{s}\right]=\left[\begin{array}{ccccc}z_{11}^{s} & \cdot & \cdot & \cdot & z_{1 n}^{s} \\ \cdot & \cdot & \cdot & \cdot & \cdot \\ \cdot & \cdot & \cdot & \cdot & \cdot \\ \cdot & \cdot & \cdot & \cdot & \cdot \\ z_{n 1}^{s} & \cdot & \cdot & \cdot & z_{n n}^{s}\end{array}\right]$

A continuação será modelada os tipos de falta. 


\section{a) Cálculo Curto-Circuito Trifásico}

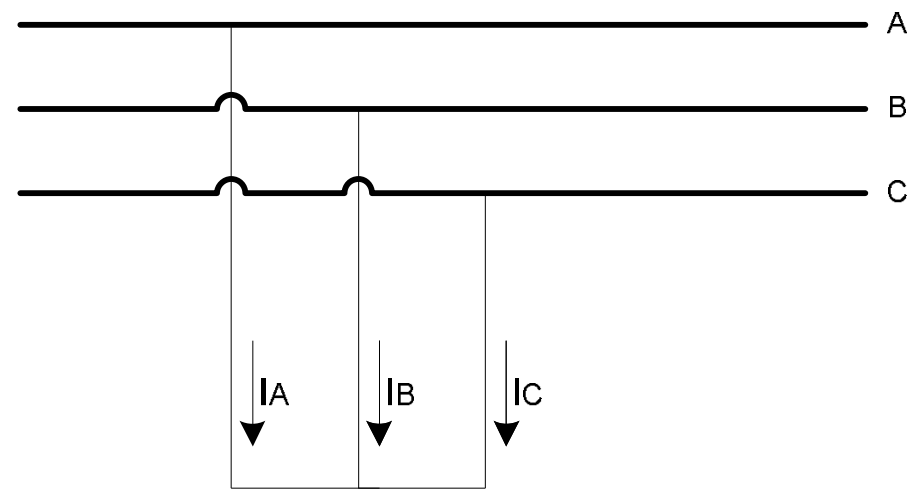

Figura B.2 - Curto-Circuito Trifásico

$\left|V_{A}\right|=\left|V_{B}\right|=\left|V_{C}\right|=0$

Decompondo em componentes simétricas:

$$
\begin{aligned}
& {\left[\begin{array}{c}
V_{A 0} \\
V_{A 1} \\
V_{A 2}
\end{array}\right]=\frac{1}{3}\left[\begin{array}{ccc}
1 & 1 & 1 \\
1 & \alpha & \alpha^{2} \\
1 & \alpha^{2} & \alpha
\end{array}\right]\left[\begin{array}{l}
V_{A} \\
V_{B} \\
V_{C}
\end{array}\right]} \\
& V_{A 0}=\frac{1}{3}\left(V_{A}+V_{B}+V_{C}\right) \\
& V_{A 1}=\frac{1}{3}\left(V_{A}+\alpha V_{B}+\alpha^{2} V_{C}\right) \\
& V_{A 2}=\frac{1}{3}\left(V_{A}+\alpha^{2} V_{B}+\alpha V_{C}\right) \\
& V_{A 0}=V_{A 1}=V_{A 2}=0
\end{aligned}
$$
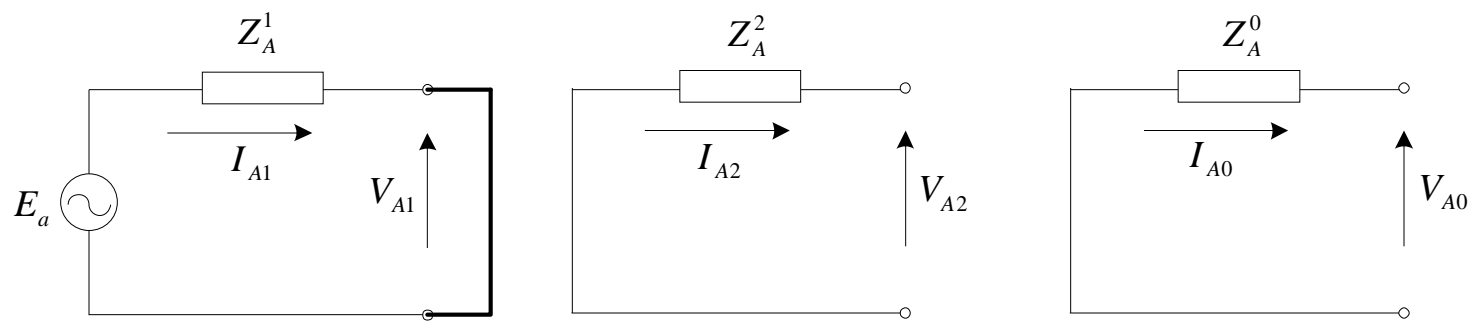

Figura B.3 - Curto-Circuito trifásico - componentes simétricas 
Da Figura B.3 se têm as seguintes expressões:

Para a sequência positiva:

$V_{A 1}=E_{a}-Z_{A}^{1} \cdot I_{A 1}$

Para a sequência negativa:

$V_{A 2}=0-Z_{A}^{2} \cdot I_{A 2}$

Para a sequência zero:

$V_{A 0}=0-Z_{A}^{0} \cdot I_{A 0}$

Colocando na forma matricial:

$$
\begin{aligned}
& {\left[\begin{array}{c}
V_{A 0} \\
V_{A 1} \\
V_{A 2}
\end{array}\right]=\left[\begin{array}{c}
0 \\
E_{a} \\
0
\end{array}\right]-\left[\begin{array}{ccc}
Z_{A}^{0} & 0 & 0 \\
0 & Z_{A}^{1} & 0 \\
0 & 0 & Z_{A}^{2}
\end{array}\right] \cdot\left[\begin{array}{c}
I_{A 0} \\
I_{A 1} \\
I_{A 2}
\end{array}\right]} \\
& V_{A 1}=E_{a}-Z_{A}^{1} \cdot I_{A 1} \\
& 0=E_{a}-Z_{A}^{1} \cdot I_{A 1} \Rightarrow I_{A 1}=\frac{E_{0}}{Z_{A}^{1}}
\end{aligned}
$$

\section{Como:}

$$
\begin{aligned}
& I_{A}=I_{A 1}+I_{A 2}+I_{A 0} \\
& I_{B}=I_{B 1}+I_{B 2}+I_{B 0} \\
& I_{C}=I_{C 1}+I_{C 2}+I_{C 0}
\end{aligned}
$$

e considerando ainda:

$$
\begin{aligned}
& I_{B 1}=\alpha^{2} \cdot I_{A 1} \\
& I_{C 1}=\alpha \cdot I_{A 1}
\end{aligned}
$$

Que leva a:

$$
\left|I_{A}\right|=\left|I_{B}\right|=\left|I_{C}\right|=E_{0} / Z_{1}
$$




\section{b) Cálculo Curto-Circuito Fase - Terra}

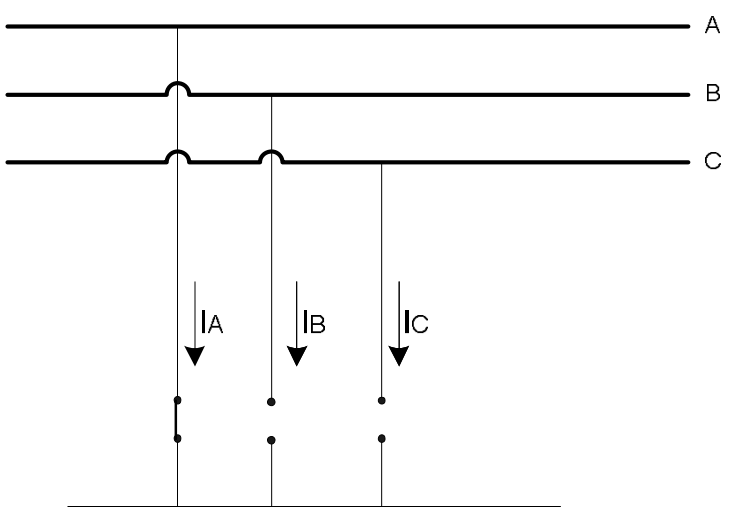

Figura B.4 - Curto-Circuito Fase-Terra.

$I_{A} \neq 0, I_{B}=0, I_{C}=0$ Correntes de falta

$V_{A}=0, V_{B} \neq 0, V_{C} \neq 0$ tensões de falta

Decompondo a corrente $\mathrm{I}_{\mathrm{A}}$ em componentes simétricas:

$$
\begin{aligned}
& {\left[\begin{array}{c}
I_{A 0} \\
I_{A 1} \\
I_{A 2}
\end{array}\right]=\frac{1}{3}\left[\begin{array}{ccc}
1 & 1 & 1 \\
1 & \alpha & \alpha^{2} \\
1 & \alpha^{2} & \alpha
\end{array}\right]\left[\begin{array}{c}
I_{A} \\
0 \\
0
\end{array}\right]} \\
& I_{A 0}=\frac{1}{3} \cdot I_{A}, I_{A 1}=\frac{1}{3} \cdot I_{A}, I_{A 2}=\frac{1}{3} \cdot I_{A}
\end{aligned}
$$

Isto é:

$$
I_{A 0}=I_{A 1}=I_{A 2}=\frac{1}{3} \cdot I_{A}
$$

O circuito equivalente para seqüência positiva, negativa e zero é mostrado a seguir: 


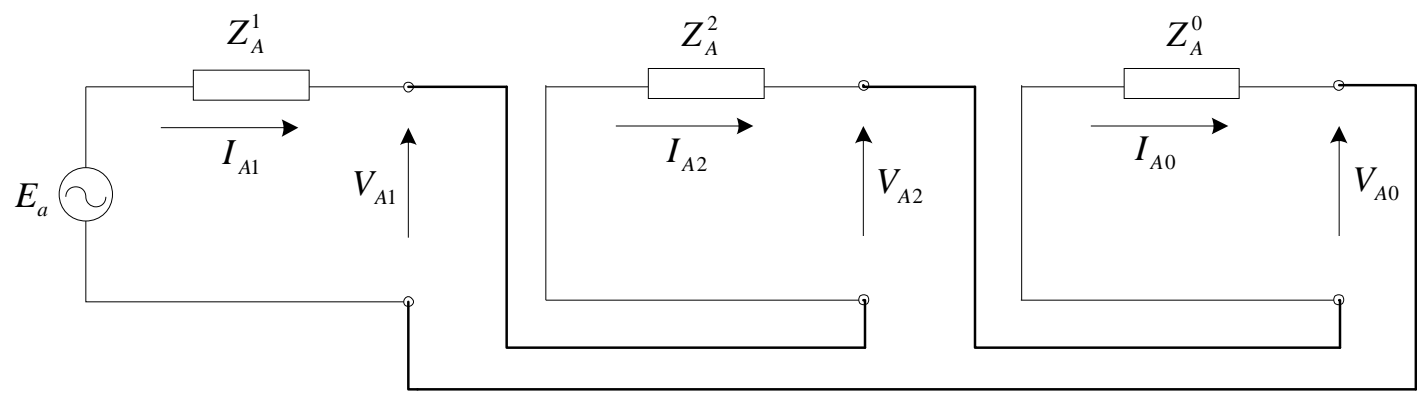

Figura 11-5 - Curto-Circuito fase-terra - componentes simétricas

$$
\begin{aligned}
& V_{A 1}=E_{a}-Z_{A}^{1} \cdot I_{1} \\
& V_{A 2}=-Z_{A}^{2} \cdot I_{2} \\
& V_{A 0}=-Z_{A}^{0} \cdot I_{0} \\
& {\left[\begin{array}{c}
V_{A} \\
V_{B} \\
V_{C}
\end{array}\right]=\left[\begin{array}{ccc}
1 & 1 & 1 \\
1 & \alpha & \alpha \\
1 & \alpha & \alpha^{2}
\end{array}\right]\left[\begin{array}{c}
V_{A 0} \\
V_{A 1} \\
V_{A 2}
\end{array}\right]} \\
& V_{A}=V_{A 0}+V_{A 1}+V_{A 2} \\
& V_{A}=-Z_{A}^{0} \cdot I_{A 0}+E_{a}-Z_{A}^{0} I_{A 1}-Z_{A}^{2} I_{A 2} \\
& V_{A}=0 \quad I_{A 0}=I_{A 1}=I_{A 2}=\frac{1}{3} I_{A} \\
& I_{A 1}=\frac{E_{a}}{Z_{A}^{0}+Z_{A}^{1}+Z_{A}^{2}} \\
& I_{A}=\frac{3 E_{a}}{Z_{A}^{0}+Z_{A}^{1}+Z_{A}^{2}}
\end{aligned}
$$

Em que:

$E_{a}: \mathrm{V}_{\text {th }}$ de sequência positiva (pré-falta) no ponto em Curto-Circuito;

$Z_{A}^{1}: Z_{\text {th }}$ de sequência positiva no ponto (fase $A$ );

$Z_{A}^{2}: Z_{\text {th }}$ de sequência negativa no ponto (fase $A$ );

$Z_{A}^{0}: Z_{\text {th }}$ de sequência zero no ponto (fase $\mathrm{A}$ );

Conhecendo-se $I_{A O}=I_{A l}=I_{A 2}$, podem-se calcular as contribuições parciais para cada sequência e depois decompô-las (pode-se desprezar ou não as correntes pré-falta). 
c) Cálculo Curto-Circuito Fase-Fase (Fases B e C)

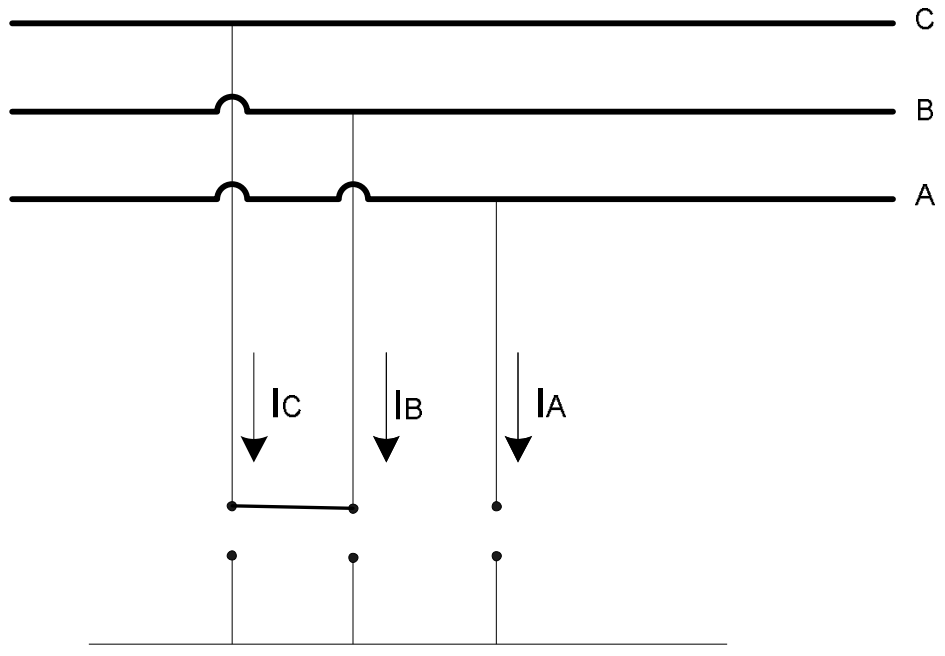

Figura B.6 - Curto-Circuito Fase-Fase

Falta nas Fases B e C:

$I_{A}=0 \quad I_{C}=-I_{B} \Rightarrow I_{C}=I_{B} e^{j 180}$

Componentes simétricas:

$\left[\begin{array}{l}I_{A 0} \\ I_{A 1} \\ I_{A 2}\end{array}\right]=\frac{1}{3}\left[\begin{array}{ccc}1 & 1 & 1 \\ 1 & \alpha & \alpha^{2} \\ 1 & \alpha^{2} & \alpha\end{array}\right]\left[\begin{array}{c}0 \\ I_{B} \\ I_{B} e^{j 180^{0}}\end{array}\right]$

$I_{A 0}=\frac{1}{3}\left(I_{B}-I_{B} e^{j 180^{0}}\right)$

$I_{A 1}=\frac{1}{3}\left(e^{j 120^{0}} I_{B}+e^{-j 120^{0}} I_{B} e^{j 180^{0}}\right)$

$I_{A 1}=\frac{I_{B}}{3}\left(-\frac{1}{2}+j \frac{\sqrt{3}}{2}+\frac{1}{2}+j \frac{\sqrt{3}}{2}\right)$

$I_{A 1}=\frac{I_{B} \sqrt{3}}{3} e^{j 90^{\circ}}$

$I_{A 2}=\frac{I_{B} \sqrt{3}}{3} e^{-j 90^{\circ}}$ 
Conclusão:

$I_{A 0}=0$

$I_{A 2}=-I_{A 1} \neq 0$

As tensões, para o ponto de Curto-Circuito, em uma falta fase-fase são:

$V_{A}=E_{a}$

$V_{B}=V_{C}$

Decompondo em componentes simétricas:

$$
\begin{aligned}
& {\left[\begin{array}{c}
V_{A 0} \\
V_{A 1} \\
V_{A 2}
\end{array}\right]=\frac{1}{3}\left[\begin{array}{ccc}
1 & 1 & 1 \\
1 & \alpha & \alpha^{2} \\
1 & \alpha^{2} & \alpha
\end{array}\right]\left[\begin{array}{c}
E_{a} \\
V_{B} \\
V_{B}
\end{array}\right]} \\
& V_{A 1}=\frac{1}{3}\left(E_{a}+V_{B} e^{j 120^{0}}+V_{B} e^{-j 120^{0}}\right) \\
& V_{A 2}=\frac{1}{3}\left(E_{a}+V_{B} e^{-j 120^{0}}+V_{B} e^{j 120^{0}}\right) \\
& \therefore V_{A 1}=V_{A 2}
\end{aligned}
$$

O circuito equivalente para seqüência positiva, negativa e zero é mostrado a seguir:

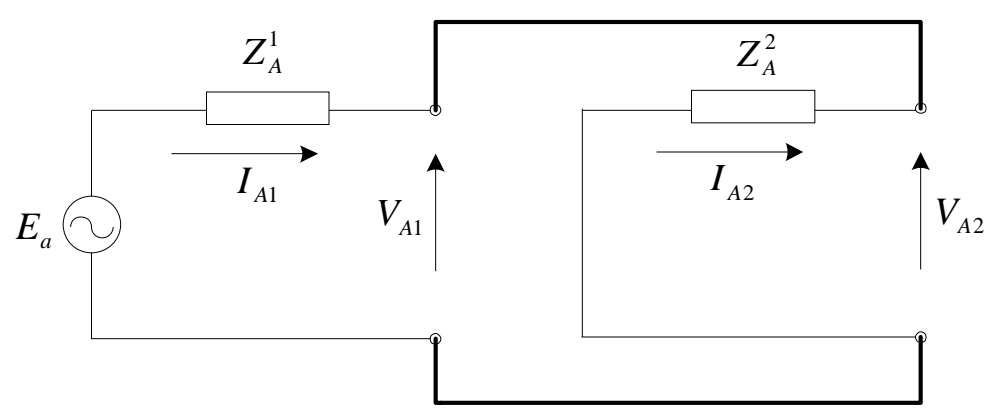

Figura B.7 - Curto-Circuito fase- fase - componentes simétricas

$$
\begin{aligned}
& V_{A 1}=E_{a}-Z_{1} \cdot I_{A 1} \\
& V_{A 2}=-Z_{A}^{2} I_{A 2}=Z_{A}^{2} I_{A 1}
\end{aligned}
$$

Como $V_{A 1}=V_{A 2}$ então: 


$$
\begin{aligned}
& E_{a}-Z_{A}^{1} \cdot I_{A 1}=Z_{A}^{2} I_{A 1} \\
& I_{A 1}=\frac{E_{a}}{Z_{A}^{1}+Z_{A}^{2}}
\end{aligned}
$$

Da Figura B.7, tem se:

$$
I_{A 1}=-I_{A 2}
$$

Usando componentes simétricas:

$$
\begin{aligned}
& {\left[\begin{array}{l}
I_{A} \\
I_{B} \\
I_{C}
\end{array}\right]=\left[\begin{array}{ccc}
1 & 1 & 1 \\
1 & \alpha^{2} & \alpha \\
1 & \alpha & \alpha^{2}
\end{array}\right]\left[\begin{array}{c}
0 \\
I_{A 1} \\
-I_{A 1}
\end{array}\right]} \\
& I_{A}=0 \\
& I_{B}=\left(\alpha^{2}-\alpha\right) I_{A 1}
\end{aligned}
$$

\section{d) Cálculo Curto-Circuito Fase-Fase-Terra}

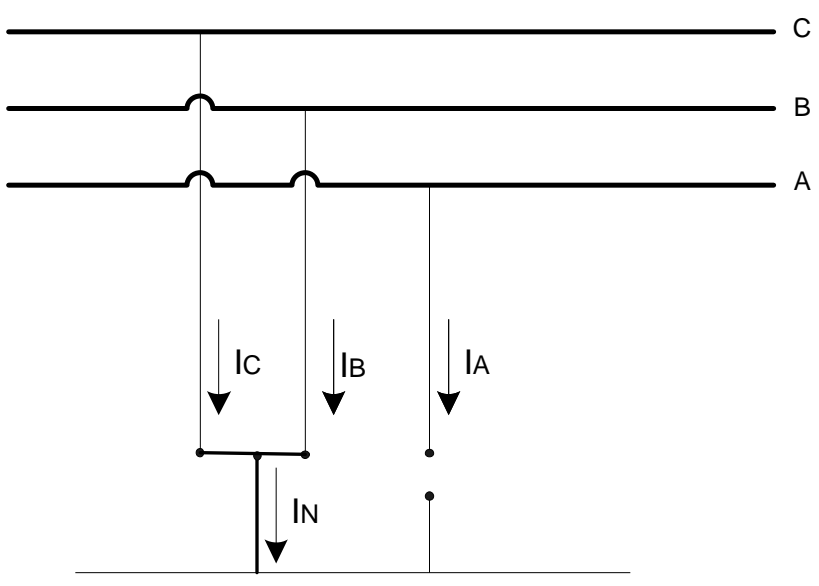

Figura B.8 - Curto-Circuito Fase-Fase-Terra - componentes simétricas Curto-Circuito Fases B e C:

$$
I_{A}=0
$$




$$
\begin{aligned}
& {\left[\begin{array}{l}
I_{A} \\
I_{B} \\
I_{C}
\end{array}\right]=\left[\begin{array}{ccc}
1 & 1 & 1 \\
1 & \alpha^{2} & \alpha \\
1 & \alpha & \alpha^{2}
\end{array}\right]\left[\begin{array}{c}
I_{A 0} \\
I_{A 1} \\
I_{A 2}
\end{array}\right]} \\
& I_{A 1}=-\left(I_{A 0}+I_{A 2}\right) \\
& V_{A} \neq 0 \\
& V_{B}=V_{C}=0 \\
& {\left[\begin{array}{l}
V_{A 0} \\
V_{A 1} \\
V_{A 2}
\end{array}\right]=\frac{1}{3}\left[\begin{array}{ccc}
1 & 1 & 1 \\
1 & \alpha & \alpha \\
1 & \alpha
\end{array}\right]\left[\begin{array}{c}
V_{A} \\
0 \\
0
\end{array}\right]} \\
& V_{A 0}=\frac{1}{3} V_{A} V_{A 1}=\frac{1}{3} V_{A} V_{A 2}=\frac{1}{3} V_{A} \\
& V_{A 0}=V_{A 1}=V_{A 2}
\end{aligned}
$$

O circuito equivalente para seqüência positiva, negativa e zero é mostrado a seguir:

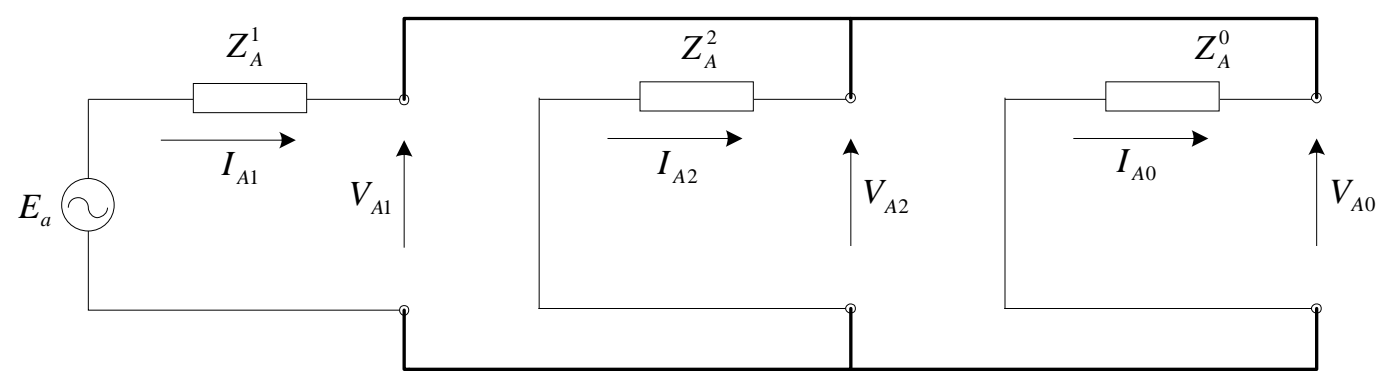

Figura B.9 - Curto-Circuito Fase-Fase-Terra

$$
\begin{aligned}
& V_{A 1}=E_{a}-Z_{{ }_{T H}^{1}}^{1} \cdot I_{A 1} \\
& V_{A 2}=-Z_{A}^{2} \cdot I_{A 2} \\
& V_{A 0}=-Z_{A}^{0} \cdot I_{A 0} \\
& V_{A 1}=V_{A 2} \\
& E_{a}-Z_{A}^{1} \cdot I_{A 1}=-Z_{A}^{2} I_{A 2} \\
& V_{A 1}=V_{A 0} \\
& E_{a}-Z_{A}^{1} \cdot I_{A 1}=-Z_{A}^{0} I_{A 0}
\end{aligned}
$$


$I_{A 0}=\frac{Z_{A}^{1} I_{A 1}-E_{a}}{Z_{A}^{0}}$

$I_{A 0}+I_{A 1}+I_{A 2}=0 \Rightarrow I_{A 2}=-\left(I_{A 0}+I_{A 1}\right)$

Substituindo (B.15) em (B.15):

$I_{A 2}=-\left(\frac{Z_{T H}^{1} I_{A 1}-E_{a}}{Z_{T H}^{0}}\right)-I_{A 1}$

Substituindo (B.17) em (B.14):

$$
\begin{aligned}
& E_{a}-Z_{A}^{1} \cdot I_{A 1}=Z_{A}^{2}\left(\frac{Z_{A}^{1} I_{A 1}-E_{a}}{Z_{A}^{0}}\right)+Z_{A}^{2} I_{A 1} \\
& E_{a}+\frac{Z_{A}^{2} E_{a}}{Z_{A}^{0}}=Z_{A}^{1} I_{A 1}+\frac{Z_{A}^{2} Z_{A}^{1}}{Z_{A}^{0}} I_{A 1}+Z_{A}^{2} I_{A 1} \\
& E_{a}+\frac{Z_{A}^{2} E_{a}}{Z_{A}^{0}}=\left(Z_{A}^{1}+\frac{Z_{A}^{2} Z_{A}^{1}}{Z_{A}^{0}}+Z_{A}^{2}\right) I_{A 1} \\
& \left(Z_{A}^{0}+Z_{A}^{2}\right) E_{a}=\left(Z_{A}^{1} Z_{A}^{0}+Z_{A}^{2} Z_{A}^{1}+Z_{A}^{2} Z_{A}^{0}\right) I_{A 1} \\
& I_{A 1}=\frac{E_{a}^{1}\left(Z_{A}^{0}+Z_{A}^{2}\right)+Z_{A}^{2} Z_{A}^{0}}{\left(Z_{A}^{0}+Z_{A}^{2}\right)} \\
& I_{A 1}=\frac{E_{a}}{Z_{A}^{1}+\frac{Z_{A}^{2} Z_{A}^{0}}{\left(Z_{A}^{0}+Z_{A}^{2}\right)}}
\end{aligned}
$$

Para a interligação dos diagramas deve-se obedecer:

$$
\begin{aligned}
& I_{A}=0 \quad I_{A 1}+I_{A 2}+I_{A 0}=0 \Rightarrow I_{A 1}=-\left(I_{A 2}+I_{A 0}\right) \\
& I_{A 1}=\frac{E_{a}}{Z_{A}^{1}+\frac{Z_{A}^{2} Z_{A}^{0}}{\left(Z_{A}^{0}+Z_{A}^{2}\right)}}
\end{aligned}
$$




\section{ANEXO C - LISTA DE ARTIGOS PUBLICADOS}

Durante o desenvolvimento desta tese de doutorado foram publicados trabalhos que estão diretamente envolvidos no tema, assim como trabalhos indiretamente relacionados, com a finalidade de aprofundar conhecimentos em técnicas de otimização. Todos os trabalhos publicados ajudaram a aprimorar este trabalho de doutorado. É importante mencionar que a participação nestes eventos foi possibilitada a partir de auxílio financeiro da CAPES, da Universidade de São Paulo (Pró-reitoria de pesquisa) e do ENERQ - Centro de Estudos em Regulação e Qualidade de Energia da USP.

\section{Artigos publicados em Congressos Nacionais:}

[1] Guerra, W.; Kagan, N. "Balanço de fases para melhorar os níveis de tensão utilizando a metaheurística busca em vizinhança variável". In: Conferência Brasileira sobre Qualidade da Energia Elétrica, 2007, Santos - São Paulo. Programa e resumos. São Paulo: Polo Editora, 2007. v. 01.p. 140-140.

[2] Guerra, W.; Kagan, N. "Restauração de energia em sistemas de distribuição elétrica utilizando algoritmos meméticos". In: Seminário Nacional de Distribuição de Energia Elétrica, 2008, Recife. XVIII Seminário Nacional de Distribuição de Energia Elétrica, 2008.

[3] Guerra, W.; Kagan, N. "Reconfiguração de sistemas de distribuição de energia elétrica utilizando uma técnica híbrida entre busca em vizinhança variável e busca tabu". In: Simpósio Brasileiro de Sistemas Elétricos, 2008, Belo Horizonte. Anais do SBSE, 2008. v. 2. p. $1-6$.

[4] Guerra, W.; Kagan, N. "Reconfiguração de sistemas de distribuição utilizando colônia de formigas”. In: Simpósio Brasileiro de Sistemas Elétricos, 2008, Belo Horizonte. Anais do SBSE, v. 1. p. 1-6.

[5] Guerra, W.; Kagan. N. "Localizador de faltas em sistemas elétricos aplicando algoritmos evolutivos ". In: Conferëncia Brasileira sobre Qualidade da Energia Elétrica, Blumenau - Santa Catarina. Programa e resumos. São Paulo: Polo Editora, 2009.

[6] Guerra, W.; Kagan, N.; Cebrian, J. C. ; Guaraldo, J. C.; Duarte, S. X. "Analisador de eventos em tempo quase-real". In: Seminário Nacional de Produção e Transmissão de Energia Elétrica SNPTEE, Recife, Novembro, 2009.

[7] Guerra, W.; Kagan, N. "Fault location and voltage estimation in transmission systems by evolutionary algorithms". In: 15th International Conference on. Intelligent System Applications to Power Systems (ISAP 2009), Curitiba, Novembro, 2009. 
[8] Guerra, W.; Kagan, N. "Alocação ótima de medidores de qualidade de energia utilizando busca em vizinhança variável”. In: Simpósio Brasileiro de Sistemas Elétricos, 2010, Belém.

[9] W. G. Zvietcovich.; Nelson Kagan. "Alocação ótima de medidores de qualidade de energia visando monitoramento de VTCDs utilizando estratégias evolutivas". In: Latin American IEEE, 2010, São Paulo.

[10] W. Guerra ; Nelson Kagan. “Alocação Ótima de Medidores de Qualidade de Energia Elétrica visando o monitoramento de VTCDs frente às condições de simetria utilizando Estratégias Evolutivas". In: Conferëncia Brasileira sobre Qualidade da Energia Elétrica CBQEE, 2011, Cuiába.

[11] Guerra W. ; Unsihuay-Vila, C. ; Nelson Kagan "Impacto da Geração Distribuída na Reconfiguração de Sistemas de Distribuição de Energia Elétrica utilizando Busca em Vizinhança Variável". In: XLIII Simpósio Brasileiro de Pesquisa Operacional SBPO, 2011, Ubatuba -São Paulo.

\section{Artigo publicado em Congressos no Exterior:}

[12] Guerra, W.; Kagan, N. "Fault locations in transmission systems by evolutionary algorithms". In International Conference on Renewable Energies and Power Quality (ICREPQ’09), 2009, Valencia, España. April, Paper 334. 